九州大学学術情報リポジトリ

Kyushu University Institutional Repository

Taxonomic Study of the Japanese Species of the Nomada ruficornis Species Group (Hymenoptera, Apidae) with Remarks on Japanese Fauna of the Genus Nomada

Mitai, Katsushi

Entomological Laboratory, Faculty of Agriculture, Kyushu University

Tadauchi, Osamu

Entomological Laboratory, Faculty of Agriculture, Kyushu University

https://doi.org/10.5109/8324

出版情報: ESAKIA. 47，pp. 25-167，2007-10-31. Entomological Laboratory，Faculty of Agriculture， Kyushu University

バージョン：

権利関係 : 


\title{
Taxonomic Study of the Japanese Species of the Nomada ruficornis Species Group (Hymenoptera, Apidae) with Remarks on Japanese Fauna of the Genus Nomada
}

\author{
Katsushi Mitai and Osamu TADAUCHI \\ Entomological Laboratory, Faculty of Agriculture, Kyushu University, Fukuoka, \\ 812-8581 Japan
}

\begin{abstract}
The ruficornis species group of genus Nomada in Japan is taxonomically revised. Thirty species are recognized, including two new species and one species newly recorded from Japan. Thirty-two species and two subspecies are synonymized. In comparison with the faunas of European countries, the fauna of the Japanese Nomada is moderate in terms of the number of species, and is characterized by (1) a rich roberjeotiana species group, and (2) the absence of the integra and superba species groups, which are distributed widely in the Palearctic region.
\end{abstract}

Key words: taxonomy, Hymenoptera, Nomada, ruficornis species group, revision, new species, new synonymies, Japan.

\section{Introduction}

This paper is the fifth contribution to the taxonomic study of the cleptoparasitic bee genus Nomada. In this paper, the Japanese species of the ruficornis species group, the largest species group within the genus $\mathrm{No}$ mada, are taxonomically revised.

According to Alexander (1994) who proposed this species group, the ruficornis species group may be a paraphyletic group corresponding to a remnant of a more inclusive monophyletic unit without the more apomorphic subunits as represented by species groups such as armata, basalis, etc. Therefore, the ruficornis species group should be phylogenetically reanalyzed in the future. Until then, we will treat it as a distinct species group. This species group includes 417 species from Holarctic Region, although the assignment of many species was tentative (Alexander \& Schwarz, 1994).

In Japan, 58 species of the ruficornis species group had been listed, although the assignment of some of these species was also tentative (Alexander \& Schwarz, 1994). There are quite a few problems in the species-level taxonomy of the Japanese species; many species were described based on a single or a few specimens of either sex, and some of these species had not been recorded since the publish of the original descriptions. In Japan, species of this genus are nearly always listed in studies involving a regional faunal survey or of phenological ecology of anthophilous insects, but they are frequently not identified at the species-level or recorded as questionable species. This is due to inadequate knowledge regarding the Japanese fauna of the genus Nomada and the lack of a useful key to facilitate identification.

We revised the Japanese species of the ruficornis group based on a re-examination of the holotypes, and recognized 30 species, including two new species, synonymizing 32 species and one subspecies. Descriptions or supplementary descriptions including male terminalia, and a key detailing all Japanese species are presented.

\section{Materials and methods}

\section{Materials}

The examination was based on approximately 6,500 dried pinned specimens. They comprised 350 specimens from Hokkaido, 3,700 from Honshu, 40 from Shikoku, 1,750 from Kyushu, 50 from the Nansei Islands, and 600 from foreign countries (mainly from Central Europe and the Korean Peninsula).

E-mail: mkatusi@agr.kyushu-u.ac.jp 
Most specimens were collected by a looking-andsweeping method as a general collecting technique, and some were collected with yellow pan traps or Malaise traps.

\section{Depository}

The specimens examined are deposited in the following museums and institutions. Specimens without the depository are in the private collection of the respective collectors:

APM

Aomori Prefectural Museum, Aomori, Japan.

BMNH British Museum of Natural History, London, UK.

EBSU Division of Environmental Biology, Faculty of Life and Environmental Science, Shimane University, Matsue, Japan.

ELKU Entomological Laboratory, Faculty of Agriculture, Kyushu University, Fukuoka, Japan.
FFPRI Forestry and Forest Products Research Institute, Tsukuba, Japan.

MNHAH Museum of Nature and Human Activities, Sanda, Japan.

NIAES National Institute of Agro-Environmental Sciences, Tsukuba, Japan.

NSMT Department of Zoology, National Science Museum (Natural History), Tokyo, Japan.

SEHU Systematic Entomology, Faculty of Agriculture, Hokkaido University, Sapporo, Japan.

TIM Tainai Insect Museum, Tainai, Japan.

TSM Toyama Science Museum, Toyama, Japan.

USNM United States National Museum of Natural History, Smithsonian Institution, Washington, D. C, USA.

The examination of specimens for morphological measurements was made using a Nikon SMZ-U stereo-

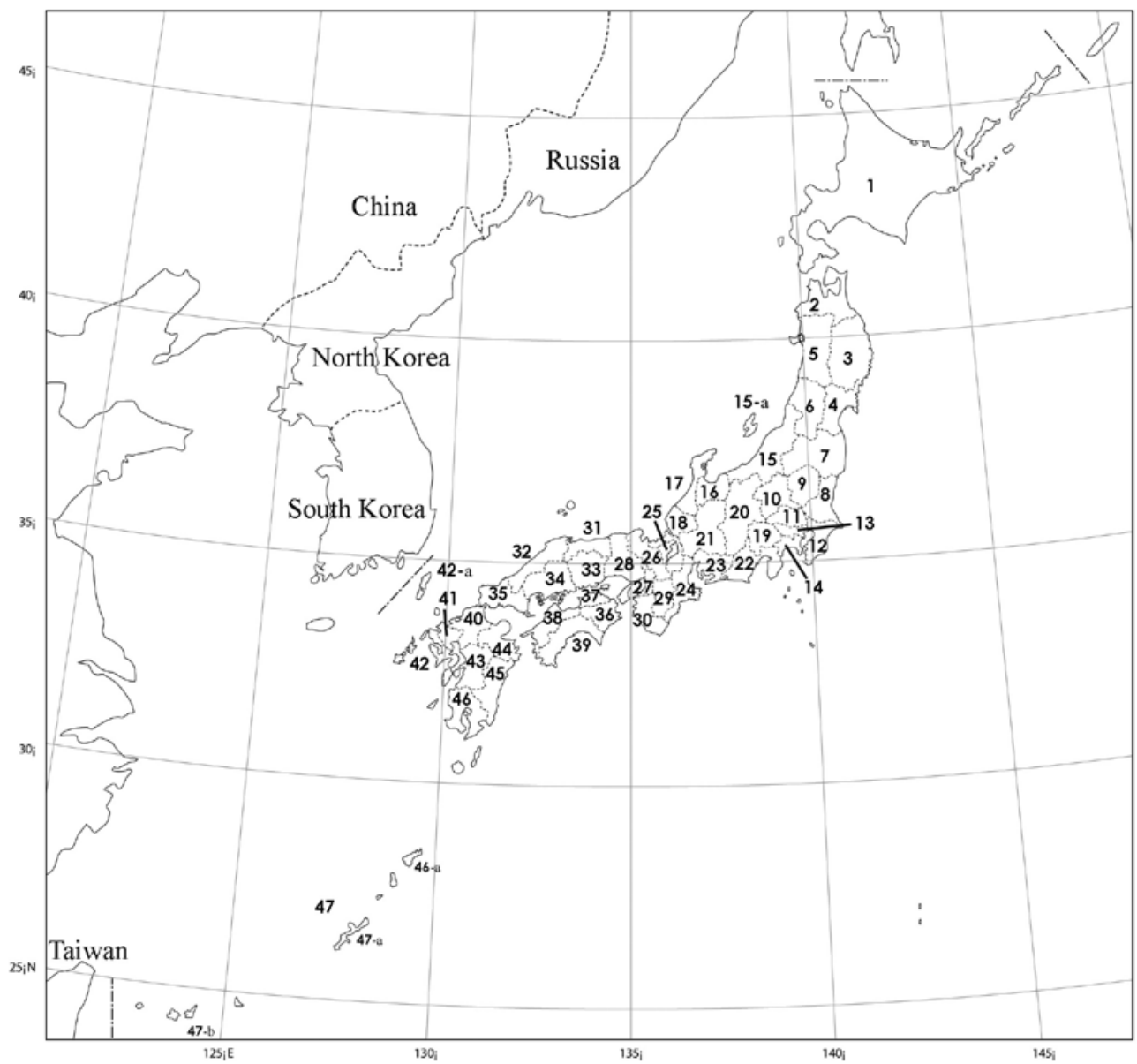

Fig. 1. The division of Japan into prefectural areas as referred in the text, see Table 2. 
Tabale 1. Names and arrangement of main islands and prefctures in Japan referred in the text, see Fig. 1.

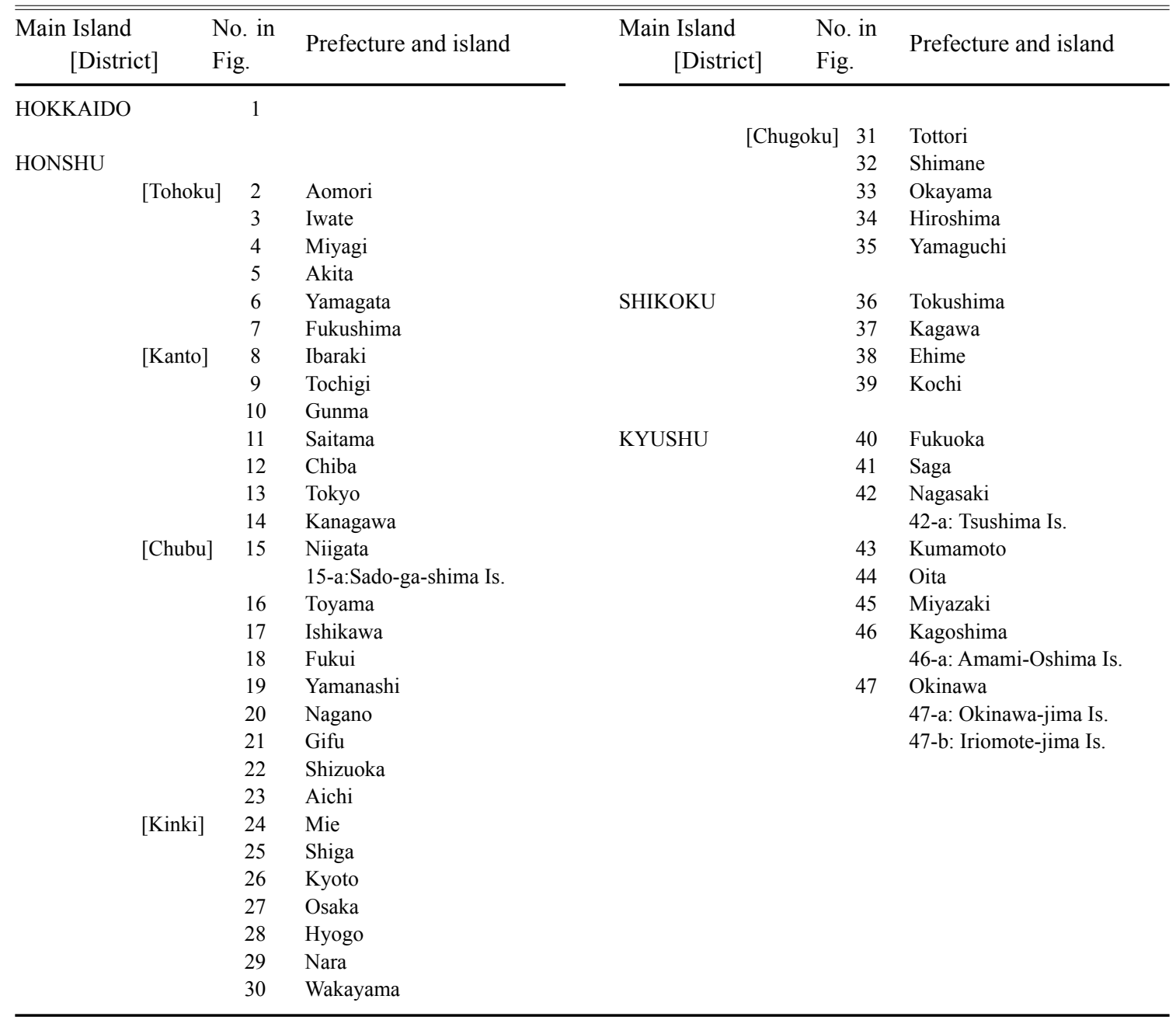

scopic microscope with an ocular micrometer at $10 \mathrm{X}$ to $70 \mathrm{X}$ magnification. Photographs were prepared with a Nikon COOLPIX 995 Digital Camera. The sculpture appearance of the integument is affected considerably by the type of light source under which the specimens are examined. In the present study, examinations were made using a fluorescent daylight light source.

The male terminalia were macerated with $10 \% \mathrm{KOH}$ for at least half a day, and transferred to distilled water for dissection. They were then mounted on glass slides using glycerin as a mounting medium and examined under the stereoscopic microscope. The dissected parts were stored in glycerin in genitalia vials on the same pins as the specimens from which they were dissected.

The species below are arranged in alphabet order. Only synonymies relevant to Japan are listed in the synonymic list because detailed synonymic lists are presented in Alexander and Schwarz (1994).

The morphological terms used in descriptions gener- ally followed Alexander (1994) and Michener (2000).

The abbreviations used are as follows:

CD clypeocellar distance (distance from apicomedian margin of clypeus to apical margin of median ocellus)

UID upper interocular distance

LID lower interocular distance

OCD ocelloccipital distance

LOD lateral ocellar diameter

$\mathrm{T}$ tergum or terga. For example, the first tergum is referred to as $\mathrm{T} 1$, the second as $\mathrm{T} 2$

$\mathrm{S} \quad$ sternum or sterna

FL flagellar segment

Because there is little variation among most Japanese species of the ruficornis species group, the following characters are excluded from descriptions: the sculpture on the scutum in both sexes (usually densely punctate, the punctures are separated less by a puncture 
diameter); the vestiture on female legs (usually much sparer and shorter than in the male, feebly plumose); the erect, brown bristle on the head in both sexes, and the male subgenital brush. These characters are described only in cases those deserve special mention.

Label data of the specimens were all recorded as long as the localities could be specified. All label data are given in "specimens examined" in the case of new species and uncommon species. In the case of common and abundant species, only the data of specimens from the prefectures without previous records are listed in detail.

The seasonal changes of the number of captured individuals are shown in tables for all species in order to illustrate the activity patterns of species.

Distributional maps were made based on data for specimens examined in the present study and records found in the literature. Records in the literature were cited when: (1) as a rule, they were published after 1973 (Most Japanese species were described after 1973, so that identifications of species in papers published before 1973 are in need of re-examining), and (2) identifications of species are reliable judged from the contents. In the maps, prefectural areas with examined specimens are densely shaded, and prefectural areas without examined specimens but with records in the literature are lightly shaded. In the case of species with relatively a few collecting localities, each locality is indicated by a dot.

Japanese prefectural areas and islands referred in the text are shown in Fig. 1 and listed in Table 1. The localities of the examined specimens in descriptions are arranged according to the list in Table 1.

\section{The ruficornis species group Alexander}

It may be a paraphyletic group and may correspond to the remnant of more inclusive monophyletic unit minus the more apomorphic subunits such as the armata, basalis etc. species groups (Alexander, 1994).

\section{Diagnosis.}

Scape cylindrical. First flagellar segment shorter than second. Paraocular area distinct in female. Malar area posteriorly closed. Lateral ridge on pronotum rounded, indistinct. Boundary of propodeal triangle not distinctly carinated. Subgenital brush moderately long, suberect mesally and semi-recumbent laterally. Protarsal brush present. Male hind femur without flocculus on ventral surface. S8 with median process laterally compressed, long, narrow, parallel-sided basally, slightly widened apically. Penis valve without ventral hook, inner ridge, and outer ridge. Gonocoxite with dorsal invagination and dorsal lobe. Gonostylus usually cylindrical, basoventral lobe usually present; vestiture not distinctly separated into basal and apical tufts.

1. Nomada abtana Tsuneki, 1973

[Japanese name: Abuta-kimadara-hanabachi]

(Figs. 2-4; Table 2)

Nomada abtana Tsuneki, 1973, Etizenia, 66: 126-128

[Holotype: Male. Type locality: Kyogoku, Hokkaido, Japan]; Alexander \& Schwarz, 1994, Univ. Kansas Sci. Bull., 55: 244 [in list].

\section{Redescription. (female new to science) \\ Female.}

Color: Head reddish brown, frequently tinged with yellow on lower paraocular area; the following portions are black: large macula on antennal area, small transverse elliptical macula surrounding ocelli on vertex (these two maculae partially connected), genal area except line along outer eye margin. Mandible reddish brown except apical one-third dark red. Scape black with variously developed reddish brown portion, flagellar segments reddish brown anteriorly, blackish posteriorly, sometimes wholly reddish brown.

Mesosoma black; the following portions are reddish brown: collar on the top, pronotal lobe, tegula, four well-separated longitudinal lines on scutum, axillae, scutellum, large macula on mesopleuron (sometimes divided into two maculae, the one on hypoepimeral area small, the other below scrobe much larger), a pair of small maculae on dorsal surface of propodeum or sometimes lacking.

Metasoma dark reddish brown, T1 black on basal half, apical margin of each $\mathrm{T}$ blackish; the following portions are yellow: a pair of maculae each on $\mathrm{T} 2$ and $\mathrm{T} 3$ (the former on T2 round or oval, the latter on T3 much smaller, transversely elliptical), narrowed or interrupted medially, thin band on T4, roughly rectangular macula on T5 medially. S5 blackish basally, reddish brown apically. Pygidial plate black.

Legs reddish brown; the following portions are blackish or black: anterior portion of fore coxa except apical margin, trochanter posteriorly, fore femur basoventrally, mid coxa and mid trochanter posteriorly, mid femur except dorsal and apical annular portions, hind leg except dorsal portion.

Sculpture: Punctures on labrum distinct, small, dense. Those on clypeus and supraclypeal area dense, becoming slightly gradually smaller apically. 


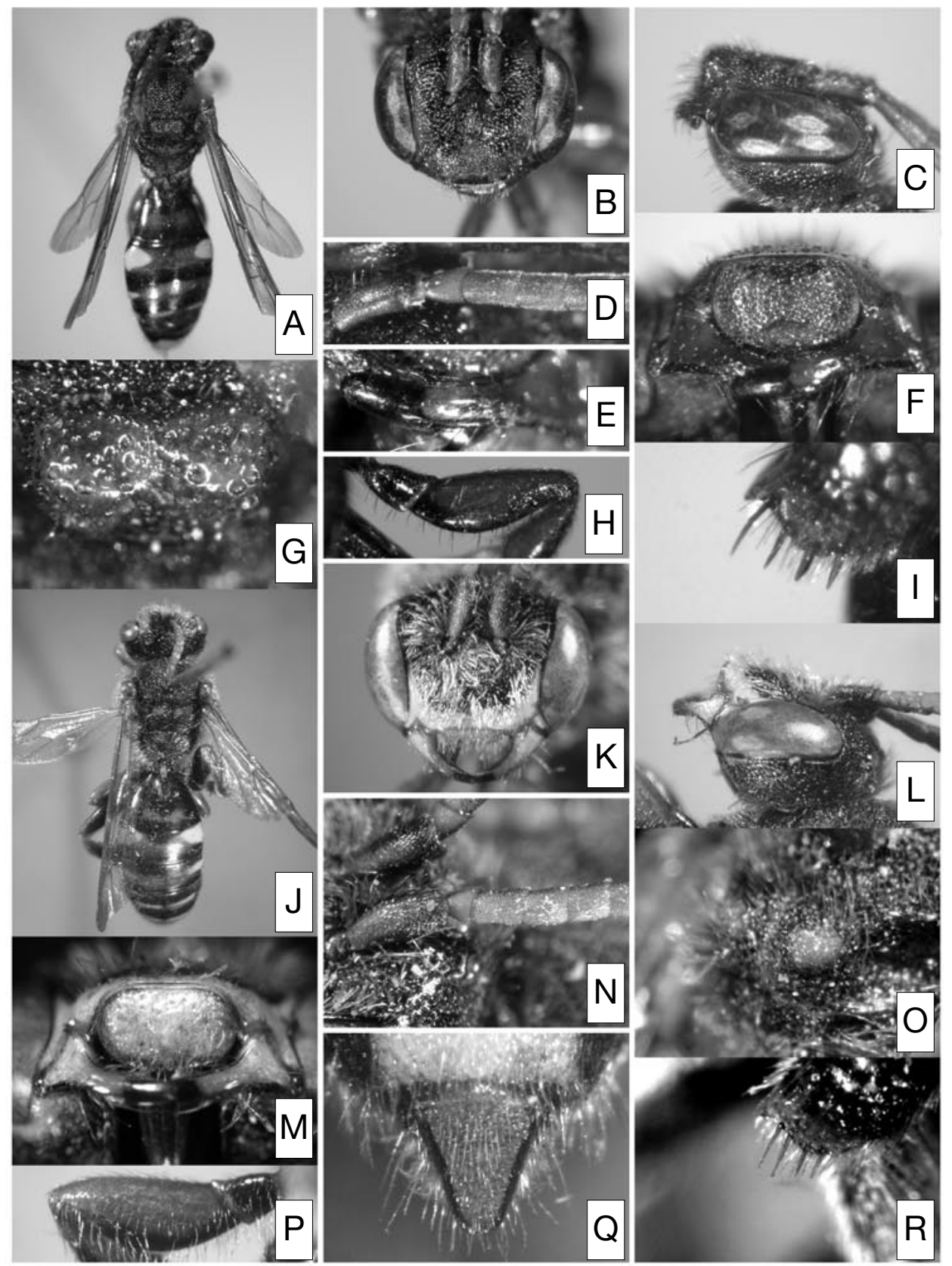

Fig. 2. Nomada abtana Tsuneki. Female: A-I. Male: J-R. A, J: habitus, dorsal view. B, C, K, L: head. D, N: antenna. E: mandible. F, M: labrum. G, O: scutellum. H, P: fore femur, posterior view. I, R: apicomedian setae on hind tibia. Q: pygidial plate.

Punctures on anterior half of scutellum sparser than or as dense as on scutum, on posterior half much sparser. Mesopleuron deeply areolate. Lower side below the propodeal spiracle of propodeum rugose with sparse, obliterated punctures; upper side and dorsal surface outside triangle densely punctate or coarsely areolate, evidently denser than on mesopleuron. Propodeal triangle irregularly rugose at base narrowly, longitudinal rugae relatively prominent basolaterally, the remaining por- tion tessellate. Pygidial plate with punctures small and dense.

Vestiture: Vestiture on labrum considerably sparse, weakly plumose, short, but longer on narrow apical margin. That on clypeus and supraclypeal area also considerably short and sparse, appressed, indistinct. That on lower genal area pale brown, sparse, as long as on apical margin of labrum.

Vestiture on scutum and scutellum scarcely discern- 
ible. That on mesopleuron whitish, plumose, suberect hairs, sparser centrally. Propodeum largely nearly hairless except posterolateral corner provided with a loose patch of white, short, plumose, suberect hairs, but frequently sparse, not to form such hair patch.

Pseudopygidium well developed as normal in female Nomada. Pygidial plate covered with dense hairs obscuring integument.

Structure: Body length 7-9 mm. CD:UID:LID 50:50:42. OCD/LOD 1.6.

Interantennal elevation highly raised. Inner eye margins moderately convergent below. Clypeus moderately raised and produced anteriorly. Labrum 1.6 times as wide as long; labral tooth present at one-third from apex, accompanied by indistinct carina; apical portion weakly produced anteriorly, weakly or not upcurved; apical margin serrated. Mandible simple, rounded or truncate at apex. Preoccipital ridge distinctly carinated. Relative length of FL1-3 1:1.4:1.2, relative length to apical width of FL1 nearly equal, FL2 1.5 times, FL3 1.3 times.

Scutellum highly raised, anterior face more or less flat, median furrow wide and deep. Fore femur robust, dilated medially. Pygidial plate triangular at apical portion.

Apicomedian setae on hind tibia four in number, black, evenly spaced, even in length except posteriormost seta slightly longer than others.

\section{Male.}

Color: Head and mesosoma largely black; the following portions are yellow: mandible except apical onethird black, labrum, clypeus on apical half with upper margin of the yellow arched upwards, malar area, lower paraocular area along inner eye margin extending up to level of antennal socket, lower outer eye margin extending shortly from hypostoma, collar on the top but sometimes lacking, small elliptical spot on anterior portion of mesopleuron; the following portions are reddish brown: tegula and two maculae (sometimes tinged with yellow) on scutellum. Scape and flagellar segments reddish brown anteriorly, distinctly black posteriorly at least from base to fifth segments, paler apically.

Terga dark brown, $\mathrm{T} 1$ black on basal half, $\mathrm{T} 2$ and $\mathrm{T} 3$ brown on intermacular areas; the following portions are yellow: a pair of maculae each on T2 and T3 (the former on T2 large, oval, the latter on T3 much smaller, elliptical), band each on T4 and T5 (that on T4 interrupted narrowly in the middle), large transverse elliptic macula on T6 medially. Sterna dark reddish brown, further darker apically, T3-5 each with medially upcurved thin yellow band, T6 yellow medially.
Legs reddish brown; the following portions are blackish or black: fore coxae except apical narrow margin, fore femur ventrally, mid legs ventrally, hind leg except narrowly dorsal portion of femur and ventral side of tibia.

Sculpture: As in female, but denser and coarser on scutum, scutellum, mesopleuron and terga.

Vestiture: Vestiture on labrum pale brown, moderately dense, plumose. That on clypeus and supraclypeal area silvery shining, appressed, plumose, dense as to obscure integument. That on lower genal area near hypostoma brown, slightly longer than on labrum.

Vestiture on scutum and scutellum brown tinged with golden, moderately long, the latter plumose, slightly longer and darker. That on mesopleuron whitish but slightly darker on upper portion, plumose, suberect, not dense to form hair patch. That on posterolateral to dorsal surface of propodeum outside propodeal triangle plumose, erected, sparse, not forming hair patch, as long as those on mesopleuron.

Vestiture on ventral side of fore femur somewhat shorter than half of the maximum width of segment, that of mid femur much shorter than half of the maximum width of segment. That on basoventral flattened surface of hind femur straight, sparse, suberect, posteriorly directed.

Structure: Body length $9 \mathrm{~mm}$. CD:UID:LID 50:48:40. OCD/LOD 1.6.

The following aspects are different from female: scape wider than flagellar segments; relative length of FL1-3 1:1.7:1.5, relative length to apical width of FL1 0.9 times, FL2 1.5 times, FL3 1.2 times, tyloidea on FL1 absent, those on FL2 distinctly delimited, ridge-shaped, those on FL3-5 distinctly delimited, highly raised, elliptical, those on the following segments successively less indistinct; pygidial plate entire or minutely emarginated at apex; apicomedian setae slightly thinner than in female, otherwise as in female; hind femur robust, evidently thicker medially.

Male terminalia: 7th metasomal sternum as in Fig. 3-A. 8th as in Fig. 3-B, C. Gonostylus thick, comparatively short; vestiture simple, weakly sinuate apically; basoventral lobe distinct with long simple vestiture. Penis valve produced posteriorly beyond gonostylus, apex extending ventrally beyond apex of gonostylus in lateral view. Gonocoxite with deep dorsal invagination; inner dorsal lobe somewhat longer than wide, with apex truncate.

Distribution. Japan (Hokkaido).

Specimens examined. Holotype (MNHAH), $\sigma^{7}$, attached with two labels as follows: "Kyogoku/ Abuta/ 

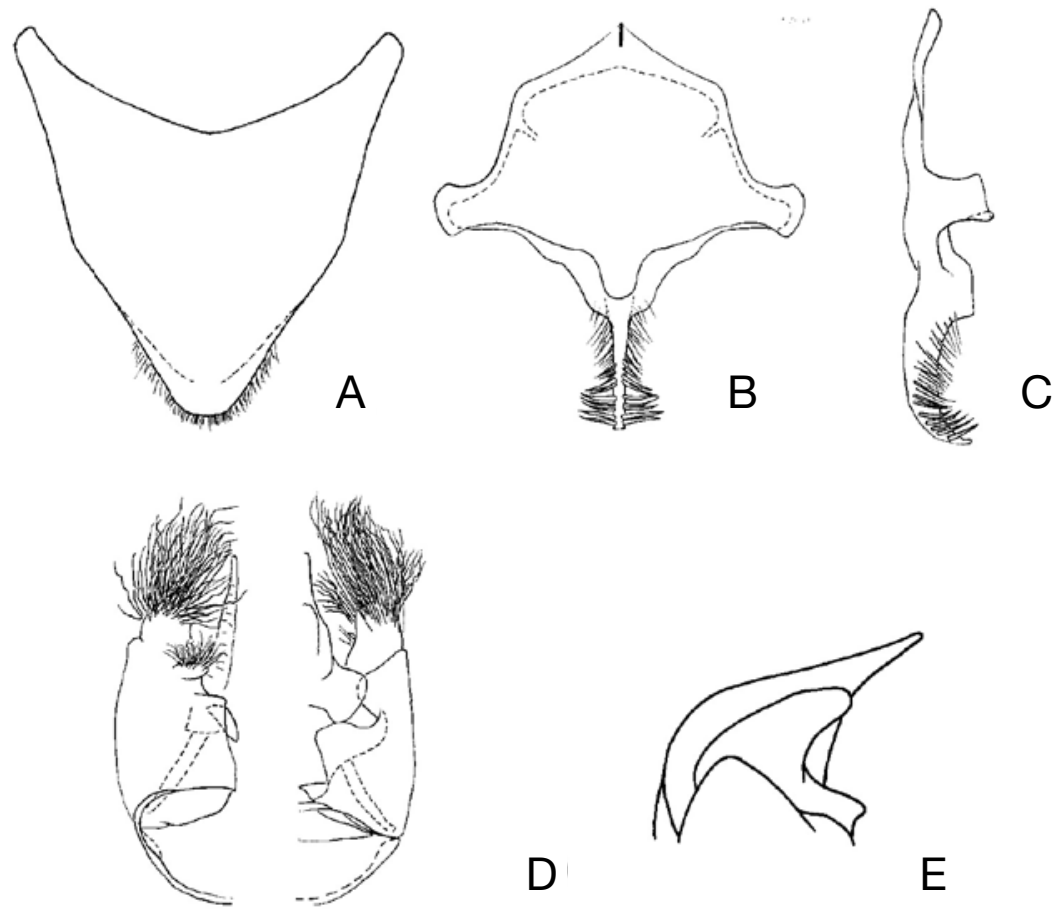

D

E

Fig. 3. Nomada abtana (male). A: 7th metasomal sternum, ventral view. B: 8 th sternum, dorsal view. C: the same, lateral view. D: genital capsule (left, ventral view; right, dorsal view). E: penis valve and gonostylus, lateral view (vestiture omitted).

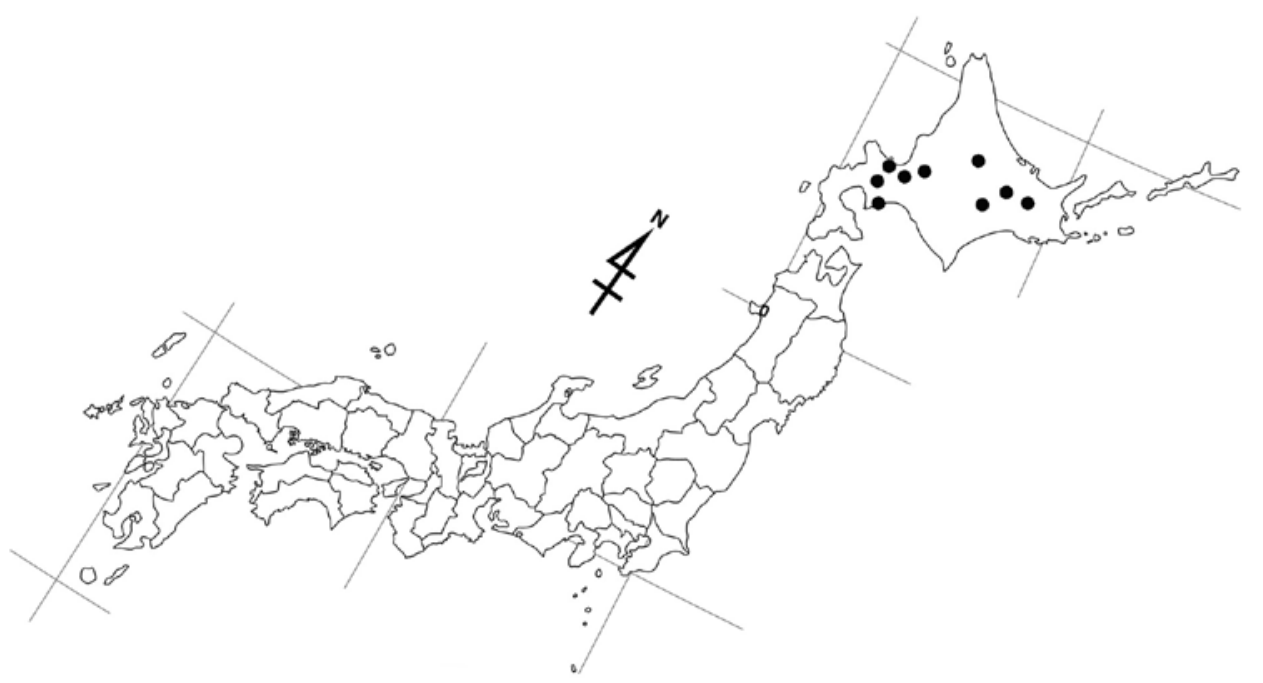

Fig. 4. Distribution of $N$. abtana on the Japanese mainlands. Dots: localities of the specimens examined in the present study. 
Table 2. Seasonal change of number of the captured individual of N. abtana in Japan (Number of females indicates at the left of slash in cell, that of males at the right. E: early, M: mid, L: late).

\begin{tabular}{c|ccc|ccc}
\hline & \multicolumn{3}{|c|}{ June } & \multicolumn{3}{c}{ July } \\
\cline { 2 - 7 } & $\mathrm{E}$ & $\mathrm{M}$ & $\mathrm{L}$ & $\mathrm{E}$ & $\mathrm{M}$ & $\mathrm{L}$ \\
\hline \hline HOKKAIDO & & & $6 / 3$ & $4 / 1$ & $11 / 2$ & $2 /$ \\
\hline Total & 0 & 0 & 9 & 5 & 13 & 2 \\
\hline
\end{tabular}

Hokkaido/ 17. VII. 1966/ M. Munakata [white rectangle with handwritten letters]", "Nomada/ abtana/ Tsuneki 우/ Holotype [red rectangle with handwritten letters]".

Other specimens: We have examined 23 females and 5 males from Hokkaido, Japan as follows: $1 \sigma^{\nearrow}$, Bibai, 5. vii. 1971 (S. Momoi, Nambu Coll.); 7우1ㅈ, Kussharoko, Teshikaga, 21. vii. 1984 (O. Tadauchi, ELKU); 1 우, Kyohgoku, Shiribeshi, 22. vii. 1959 (M. Munakata, ELKU); 1오, Lake Daisetsu, Kamikawa-cho, 30. vii. 2004 (Y. Maeta); 2우107, Mt. Tenguyama, Otaru City, 28. vi. 1999 (H. Suda); 1우, Nishiashoro (Tokachi), 9. vii. 1953 (Y. Hirashima, ELKU); 1우1ð', Tokachimitsumata, Kamiashihoro, 26. vii. 1984 (O. Tadauchi, ELKU); 4우 10', University Campus, Sapporo Hokkaido, 1, 10, 16, 23. vii. 1979 (Toda, NIAES); 1우, Taru River, Otaru, 28. vi. 2003 (K. Kinota); 10', Tochachimitsumata, Kamishihoro-chô, Katô-gun, 28. vi. 2005 (R. Murao, ELKU); 1 우, Rikubetsu-chô, Ashoro-gun, Tokachi-shichô, 29. vi. 2005 (R. Murao, ELKU); 2 우1중, Oyochi, Rikubetsuchô, Ashoro-gun, Tokachi-shichô, 29. vi. 2005 (O. Tadauchi, ELKU); 1우, Horonobe-chô, Teshio-gun, Rumoi-shichô, 7. vii. 2005 (T. Sugimoto, ELKU).

Biology. It is a univoltine species, collected from late June to July (Table 2). Floral associations are as follows: [Cruciferae] Rorippa sylvestris; [Leguminosae] Trifolium repens; [Compositae] Picris hieracioides var. glabrescens. The host is unknown.

Remarks. It can be recognized by the combination of the following characters: the apically truncate or rounded mandible, FL2 1.5 times as long as the apical width, the robust, lunate fore femur, the highly raised and distinctly bigibbous scutellum, and the narrowly basally rugose propodeal triangle. It is similar to Nomada striata Fabricius superficially in both sexes, but differs from the latter in the more weakly convergent inner eye margins and their phenologies; $N$. striata is active in spring whereas $N$. abtana is active in summer.

2. Nomada alboguttata etizenensis Tsuneki, 1975 [Japanese name: Echizen-kimadara-hanabachi] (Figs. 5-7; Table 3)
Nomada alboguttata etizenensis Tsuneki, 1975, Kontyû, 43: 467-468 [Holotype: Female. Type locality: Mt. Akato, Fukui Pref., Honshu, Japan]; Alexander \& Schwarz, 1994, Univ. Kansas Sci. Bull., 55: 244 [in list].

\section{Redescription. \\ Female.}

Color: Head black; the following portions are reddish brown: mandible except apical one-third dark red, labrum, malar area, clypeus on apical one-third, lower paraocular area extending up along inner eye margin shortly to level of antennal socket, sometimes narrowly extending up to top of compound eye, where reddish brown expanded mesally, line on genal area along lower outer eye margin extending shortly from hypostoma. Antenna reddish brown anteriorly, scape black posteriorly, flagellar segments darker posteriorly.

Mesosoma black; the following portions are reddish brown: collar on the top, pronotal lobe, tegula, four well-separated longitudinal lines on scutum, but sometimes lacking, axillae, two maculae on scutellum, or frequently fused into one large macula, irregular vague macula on mesopleuron.

Metasoma dark brown; medial portion of T1, intermacular area on T2 and T3 paler; the following portions are yellow: a pair of maculae each on T2 and T3 (the former on T2 larger and oval, the latter on T3 much smaller, irregular in size), narrowed or medially interrupted band on T4, large macula on T5 medially. Sterna dark yellow, apical transparent margin blackish.

Legs black; the following portions are reddish brown: apical portions of all coxae, fore femora anteriorly, darker posteriorly, middle and hind femora apically and dorsally, all tibiae and tarsi, the latter two somewhat paler in color.

Sculpture: Punctures on labrum small, indistinct. Those on clypeus dense, distinct, small. Those on supraclypeal area slightly larger.

Punctures on scutellum as on scutum. Mesopleuron deeply areolate. Lateral and dorsal sides outside propodeal triangle of propodeum shallowly areolate except 


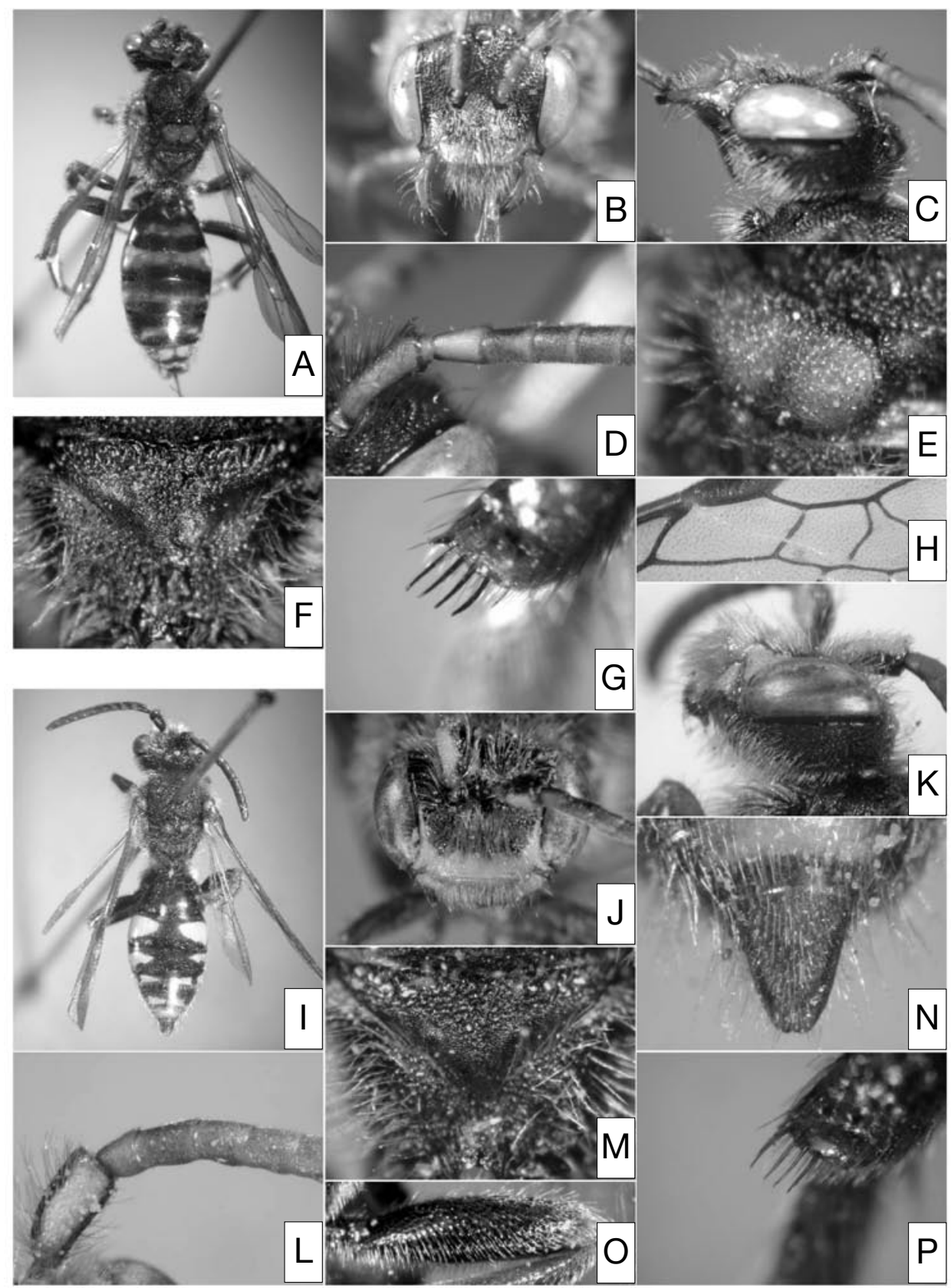

Fig. 5. Nomada alboguttata etizenensis Tsuneki. Female: A-H. Male: I-Q. A, I habitus, dorsal view. B, C, J, K: head. D, L: antenna. E: scutellum. F, M: propodeal triangle. G, P: apicomedian setae on hind tibia. H: submarginal cell in fore wing. $\mathrm{N}$ : pygidial plate. O: hind femur, frontal view.

weakly rugose portion under spiracle. Propodeal triangle irregularly coarsely rugose on basal half and central portion, remaining portion tessellate. Terga matt, faintly microsculptured, with sparse, weak punctules (on T3 and 4 punctules nearly obliterate).

Vestiture: Vestiture on labrum pale brown, plumose; that on apical margin long, otherwise much shorter. That on clypeus and supraclypeal area pale brown, fine, weakly plumose, appressed. That on lower genal area pale brown, evidently shorter than on apical portion of labrum.

Vestiture on scutum and scutellum dark brown tinged with golden, short. That on mesopleuron and posterolateral to dorsal surface of propodeum outside triangle erect, weakly plumose, whitish hairs. That on posterolateral to dorsal surface of propodeum outside 
triangle sparse, erect, brown tinged with golden, weakly plumose.

Pseudopygidium well developed as normal in female Nomada.

Structure: Body length 6-9 mm. CD:UID:LID 50:53:47. OCD/LOD 1.5.

Interantennal elevation weakly raised. Inner eye margins nearly straight, moderately convergent below. Clypeus weakly raised and produced anteriorly. Labrum 1.6 -1.7 times as wide as long; small labral tooth present before the center; apical portion below labral tooth moderately produced anteriorly, not upcurved; apical margin not or sometimes weakly serrated. Mandible slender. Preoccipital ridge distinctly carinate. Relative length of FL1 to FL3 equal in length, relative length to apical width of FL1 1.2 times, FL2 1.3 times, FL3 1.3 times.

Scutum roundly highly raised. Scutellum moderately or highly, roundly raised, distinctly bigibbous, usually median furrow deep.

Pygidial plate brown, triangular at apical portion, covered with sparse hairs; punctures large, impunctate margin wide and smooth.

Fore femur moderately built. Procoxa weakly produced apically, but not forming a spine. Apicomedian setae on hind tibia four or five in number, black, all similar in shape, long, slightly curved downward, bluntly pointed at apex, somewhat shorter anteriorly but sometimes appears all the same in length. Second radiusmedia vein in fore wing strongly curved mesally, so that third submarginal cell strongly narrower apically. Pygidial plate entire or minutely emarginated at apex.

\section{Male.}

Color: Head and mesosoma black; the following portions are yellow: mandible except apical one-third or -fourth black, labrum, clypeus on apical half or twofifth, malar area, lower paraocular area extending up along inner eye margin to antennal socket, pronotal lobe, two macula on scutellum (frequently lacking). Scape yellow anteriorly, flagellar segments brown anteriorly, antenna wholly black posteriorly.

Metasoma black; the following portions are yellow: a pair of oval maculae each on T2 and T3 (maculae on T3 much smaller), a band each on T4 and T5 (interrupted narrowly in the middle), a large macula on T6 medially; all maculae and bands with a round emargination on lateral portion which gives appearance of a black spot. In specimens with less developed maculae, such spot-like emargination disappearing. Sterna largely blackish, S 3-5 each with an obliterated thin yellow band, S6 yellow apicomedially.

Legs largely blackish or black; the following por- tions are brown: fore femur and tibia except ventrally, dorsal half of mid femur, mid tibia anteriorly, narrow dorsal portion of hind femur, hind tibia except blackish spot on anterior and posterior surface. Sometimes mid and hind legs wholly blackish.

Sculpture: Sculpture as in female, but slightly shallower on head and mesosoma, more distinct on metasoma.

Vestiture: Vestiture on labrum yellowish, dense and long (evenly in density and length wholly), plumose, erect. That on clypeus and supraclypeal area similar to that on labrum, but slightly obliquely erect. That on lower genal area slightly shorter than on labrum.

Vestiture on scutum, scutellum, mesopleuron and posterolateral to dorsal surface of propodeum outside triangle similar in color and length to that on clypeus (darker on scutellum), but erect, sparser, more weakly plumose.

Vestiture on ventral surface of fore femur slightly shorter than the maximum width of segment (slightly shorter than that of fore trochanter), that of mid trochanter and femur about as long as the half of maximum width of segment, that of hind trochanter and femur nearly straight, shorter than the maximum width of segment, that on ventral surface of hind femur sparse, posteriorly directed suberect straight.

Structure: Body length 7-9.5 mm. CD:UID:LID 50:56:45. OCD/LOD 1.6.

The following aspects are different from female: interantennal carina raised slightly higher than in female, lowered abruptly at level of anterior margin of antennal socket in profile; scape wider than flagellar segments; relative length of FL1-3 1:1.5:1.3, relative length to apical width of FL1 0.9 times, FL2 1.6 times, FL3 1.4 times, tyloidea on FL1 absent, those on FL2 indistinct ridge-shaped, those on FL3-10 elliptical or oval, sharply delimited but not highly raised; pygidial plate relatively narrow, triangular in apical portion, entire at apex, fore femur robust, dilated medially; apicomedian setae on hind tibia slenderer and paler than in female, otherwise as in female; basoventral flattened surface on hind femur reaching to midpoint of segment, shallowly depressed in posterior view.

Male terminalia: 7th metasomal sternum as in Fig. 6-A. 8th as in Fig. 6-B, C. Gonostylus long; vestiture dense, simple, weakly sinuate, not long; basoventral lobe developed with plumose dense vestiture. Penis valve produced posteriorly beyond gonostylus, apex not extending ventrally beyond apex of gonostylus in lateral view. Gonocoxite with deep dorsal invagination; inner dorsal lobe evidently wider than long, with apex trun- 

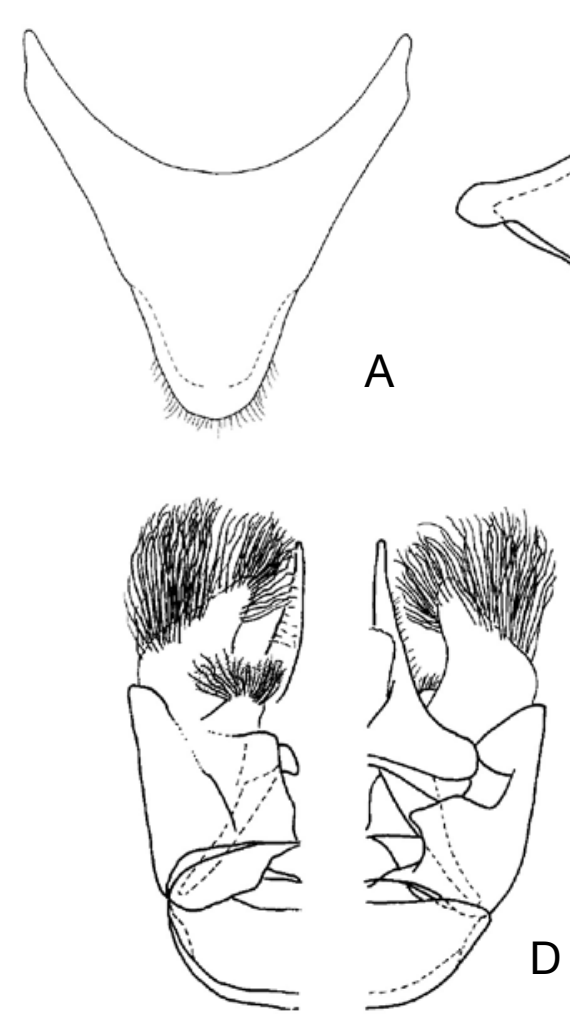

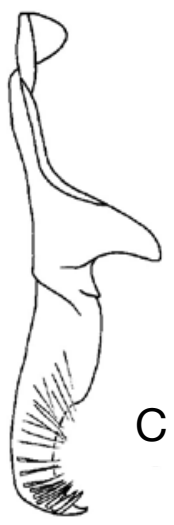

Fig. 6. Nomada alboguttata etizenensis (male). A: 7th metasomal sternum, ventral view. B: 8th sternum, dorsal view. C: the same, lateral view. D: genital capsule (left, ventral view; right, dorsal view). E: penis valve and gonostylus, lateral view (vestiture omitted).

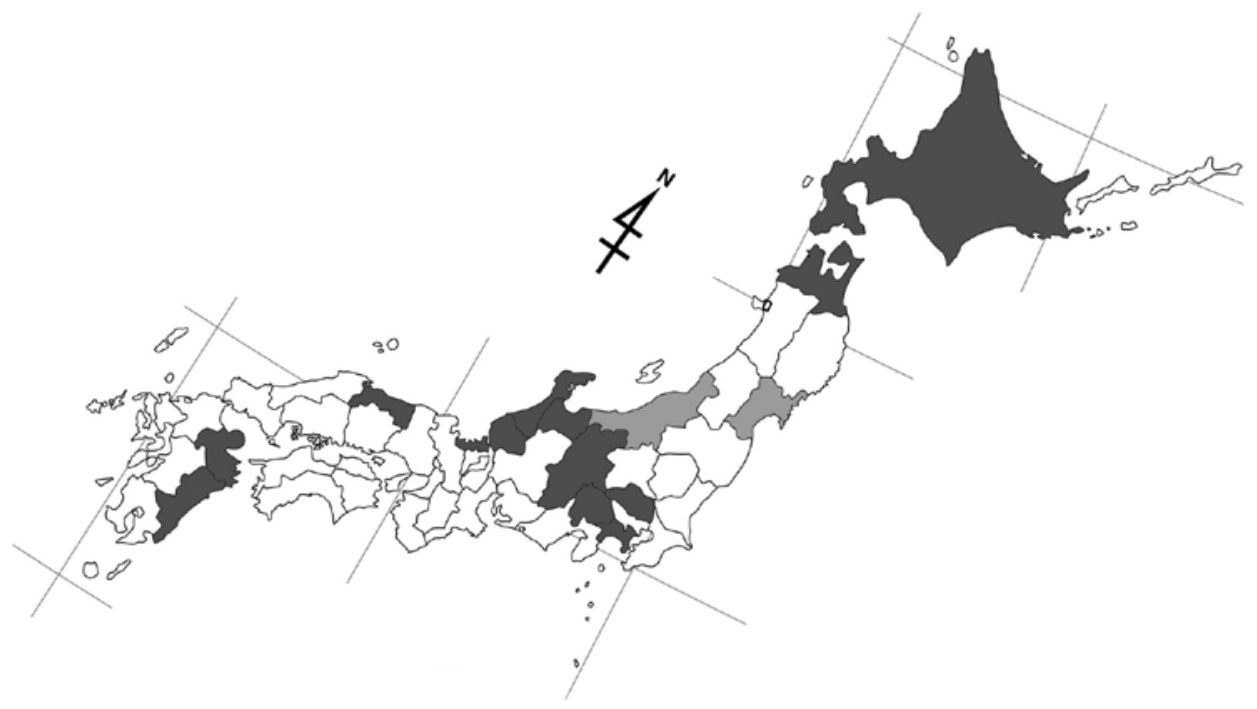

Fig. 7. Distribution of $N$. alboguttata etizenensis on the Japanese mainlands. Densely shaded: prefectures with the specimens examined in the present study. Lightly shaded: prefectures with records in literature, but no specimens examined in the present study. 
Table 3. Seasonal change of number of the captured individual of $N$. alboguttata etizenensis in Japan (Number of females indicates at the left of slash in cell, that of males at the right. E: early, M: mid, L: late).

\begin{tabular}{|c|c|c|c|c|c|c|c|c|c|c|c|c|c|}
\hline \multirow[b]{2}{*}{ Main island } & \multirow[b]{2}{*}{ Prefecture } & \multicolumn{3}{|c|}{ April } & \multicolumn{3}{|c|}{ May } & \multicolumn{3}{|c|}{ June } & \multicolumn{3}{|c|}{ July } \\
\hline & & $\mathrm{E}$ & $\mathrm{M}$ & $\mathrm{L}$ & $\mathrm{E}$ & $\mathrm{M}$ & $\mathrm{L}$ & $E$ & $M$ & $\mathrm{~L}$ & $\mathrm{E}$ & $\mathrm{M}$ & $\mathrm{L}$ \\
\hline HOKKAIDO & & & & & & & & & & $3 / 3$ & & & \\
\hline \multicolumn{14}{|l|}{ HONSHU } \\
\hline [Tohoku] & Aomori & & & & & & 13 & $1 / 1$ & & $1 / 1$ & & & \\
\hline [Kanto] & $\begin{array}{l}\text { Saitama } \\
\text { Kanagawa }\end{array}$ & & & & & & & $\begin{array}{l}2 / \\
1 /\end{array}$ & $/ 9$ & & $/ 4$ & & \\
\hline \multirow[t]{4}{*}{ [Chubu] } & Ishikawa & & & & & & & & $/ 1$ & & & & \\
\hline & Fukui & & & & & $2 / 7$ & $7 / 8$ & $21 / 6$ & $2 / 1$ & & & & \\
\hline & Yamanashi & & & & & & $1 / 1$ & $1 / 3$ & $2 /$ & & & & \\
\hline & Nagano & & & & & & $/ 1$ & $1 /$ & & & & & \\
\hline [Chugoku] & Tottori & & & & & $/ 1$ & & & & & & & \\
\hline \multirow[t]{2}{*}{ KYUSHU } & Oita & & & & & & $1 /$ & & & & & & \\
\hline & Miyazaki & & & $/ 1$ & & & & & & & & & \\
\hline \multicolumn{2}{|l|}{ Total } & 0 & 0 & 1 & 0 & 10 & 22 & 37 & 15 & 8 & 4 & 0 & 0 \\
\hline
\end{tabular}

cate.

Distribution. Japan (Hokkaido, Honshu, Kyushu). Specimens examined. Holotype (MNHAH), 우, Mt. Akato, Fukui Pref., Japan, 1-2. vi. 1974 (M. Munakata).

Other specimens: We have examined 48 females and 51 males. On the localities, see Fig. 7. Some of them are listed as follows: JAPAN [Hokkaido] 3우2 $\sigma^{\top}$, Mt. Tenguyama, Otaru City, 28. vi. 1999 (H. Suda). [Honshu] Aomori: 10', Mt. Bonju (Namioka), 27. v. 1995 (M. Yamada). Saitama: 9우, Nagakubo, Ogano-machi, 17. vi. 1990 (A. Shimizu, Nambu Coll.). Kanagawa: 1우, Mikunitoge, 1100m, Yanakita, 9. 6. 2002 (H. Nagase). Ishikawa: Haku [Maybe Mt. Haku], 20. vi. 1971. Fukui: 30', Kamikoike, Ono-shi, 14. v. 2002 (K. Mitai). Yamanashi: 1우3 $\sigma^{\top}$, Kitahara, Makioka, Higashiyama, 6. vi. 1978 (H. Suda). Nagano: 10', Tokiwa, Saku, 1. vi. 1999 (T. Nambu). Tottori: 10', Mt. Daisetsu, 13. v. 2002 (Y. Maeta). [Kyushu] Miyazaki: 10', Kiuragi, Kobayashi-shi, 28. iv. 2003 (K. Mitai). Oita: 1우, Jusanmagari (Bungo), 29. v. 1932 (H. Hori).

Biology. It is a univoltine species, collected from May to July (Table 3). Suda (1980) suggested that $A n$ drena richardsi Hirashima is the host, based on his multiple observations that many adults of $N$. alboguttata etizenensis were flying near the ground, where $A$. richardsi are building their nests. Maeta et al. (1996) also reported the observation of $N$. a. etizenensis collected on the nesting site of $A$. richardsi, and supported Suda's suggestion. Floral associations are as follows: [Crucif- erae] Brassica sp.; [Caprifoliaceae] Weigela hortensis.

Remarks. The most striking character of this species is apicomedian setae on hind tibia, as described in the description above, and can be easily distinguished from the other Japanese congeners by this character alone. Other characters helpful for recognizing this species are as follows: the FL1-3 of equal length in female, the strongly narrower upward third submarginal cell in forewing in both sexes.

The Japanese subspecies etizenensis differs from European nominotypical subspecies alboguttata in the slightly longer flagellar segments, and the third submarginal cell narrower upward (not so in spp. alboguttata). Here, although we treat $N$. a. etizenensis as subspecies, these differences would not appear discrete if more specimens from various localities were available for study.

3. Nomada amurensis Radoszkowsky, 1876 [Japanese name: Esaki-kimadara-hanabachi] (Figs. 8-10; Table 4)

Nomada amurensis Radoszkowsky, 1876, Hor. Soc. Entom. Ross., 12: 91-93 [Type locality: l'Ussuri (Sibérie Orientale)]; Alexander \& Schwarz, 1994, Univ. Kansas Sci. Bull., 55: 244 [in list].

Nomada esakii Yasumatsu et Hirashima, 1953, Kontyû, 20: 31-34 [Holotype: Male]; Tsuneki, 1973, Etizenia, 66: 92-95, 120 [redescription]; Alexander \& 
Schwarz, 1994, Univ. Kansas Sci. Bull., 55: 246 [in list]. syn. nov.

Nomada sudai Tsuneki, 1976, Kontyû, 44: 152-154 [Holotype: Male]; Alexander \& Schwarz, 1994, Univ. Kansas Sci. Bull., 55: 252 [in list]. syn. nov.

\section{Redescription.}

\section{Female.}

Color: Head reddish brown, the following portions are black: macula on antennal area, transverse ellipti- cal macula surrounding ocelli on vertex, broad line on genal area extending up along preoccipital ridge from hypostoma to vertex; in specimens with widened black portions, three maculae above widened and connected, the reddish brown on face restricted to narrow lines along inner and outer eye margin and apical narrow margin of clypeus, malar area; in specimens with less developed black portions, black maculae wellseparated, a reddish brown spot present on supraclypeal area, black portion on clypeus restricted narrowly to on

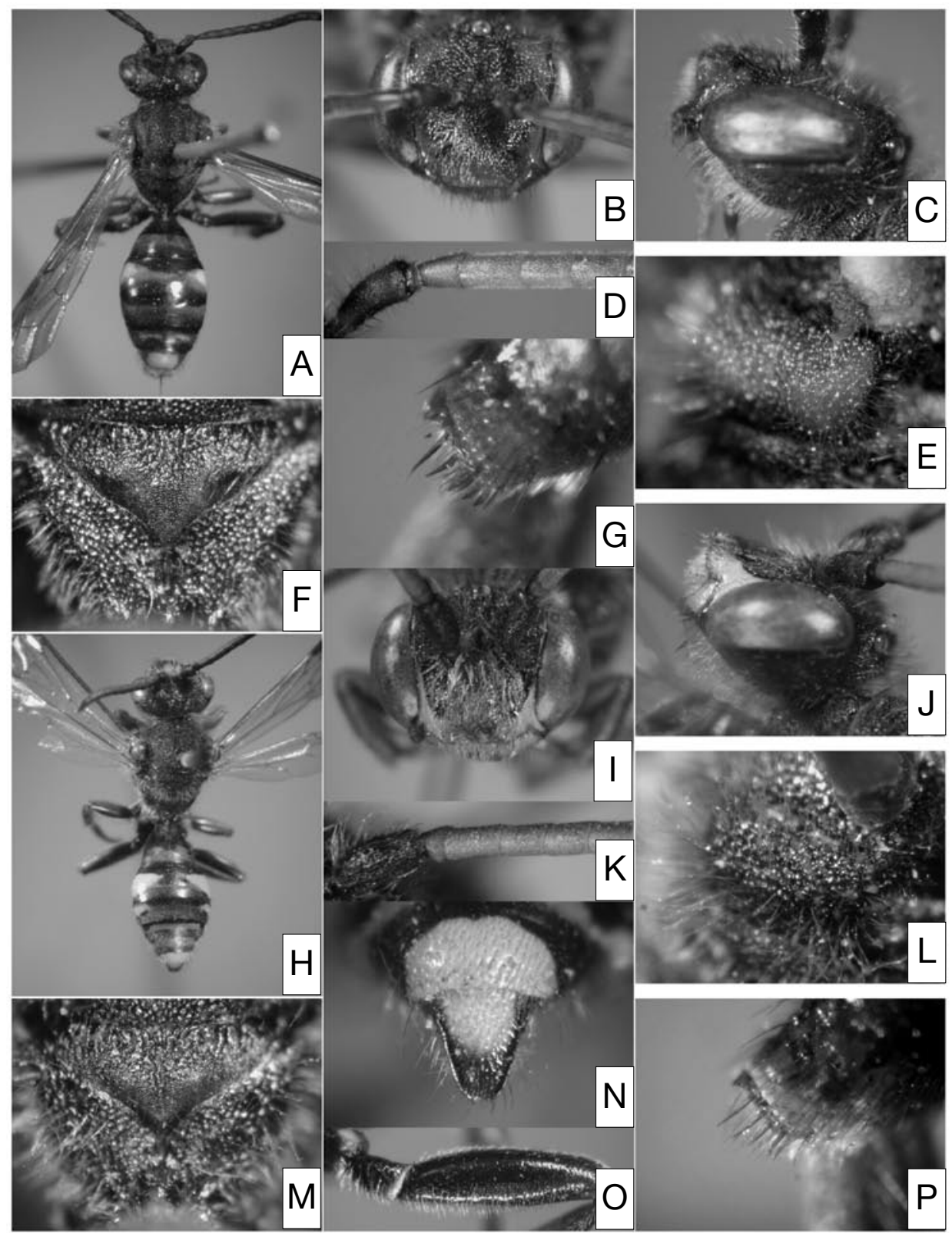

Fig. 8. Nomada amurensis Radoszkowski. Female: A-G. Male: H-P. A, H: habitus, dorsal view. B, C, I, J: head. D, K: antenna. E, L: scutellum. F, M: propodeal triangle. G, P: apicomedian setae on hind tibia. N: pygidial plate. O: hind femur, posterior view. 
epistomal suture. Mandibles reddish brown except apical one-third dark red to black. Color of antenna greatly variable, scape reddish brown to black anteriorly, black posteriorly, anterior surface of flagellar segments pale brown wholly or darker apically, posterior surface pale brown darker apically, apical three segments nearly always black posteriorly, rarely antennae wholly pale reddish or, on the contrary, nearly wholly black except basal flagellar segments narrowly pale reddish brown.

Mesosoma black; the following portions are reddish brown, though highly variable in size: collar on the top, anterior margin of pronotum but frequently lacking, pronotal lobe, tegula, maculae on scutum (variable from four well-separated longitudinal lines to two broad lines occupying scutum nearly wholly except medial longitudinal black line), scutellum nearly wholly, one large or two small spots on metanotum but frequently lacking, macula on mesopleuron (variable from rather a small spot to a large macula occupying lateral surface nearly wholly), a pair of maculae on propodeum (that variable from small spot to large macula on the posterolateral corner of propodeum stretching into triangle, sometimes lacking, thus propodeum wholly black).

Metasoma largely reddish brown to largely black, T1 with a reddish brown band in the middle or reddish brown on apical half; the following portions are yellow: a pair of oval maculae on T2 with intermacular area pale reddish brown, a pair of spots on T3, but frequently lacking, thin, sometimes narrowly interrupted band on T4, large square maculae on T5 medially. Pygidial plate reddish brown.

Legs largely reddish brown; the following portions are blackish or black: fore coxa dorsally and posteriorly, mid and hind coxae posteriorly, fore and mid femora basally, hind femur medioanteriorly and posteriorly, hind tibia posteriorly. Sometimes legs nearly wholly reddish brown.

Sculpture: Punctures on labrum small and distinct. Those on clypeus and supraclypeal area larger and distinct, those on clypeus longitudinally elliptical.

Punctures on scutellum as on scutum. Mesopleuron moderately areolate. Propodeum outside triangle much more densely but more shallowly than on mesopleuron except weakly rugose portion under spiracle. Propodeal triangle irregularly rugose basally, the remaining portion distinctly to weakly tessellate. Pygidial plate with punctures sparse, interpunctural space granulose, becoming smooth apically.

Vestiture: Vestiture on labrum pale brown tinged with golden, relatively sparse, weakly plumose, not long except apical portion much longer. That on clypeus and supraclypeal area inconspicuous, very short, dense, fine. That on lower genal area near hypostoma slightly longer than on apical margin of labrum.

Vestiture on scutum and scutellum pale brown tinged with golden, erect, weakly plumose, on scutum somewhat shorter. That on mesopleuron whitish, longer, denser. That on posterolateral to dorsal surface of propodeum outside triangle, whitish, erect to suberect, sparse, fine, weakly plumose.

Pseudopygidium well developed but short in longitudinal length. Pygidial plate covered with sparse brown hairs.

Structure: Body length 8-12 mm. CD:UID:LID 50:45:41. OCD/LOD 1.4.

Interantennal elevation highly raised. Inner eye margins convergent below. Clypeus highly raised, and moderately produced anteriorly. Labrum 1.6 times as wide as long; labral tooth present at or slightly before the center, accompanied by indistinct carina on each side; apical portion below labral tooth weakly produced anteriorly, not upcurved; apical margin not or indistinctly serrated with small triangular protuberance medially. Preoccipital ridge distinctly carinate behind vertex, gradually rounded apically. Relative length of FL1-3 1:1.6:1.3, relative length to apical width of FL1 0.9-1.0 times, FL2 1.7-1.8 times, FL3 1.4 times.

Scutellum highly raised, anterior face flat, median furrow wide and deep. Hypoepimeral area evidently, but not prominently, convex. Area over propodeal spiracle weakly produced more or less like a ridge.

Pygidial plate triangular at apical portion, usually not notched at apex.

Fore femur moderately built. Apicomedian setae on hind tibia usually seven to ten in number, posteriormost seta slightly longer than others, all setae except posteriormost one considerably short, shorter than surrounding hairs, closely and irregularly spaced, usually black, sometimes paler; sometimes setae five to seven in number, slenderer and longer, paler in color.

Third sub-marginal cell of fore wing with bottom side approximately slightly shorter or as long as that of second sub-marginal cell, thought it is very variable.

Male.

Color: Head and mesosoma black; the following portions are yellow: mandible except apical twofifths reddish brown, labrum, clypeus on apical half, malar area, lower paraocular area extending up along inner eye margin to level of lower margin of antennal socket, macula on anterior portion of mesopleuron but sometimes lacking. Pronotal lobe and tegula brown to reddish brown. Rarely two reddish brown spots present 
on scutellum. Scape black or partially reddish brown anteriorly, black posteriorly, flagellar segments brown to dark brown anteriorly, black posteriorly.

T1 black, with apical half brown, $\mathrm{T} 2$ with a medially widening black band, and a pair of oval yellow maculae of variable size, otherwise brown to dark brown; T3 with similar collar pattern but the macula small, oval to transverse narrow elliptical; T4 largely dark brown to black, with two elliptical, close together yellow maculae, sometimes maculae fused into a complete band; T5 largely dark brown, with a complete yellow band; T6 black with an elliptical yellow band. S3-6 with yellow band or spot.

All coxae black except apical margin brown; all trochanters largely black except anterior surface partially brown, all femora and tibiae largely reddish brown; the following portions dark brown or black: fore and mid femora ventrally, hind femur anteriorly and ventrally, all tibiae partially posteriorly.

Sculpture: Punctures on labrum small and distinct. Those on clypeus larger and distinct, roughly circular. Those on supraclypeal area coarser, sometimes irregularly shaped. Punctures on scutellum denser or as on scutum. Mesopleuron similar to that in female. The remaining portion as in female.

Vestiture: Vestiture on labrum whitish or yellowish, similar in shape and density to that in female. That on clypeus and supraclypeal area appressed, more strongly plumose, obscuring integument. That on lower genal area near hypostoma similar to on labrum but evidently longer.

Vestiture on dorsal and lateral surface of mesosoma erect, long, weakly plumose, whitish or yellowish, on mesopleuron slightly strongly plumose. That on posterolateral to dorsal surface of propodeum similar to that in female, not forming a hair patch.

Vestiture on terga appressed, dense, short, but longer than that in female.

Vestiture on ventral surface of fore femur as long as the maximum width of segment, that of mid femur evidently shorter than the maximum width of segment. That on ventral surface of hind femur sparse, posteriorly directed straight.

Structure: Body length 8-11 mm. CD:UID:LID 50:47:40. OCD/LOD 1.5 .

The following aspects are different from female: interantennal elevation and carina roughly similar in shape to those in female, but the carina somewhat abruptly lowered anteriorly from level of anterior margin of antennal socket in profile; preoccipital ridge angulated, not carinate as in female; scape wider than flagellar segments; relative length of FL1-3 1:2.3: 1.7, relative length to apical width of FL1 0.7 times, FL2 1.7-1.8 times, FL3 1.3-1.4 times, tyloidea on FL1 absent, that on FL2 narrowly ridge-shaped, those on FL3-5 distinctly delimited, oval, evidently successively wider apically, highly raised, those on the following segments indistinctly delimited, successively more weakly raised.

Scutellum moderately raised, convexities rounded, median furrow shallow to moderately deep. Pygidial plate usually widely but shallowly triangularly emarginated at apex.

Fore femur moderately built, or robust and dilated medially. Hind femur moderately built; basoventral flattened surface reaching to midpoint of segment, shallowly depressed in posterior view. Apicomedian setae on hind tibia similar to those in female, but five to seven in number, slightly slenderer, difficult to discern among surrounding dense white hairs; sometimes very robust as in female.

Usually third sub-marginal cell of fore wing similar to that in female, but more highly variable in shape than that in female.

Male terminalia: 7th metasomal sternum as in Fig. 10-A. 8th as in Fig. 10-B, C. Gonostylus weakly flattened apically; vestiture dense, long, simple; basoventral lobe strongly produced, with plumose dense vestiture. Penis valve not produced posteriorly beyond gonostylus, apex extending beyond apex of gonostylus in lateral view. Gonocoxite with deep dorsal invagination; inner dorsal lobe small, truncate at apex.

First generation.

\section{Female.}

Color: Body color much more darkened than in wintering generation. Head and mesosoma largely black; the following portions are dim dark brown or reddish brown, or frequently strongly darkened: mandible, labrum, clypeus on narrow apical margin, narrow line along inner eye margin (widened mesad at top of compound eye), collar on the top, four lines on scutum, two maculae on scutellum (frequently these maculae reduced to small spots, or rarely scutellum wholly black), macula on anterior portion of mesopleuron. Scape black wholly, flagellar segments dark brown anteriorly, black posteriorly, frequently apical five segments wholly black.

Metasoma black; the following portions are yellow: a pair of oval maculae each on T2 and T3 (the former smaller, sometimes lacking), thin band on T4 which frequently narrowly interrupted at the middle and the lateral, large square maculae on T5 medially. 

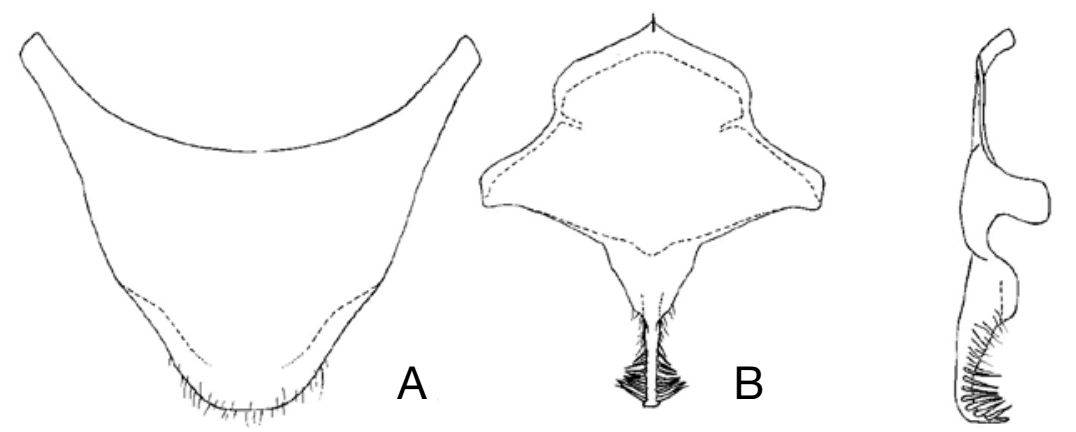

C
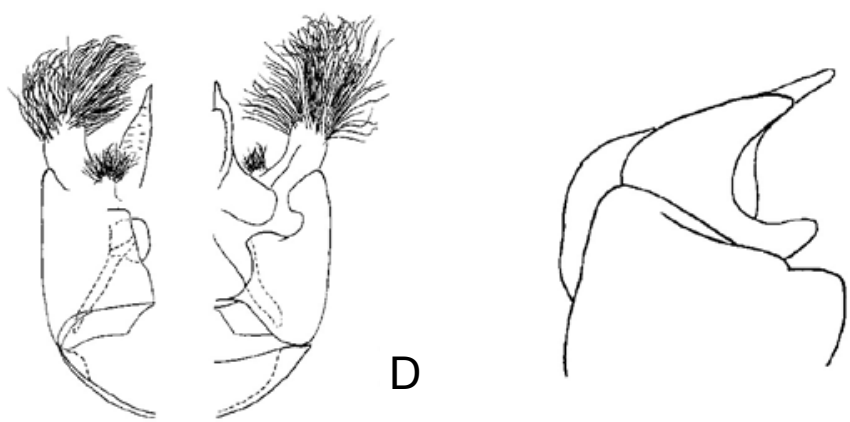

$E$

Fig. 9. Nomada amurensis (male). A: 7th metasomal sternum, ventral view. B: 8th sternum, dorsal view. C: the same, lateral view. D: genital capsule (left, ventral view; right, dorsal view). E: penis valve and gonostylus, lateral view (vestiture omitted).

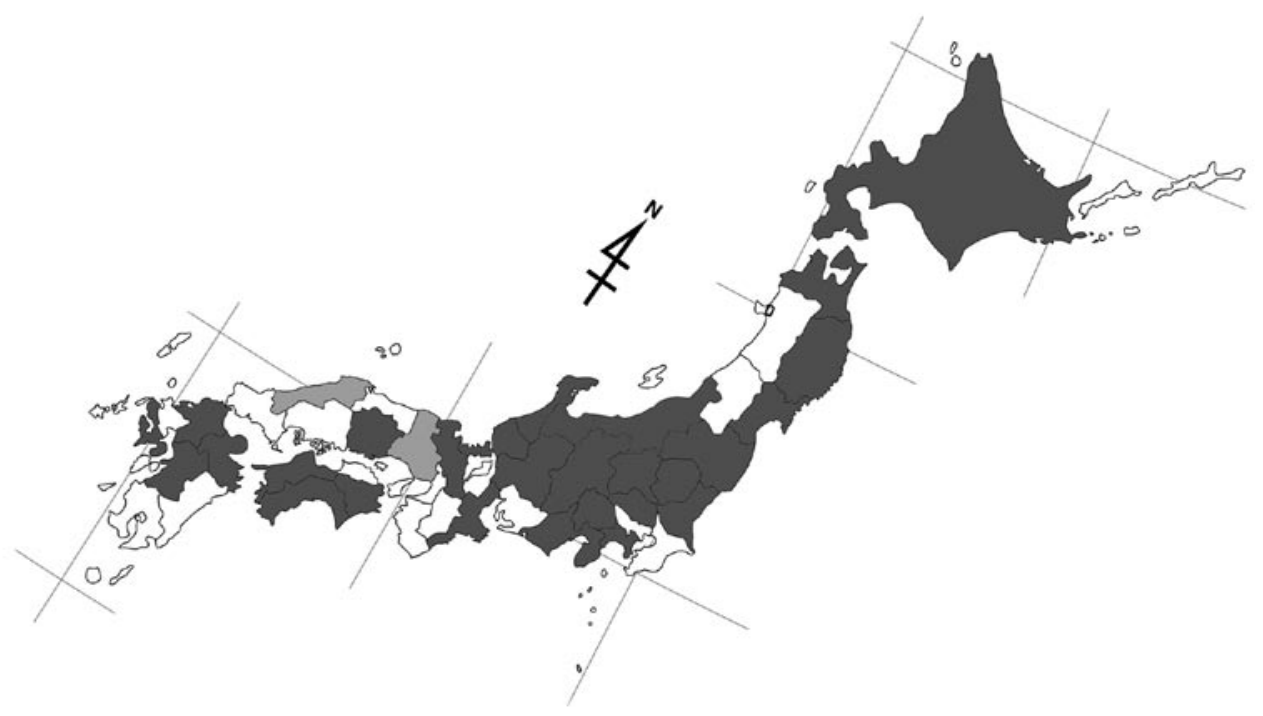

Fig. 10. Distribution of $N$. amurensis on the Japanese mainlands. Densely shaded: prefectures with the specimens examined in the present study. Lightly shaded: prefectures with records in literature, but no specimens examined in the present study. 
Legs largely black or dark brown except all femora slightly paler dorsally and apically.

Sculpture: More conspicuous than in the wintering generation.

Vestiture: Vestiture on body inconspicuous, greatly shorter than in wintering generation, especially on scutum and mesopleuron.

Structure: Body length 9-11 mm. The following aspects are different from the wintering generation as follows: scutellum greatly highly raised, median furrow deep, convexities variable from roughly triangular conical to rounded as in wintering generation. All femora slightly robuster than in wintering generation.

Male.

Color: As in wintering generation, but pronotal lobe and tegula more darkened, terga outside yellow maculae black, legs more largely darkened.

Sculpture: Generally, more or less conspicuous than in the wintering generation.

Vestiture: Vestiture on body evidently shorter than in wintering generation, especially on ventral surface of femora much shorter than the maximum width of each segment.

Structure: Body length 7-10.5 mm.

The following aspects are different from the wintering generation as follows: all femora slightly robuster than in wintering generation, distinctly dilated medially.

Distribution. Japan [Hokkaido, Honshu, Shikoku, Kyushu]; Far East Russia (Primorsky).

Specimens examined. Lectoholotype (Zoological

Table 4. Seasonal change of number of the captured individual of N. amurensis in Japan (Number of females indicates at the left of slash in cell, that of males at the right. E: early, M: mid, L: late).

\begin{tabular}{|c|c|c|c|c|c|c|c|c|c|c|c|c|c|c|c|c|c|c|c|c|c|c|c|c|c|}
\hline \multirow[b]{2}{*}{ Main island } & \multirow[b]{2}{*}{ Prefecture } & \multicolumn{3}{|c|}{ March } & \multicolumn{3}{|c|}{ April } & \multicolumn{3}{|c|}{ May } & \multicolumn{3}{|c|}{ June } & \multicolumn{3}{|c|}{ July } & \multicolumn{3}{|c|}{ August } & \multicolumn{3}{|c|}{ September } & \multicolumn{3}{|c|}{ October } \\
\hline & & $\mathrm{E}$ & $\mathrm{M}$ & $\mathrm{L}$ & $\mathrm{E}$ & $\mathrm{M}$ & $\mathrm{L}$ & $E$ & $\mathrm{M}$ & $\mathrm{L}$ & $\mathrm{E}$ & $\mathrm{M}$ & $\mathrm{L}$ & $\mathrm{E}$ & $\mathrm{M}$ & $\mathrm{L}$ & $\mathrm{E}$ & $\mathrm{M}$ & $\mathrm{L}$ & $E$ & $\mathrm{M}$ & $\mathrm{L}$ & $\mathrm{E}$ & $\mathrm{M}$ & $\mathrm{L}$ \\
\hline HOKKAIDO & & & & & & & & & & $2 /$ & & $1 /$ & & & $1 / 2$ & & & $1 /$ & & & & & & & \\
\hline \multicolumn{26}{|l|}{ HONSHU } \\
\hline \multirow[t]{4}{*}{ [Tohoku] } & Aomori & & & & & & $2 / 1$ & & $2 / 2$ & $/ 1$ & 1/ & $6 / 2$ & $2 /$ & & $1 /$ & & 12 & 12 & 12 & $1 / 5$ & $2 / 3$ & & & & \\
\hline & Iwate & & & & & & $1 / 2$ & $2 / 3$ & $1 /$ & $1 / 1$ & & & & & 1/ & 12 & & & & & $1 /$ & & 1/ & & \\
\hline & Miyagi & & & & & & $5 / 32$ & $2 /$ & $/ 12$ & $1 /$ & & $1 /$ & & & & $/ 1$ & & & & $7 / 3$ & $2 /$ & & & & \\
\hline & Fukushima & & & & & & & & & $1 /$ & & & & & & & & & $1 /$ & & & & & & \\
\hline \multirow[t]{4}{*}{ [Kanto] } & Tochigi & & & & & & $/ 1$ & $7 / 4$ & $2 / 1$ & & 1/ & & & & $/ 1$ & & $/ 1$ & & & & $2 /$ & & & & \\
\hline & Gumma & & & & & & & & & & & & & & & & & & $1 /$ & & & & & & \\
\hline & Chiba & & & & & & & & $2 /$ & & & & & & & & $1 /$ & $1 / 1$ & & $1 /$ & & & & & \\
\hline & Kanagawa & & & & & & & $1 /$ & $/ 1$ & & & & & & & & & & & & & & & & \\
\hline \multirow[t]{7}{*}{ [Chubu] } & Niigata & & & & & & & & & & & & $1 /$ & & & & & & $/ 1$ & $1 /$ & & & & & \\
\hline & Ishikawa & & & & & & & $1 / 2$ & & & & & & & & & & & & & & & & & \\
\hline & Fukui & & & & 13 & & $1 / 1$ & $7 / 17$ & $2 / 5$ & $1 / 1$ & $1 / 1$ & $1 /$ & & & $5 / 12$ & & $1 / 1$ & & $3 / 1$ & $/ 1$ & & $2 /$ & & & \\
\hline & Yamanashi & & & & & & & & $1 /$ & $4 / 1$ & & & & & $1 /$ & & $1 /$ & & & & & & & & \\
\hline & Nagano & & & & & & & & $4 / 1$ & & & & & & $/ 1$ & & $1 / 1$ & & & & & & & & \\
\hline & Gifu & & & & & & & $3 / 2$ & & & & & & & & & & & & & & & & & \\
\hline & Shizuoka & & & & & & & $1 /$ & & & & & & & & & & & $1 /$ & & & & & & \\
\hline \multirow[t]{2}{*}{ [Kinki] } & Mie & & & & & & & & & & & & & & & & & & & & & & & & \\
\hline & Kyoto & & & & & & & & $/ 1$ & & & & & & & & & & & & & & & & \\
\hline \multirow[t]{3}{*}{ SHIKOKU } & Tokushima & & & & & & & & $2 /$ & & & & & & & & & & & & & & & & \\
\hline & Ehime & & & & & & & & $1 /$ & & & & & & & & & & & & & & & & \\
\hline & Kochi & & & & & & 2/ & & & & & & & & & & & & & & & & & & \\
\hline \multirow[t]{4}{*}{ KYUSHU } & Fukuoka & & & & & & $/ 8$ & 17 & $1 /$ & & & & & & & & & & & & & & & & \\
\hline & Nagasaki & & & & 1/ & & & & & & & & & & & & & & & & & & & & \\
\hline & Kumamoto & & & 12 & & & & & & & & & & & & & & & & & & & & & \\
\hline & Oita & & & $/ 1$ & $1 / 2$ & & $/ 1$ & & & & & & & & & & & & & & & & & & \\
\hline \multicolumn{2}{|c|}{ Total } & 0 & 0 & 3 & 7 & 0 & 57 & 59 & 41 & 14 & 4 & 11 & 3 & 0 & 25 & 3 & 9 & 6 & 12 & 18 & 10 & 2 & 1 & 0 & 0 \\
\hline
\end{tabular}


Institute, Russian Academy of Science, St. Petersburg), 우, attached with five labels as follows: "Radoszkowski/ Apidae, L. 185./ Siberia Or (?). (white rectangular and handwritten with typed until L.)", "Dy- bows (white rectangular and typed)", "determ. Lozinski/ N. ruficornis 1. var/ amurensis Ras./ 우 Typus (white rectangular, the top line typed, the other handwritten)", "amurensis (discolored white rectangular with handwritten letters)" and "LECTOTYPUS/ NOMADA ㅇ / amurensis Rad./ M. Schwarz, 1966 (red rectangular and typed except “우, "amurensis Rad." and "66" are handwritten)".

Other specimens: We have examined about 200 females and 100 males. On the localities, see Fig. 10. Some of them are listed as follows: SIBERIA: 1우1 $\sigma^{7}$ without the collecting data (both Lectoparatypes, Zoological Institute, Russian Academy of Science, St. Petersburg). JAPAN [Honshu] Fukushima: 1우, Kashionsen, 24. viii. 1979. (T. Nambu); Mie: 1우, Kawakami, Misugi-mura, Ichishi-gun, 16. v. 2005. (H. Hirano, ELKU). [Shikoku] 2우, Tokushima: Ichiu, Ichiu, 17. v. 1976. (O. Tadauchi, ELKU); 2우, Nakamura-shi (Shikoku), 27. iv. 1957. (Y. Hirashima, ELKU). [Kyushu] Nagasaki: 10', Mt. Tatera, Tsushima Is., 2. iv. 2006. (N. Sugiura).

Biology. It is a bivoltine species. The wintering generation has collected from late March to June, the first generation from July to October (Table 4). Floral associations are as follows: [Salicaceae] Salix hultenii var. angustifolia. [Cruciferae] Capsella bursa-pastoris. [Umbelliferae] Angelica pubescens, Heracleum nipponicum. [Ericaceae] Pieris japonica. [Valerianaceae] Patrinia villosa. [Compositae] Erigeron philadelphicus, Petasites japonicus, Stenactis annuus. The host is unknown.

Remarks. It is similar to Nomada fervens Smith in both sexes, the differences between them are described in detail in Tsuneki (1975) [cited as Nomada esakii. Nomada fervens is cited as N. koebelei]. Furthermore, we found the additional diagnostic characters as follows: the finer tessellate propodeal triangle in both sexes and the slightly shorter vestiture on female mesosoma in female in $N$. amurensis.

The taxonomic treatment about the synonymy of Nomada esakii Yasumatsu et Hirashima is based on our examination of the holotypes and paratypes of both species. The same conclusion are already suggested by $\mathrm{Mr}$. Schwarz (personal communication), who also has examined the types of $N$. amurensis. The record of N. esakii (female) from the South Korea by Tsuneki (1986) is misidentification. It should to be assigned to $N$. fervens.

\author{
4. Nomada asozuana Tsuneki, 1976 \\ [Japanese name: Asozu-kimadara-hanabachi] \\ (Figs. 11, 12; Table 5)
}

Nomada asozuana Tsuneki, 1975, Kontyû, 43: 475-476

[Holotype: Female. Type locality: Asozu, Fukui Pref., Honshu, Japan].

Nomada ohnonis Tsuneki, 1976, Kontyû, 44: 61-63 [Holotype: Female]. syn. nov.

\section{Redescription. \\ Female.}

Color: Head black; the following portions are reddish brown: mandible except apical one-fourth or onefifth dark red, labrum, clypeus except narrow basal margin or basal half black, a spot on supraclypeal area but sometimes lacking, malar area, line along inner and outer eye margin, which narrower or interrupted at lower inner eye margin, wider at top of compound eye. Antenna pale brown anteriorly and blackish posteriorly.

Mesosoma black; the following portions are reddish brown: collar on the top, apical margin of pronotum, pronotal lobe, tegula, four well-separated longitudinal lines on scutum, scutellum, axillae, spot above mesopleural scrobe and large macula below the spot (these two macula connected in two specimens), two pairs of small macula on dorsal surface of propodeum (one pair in propodeal triangle, the other one on the lower dorsal).

Metasoma dark brown to black, T1 black on basal half, T2 black on basal and apical narrow margin, intermacular area reddish brown; the following portions are yellow: a pair of close together, large oval maculae on $\mathrm{T} 2$, thin band each on T3 and T4 (sometimes that on T3 reduced into two or four spots), a roughly rectangular macula on T5 medially. Pygidial plate brown.

Legs largely black; the following portions are reddish brown: all coxae except dorsal and inner portions, fore and mid trochanters anteriorly, hind trochanter except ventral portion, fore femur except dorsal and ventral portions, mid and hind femora except dorsal and apico-ventral portions. In one specimens, all trochanters wholly reddish brown.

Sculpture: Punctures on labrum small and indistinct. Those on clypeus and supraclypeal area successively larger and more distinct.

Punctures on scutellum as same as or smaller and denser than those on scutum. Propodeum outside triangle areolate more minutely on mesopleuron except weakly rugose below spiracle. Propodeal triangle coarsely irregularly rugose basally and centrally, the remaining portion transversely striolate to tessellate. 


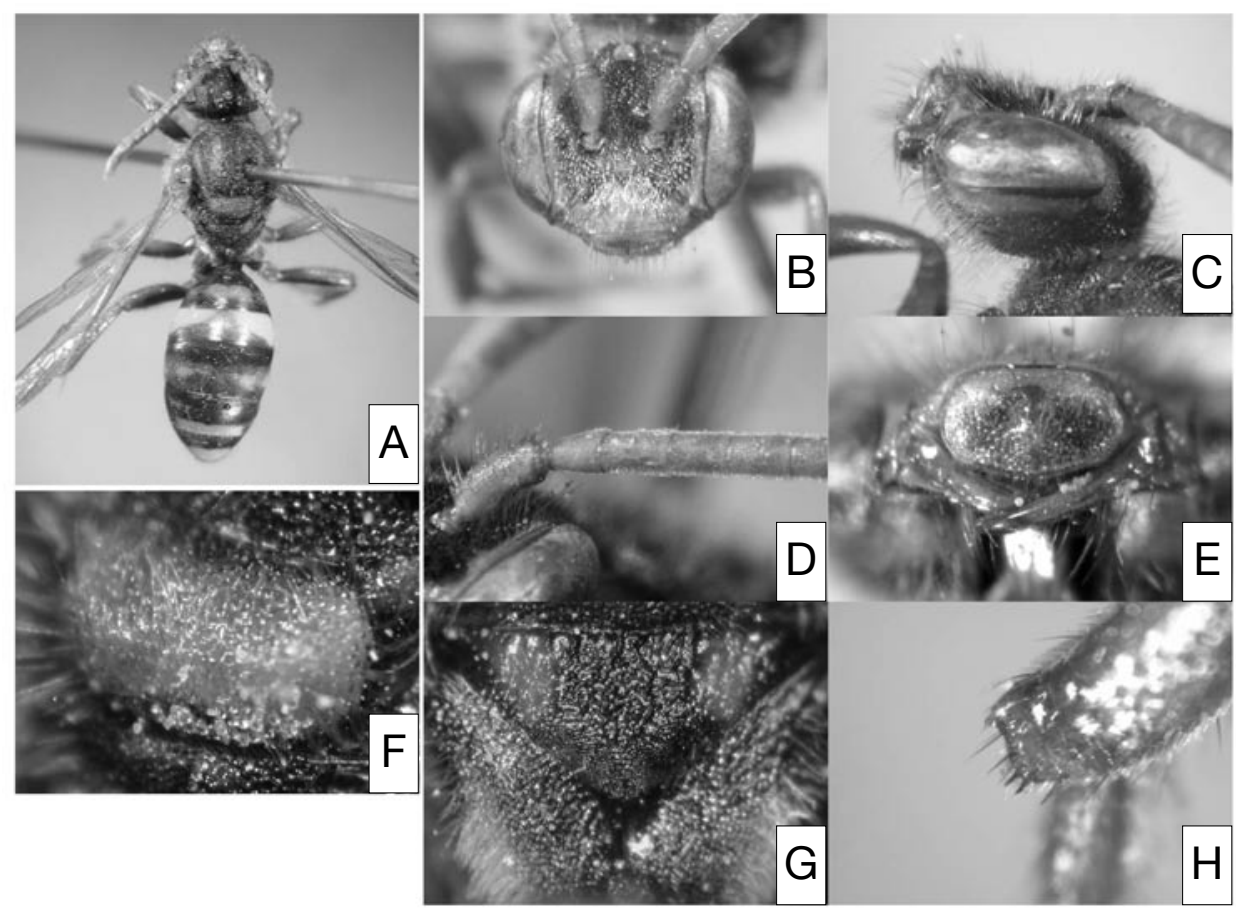

Fig. 11. Nomada asozuana Tsuneki (female). A: habitus, dorsal view. B, C: head. D: antenna. E: labrum. F: scutellum. G: propodeal triangle. H: apicomedian setae on hind tibia.

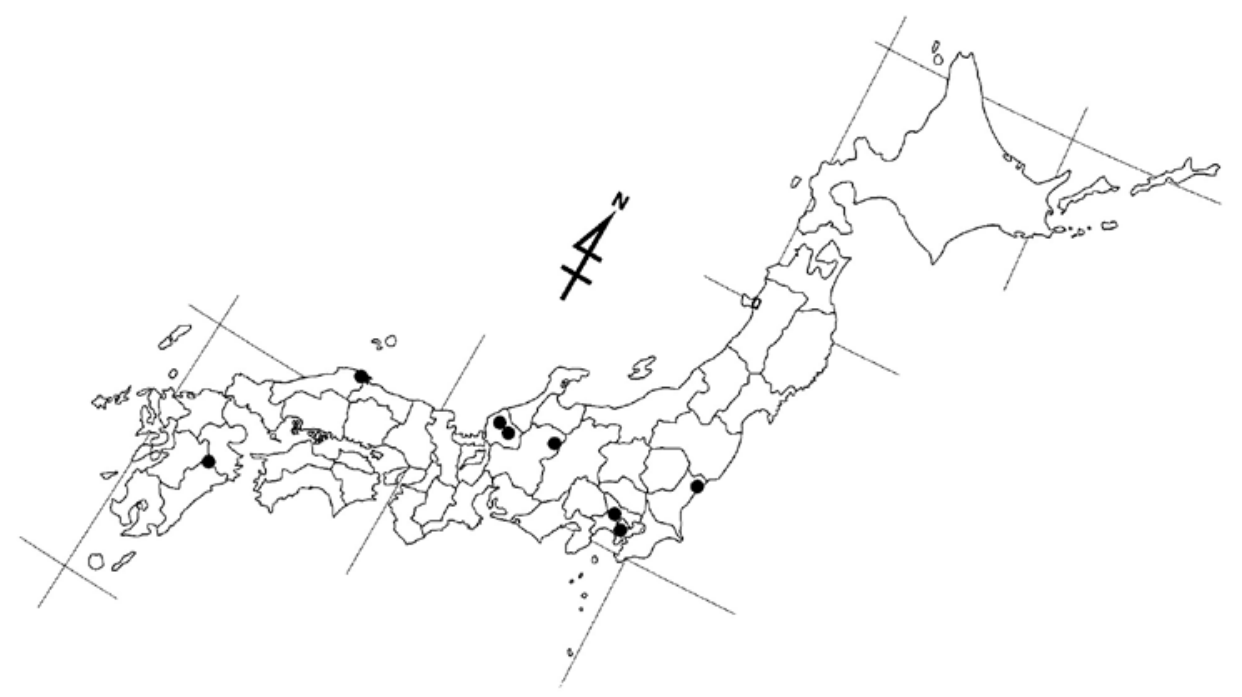

Fig. 12. Distribution of N. asozuana on the Japanese mainlands. Dots: localities of the specimens examined in the present study.

Metasoma matt, faintly microsculptured, superposed with indistinct, small, very dense punctules. Pygidial plate with small, dense punctures, impunctate margin narrow.

Vestiture: Vestiture on labrum pale brown, plumose, long on apical margin, otherwise much shorter. That on clypeus and supraclypeal area short, strongly plumose, appressed. That on lower genal area pale brown, moderately dense and long, as long as on apical margin of labrum.

Vestiture on scutum and scutellum pale brown tinged with golden except darker on apical portion on scutum, 
Table 5. Seasonal change of number of the captured individual of N. asozuana in Japan (Number of females indicates at the left of slash in cell, that of males at the right. E: early, M: mid, L: late).

\begin{tabular}{|c|c|c|c|c|c|c|c|}
\hline \multirow[b]{2}{*}{ Main island } & \multirow[b]{2}{*}{ Prefecture } & \multicolumn{3}{|c|}{ April } & \multicolumn{3}{|c|}{ May } \\
\hline & & $\mathrm{E}$ & $\mathrm{M}$ & $\mathrm{L}$ & $\mathrm{E}$ & $\mathrm{M}$ & $\mathrm{L}$ \\
\hline \multicolumn{8}{|l|}{ HONSHU } \\
\hline \multirow[t]{2}{*}{ [Kanto] } & Tokyo & $1 /$ & 1/ & & & & \\
\hline & Kanagawa & & & & $1 /$ & & \\
\hline \multirow[t]{2}{*}{ [Chubu] } & Fukui & & 1/ & & 1/ & & \\
\hline & Gifu & & & & $1 /$ & & \\
\hline [Chugoku] & Shimane & $1 /$ & & & & & \\
\hline KYUSHU & Oita & & 1/ & & & & \\
\hline \multicolumn{2}{|l|}{ Total } & 2 & 3 & 0 & 3 & 0 & 0 \\
\hline
\end{tabular}

suberect to erect, weakly plumose. That on mesopleuron much longer than on scutum, more strongly plumose, denser and slightly paler. That on lower posterolateral to dorsal surface of propodeum outside triangle whitish, short, shorter than on scutum, suberect, posteriorly or laterally directed, moderately dense, strongly plumose.

Lateral sides of T3-5 with white appressed pubescence, which evidently longer and denser than other portions of the terga, but those on T3 and T5 sometimes indistinct. Pseudopygidium small, compact. Pygidial plate covered with thin, moderately dense, short hairs.

Structure: Body length 10-11.5 mm. CD:UID:LID 50:45:45. OCD/LOD 1.5.

Interantennal elevation weakly raised. Inner eye margins moderately convergent below. Clypeus highly raised and strongly produced anteriorly. Labrum 1.6 times as wide as long; labral tooth present slightly or evidently before the center, not accompanied by a carina; apical portion below labral tooth weakly produced anteriorly, not upcurved; apical margin weakly or sometimes distinctly serrated. Mandible slender. Preoccipital ridge weakly angulated, not carinate. Relative length of FL1-3 1:1.3-1.4:1.1-1.2, relative length to apical width of FL1 1.1-1.2 times, FL2 1.5-1.6 times, FL3 1.3 times.

Scutellum weakly or moderately raised, anterior face flat, median furrow very feeble. Fore femur moderately built. Apicomedian setae on hind tibia five or six in number, posteriormost seta slender, slightly curved downward, evidently longer than others, others robust, dark brown, usually irregularly spaced.

Pygidial plate triangular at apical portion.

Male. Unknown.

Distribution. Japan (Honshu, Kyushu).

Specimens examined. Holotype (MNHAH), 우, attached two labels as follows: "Asozu/ Fukui, Jap./ 12.
IV. 1958/ K. TSUNEKI (white rectangular and typed)", "Nomada/ asozuana 우/ TSUNEKI/ HOLOTYPE (red rectangular with handwritten letters)".

Other specimens: We have examined nine females as follows: JAPAN [Honshu] Ibaraki: 1오, Sadanami, Kitaibaraki-shi, 28. iv - 8. v. 2004 (H. Goto, ELKU). Tokyo: 1우, Machidamachi, 19. iv. 1958 (K. Sugiyama, ELKU); 1우, Kobotoke, Minamitama-dist., 4. iv. 1950 (R. Ishikawa, ELKU). Kanagawa: 1우, Yokohama, 4. v. 1936 (K. Sato, ELKU). Fukui: 1오, Sunayama Hills, Ohno City, 1. v. 1965 (= the holotype of Nomada ohnonis Tsuneki; Y. Haneda, MNHAH). Gifu: 1우, Hatahoko, Mt. Norikura, 8. v. 1976 (O. Tadauchi, ELKU). Shimane: 1우, Mt. Makuragi, 7. iv. 1984 (M. Fujiwara, Y. Haneda Coll.). [Kyushu] Oita: 1우, Sobo, 17. iv. 1936 (I. Okada, ELKU).

Biology. It is a rare species, collected from early April to early May (Table 5). The host and floral association are unknown.

Remarks. The female is similar to Nomada leucophthalma (Kirby) and Nomada fusca Schwarz, but differs from them in the combination of the following characters: the presence of the loose patch of appressed white pubescence on the lateral side of T3-5, the strongly produced clypeus, the longer and plumose vestiture on propodeum outside propodeal triangle (minute, thus indistinct in N. leucophthalma and N. fusca), and the much closer together, nearly touching yellow maculae on T2, and the small, compact pseudopygidium.

The record of this species from Oita Pref. (Yamazaki and Kato, 2003) were based on misidentification. 
5. Nomada aswensis Tsuneki, 1973

[Japanese name: Asuwa-kimadara-hanabachi]

(Figs. 13-15; Table 6)

Nomada aswensis Tsuneki, 1973, Etizenia, 66: 100-103 [Holotype: Female. Type locality: foot of Mt. Somayama, Fukui Pref., Honshu, Japan]; Alexander \& Schwarz, 1994, Univ. Kansas Sci. Bull., 55: 245 [in list]; Ikudome, 1999, in: Ident. Guide Aculeata Nansei Is., Jap.: 655.

\section{Redescription.}

Female.

Color: Head black; the following portions are yellow or sometimes yellow tinged with brown: mandible except apical one-third red or dark red, labrum with a
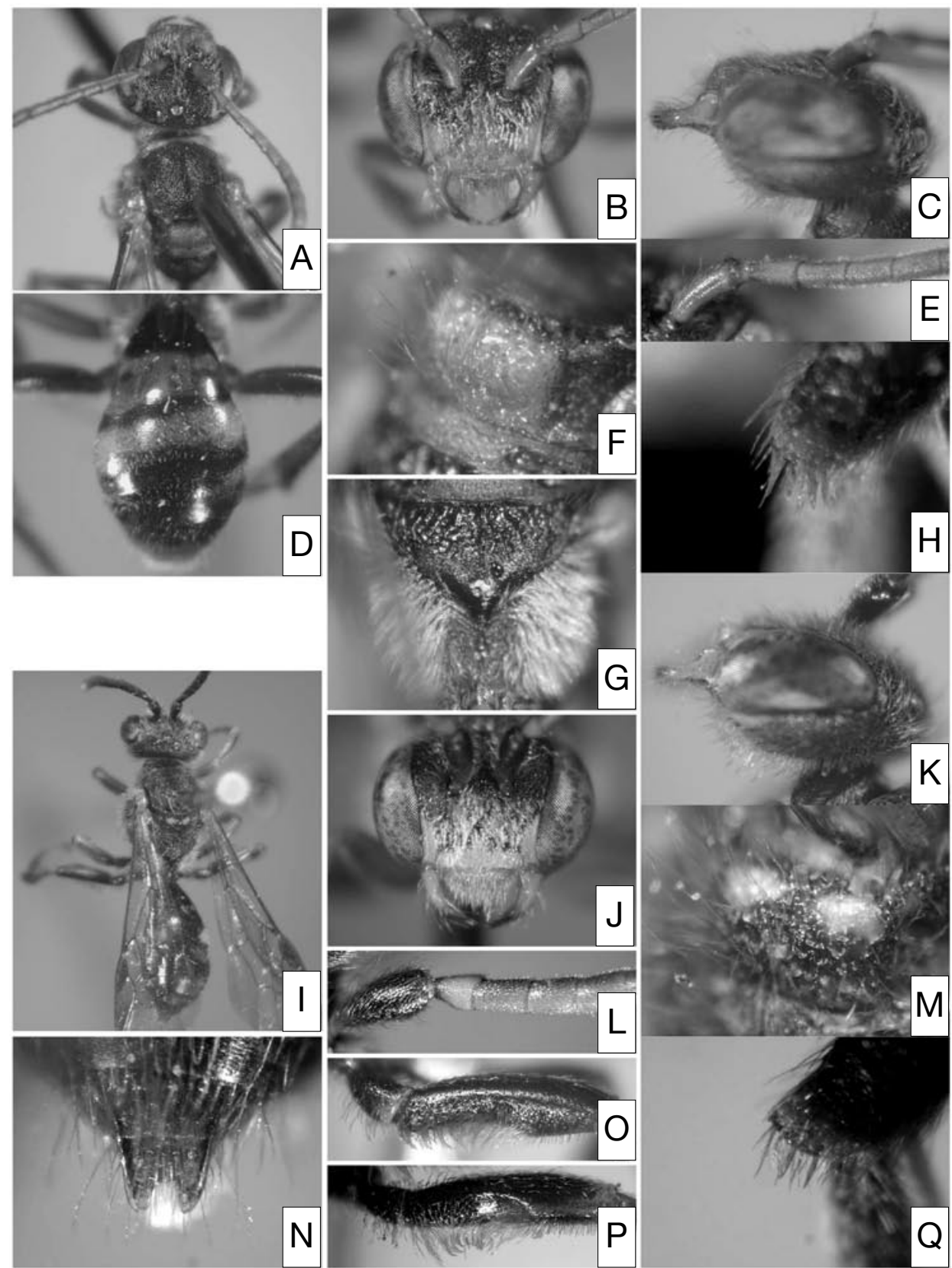

Fig. 13. Nomada aswensis Tsuneki. Female: A-H. Male: I-Q. A, I habitus, dorsal view. B, C, J, K: head. D: metasoma, dorsal view. E, L: antenna. F, M: scutellum. G: propodeal triangle. H, Q: apicomedian setae on hind tibia. N: pygidial plate. O, P: hind femur (O: posterior view, P: ventral view). 
pair of round translucent spots, lower face below top of clypeus, supraclypeal area, narrow line along inner eye margin reaching to top of compound eye, line along lower outer eye margin narrowly extending up beyond midpoint of compound eye in profile. Antenna pale brown wholly.

Mesosoma black, the following portions are reddish brown; anterior margin of pronotum, collar on the top, pronotal lobe, tegula, a longitudinal line along each lateral margin of scutum, axilla, metanotum, large irregular macula on lateral surface of mesopleuron.

Metasoma largely blackish or black, apical broad margin of each of terga highly transparent, T1 pale brown on apical half; the following portions are yellow: a pair of maculae each on T2 and T3 (the former larger and oval, the latter smaller; intermacular area on T2 pale brown), macula T5 medially but strongly dark.

Legs largely pale brown; the following portions are brown or blackish: fore coxa ventrally and posteriorly, fore femur basoventrally, mid trochanter anteriorly and posteriorly, mid femur ventrally, hind coxa posteriorly, hind trochanter dorsally, hind femur and tibia posteriorly.

Sculpture: Punctures on labrum sparse, shallow. Those on clypeus smaller and denser. Those on supraclypeal area irregularly shaped, evidently denser than on lower paraocular area. Punctures on anterior surface of scutellum larger and sparser than on scutum. Mesopleuron moderately areolate. Propodeum outside triangle areolate more minutely than on mesopleuron. Propodeal triangle coarsely irregularly on narrowly basally and centrally, the remaining portion smooth and polished.

T1 impunctate, smooth and polished, the following terga impunctate, faintly tessellate, mat except each apical margin smooth and polished. Pygidial plate with punctures obliterated, sparse.

Vestiture: Vestiture on labrum yellowish brown, plumose, long on apical half, otherwise much shorter. That on clypeus and supraclypeal area similar to that on labrum, appressed. That on lower genal area pale brown, moderately dense and long, as long as on apical half of labrum.

Vestiture on scutum golden, simple, appressed, not dense. That on scutellum evidently longer than on scutum and erect. That on lateral surface of mesopleuron, upper portion of metapleuron, upper lateral portion through posterolateral portion to dorsal side of propodeum outside triangle whitish, long, strongly plumose, appressed except suberect or erect on upper lateral portion of propodeum, dense to form a distinct hair patch.
T1 hairless, T2-5 each with loose patches of plumose, appressed hairs on lateral side; those on T2 and T5 very feeble. Pseudopygidium well developed as normal in female Nomada. Pygidial plate covered with fine, considerably sparse hairs.

Structure: Body length 5-6 mm. CD:UID:LID 50:48:41. OCD/LOD 1.5.

Interantennal elevation weakly raised. Inner eye margins moderately convergent below. Clypeus very weakly raised and produced. Labrum 1.6 times as wide as long; distinct three labral teeth present, arranged in a line at one-third from apex, not accompanied by a carina; apical portion below labral teeth roundly produced anteriorly, not upcurved; apical margin usually not serrated but sometimes so. Preoccipital ridge rounded. Relative length of FL1-3 1:1:0.9, relative length to apical width of FL1 1.5 times, FL2 2.0 times, FL3 1.8-1.9 times.

Scutellum moderately and roundly raised, median furrow absent. Pygidial plate pale brown, constricted and upcurved subapically, widely emarginated at apex.

Fore femur moderately built. Hind femur slender, shallowly depressed on basoventrally. Apicomedian setae on hind tibia three or four in number, posteriormost seta slender, pale brown, difficult to discern among surrounding hairs, others slightly shorter, pale brown, modified to flat, slender leaf-like shaped.

Male.

Color: Head largely black, the following portions are yellow: mandible except apical one-third blackish, labrum, clypeus on apical one-third to half, malar area, lower paraocular area extending up along inner eye margins near to lower margin of antennal socket, small spot along top of compound eye, line on genal area along outer eye margin from hypostoma extending up to the same level of macula along inner margin in profile. Sometimes black line present on epistomal suture, reaching to apical margin of clypeus. Scape black wholly, flagellar segments reddish brown anteriorly, much darker posteriorly.

Mesosoma largely black except scutellum always with two spots and collar on the top tinged with reddish brown to yellow or sometimes collar black wholly.

Metasoma similar in color to female, but intermacular area on T2 blackish or black, T4 and the following terga without macula.

Legs pale brown; the following portions are blackish or black: all coxae and trochanters, fore femur ventrally, fore tibia posteriorly, mid femur ventrally and posteriorly, mid tibia posteriorly, hind femur except upper portion, hind tibia wholly. Sometimes a line running from 

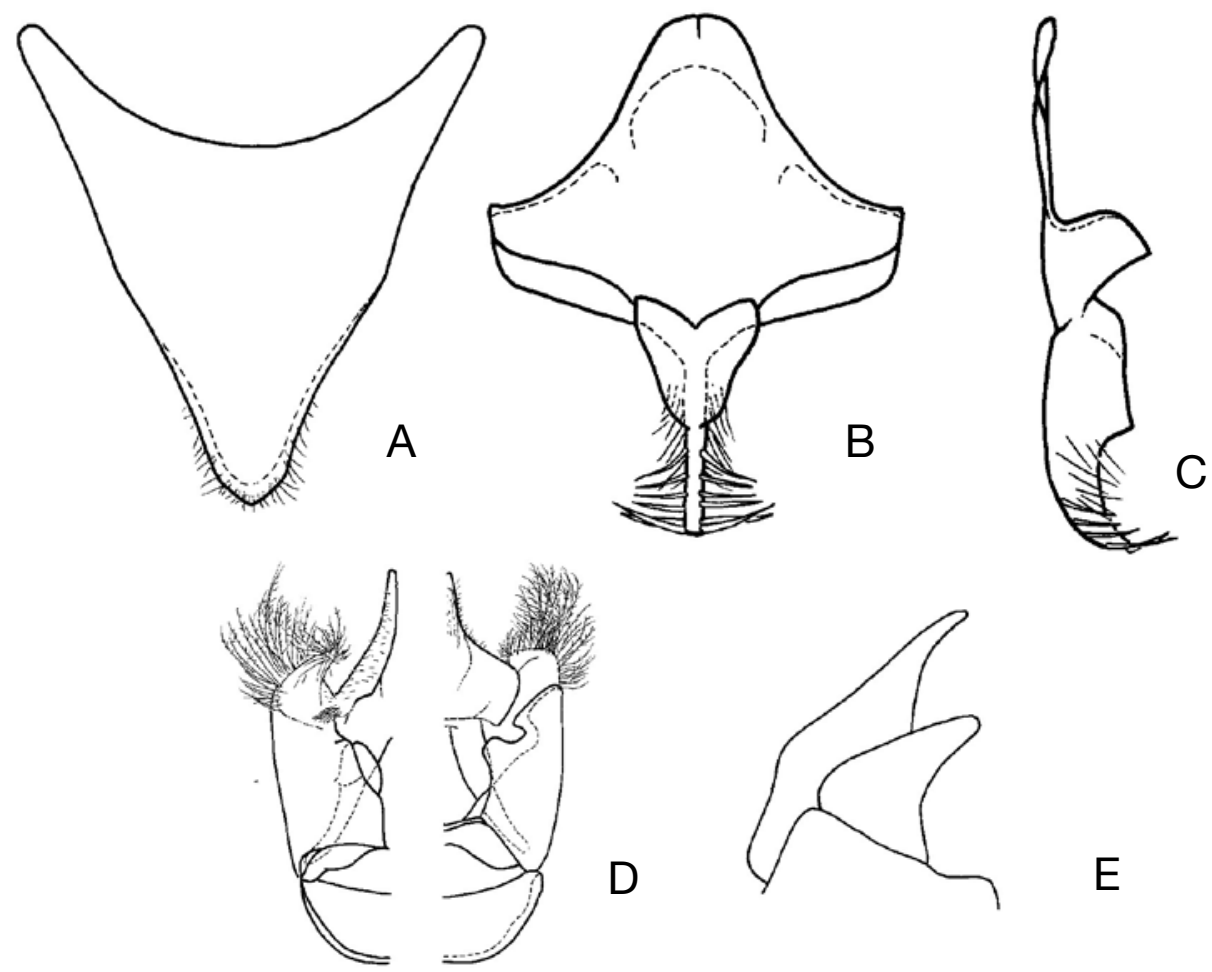

$\mathrm{E}$

Fig. 14. Nomada aswensis (male). A: 7th metasomal sternum, ventral view. B: 8th sternum, dorsal view. C: the same, lateral view. D: genital capsule (left, ventral view; right, dorsal view). E: penis valve and gonostylus, lateral view (vestiture omitted).

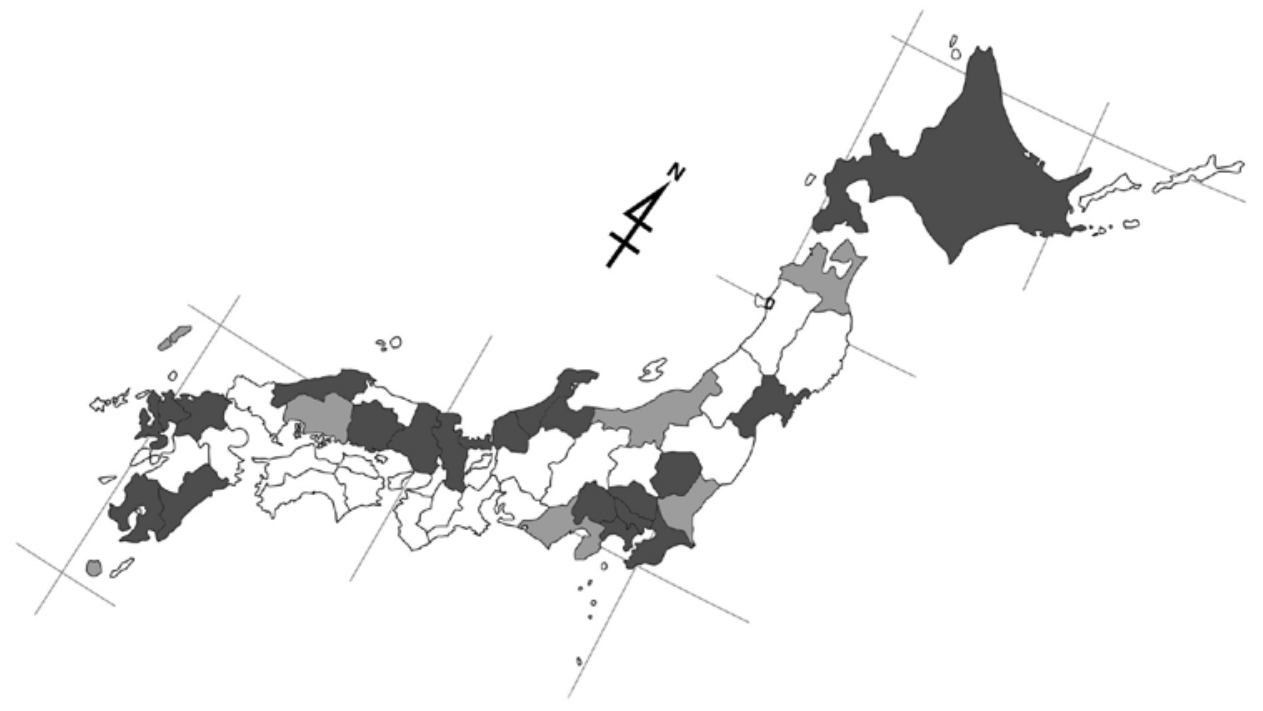

Fig. 15. Distribution of $N$. aswensis on the Japanese mainlands. Densely shaded: prefectures with the specimens examined in the present study. Lightly shaded: prefectures with records in literature, but no specimens examined in the present study. 
Table 6. Seasonal change of number of the captured individual of $N$. aswensis in Japan (Number of females indicates at the left of slash in cell, that of males at the right. E: early, M: mid, L: late).

\begin{tabular}{|c|c|c|c|c|c|c|c|c|c|c|}
\hline \multirow[b]{2}{*}{ Main island } & \multirow[b]{2}{*}{ Prefecture } & \multicolumn{3}{|c|}{ April } & \multicolumn{3}{|c|}{ May } & \multicolumn{3}{|c|}{ June } \\
\hline & & $\mathrm{E}$ & $\mathrm{M}$ & $\mathrm{L}$ & $\mathrm{E}$ & $\mathrm{M}$ & $\mathrm{L}$ & $\mathrm{E}$ & $\mathrm{M}$ & $\mathrm{L}$ \\
\hline \multicolumn{11}{|l|}{ HONSHU } \\
\hline [Tohoku] & Aomori & & & & $/ 1$ & $1 /$ & & $1 / 2$ & & \\
\hline \multirow[t]{5}{*}{ [Kanto] } & Tochigi & & $5 / 8$ & $/ 1$ & $2 / 7$ & $1 /$ & $2 /$ & & & \\
\hline & Saitama & & $6 / 5$ & $/ 1$ & $3 / 3$ & $1 / 1$ & $2 /$ & & & \\
\hline & Chiba & & $1 / 3$ & & $3 / 2$ & $2 /$ & $1 /$ & & & \\
\hline & Tokyo & & $/ 1$ & & & $1 / 1$ & $1 /$ & $1 /$ & & \\
\hline & Kanagawa & & $2 /$ & & & $1 /$ & $/ 1$ & & & \\
\hline \multirow[t]{3}{*}{ [Chubu] } & Ishikawa & $1 /$ & $/ 1$ & & & & & & & \\
\hline & Fukui & & 15 & & $1 /$ & $/ 1$ & $3 / 2$ & $/ 1$ & & \\
\hline & Yamanashi & & & & & & $/ 1$ & & & \\
\hline \multirow[t]{2}{*}{ [Kinki] } & Kyoto & & & & & & $/ 1$ & & & \\
\hline & Hyogo & & & & & & $/ 1$ & & & \\
\hline [Chugoku] & Shimane & & & $/ 1$ & & & & & & \\
\hline \multirow[t]{5}{*}{ KYUSHU } & Fukuoka & & & & 12 & & & $/ 1$ & & \\
\hline & Saga & $/ 1$ & & & & & & & & \\
\hline & Nagasaki & & & & & $/ 1$ & & & & \\
\hline & Miyazaki & & $4 / 2$ & $1 / 4$ & $/ 1$ & & & & & \\
\hline & Kagoshima & $/ 1$ & & & & & & & & \\
\hline \multicolumn{2}{|l|}{ Total } & 3 & 43 & 8 & 25 & 11 & 15 & 6 & 0 & 0 \\
\hline
\end{tabular}

base to apex medially on posterior surface of mid femur.

Sculpture: As in female.

Vestiture: Vestiture similar generally to that in female, but that on clypeus and supraclypeal area more strongly plumose than in female. That on mesosoma similar to that in female, but sparser on propodeum than in female, but still hair patch distinct. That on ventral surfaces of fore and mid femora sparse, shorter than the maximum width of each segment. Hind femur with depressed ventral surface provided with modified hairs which plumose, basally-directed on middle ventral area, gradually basally changed in orientation to be posteriorly directed, upcurved at apical portion of each hairs

Structure: Body length 4.5-6 mm. CD:UID:LID 50:50:38. OCD/LOD 1.3.

The following aspects are different from female: scape slightly wider than flagellar segments; relative length of FL1-3 1:1.2-1.3:1.2, relative length to apical width of FL1 equal, FL2 1.4 times, FL3 1.3 times, tyloidea not recognized, but impunctate areas recognized at corresponding portions; scutellum moderately raised, anterior face flat, median furrow absent; Pygidial plate with narrow, deep, U-shaped emargination at apex; fore femur more or less robust, dilated medially; hind femora slender; basoventral surface reaching to twothird of ventral side from base of segment, prominently depressed in posterior view; apicomedian setae on hind tibia three or, rarely four in number, all pale brown, short, similar in shape to those in female but slenderer, difficult to discern among surrounding hairs.

Male terminalia: 7th metasomal sternum as in Fig. 14-A. 8th as in Fig. 14-B, C. Gonostylus short, greatly narrowed apically; vestiture plumose, denser on apical and middle portion (that on apical portion shorter), otherwise much sparser; basoventral lobe absent, but moderately plumose, long vestiture on the corresponding portion. Penis valve greatly produced posteriorly beyond gonostylus, apex extending ventrally not beyond apex of gonostylus in lateral view. Gonocoxite with deep dorsal invagination; inner dorsal lobe small, as wide as long, rounded at apex.

Distribution. Japan (Honshu, Kyushu)

Specimens examined. Holotype (MNHAH), 우, attached with two labels as follows: "Somayama f/ Fukui, Japan/ 11. v. 1972/ K. Tsuneki [white rectangle and typed]", "Nomada/ aswensis 우/ Tsuneki/ Holotype [red 
rectangle with handwritten letters]"

Other specimens: We have examined about $60 \mathrm{fe}-$ males and 70 males. On the localities, see Fig. 15. Some of them are listed as follows: JAPAN [Honshu] Yamanashi: 10', Kawai, Uenohara Town, 14. 5. 1991. (H. Suda). Hyogo: 1б', Sasayama, 18. v. 19?? (S. Taniguchi, ELKU). Shimane: 1우, Nishikawazu, 15. 4. 1983. (A. Yoshida, EBSU). [Kyushu] Fukuoka: 1б', Hiko-san, 2. 5. 1975. (K. Ohara, ELKU). Saga: 1б', Kami-ozoegawa, Fuji, 5. 4. 2002. (K. Mitai). Miyazaki: Kuruson-kyo, Ebino-City, 20. 4. 1976. (K. Ohara, ELKU).

Biology. It is univoltine species, collected from late March to early June (Table 6). This species is not abundant locally, but widely distributed from Yakushima Island, the southern island a little apart from Kyushu, to Aomori, the northern part of Honshu. Maeta et al. (1996) reported Lasioglossum allodalum Ebmer et Sakagami as host of this species in Miyagi Pref., northern part of Honshu, Japan. According to the paper, the host association is proved by excavating a nest of $L$. allodalum and fining two, seemingly newly emerged adults of $N$. aswensis. Floral associations are as follows: [Papaveraceae] Corydalis incisa; [Oleaceae] Ligustrum japonicum.

Remarks. Nomada aswensis, like those of Nomada okubira Tsuneki, Nomada ginran Tsuneki and Nomada taicho Tsuneki, has conspicuously the depressed ventral surface of hind femur with appressed dense vestiture in male, and the dense vestiture on posterolateral surface of propodeum in female. In the case of male, compared with the latter three species, the depression on ventral surface is prominently deep in posterior view and wide, reaching to two-thirds of hind femur from apex. In the case of female, the combination of the roughly pentagonal labrum, the slender mandible, the wholly reddish brown scutellum will distinguish $N$. aswensis from the others.

6. Nomada calloptera Cockerell, 1918

[Japanese name: Yamato-kimadara-hanabachi] (Figs. 16-18; Table 7)

Nomada calloptera Cockerell, 1918, Ann. Mag. Nat. Hist. Lond., (9)2: 479 [Holotype: Male. Type locality: Tokyo, Honshu, Japan; Yasumatsu, 1950, Icon. Ins. Jap., 2nd ed.: 1490; Hirashima, 1965, Icon. Ins. Jap., Col. Nat. ed., Vol. III: 309, pl. 155; Tsuneki, 1973, Etizenia, 66: 62-66 [redescription]; Alexander \& Schwarz, 1994, Univ. Kansas Sci. Bull., 55: 245 [in list].

Nomada rengnio Tsuneki, 1973, Etizenia, 66: 91-92 [Holotype: Female]; Alexander \& Schwarz, 1994,
Univ. Kansas Sci. Bull., 55: 251 [in list]; Ikudome, 1999, in: Ident. Guide Aculeata Nansei Is., Jap.: 654-655. syn. nov.

Nomada sakura Tsuneki, Kontyû, 44: 150-152 [Holotype: Male]. syn. nov.

\section{Redescription.}

Female.

Wintering generation.

Color: Head largely reddish brown, frequently tinged with yellow on lower paraocular area; the following portions are black: macula on antennal area with supraclypeal area reddish brown, line on epistomal suture, small transverse elliptical macula surrounding ocelli on vertex, broad line on genal area along preoccipital ridge extending from the hypostoma up to level of compound eye in profile. Antenna reddish brown wholly.

Mesosoma black; the following portions are reddish brown: anterior margin of pronotum but sometimes lacking, collar on the top but sometimes tinged with yellow, pronotal lobe, tegula, four longitudinal lines on scutum, frequently fused partially, sometimes largely fused into broad two lines, scutellum, axilla, metanotum, large maculae almost occupying lateral surface of mesopleuron, propodeum except black area anterior to spiracle and longitudinal black line on dorsal surface.

Metasoma dark reddish brown, each terga blackish apically, T1 black on basal half; the following portions are yellow: a pair of elliptical or oval maculae on $\mathrm{T} 2$, two pairs of small spot on T3 (those of the outer pair round, those of inner pair elliptical, sometimes disappear), narrowly interrupted band on T4, square maculae on T5 medially. Pygidial plate reddish brown.

Legs reddish brown; the following portions are black: fore coxa basally, fore femur basoventrally, mid coxa wholly, mid femur basally, hind coxa posteriorly, hind femur posteriorly and anteriorly, dark reddish brown dorsally.

Sculpture: Punctures on labrum and clypeus small, distinct, dense. Those on supraclypeal area much larger. Punctures on scutellum variable but usually larger and sparser than on scutum. Propodeum outside propodeal triangle shallowly areolate except weakly rugose portion with sparse punctures under spiracle. Propodeal triangle irregularly rugose at the base, longitudinal rugae relatively prominent basolaterally, the remaining portion finely tessellate or nearly smooth. Terga smooth, with dense, distinct punctules. Pygidial plate with punctures moderately large and sparse, impunctate margin moderately wide, smooth.

Vestiture: Vestiture on labrum pale brown, weakly 


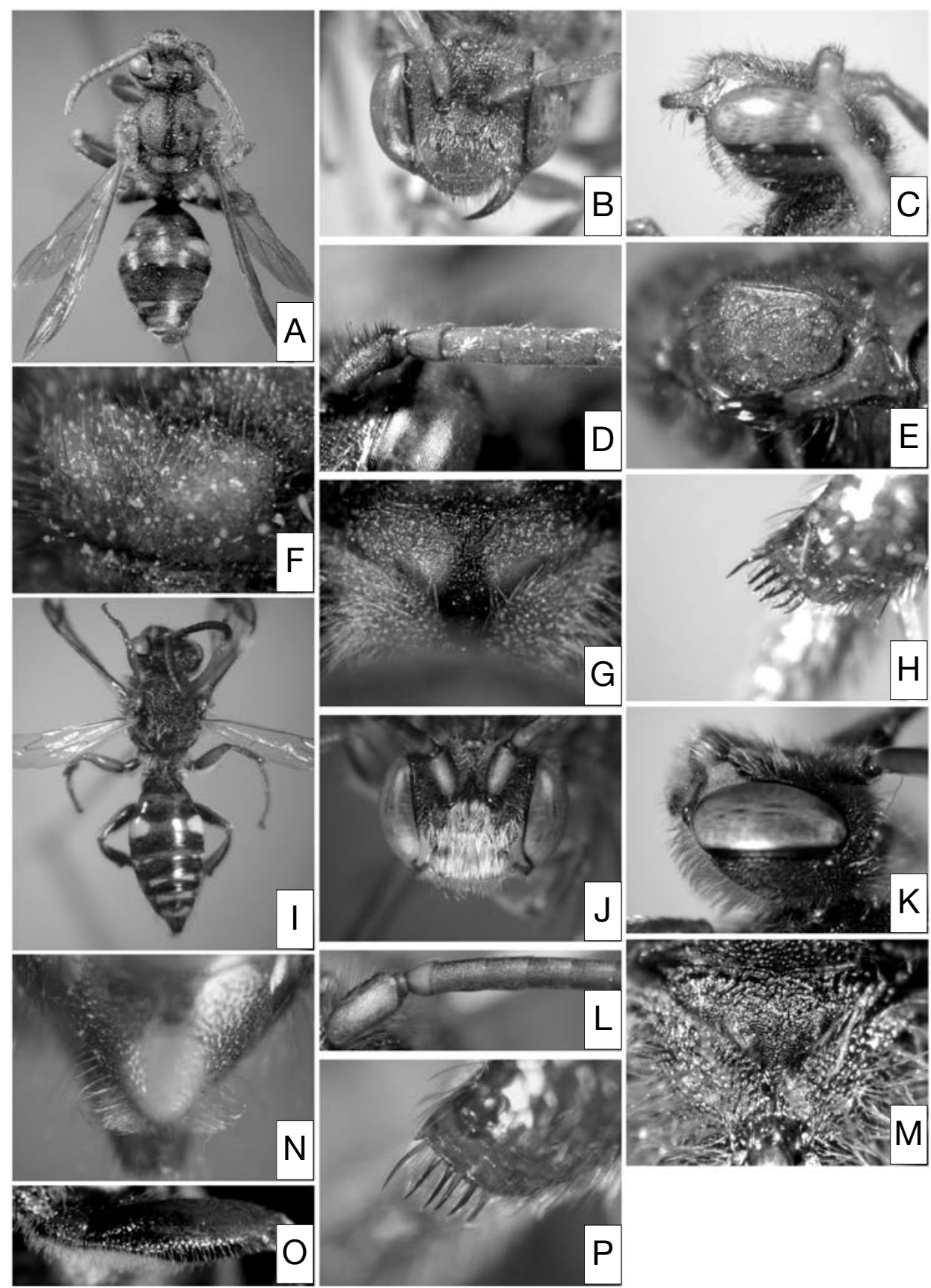

Fig. 16. Nomada calloptera Cockerell. Female: A-H. Male: I-P. A, I: habitus, dorsal view. B, C, J, K: head. D, L: antenna. F: scutellum. G, M: propodeal triangle. H, P: apicomedian setae on hind tibia. N: subgenital brush. O: hind femur, anterior view.

plumose, sparse, long on apical portion, otherwise much shorter. That on clypeus and supraclypeal area pale brown, fine, weakly plumose, appressed. That on lower genal area pale brown, about as long as on apical portion of labrum.

Vestiture on scutum, scutellum moderately long, brown to dark brown, suberect. That on mesopleuron longer, finer, weakly plumose. That on posterolateral to dorsal surface of propodeum outside triangle golden, as long as on mesopleuron, erect, dense, but still integument can be seen clearly.

Pseudopygidium dark brown, well developed as normal in female Nomada. Pygidial plate covered with sparse, robust hairs.

Structure: Body length $9-10 \mathrm{~mm}(6.5 \mathrm{~mm}$ in one extraordinarily small specimen). CD:UID:LID 50:50:43. 


\section{OCD/LOD 1.4.}

Interantennal elevation moderately raised. Inner eye margins nearly straight, weakly convergent below. Clypeus weakly or moderately raised and produced anteriorly. Labrum 1.6 times as wide as long; labral tooth at one-fourth from apex, accompanied by distinct longitudinal ridge above and lateral serrate carina on each side; apical portion below labral teeth weakly produced anteriorly, not upcurved; apical margin distinctly serrated. Preoccipital ridge distinctly carinated. Relative length of FL1-3 1:1.6-1.7:1.3, relative length to apical width of FL1 0.9 times, FL2 1.6-1.7 times, FL3 1.3 times.

Scutellum highly raised, anterior face flat, median furrow moderately or strongly deep. Pygidial plate triangular at apical portion.

Fore femur robust, dilated medially. Apicomedian setae six to eight in number, robust, dark brown to black, flattened, acute at apex, arranged in a row, straight or slightly curved downward.

Forewing second radius-media vein strongly curved outward.

First generation.

Color: Color pattern the same as in wintering generation, but generally slightly darker than in wintering generation.

Sculpture: Generally punctures on body slightly deeper and denser than in wintering generation, especially on mesopleuron and terga.

Vestiture: Similar to that in wintering generation, but that on mesosoma more weakly plumose and somewhat shorter than in wintering generation.

Structure: Apicomedian setae on hind tibia shorter, otherwise as in wintering generation.

Male.

Wintering generation.

Color: Head and mesosoma black; the following portions are yellow: mandible with one-third black, labrum, clypeus on apical one-third, malar area, lower paraocular area extending up along inner eye margin but not reaching to level of lower margin of antennal sockets, small spot on anterior portion of mesopleuron but sometime lacking. Scape yellow anteriorly, black posterior, flagellar segments pale brown anteriorly, black posteriorly, but paler apically. Scutellum usually wholly black, sometimes with two reddish brown to red, small spots.

T1 black on basal half, yellowish to reddish brown on apical half, sometimes a pair of dark spots present in brown portion, and in melanic specimens, brown por- tion reduced to small spot. T1-4 pale to dark brown with yellow maculae as follows: a pair of round maculae on lateral side of $\mathrm{T} 2$ with intermacular area pale brown, two pairs of small macula on T3 (inner pair small or lacking, sometimes inner and outer maculae fused into irregularly transverse maculae), two pairs of transversely long maculae on T4, yellow band on T5, square macula almost occupying T6. Each S2-6 with a yellow band or spot.

Legs pale brown to brown; the following portions are dark brown to black: all coxae except apical tip brown, fore femur basally, mid trochanter posteriorly, basal mid femur posteriorly, small stripe on hind trochanter, hind femur posteriorly and anteriorly.

Sculpture: Similar to that of female, but slightly weaker in general and evidently weaker on scutellum. Pygidial plate covered by dense, longitudinally elliptical punctures.

Vestiture: Vestiture on labrum yellowish brown, dense and moderately long, evenly in density and length, plumose, erect. That on clypeus and supraclypeal area white, strongly plumose, appressed, dense as to completely conceal integument. That on lower genal area near hypostoma similar to on labrum, but much sparser.

Vestiture on scutum, scutellum, mesopleuron and posterolateral to dorsal surface of propodeum outside triangle pale brown to brown, weakly plumose, erect, that on scutellum slightly shorter, that on propodeum much sparser than in female.

Subgenital brush composed of plumose, golden hairs, moderately dense in the middle, denser on the lateral portion forming a loose tuft.

Vestiture on ventral surfaces of trochanters and femora of fore- and mid legs golden, plumose, weakly laterally directed curved, very dense. That on ventral surface of hind femur moderately dense, posteriordirected suberect straight.

Structure: Body length 8-10.5 mm. CD:UID:LID 50:51:42. OCD/LOD 1.8.

The following aspects are different from female as follows: interantennal carina horizontally straight on top in profile, and lowered abruptly anteriorly from level of anterior margin of antennal socket in profile; clypeus moderately raised and produced anteriorly; preoccipital ridge strongly angulated behind vertex, otherwise gently angulated; scape much wider than flagellar segments; relative length of FL1-3 1:2.0:1.7-1.8, relative length to apical width FL1 0.7 times, FL2 1.7 times, FL3 1.3-1.4 times, tyloidea on FL1 absent, those on FL2 and FL3 oval, weakly raised, those on the following segments 

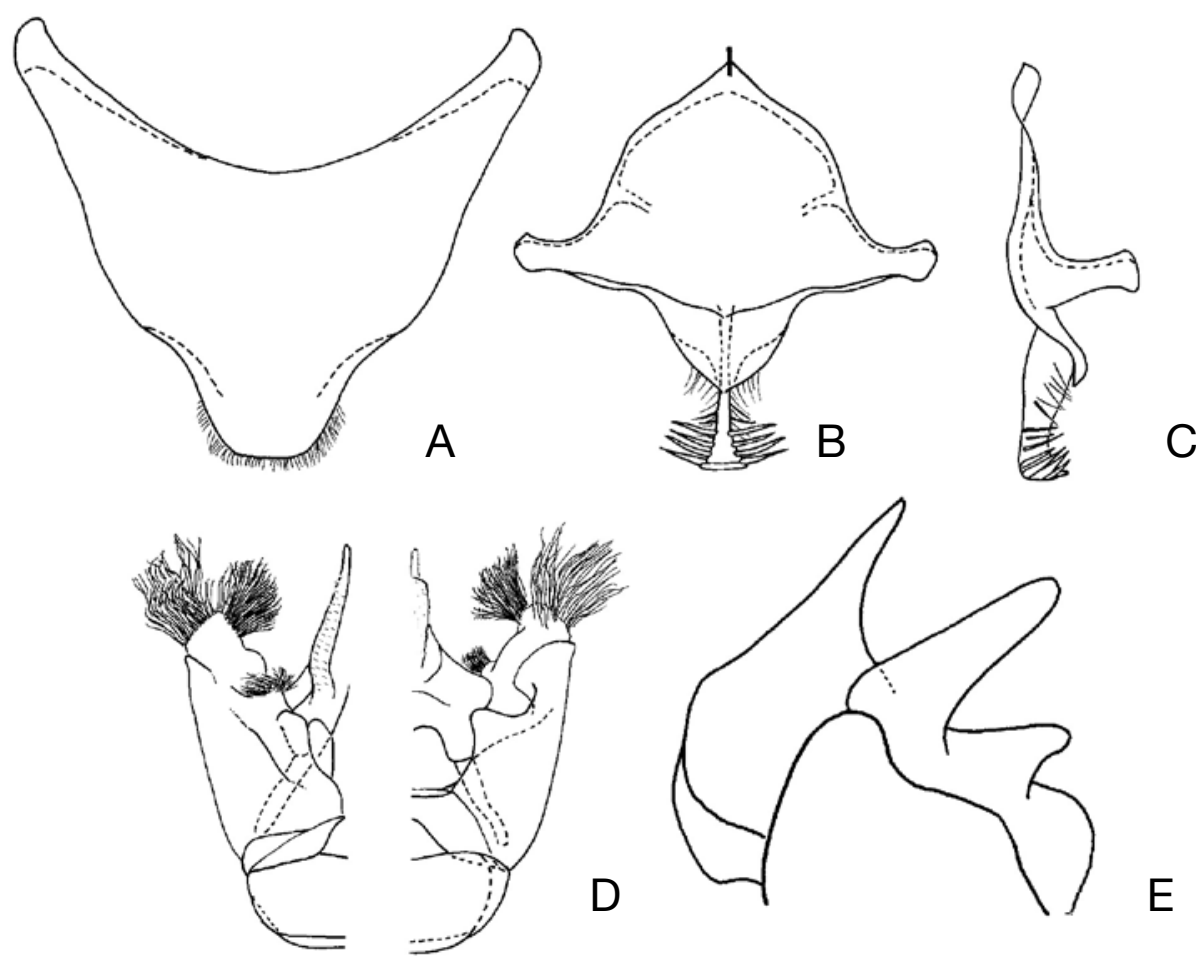

$E$

Fig. 17. Nomada calloptera (male). A: 7th metasomal sternum, ventral view. B: 8th sternum, dorsal view. C: the same, lateral view. D: genital capsule (left, ventral view; right, dorsal view). E: penis valve and gonostylus, lateral view (vestiture omitted).

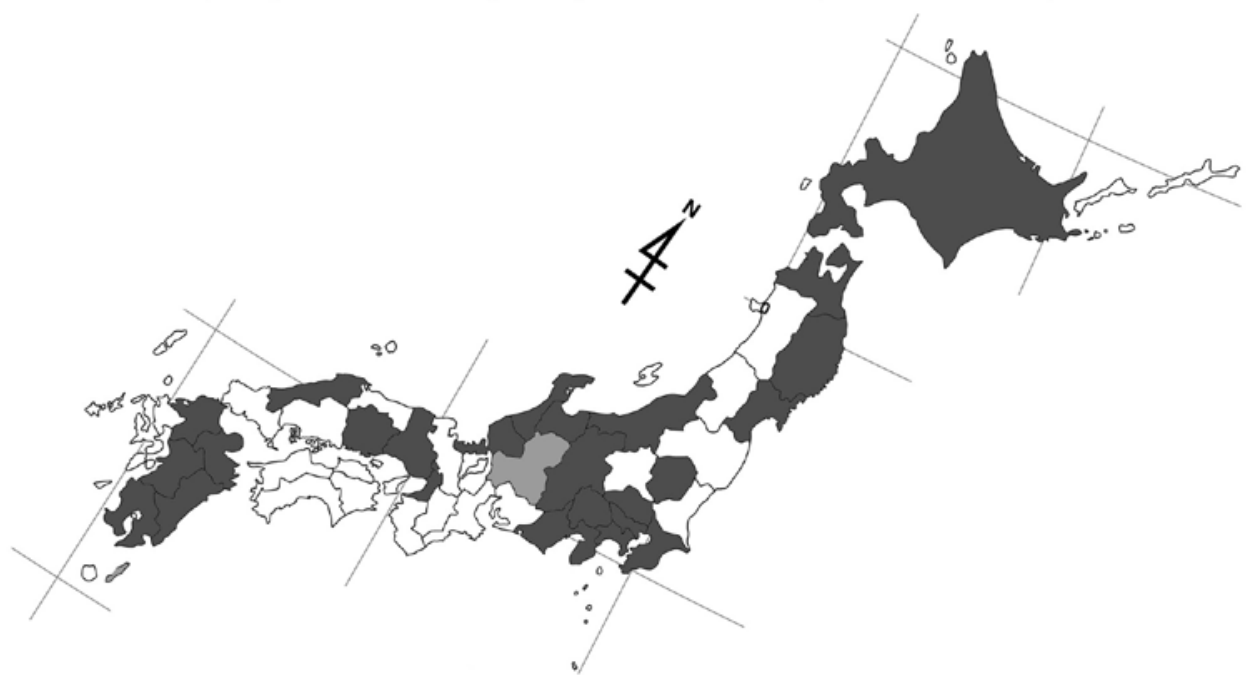

Fig. 18. Distribution of $N$. calloptera on the Japanese mainlands. Densely shaded: prefectures with the specimens examined in the present study. Lightly shaded: prefectures with records in literature, but no specimens examined in the present study. 
recognized as obscure convex; pygidial plate shallowly emarginated at apex; hind femur robust; basoventral flattened surface wide, reaching to midpoint of segment, evidently depressed in posterior view, degree of depression variable, sometimes rather shallow, boundary between basoventral flattened surface and posterior surface of segment sharply angulated); apicomedian setae on hind tibia less robust and slightly shorter than in female, otherwise as in female.

Male terminalia: 7th metasomal sternum as in Fig. 17-A. 8th as in Fig. 17-B, C. Gonostylus slender, roughly cylindrical; vestiture moderately long, much denser on apical and mediolateral portion, otherwise sparser (that on apical portion plumose); basoventral lobe greatly produced, with plumose dense vestiture. Penis valve produced posteriorly much beyond gonostylus, apex strongly narrower in lateral view. Gonocoxite with shallow dorsal invagination; inner dorsal lobe small, evidently narrower apically, rounded at apex.

First generation.

The differences between the males of wintering and first generations are similar to those between the female of wintering and first generations, namely, body color darker, sculpture coarser, vestiture shorter and somewhat sparser, apicomedian setae on hind tibia shorter in first generation, compared with the wintering generation.

Distribution. Japan (Hokkaido, Honshu, Kyushu, Nansei Islands); South Korea.

Table 7 . Seasonal change of number of the captured individual of N. calloptera in Japan (Number of female indicates at the left of slash in cell, that of male at the right. E: early, M: mid, L: late).

\begin{tabular}{|c|c|c|c|c|c|c|c|c|c|c|c|c|c|c|c|c|c|c|c|}
\hline \multirow[b]{2}{*}{ Main island } & \multirow[b]{2}{*}{ Prefecture } & \multicolumn{3}{|c|}{ March } & \multicolumn{3}{|c|}{ April } & \multicolumn{3}{|c|}{ May } & \multicolumn{3}{|c|}{ June } & \multicolumn{3}{|c|}{ July } & \multicolumn{3}{|c|}{ August } \\
\hline & & $\mathrm{E}$ & $\mathrm{M}$ & $\mathrm{L}$ & $\mathrm{E}$ & $\mathrm{M}$ & $\mathrm{L}$ & $\mathrm{E}$ & M & $\mathrm{L}$ & $E$ & $\mathrm{M}$ & $\mathrm{L}$ & $\mathrm{E}$ & M & $\mathrm{L}$ & $E$ & $\mathrm{M}$ & $\mathrm{L}$ \\
\hline HOKKAIDO & & & & & & & & & & $1 /$ & & & & & & & & & \\
\hline \multicolumn{20}{|l|}{ HONSHU } \\
\hline \multirow[t]{3}{*}{ [Tohoku] } & Aomori & & & & & & $1 /$ & & & & & $3 /$ & & & & & $1 /$ & & \\
\hline & Iwate & & & & & & $/ 1$ & & $2 /$ & $2 /$ & & & & & $1 / 2$ & $2 / 2$ & $2 / 1$ & & \\
\hline & Miyagi & & & & & & 128 & & & & & & & $1 / 1$ & & & & & \\
\hline \multirow[t]{5}{*}{ [Kanto] } & Tochigi & & & 1/ & & $/ 1$ & & & $1 /$ & & $1 / 1$ & & & & & & & & \\
\hline & Saitama & & & & & $3 /$ & & $2 /$ & & & & $1 /$ & & $2 /$ & & & & & \\
\hline & Chiba & & & $/ 1$ & $1 / 2$ & $5 /$ & 1/ & & & & & $2 /$ & $2 /$ & & $1 /$ & & & & \\
\hline & Tokyo & & & & $3 /$ & & & & & & & & $/ 1$ & & & & & & \\
\hline & Kanagawa & & & & $2 /$ & & $1 / 1$ & & & & & $/ 1$ & $/ 1$ & & & & & & \\
\hline \multirow[t]{7}{*}{ [Chubu] } & Niigata & & & & & & & $2 /$ & $2 / 1$ & $1 / 1$ & & & & & & $1 /$ & & & \\
\hline & Toyama & & & & & $2 /$ & & & & & & & & & & & & & \\
\hline & Ishikawa & & & & $1 /$ & & & & & & & & & & & & & & \\
\hline & Fukui & & & & $5 /$ & $6 / 3$ & $4 / 3$ & $2 / 6$ & 15 & & $/ 1$ & $1 /$ & $/ 1$ & & & $4 /$ & $1 /$ & & $1 / 1$ \\
\hline & Yamanashi & & & & & & & & & & & & & & & $1 /$ & & & \\
\hline & Nagano & & & & & $1 / 1$ & & & $1 /$ & $/ 1$ & & & & & & & & & \\
\hline & Shizuoka & & & & & $1 /$ & & & & & & & & & & & & & \\
\hline \multirow[t]{3}{*}{ [Kinki] } & Mie & & & & & & & & & & & & & & & & & & \\
\hline & Osaka & & & $/ 1$ & & & & & & & & & & & & & & & \\
\hline & Hyogo & & & & $1 /$ & & & & $/ 1$ & & & & & & & & & & \\
\hline [Chugoku] & Shimane & & & 13 & & $12 /$ & $5 /$ & & & & & & & & & & & & \\
\hline \multirow[t]{5}{*}{ KYUSHU } & Fukuoka & $1 / 1$ & $7 / 20$ & $2 / 4$ & $6 / 6$ & $12 / 4$ & $1 / 7$ & & & & $6 /$ & $6 /$ & $4 / 2$ & & & & & & \\
\hline & Kumamoto & & & $4 / 2$ & & $2 /$ & & & & & 12 & $/ 1$ & & & & & & & \\
\hline & Oita & & & & $7 / 3$ & & $/ 1$ & & & & & & & & & & & & \\
\hline & Miyazaki & & & & $/ 1$ & & & & & & & & & & & & & & \\
\hline & Kagoshima & & & $/ 1$ & & $1 /$ & & & & & & $1 /$ & & & & & & & \\
\hline \multicolumn{2}{|c|}{ Total } & 2 & 27 & 19 & 38 & 54 & 44 & 12 & 13 & 6 & 11 & 16 & 12 & 5 & 4 & 10 & 5 & 0 & 2 \\
\hline
\end{tabular}


Specimens examined. Holotype (USNM), $\sigma^{7}$, attached with four labels as follows: "Type No./ 23182/ U. S. N. M.[white rectangle and typed except for the numerals handwritten]", “Tokyo/ 12. iv. 1909/ Yamada [white rectangle with handwritten letters. "sasaki" is handwritten on the underside]", "no. 133 [small white rectangle and typed]" and "Nomada/ calloptera. Ckll TYPE [white rectangle with handwritten letters]".

Other specimens: We have examined about 160 females and 140 males. On the localities, see Fig. 18. Some of them listed as follows: JAPAN [Hokkaido] 1우, Ashoro, 31. v. 1957. (M. Takahashi, ELKU). [Honshu] Aomori: 1우, Nonai (Aomori), 3. viii. 2000. (M. Yamada). Nagano: 10', Kijimadaira, 24. v. 1976. (O. Tadauchi, ELKU). Shizuoka: 1우, Mishima, 15. iv. 1988. (K. Tsuneki, MNHAH). Osaka: 1우, Minô-shi, 31. iii. 1951. (Collector unknown). Hyogo: 10', Kiyoshikojin, Settsu, 3. iv. 1951. (K. Komatsu). Shimane: 11우, Koyama-cho, 18. iv. 2001. (Y. Maeta). [Kyushu] Kumamoto: $10^{\top}$, Tatsuda-Yama, Kumamoto City, 24. iii. 2006. (N. Sugiura). Oita: Mt. Kuroiwayama, Kokonoe-machi, Kusu-gun, 28. iv. 2006. (K. Mitai). Miyazaki: Miyakonojo, 5. iv. 1949. (Y. Hirashima). SOUTH KOREA, Shoyo, 2. vii. 1943. (K. Tsuneki, MNHAH).

Biology. It is a bivoltine species. The wintering generation has collected March to late May, and the first generation from June to August (Table 7). Andrena japonica Hirashima is reported as the host by Murota and Kurokawa (2002), and Maeta et al. (2004). Suda (1980) observed females of $N$. calloptera flied about on nest site of Lasioglossum sp. in Chiba Pref., and suggested the Lasioglossum sp. may be a host.

Remarks. The female is similar in coloration to $\mathrm{No}$ mada sabaensis Tsuneki, but can be separated by the much robust setae on apicomedian hind tibia, the larger body size, and the coarsely punctate scutellum. The female is also similar to Nomada alboguttata etizenensis Tsuneki, but can be recognized by the FL2 which much longer than FL1, whereas FL2 as long as FL1 in N. $a$. etizenensis.

The male is superficially similar to Nomada amurensis Radoszkowsky and Nomada fervens Smith, but easily distinguished from them by the much longer setae on apicomdian hind tibia.

7. Nomada erythra Mitai, Hirashima et Tadauchi, sp. nov.

[Japanese name: Arame-kimadara-hanabachi] (Figs. 19, 20; Table 8)

\section{Description.}

\section{Female.}

Color: Head and mesosoma largely black; the following portions are reddish brown: mandible except apical one-fourth red, labrum, clypeus on narrow apical margin, malar area, lower paraocular area extending up along inner eye margin to top of compound eye, outer eye margin extending up very narrowly along inner eye margin, but not connecting line along inner eye margin, collar on the top, pronotal lobe, a transverse elliptical macula on anterior portion of mesopleuron, narrowly separated two maculae on scutellum.

Metasoma largely reddish brown except basal half of T1 blackish and central T5 tinged with vague yellow. Pygidial plate brown.

Legs brown; the following portions are blackish: all coxae, all femora ventrally, all tibiae.

Sculpture: Punctures on labrum small, indistinct. Those on clypeus and supraclypeal area large, irregularly spaced varying from contiguous to separated by a puncture diameter.

Punctures on scutellum as on scutum. Mesopleuron deeply areolate. Propodeum outside triangle distinctly areolate except rugose portion under spiracle. Propodeal triangle irregularly coarsely rugose basally, the remaining portion distinctly or faintly tessellate.

Terga smooth, T1 virtually impunctate, the following terga faintly punctuate. Pygidial plate with punctures small and dense, impunctate margin wide and smooth.

Vestiture: Vestiture on labrum plumose, moderately dense, much sparser on basal portion, slightly shorter laterally. That on clypeus simple. That on supraclypeal area and lower paraocular area slightly plumose, extremely short, fine, sparse, thus seemingly blackish bristles alone depending on perspective. That on lower genal area near hypostoma whitish, plumose, slightly longer than on labrum.

Vestiture on scutum and scutellum blackish, short; much shorter on scutum, so that scutum seems to be hairless in dorsal view. That on mesopleuron whitish, fine, plumose, sparser centrally. That on posterolateral to dorsal surface of propodeum outside propodeal triangle silvery-white, strongly plumose, suberect, hairs themselves prominent, but not dense to forming a hair patch, as long as on mesopleuron. Pseudopygidium well developed as normal in female Nomada. Pygidial plate covered with dense short hairs, much sparser apically.

Structure: Body length $8.5 \mathrm{~mm}$. CD:UID:LID 50:46:46. OCD/LOD 1.0.

Interantennal elevation moderately raised, with highly raised keeled carina. Inner eye margins moderately convergent below. Clypeus moderately raised and 
weakly produced.

Labrum nearly flat; distinct tooth present in the center, accompanied by indistinct carina on each side; apical portion below labral tooth moderately produced anteriorly, not upcurved; apical margin serrated with a small triangular protuberance medially (measurement of proportion could not be obtained because all examined specimens have mandibles closed so that apical margins of labra were concealed when viewed in front). Mandible slender. Preoccipital ridge angulated behind vertex, carinate at lateral portion. Relative length of FL1-3 1:1.6:1.4, relative length to apical width of FL1 equal, FL2 1.6 times, FL3 1.4 times.

Scutellum moderately or highly raised, anterior facet flat, median furrow wide and deep. Pygidial plate triangular at apical portion, shallowly notched at apex.

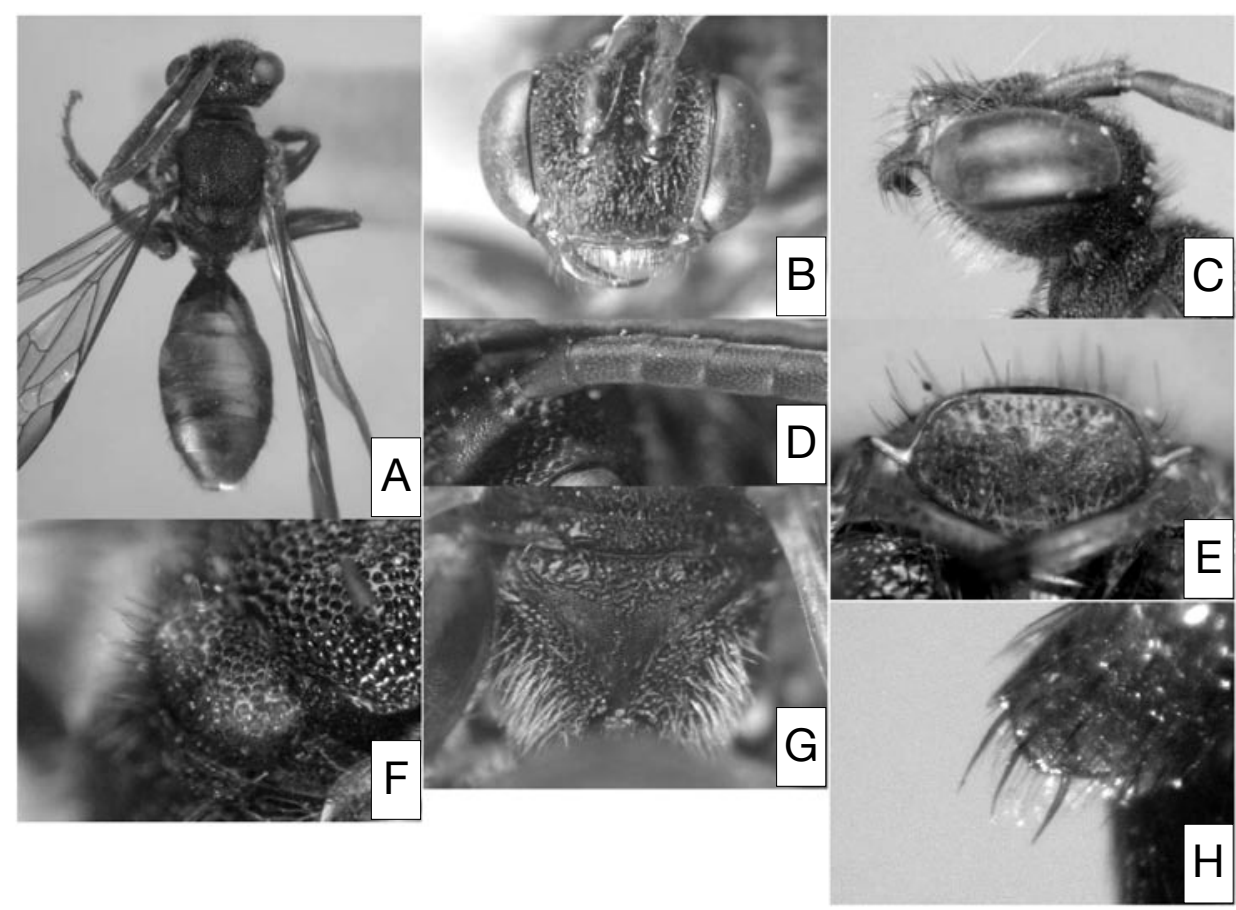

Fig. 19. Nomada erythra sp. nov. (female). A: habitus, dorsal view. B, C: head. D: antenna. E: labrum. F: scutellum. G: propodeal triangle. H: apicomedian setae on hind tibia.

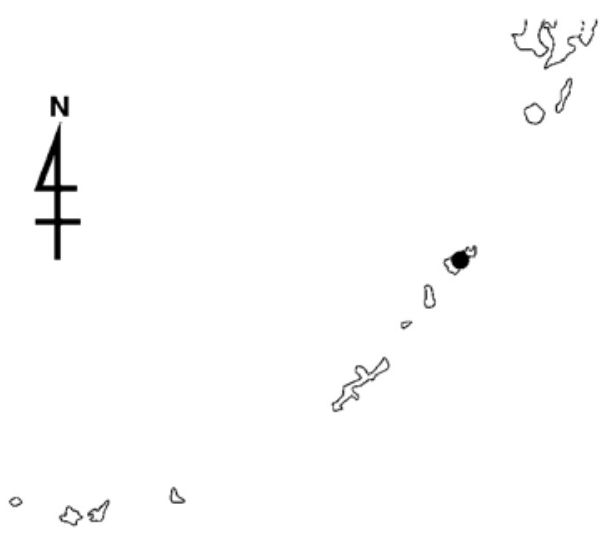

Fig. 20. Distribution of $N$. erythra sp. nov. on the Nansei Islands. Dot: locality of the specimens examined in the present study. 
Table 8. Seasonal change of number of the captured individual of N. erythra sp. nov. in Japan (Number of females indicates at the left of slash in cell, that of males at the right. E: early, M: mid, L: late).

\begin{tabular}{c|ccc}
\hline \multirow{2}{*}{ Nansei Islands } & \multicolumn{3}{|c}{ May } \\
\cline { 2 - 4 } & $\mathrm{E}$ & $\mathrm{M}$ & $\mathrm{L}$ \\
\hline \hline Amami-Oshima Is. & & $3 /$ & 0 \\
\hline Total & 0 & 3 & \\
\hline
\end{tabular}

Fore femur slender. Apicomedian setae on hind tibia three or four in number, dark brown, moderately long, similar in length, well-separated.

Male. Unknown.

Distribution. Japan (Amami-Oshima Is., the Nansei Islands).

Specimens examined. Holotype (Type No. 3247. ELKU), 우, Shinokawa, Amami-Oshima, Is. the Nansei Islands, Japan, 15. v. 1953 (T. Shiraki). The original label is white rectangular, which is typed as follows: "V-15-1953/ Ryukyu Is./ T. SHIRAKI" "Amami/ Shinokawa (on the underside)".

Paratypes: 2 우, the same locality as the holotype, 11. v. 1953 (T. Shiraki, ELKU).

Biology. At present it is endemic to Amami-Oshima Is, collected only in mid May (Table 8). The host and floral associations are unknown.

Remarks. It is similar to Nomada shirakii Yasumatsu et Hirashima, but differs from it in the slenderer fore femur, the larger punctures on face, the highly raised and densely punctate scutellum with the anterior surface evidently flattened, and the T1-4 without yellow macula.

8. Nomada fervens Smith, 1873

[Japanese name: Kêberu-kimadara-hanabachi] (Figs. 21-23 Table 9)

Nomada fervens Smith, 1873, Trans. Ent. Soc. London, 2: 203 [Holotype: Female. Type locality: Hyogo, Honshu, Japan]; Alexander \& Schwarz, 1994, Univ. Kansas Sci. Bull., 55: 247 [in list].

Nomada ruficornis koebelei Cockerell, 1911a, Proc. U. S. Nat. Mus., 39: 645-646 [Holotype: Female]. syn. nov.

Nomada koebelei: Yano, 1932, Icon. Ins. Jap., 1st ed.: 261; Pittioni, 1953, Ann. Nat. Mus. Wien, 59: 272; Tsuneki, 1973, Etizenia, 66: 66-68 [redescription]; Alexander \& Schwarz, 1994, Univ. Kansas Sci. Bull., 55: 249 [in list].

Nomada miensis Tsuneki, 1973, Etizenia, 66: 73-75 [Holotype: Female], synonymized by Tsuneki, 1975: 464.
Nomada hiackogawa Tsuneki, 1973, Etizenia, 66: 134-135 [Holotype: Male]; Alexander \& Schwarz, 1994, Univ. Kansas Sci. Bull., 55: 248 [in list]. syn. nov.

\section{Redescription.}

Female.

Color: Head reddish brown; the following portions are black: macula on antennal area except supraclypeal area always with a reddish brown spot, transverse elliptical macula surrounding ocelli (two macula above narrowly connected on frons, but always a reddish brown spot present just before median ocellus), broad line on genal area along preoccipital from hypostoma up to near vertex. Mandible reddish brown except apical one-third dark red to black. Scape reddish brown wholly, flagellar segments reddish brown anteriorly, darker apically and posteriorly, sometimes apical four segments black wholly.

Mesosoma black; the following portions are reddish brown: anterior margin of pronotum, collar on the top but sometimes tinged with bright yellow, pronotal lobe, tegula, maculae of size variable from well-separated four longitudinal lines to two broad lines occupying scutum nearly wholly except medial longitudinal black line on scutum, axilla, scutellum nearly wholly, two small or one large macula on metanotum, large macula almost occupying lateral surface of mesopleuron, a pair of maculae of size variable from rather small spot to large macula on posterolateral corner, stretching into triangle on propodeum.

Metasoma largely reddish brown, T1 black on basal half; the following portions are yellow: a pair of oval maculae on T2 with intermacular area pale reddish brown, thin band medially, sometimes interrupted narrowly in the middle on T4, large square maculae on T5 medially. S3 largely tinged with yellow. Pygidial plate reddish brown.

Legs largely reddish brown; the following portions are blackish or black: fore coxa dorsally and posteriorly, mid and hind coxae posteriorly, fore and mid femora basally, hind femur apico-medially and posteriorly, hind 


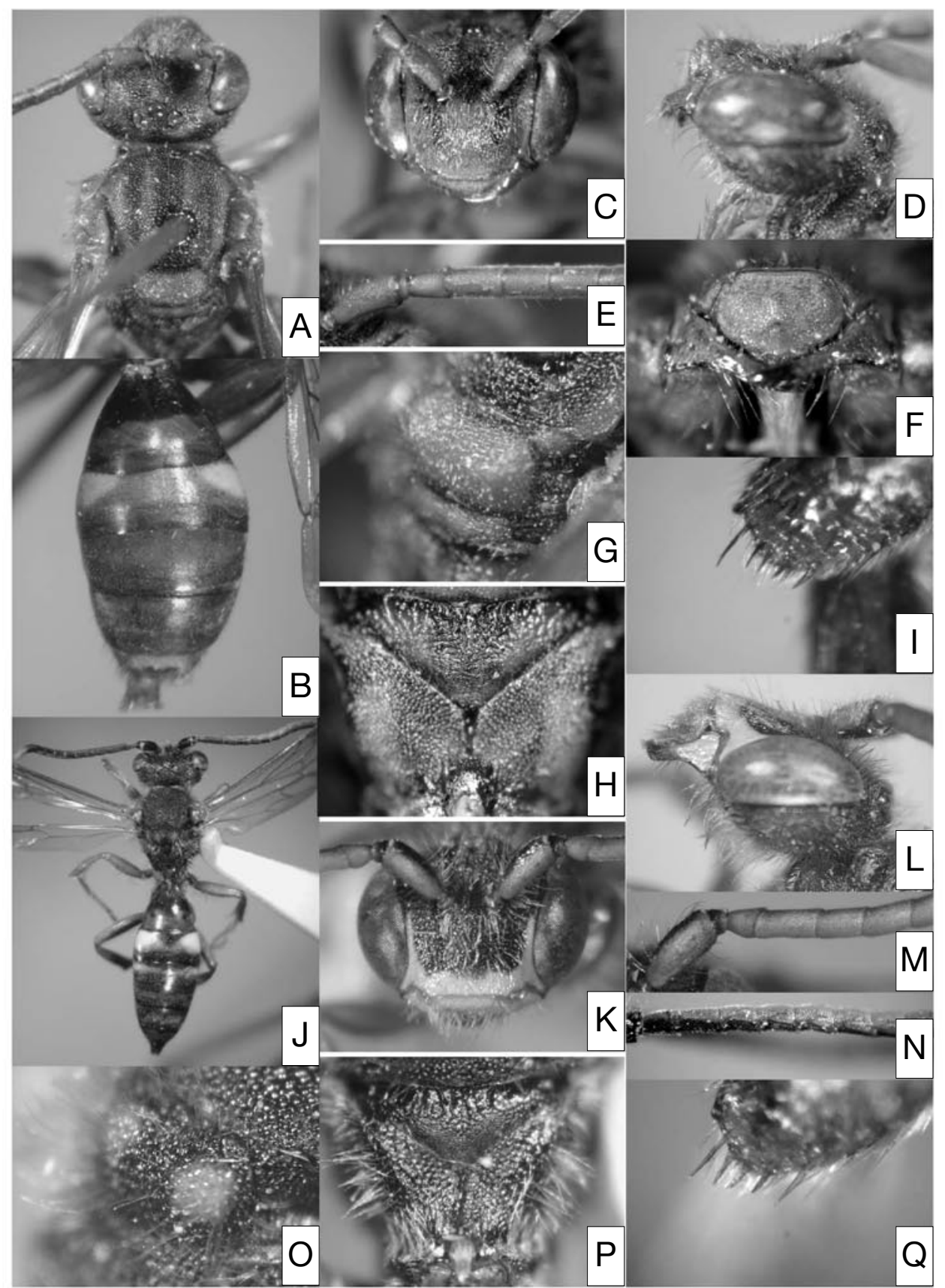

Fig. 21. Nomada fervens Smith. Female: A-I. Male: J-Q. A, B, J: habitus, dorsal view. C, D, K, L: head. E, M, N: antenna. F: labrum. G, O: scutellum. H, P: propodeal triangle. I, Q: apicomedian setae on hind tibia.

tibia posteriorly; sometimes legs nearly wholly reddish brown.

Sculpture: Punctures on labrum small, distinct, dense. Those on clypeus and supraclypeal area successively larger and deeper.

Punctures on scutellum as on scutum, but slightly smaller and denser on medial furrow. Mesopleuron densely areolate. Propodeum outside triangle densely areolate, denser than on mesopleuron. Propodeal triangle irregularly coarsely rugose basally, the rugae highly raised, medial to apico-medial portions finely transversely rugose, the remaining portion faintly tessellate.

Terga faintly microsculptured, with dense punctules except T1 usually impunctate. Pygidial plate with sparse punctures, interpunctural space granulose.

Vestiture: Vestiture on labrum pale brown, weakly 


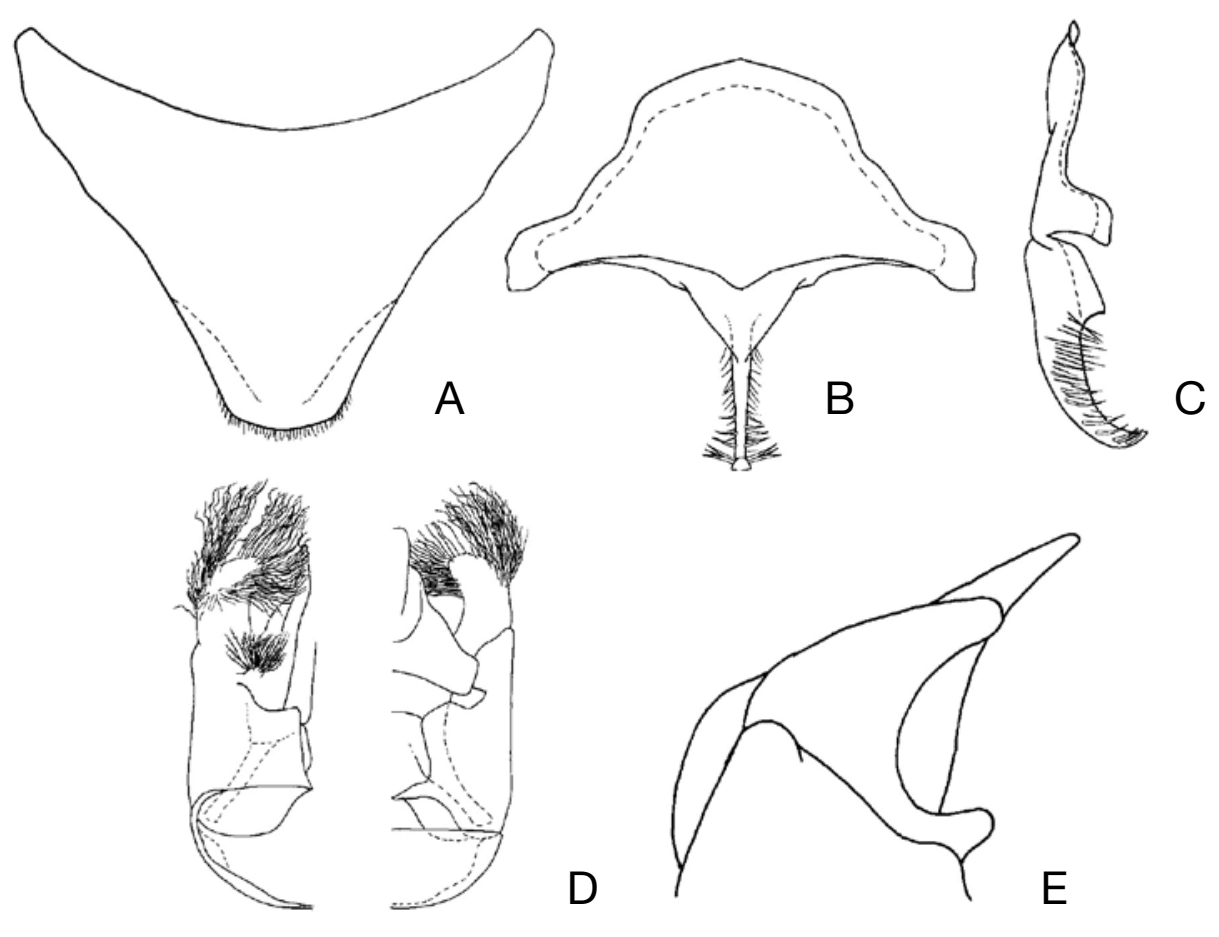

Fig. 22. Nomada fervens (male). A: 7th metasomal sternum, ventral view. B: 8th sternum, dorsal view. C: the same, lateral view. D: genital capsule (left, ventral view; right, dorsal view). E: penis valve and gonostylus, lateral view (vestiture omitted).

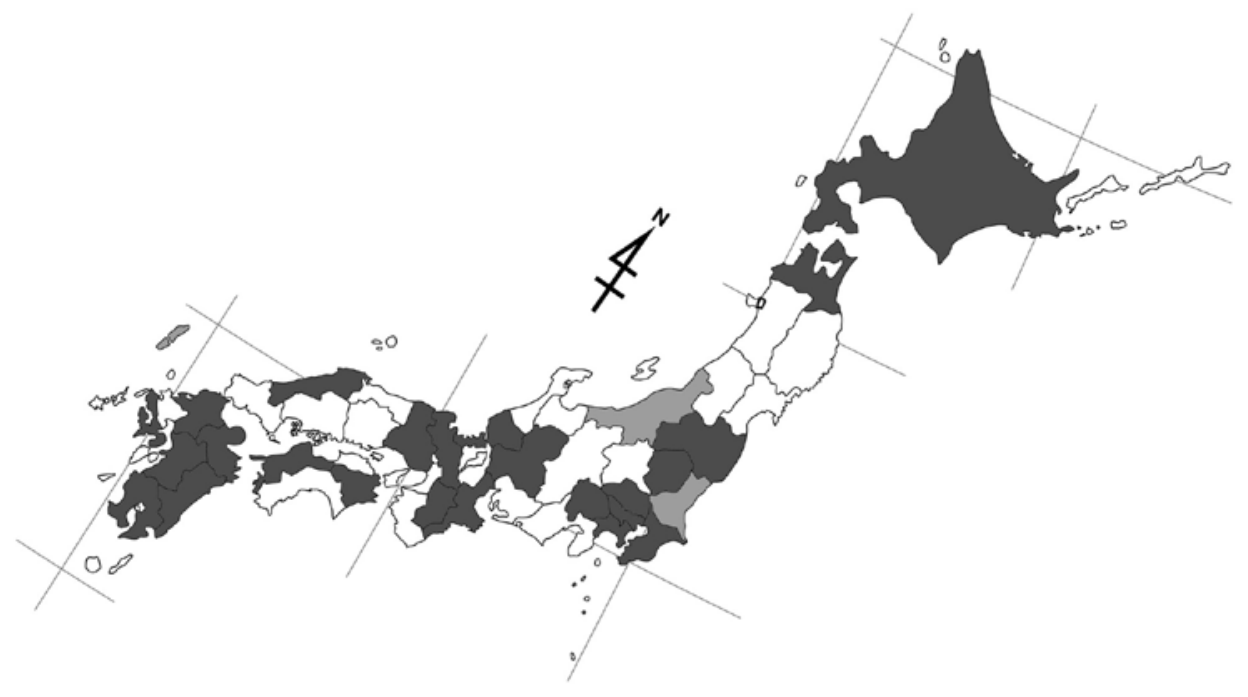

Fig. 23. Distribution of $N$. fervens on the Japanese mainlands. Densely shaded: prefectures with the specimens examined in the present study. Lightly shaded: prefectures with records in literature, but no specimens examined in the present study. 
plumose, long on narrowly apical margin, otherwise much shorter, usually sparse, sometimes moderately dense. That on clypeus and supraclypeal area short, sparse, appressed, plumose. That on lower genal area near hypostoma somewhat longer than on apical margin of labrum.

Vestiture on scutum and scutellum pale brown tinged with golden, darker posteriorly, fine, short, erect, minutely plumose or simple. That on mesopleuron whitish, much longer, more strongly plumose than on scutum. That on posterolateral to dorsal surface of propodeum outside triangle inconspicuous, fine, weakly plumose, extremely short, as long as on metasomal terga.

T1 virtually hairless. Pseudopygidium well developed as normal in female Nomada. Pygidial plate covered with sparse hairs.

Structure: Body length 7-11 mm. CD:UID:LID 50:48:44. OCD/LOD 1.5 .

Interantennal elevation highly raised. Inner eye margins strongly convergent below. Clypeus highly raised, and moderately produced anteriorly. Labrum 1.6 times as wide as long; labral tooth present at or slightly before the center, accompanied by indistinct carina on each side; apical portion below labral tooth weakly produced anteriorly, not upcurved; apical margin weakly serrated only medially. Mandible somewhat slender. Preoccipital ridge distinctly carinate behind vertex, gradually becoming somewhat gently, but still distinctly angulated. Relative length of FL1-3 1:1.7:1.3, relative length to apical width of FL1 1.2 times, FL2 2.2-2.3 times, FL3 1.8 times.

Scutellum highly raised, anterior face flat, median furrow usually wide and shallow, sometimes moderately deep. Area over spiracle weakly developed more or less like a ridge.

Pygidial plate triangular at apical portion, without or with a shallow notch at apex.

Fore femur slender or moderately built. Apicomedian setae on hind tibia five to eight in number, straight, posteriormost seta evidently longer, others much shorter, roughly evenly spaced, pale brown.

Usually third sub-marginal cell of fore wing with bottom side evidently longer (1.2-1.4 times) than that of second sub-marginal cell, second radius-media vein strongly curved outward, though these characters variable.

Male.

Color: Head and mesosoma black; the following portions are yellow: mandible except apical two-fifths reddish brown, labrum, clypeus on apical half, malar area, lower paraocular area extending up along inner eye margin to level of antennal socket, collar on the top, macula on anterior portion of mesopleuron. Pronotal lobe and tegula brown to reddish brown. Two maculae on scutellum usually reddish brown or rarely bright yellow. Scape yellow to yellowish brown anteriorly, black posteriorly, flagellar segments brown anteriorly, black posteriorly.

Metasoma dark brown to black, T1 black on basal half; the following portions are yellow: a pair of round maculae each on T2 and T3 (the latter much smaller), short band each on $\mathrm{T} 4$ and $\mathrm{T} 5$, both frequently interrupted medially, the former frequently too vague to discern, large macula on T6 medially, band or spot each on S2-6.

All coxae black except apical margin yellow on fore and mid coxae and brown on hind coxa; trochanters, femora and tibia largely brown; the following portions dark brown or black: all trochanters posteriorly, fore and mid femora ventrally, hind femur ventrally and anteriorly, hind tibia posteriorly.

Sculpture: Punctures on clypeus shallower than in female, T1 with sparse punctules, otherwise in female.

Vestiture: Vestiture on labrum white, strongly plumose, dense, longer on apical portion, otherwise slightly shorter. That on clypeus, supraclypeal area similar that on labrum, but much longer, appressed, obscuring the integument. That on lower genal area near hypostoma much longer than on labrum.

Vestiture on scutum, scutellum and mesopleuron erect, very long, dense, whitish, somewhat darker apically on scutum, weakly plumose but on mesopleuron more strongly so. That on posterolateral to dorsal surface of propodeum outside triangle white, fine, erect, plumose, sparse, not forming hair patch.

Vestiture on ventral surfaces of fore and mid femora slightly longer, or as long as the maximum width of each segment, that on ventral surface of hind femur with dense, posteriorly directed suberect, straight.

Structure: Body length 8- $12 \mathrm{~mm}$. CD:UID:LID 50:45:40. OCD/LOD 1.5.

The following aspects are different from female as follows: preoccipital ridge angulated, not carinate as in female; scape wider than flagellar segments; relative length of FL1-3 1:1.8:1.5, relative length to apical width of FL1 equal, FL2 1.9-2.1 times, FL3 1.4-1.5 times, tyloidea on FL1 absent, that on FL2 narrowly ridgeshaped, those on FL3-5 more or less delimited, long elliptical or oval, evidently successively wider, not highly raised, those on the following segments indistinctly delimited, successively more weakly raised; scutellum moderately raised, convexities rounded, median furrow 
shallow to moderately deep; shape around propodeal spiracle as in female, but sometimes ridge highly developed in large-sized specimens; fore femur slender; apicomedian setae on hind tibia slenderer than in female, otherwise as in female; hind femur slender; basoventral flattened surface indistinct, not reaching to midpoint of segment, shallowly depressed in posterior view; usually third sub-marginal cell similar to that in female, but more highly variable in shape than that in female; pygidial plate weakly tapering toward apex, usually shallow but widely triangularly emarginated at apex.

Male terminalia: 7th metasomal sternum as in Fig. 22-A. 8th as in Fig. 22-B, C. Gonostylus moderately long; vestiture long, simple, moderately dense, sinuate apically; basoventral lobe greatly produced, with plumose, long vestiture. Penis valve produced posteriorly not beyond gonostylus, apex extending much beyond apex of gonostylus in lateral view. Gonocoxite with distinct and narrow dorsal invagination; inner dorsal lobe wider than long, with apex truncate.

Distribution. Japan (Hokkaido, Honshu, Shikoku, Kyushu); South Korea.

Specimens examined. Holotype (USNM), 우, attached with four labels as follows: "type/ F. Sm. Coll. 79. 22 (white rectangular and typed except for "type" handwritten)", "Type/ HT (white circular and typed, the edge colored red)", "B. M. TYPE/ HYM/ 17. B. 530 (white rectangular and typed except the bottom line handwritten)", "Nomada/ fervens/ Japan Sm (white rectangular with handwritten letters)", "Hiogo/ Japan (small rectangular, and the upper line is handwritten, the lower line is typed)".

Other specimens: We have examined about 45 females and 100 males. On the localities, see Fig. 23.

Table 9. Seasonal change of number of the captured individual of $N$. fervens in Japan (Number of females indicates at the left of slash in cell, that of males at the right. E: early, M: mid, L: late).

\begin{tabular}{|c|c|c|c|c|c|c|c|c|c|c|c|c|c|c|c|c|}
\hline \multirow[b]{2}{*}{ Main island } & \multirow[b]{2}{*}{ Prefecture } & \multicolumn{3}{|c|}{ March } & \multicolumn{3}{|c|}{ April } & \multicolumn{3}{|c|}{ May } & \multicolumn{3}{|c|}{ June } & \multicolumn{3}{|c|}{ July } \\
\hline & & $\mathrm{E}$ & $\mathrm{M}$ & $\mathrm{L}$ & $\mathrm{E}$ & $\mathrm{M}$ & $\mathrm{L}$ & $\mathrm{E}$ & $\mathrm{M}$ & $\mathrm{L}$ & $\mathrm{E}$ & $\mathrm{M}$ & $\mathrm{L}$ & $\mathrm{E}$ & $M$ & $\mathrm{~L}$ \\
\hline HOKKAIDO & & & & & & & & & & $/ 14$ & & 1/ & & $2 /$ & & \\
\hline $\begin{array}{l}\text { HONSHU } \\
\qquad \text { [Tohoku] }\end{array}$ & $\begin{array}{l}\text { Aomori } \\
\text { Fukushima }\end{array}$ & & & & & & & $/ 4$ & & $\begin{array}{l}/ 1 \\
/ 1\end{array}$ & & 17 & & & & \\
\hline [Kanto] & $\begin{array}{l}\text { Tochigi } \\
\text { Saitama } \\
\text { Chiba } \\
\text { Tokyo } \\
\text { Kanagawa }\end{array}$ & & & $/ 1$ & $1 / 2$ & $\begin{array}{l}1 / 1 \\
1 / 2 \\
13 \\
\end{array}$ & $\begin{array}{l}/ 1 \\
1 / 2 \\
2 / 1\end{array}$ & $\begin{array}{l}/ 5 \\
1 / \\
1 / \\
2 / 2\end{array}$ & $\begin{array}{l}1 / \\
1 / 1 \\
\\
2 / 2 \\
\end{array}$ & $/ 1$ & 1/ & & & & & \\
\hline [Chubu] & $\begin{array}{l}\text { Fukui } \\
\text { Yamanashi } \\
\text { Gifu }\end{array}$ & & & & & & $1 / 9$ & $1 /$ & $1 /$ & $1 / 8$ & & & & & & \\
\hline [Kinki] & $\begin{array}{l}\text { Kyoto } \\
\text { Hyogo } \\
\text { Nara }\end{array}$ & & & & & $2 /$ & $\begin{array}{l}4 / \\
1 /\end{array}$ & $/ 1$ & 1/ & & & & & & & \\
\hline [Chugoku] & Shimane & & & & & & & $1 / 1$ & & & & & & & & \\
\hline SHIKOKU & $\begin{array}{l}\text { Tokushima } \\
\text { Ehime }\end{array}$ & & & & & 12 & & $1 /$ & & & & & & & & \\
\hline KYUSHU & $\begin{array}{l}\text { Fukuoka } \\
\text { Nagasaki } \\
\text { Kumamoto } \\
\text { Oita } \\
\text { Miyazaki } \\
\text { Kagoshima }\end{array}$ & & $/ 1$ & $\begin{array}{l}/ 1 \\
/ 1\end{array}$ & $1 / 6$ & 1/ & $\begin{array}{l}\text { 1/ } \\
2 / \\
1 / \\
1 /\end{array}$ & $/ 1$ & $\begin{array}{l}/ 1 \\
/ 1\end{array}$ & & & & & & & \\
\hline Tota & & 0 & 1 & 4 & 10 & 21 & 27 & 21 & 11 & 26 & 1 & 8 & 0 & 2 & 0 & 0 \\
\hline
\end{tabular}


Some of them are listed as follows: JAPAN [Honshu] Fukushima: 10', Nakayama, Koriyama, 23. v. 1975 (O. Tadauchi, ELKU). Hyogo: 1우, Tamba, Sasayama, 16. v. 1955 (S. Taniguchi, ELKU). Shimane: 1우, Nishikawatsu, Matsue, 5. v. 1986 (N. Sugiura). [Shikoku] Tokushima: 1우, Hashikura, Ikeda-machi, 1. v. 1975 (O. Tadauchi, ELKU). Ehime: $2 \sigma^{\top}$, Ochiai, Kuma-machi, 15. iv. 1976 (O. Tadauchi, ELKU). [Kyushu] Fukuoka: 1 ธ', Dazaifu, 19. iii. 1959 (Y. Hirashima, ELKU). Oita: 1 ㅇ, Mt. Hanamureyama, Shônai-machi, Oita-gun, 28. iv. 2006 (K. Mitai). Miyazaki: 1우, Miyakonojo, 13. iv. 1958 (Y. Hirashima, ELKU). Kagoshima: 10', Miyanojo, 29. 3. 1959. (Y. Maeta, ELKU). SOUTH KOREA, 2ð', Mt. Hokkan, 21. v. 1942 (K. Tsuneki, MNHAH).

Biology. It is a univoltine species, collected from late March to early July in Japan (Table 9). Matsumura (1970) reported on the host of this species. He excavated ground nests of Andrena sublevigata Hirashima in Hokkaido, Japan, and collected newly emerged adults of $N$. fervens (cited as N. koebelei) from the cells. Floral associations are as follows: [Cruciferae] Brassica rapa; [Convolvulaceae] Calystegia soldanella; [Compositae] Hieracium pratense.

Remarks. It is similar to Nomada amurensis Radoszkowsky in both sexes, the differences between them are described in detail in Tsuneki (1975) [cited as Nomada koebelei. Nomada amurensis is cited as N. esakii]. Furthermore, we found the additional diagnostic characters as follows: the more coarsely tessellate propodeal triangle in both sexes and the slightly longer vestiture on mesosoma in female in $N$. fervens.

9. Nomada flavoguttata (Kirby, 1802) [Japanese name: Hime-kimadara-hanabachi] (Figs. 24-26; Table 10)

Apis flavoguttata Kirby, 1802, Monogr. Apum Angl., 2: 215-216 [Holotype: Male].

Nomada kurilensis Yasumatsu, 1939, Trans. Kansai Entomol. Soc., 9: 6-7 [Holotype: female]; Alexander \& Schwarz, 1994, Univ. Kansas Sci. Bull., 55: 258 [in list]. syn. nov.

Nomada flavoguttata japonensis Tsuneki, 1973, Etizenia, 66: 115-119 [Holotype: Female]; Alexander \& Schwarz, 1994, Univ. Kansas Sci. Bull., 55: 247 [in list]; Ikudome, 1999, in: Ident. Guide Aculeata Nansei Is., Jap.: 655-656. syn. nov.

Nomada tridentata Tsuneki, 1986, Spec. Publ. Hym. Assoc., (32): 49-50 [Holotype: Female]; Alexander \& Schwarz, 1994, Univ. Kansas Sci. Bull., 55: 253 [in list]. syn. nov.

\section{Redescription. \\ Female.}

Color: Head Black; the following portions are reddish brown: clypeus with usually black line on epistomal suture, paraocular area, supraclypeal area, line along compound eye, mandible except apical one-fourth. Labrum usually wholly blackened, sometimes partially yellow or wholly bright yellow. In specimens with less developed black maculae, black maculae restricted to upper and interspace of the antennal sockets, area surrounding the ocelli on vertex, thin line on genal area along the preoccipital ridge. In specimens with widened black macula, reddish brown maculae restricted to narrow line along inner and outer eye margins, clypeus except upper margins black, malar area.

Mesosoma and other body parts less variable in color than head. Black; the following portions are reddish brown; collar, pronotal lobe, tegula, four longitudinal lines on scutum, scutellum, axilla, metascutum, large maculae occupying mesopleuron nearly wholly, a pair of large maculae on posterolateral corner, stretching into propodeal triangle.

Metasoma dark brown to black, with reddish brown band each on T1-3; the following portions are yellow: a pair of small yellow round maculae each on T2 and T3, large maculae on T5, the latter macula somewhat dark yellow. In some specimens ground color on terga greatly paler. Pygidial plate reddish brown.

Legs largely reddish brown; the following portions are blackish: all coxae and trochanters posteriorly, all femora posteriorly and ventrally, mid and hind tibiae wholly.

Sculpture: Punctures on labrum shallow, small. Those on clypeus slightly larger, obliterated, sparse, about a puncture diameter apart. Those on supraclypeal area much larger, denser.

Punctures on scutellum as on scutum. Mesopleuron moderately areolate. Propodeum outside triangle shallowly but densely areolate, denser than on mesopleuron, except weakly rugose portion with sparse punctures under spiracle. Propodeal triangle irregularly rugose on basal half, the remaining portion weakly tessellate.

Terga impunctate and polished. Pygidial plate with punctures small, sparse, interpunctural space smooth.

Vestiture: Vestiture on labrum pale brown, plumose, long on narrowly apical margin, otherwise much shorter. That on clypeus and supraclypeal area silvery-white, strongly plumose, dense to obscure the integument, but worn out in many specimens. That on lower genal area near hypostoma erect, whitish, as long as on labrum.

Vestiture on scutum and scutellum brown tinged 
with golden, short but slightly longer on scutellum, sparse. That on mesopleuron silvery-white, strongly plumose, suberect, variable in density and extension, usually forming a distinct hair patch, sometimes not so. That on lower posterolateral corner of propodeum similar to that on mesopleuron, usually forming a distinct hair patch.

Terga virtually hairless except subapical portion provided with roughly fringe-like arranged hairs, and
T5 wholly covered with sparse hairs. Pseudopygidium small, composed of highly modified scale-like hairs, thus prominently shining. Pygidial plate covered by fine, sparse hairs.

Structure: Body length 5-6 mm. CD:UID:LID 50:50:45. OCD/LOD 1.1-1.2.

Interantennal elevation moderately raised, with highly raised keeled carina. Inner eye margins moderately convergent below. Clypeus weakly raised and

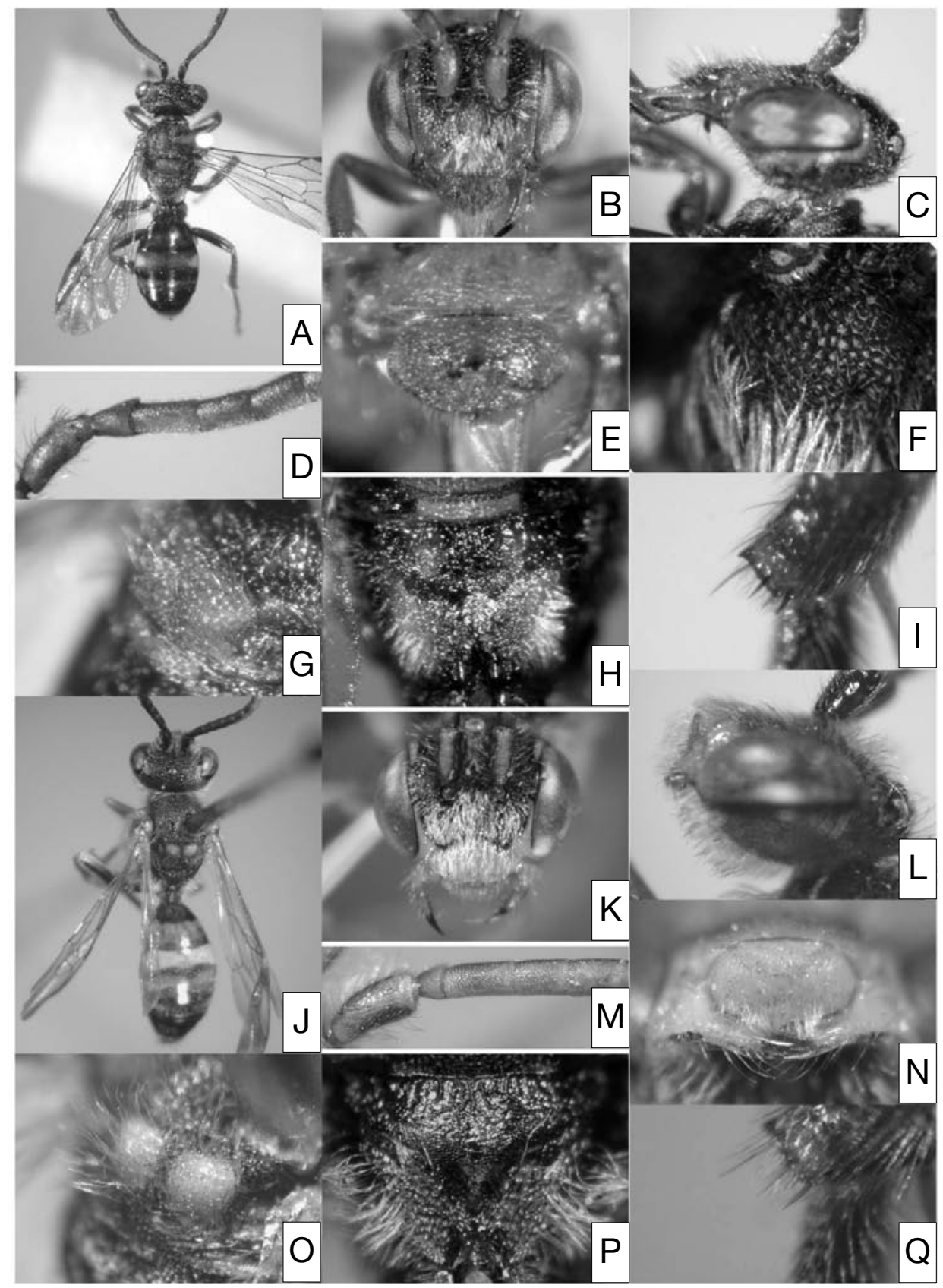

Fig. 24. Nomada flavoguttata (Kirby). Female: A-I. Male: J-Q. A, J: habitus, dorsal view. B, C, K, L: head. D, M: antenna. E, N: labrum. F: mesopleuron, G, O: scutellum. H, P: propodeal triangle. I, Q: apicomedian setae on hind tibia. 
produced anteriorly. Labrum 1.8 times as wide as long; three labral teeth arranged in a low triangle, medial tooth distinct, located in the center, usually other two indistinct, not accompanied by a carina; apical portion below labral teeth produced anteriorly, not upcurved; apical margin indistinctly serrated with a triangular protuberance medially. Preoccipital ridge angulated, but not carinated. Relative length of FL1-3 1:1.7-1.8:1.4, relative length to apical width of FL1 1.1, FL2 1.9-2.1, FL3 1.6-1.7 times.

Scutellum weakly or moderately, roundly raised, median furrow shallow or scarcely discernible. Pygidial plate narrowly triangular at apical portion, usually widely emarginated at apex.

Fore femur slender. Apicomedian setae hind tibia three to five in number, brown to black, slender, evenly spaced, posteriormost seta longer, others much shorter, sometimes robust except the posteriormost.

\section{Male.}

Color: Head and mesosoma largely black; the following portions are yellow: mandible except apical onefourth, labrum but frequently darkened, clypeus on apical half, malar area, lower paraocular area extending up along the inner eye margin to level of antennal socket, spot tinged with brown along top of compound eye. Pronotal lobe yellow to dark yellow. Scutellum with two dark red or orange maculae of size variable, very rarely wholly black.

Metasoma largely dark brown to black; T1 with apical half pale brown to brown containing two black spots, $\mathrm{T} 2$ and $\mathrm{T} 3$ each with a pair of round yellow maculae (those on T3 much smaller, intermacular space pale brown to dark brown), $\mathrm{T} 4$ and $\mathrm{T} 5$ each with indistinct dark brown band, $\mathrm{T} 6$ with a brown to dark brown, transverse elliptical macula.

Legs pale brown; the following portions are black: all coxae except narrow apical portion, fore trochanter dorsally, mid and hind trochanters dorsally and ventrally (sometimes wholly black except narrow anterior surface), fore and mid femora ventrally, hind femur except dorsally.

Sculpture: As in female, but somewhat shallower on mesosoma.

Vestiture: Vestiture on labrum, clypeus and supraclypeal area silvery-white, strongly plumose, appressed on clypeus and supraclypeal area as to obscure integument. That on lower genal area less plumose, as long as on labrum, slightly darker.

Vestiture on scutum and scutellum pale brown tinged with golden, erect, weakly plumose. That on mesopleuron pale brown, becoming whitish ventrally, plumose. That on posterolateral and dorsal surface propodeum outside triangle similar to that on mesopleuron, but slightly more weakly plumose, more whitish, not forming hair patch.

Vestiture on ventral surface of fore femur slightly shorter than the maximum width of segment, that of mid femur much shorter than the maximum width of segment, that on ventral surface of hind femur sparse, very short.

Structure: Body length 5-6 mm. CD:UID:LID 50:52:42. OCD/LOD 1.6.

The following aspects are different from female: scape much wider than flagellar segments; relative length of FL1-3 1: 2.8-2.9: 2, FL1 0.7 times, FL2 2.0-2.2 times, 1.5 times as long as each apical width, tyloidea on FL3-5 developed as obscure convex, not recognized on other segments; pygidial plate shallowly roundly emarginated at apex; fore femur moderately built; hind femur slender; basoventral flattened surface indistinct, ventral margin of segment straight in posterior view, with sparse, very short hairs; apicomedian setae on hind tibia similar to those in female, but slenderer, pale in color, difficult to discern among surrounding hairs.

Male terminalia: 7th metasomal sternum as in Fig. 25-A. 8th as in Fig. 25-B, C. Gonostylus short; vestiture long, comparatively sparse, simple, sinuate apically; basoventral lobe absent, but very long, simple, weakly sinuate vestiture on the corresponding portion. Penis valve not produced posteriorly beyond gonostylus, apex extending beyond apex of gonostylus in lateral view. Gonocoxite with dorsal invagination distinct; inner dorsal lobe as long as wide, with apex truncate.

Distribution. Palearctic Region; Japan (Hokkaido, Honshu, Shikoku, Kyushu).

Specimens examined. We have examined 250 females and 300 males. On the localities, see Fig. 26. Some of them are listed as follows: JAPAN [Honshu] Iwate: 2우10 , Kawaranobo, Mt. Hayachine, 22. vi. 1979 (T. Chiba, NIAES). Nagano: 3우, Oyanohara, Otari, 15. v. 1976 (O. Tadauchi, ELKU). Hyogo: 1우, Mt. Ohyasan, Inagawa-chô, Kawabe-gun, 5. v. 2003 (K. Mitai). [Shikoku] Ehime: 2우10', Ochiai, Kuma-machi, 15. iv. 1976 (O. Tadauchi, ELKU). [Kyushu] Fukuoka: 9우110', Kyushu Univ. Forest, Sasaguri-machi, Kasuya-gun, 31. iii. 2005 (K. Mitai). Saga: 40, Kami-ozoegawa, Fuji, 5. iv. 2002 (K. Mitai, ELKU). Oita: 8우16 $\sigma^{\prime}$, Hanamureyama, Shônai-machi, Oita-gun, 6. iv. 2006 (K. Mitai). Miyazaki: 1 우 $3 \sigma^{\top}$, Ebino Highland, Ebino-shi $\cdot$ Kobayashishi, 14. iv. 2003 (K. Mitai). SOUTH KOREA, 2우10", Kawang Nung, Pochon-Gun, Kyongi-Do, 24. iv. 1992 (T. Saigusa, ELKU). RUSSIA [Kurile Islands] 2 우 (= the 

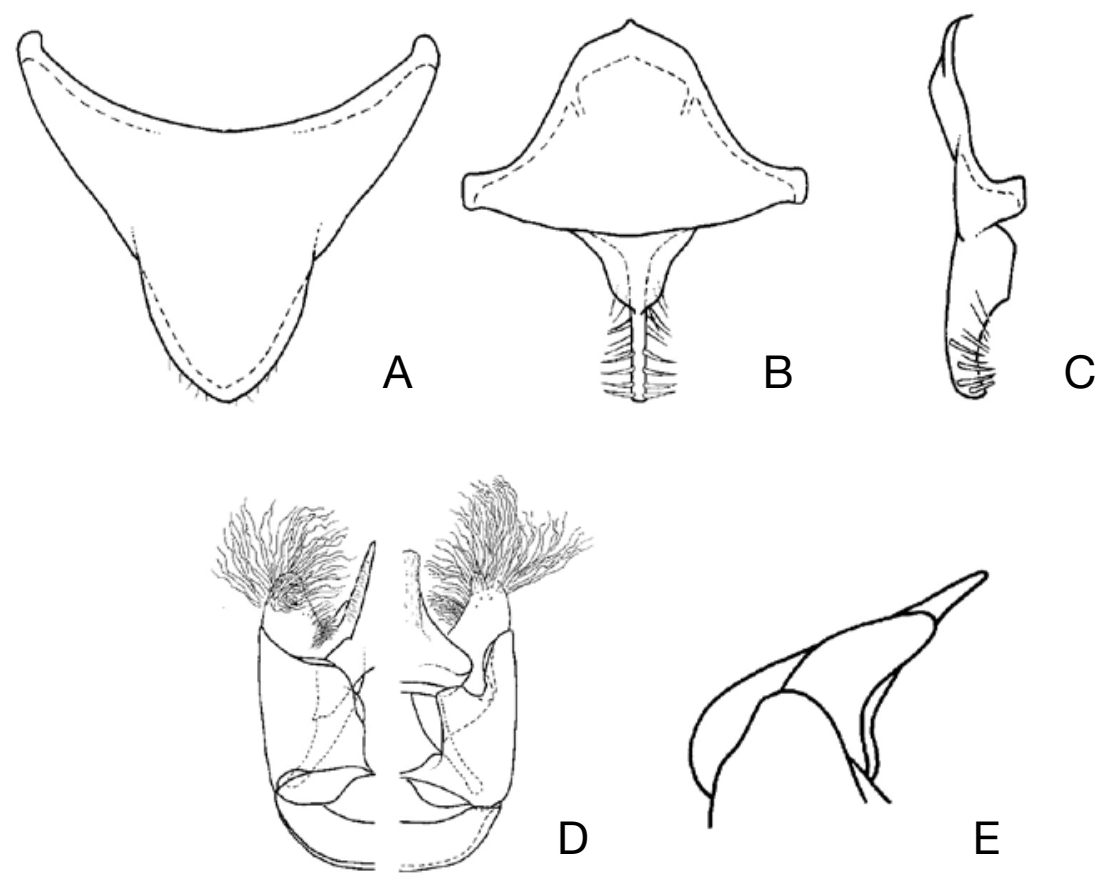

Fig. 25. Nomada flavoguttata (male). A: 7th metasomal sternum, ventral view. B: 8th sternum, dorsal view. C: the same, lateral view. D: genital capsule (left, ventral view; right, dorsal view). E: penis valve and gonostylus, lateral view (vestiture omitted).

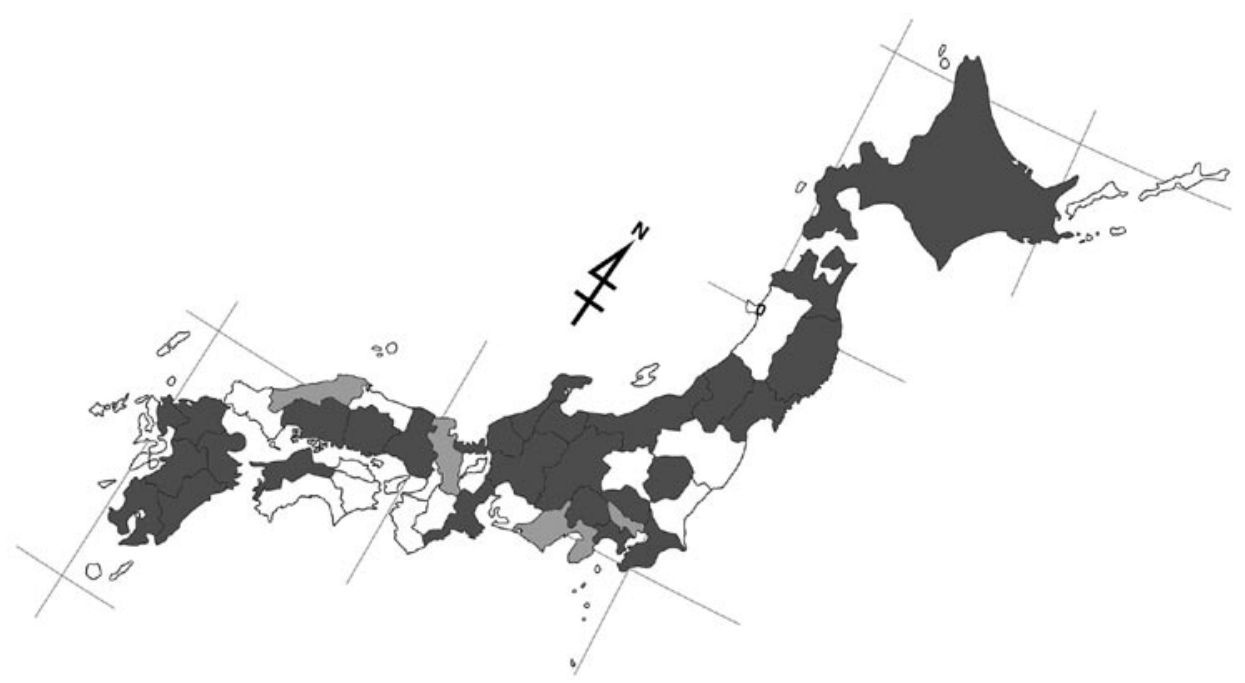

Fig. 26. Distribution of $N$. flavoguttata on the Japanese mainlands. Densely shaded: prefectures with the specimens examined in the present study. Lightly shaded: prefectures with records in literature, but no specimens examined in the present study. 
Table 10. Seasonal change of number of the captured individual of N. flavoguttata in Japan (Number of females indicates at the left of slash in cell, that of males at the right. E: early, M: mid, L: late).

\begin{tabular}{|c|c|c|c|c|c|c|c|c|c|c|c|c|c|c|c|c|c|c|c|}
\hline \multirow[b]{2}{*}{ Main island } & \multirow[b]{2}{*}{ Prefecture } & \multicolumn{3}{|c|}{ March } & \multicolumn{3}{|c|}{ April } & \multicolumn{3}{|c|}{ May } & \multicolumn{3}{|c|}{ June } & \multicolumn{3}{|c|}{ July } & \multicolumn{3}{|c|}{ August } \\
\hline & & $\mathrm{E}$ & $\mathrm{M}$ & $\mathrm{L}$ & $\mathrm{E}$ & $\mathrm{M}$ & $\mathrm{L}$ & $\mathrm{E}$ & $\mathrm{M}$ & $\mathrm{L}$ & $\mathrm{E}$ & $\mathrm{M}$ & $\mathrm{L}$ & $\mathrm{E}$ & $\mathrm{M}$ & $\mathrm{L}$ & $\mathrm{E}$ & $\mathrm{M}$ & $\mathrm{L}$ \\
\hline HOKKAIDO & & & & & & & & & $1 / 1$ & $5 /$ & $/ 1$ & $2 / 2$ & $2 / 11$ & $1 /$ & $19 / 3$ & 71 & $3 /$ & & \\
\hline \multicolumn{20}{|l|}{ HONSHU } \\
\hline \multirow[t]{4}{*}{ [Tohoku] } & Aomori & & & & & & $2 / 3$ & $1 / 6$ & & $5 /$ & 14 & & & $1 / 2$ & 1/ & $2 /$ & & & \\
\hline & Iwate & & & & & & & 1/ & $1 /$ & & & & $2 / 1$ & & & & & & \\
\hline & Miyagi & & & & 12 & 12 & $4 / 1$ & & $1 / 4$ & & & & & & & & 1/ & & \\
\hline & Yamagata & & & & & & & & & $1 / 1$ & & & & & 1/ & 1/ & & & \\
\hline \multirow[t]{4}{*}{ [Kanto] } & Tochigi & & & $3 /$ & 13 & $7 / 10$ & $3 / 11$ & $1 / 9$ & & 12 & $1 / 3$ & $1 /$ & & & & & & & \\
\hline & Saitama & & & & $1 / 2$ & $7 / 8$ & $2 / 1$ & $3 /$ & $2 /$ & & & & & & & & & & \\
\hline & Chiba & & & & & 1/ & $3 / 1$ & & & & & & & & & & & & \\
\hline & Kanagawa & & & & 1/ & 1/ & & & $/ 1$ & & & & & & & & & & \\
\hline \multirow[t]{6}{*}{ [Chubu] } & Niigata & & & & & & $1 / 1$ & 1/ & 1/ & & & & & & & & & & \\
\hline & Ishikawa & & & & $2 /$ & $/ 1$ & 12 & 2/ & & $/ 1$ & $/ 1$ & & & $1 /$ & & & & & $1 / 1$ \\
\hline & Fukui & & & 12 & & $1 / 1$ & $9 / 9$ & $16 / 11$ & $6 / 2$ & & $1 /$ & & & $/ 1$ & & 1/ & & & \\
\hline & Yamanashi & & & & & & & & $/ 1$ & 13 & & & & & & & 1/ & & \\
\hline & Nagano & & & & & 1/ & & $/ 1$ & $3 / 3$ & & $/ 1$ & & & & & & & & \\
\hline & Gifu & & & & & & & $1 / 1$ & $1 / 1$ & & & $/ 1$ & & & & & & & \\
\hline \multirow[t]{2}{*}{ [Kinki] } & Mie & & & & & & 12 & & $1 /$ & & & & & & & & & & \\
\hline & Hyogo & & & & & & & $1 / 1$ & & & & & & & & & & & \\
\hline \multirow[t]{2}{*}{ [Chugoku] } & Hiroshima & & & & & & $/ 1$ & & & & & & & & & & & & \\
\hline & Yamaguchi & & & & $/ 1$ & & & & & & & & & & & & & & \\
\hline SHIKOKU & Ehime & & & & & $3 / 2$ & & & & & & & & & & & & & \\
\hline \multirow[t]{6}{*}{ KYUSHU } & Fukuoka & & $4 / 22$ & $13 / 14$ & $12 / 15$ & $8 / 13$ & $4 / 12$ & $3 / 10$ & $3 / 5$ & 1/ & & & & & & & & & \\
\hline & Saga & & & & 14 & & & & & & & & & & & & & & \\
\hline & Kumamoto & & & $1 / 1$ & & & & & & $1 /$ & & & & & & & & & \\
\hline & Oita & & $/ 1$ & $/ 1$ & $8 / 16$ & 13 & $15 / 1$ & & $/ 1$ & & & & & & & & & & \\
\hline & Miyazaki & & & & $/ 1$ & $1 / 3$ & & 1/ & & & & & & & & & & & \\
\hline & Kagoshima & & & & & & $/ 1$ & & & & & & & & & & & & \\
\hline \multicolumn{2}{|c|}{ Total } & 0 & 27 & 35 & 68 & 73 & 87 & 70 & 48 & 20 & 12 & 6 & 16 & 6 & 24 & 11 & 5 & 0 & 2 \\
\hline
\end{tabular}

types of Nomada kurilensis Yasumatsu). TURKEY, 1 우, det. M. Schwarz. GREECE, 1б', det. M. Schwarz. AUSTRIA, 7 우8 $8 \sigma^{\nearrow}$, det. M. Schwarz. SWEDEN, 10', det. M. Schwarz.

Biology. It is a bivoltine species, common and abundant in Japan. The wintering generation is colleted from mid March to late June. The first generation collected from June to late August (Table 10). Floral associations are as follows: [Salicaceae] Salix hultenii var. angustifolia. [Ranunculaceae] Ranunculus japonicus. [Papaveraceae] Corydalis heterocarpa var. japonica, Corydalis incisa. [Rosaceae] Duchesnea chrysantha, Potentilla discolor, Potentilla recta, Rubus hirsutus. [Scrophulari- aceae] Veronica persica. [Compositae] Chrysanthemum leucanthemum, Petasites japonicus, Petasites japonicus var. giganteus, Taraxacum officinale. The host is unknown.

Remarks. It is closely similar to Nomada montverna Tsuneki. On the distinction, see the remarks of $N$. montverna.

It is also similar to Nomada hakonensis Cockerell in general appearance, but can be easily separated from it by the FL2 with 1.8-2.1 times as long as apical width of the segment (2.4-2.6 times in N. hakonensis) in female, 2.0-2.2 times (2.4-2.5 times in N. hakonensis) in male. In addition, the propodeal triangle is coarser and more 
irregularly rugose in $N$. flavoguttata whereas the triangle is sparsely rugose and somewhat smooth between the rugae in $N$. hakonensis.

In the case of specimens with developed bright yellow macula, it is similar to Nomada kinosukei Tsuneki, but differs from it in both sexes in the three submarginal cells in fore wing (two cells in N. kinosukei), the hypoepimeral area which is as punctate as the neighboring area (the hypoepimeral area is more sparsely punctate than on the neighboring area in $N$. kinosukei). In addition, $N$. flavoguttata is bivoltine, but $N$. kinosukei is univoltine, collected from early July to early September. Tsuneki (1973) pointed out that the mandible of female $N$. kinosukei is blunt at apex. Sometimes, however, that of $N$. flavoguttata is similarly blunt at apex.

Nomada tridentata Tsuneki described based on one female specimen corresponds to the first generation of $N$. flavoguttata, so that should be synonymized with the latter.

10. Nomada fukuiana Tsuneki, 1973

[Japanese name: Fukui-kimadara-hanabachi] (Figs. 27-29; Table 11)

Nomada fukuiana Tsuneki, 1973, Etizenia, 66: 75-78 [Holotype: Female. Type locality: Mt. Washigadake, Fukui Pref., Honshu, Japan]; Alexander \& Schwarz, 1994, Univ. Kansas Sci. Bull., 55: 247 [in list].

Nomada sunayamana Tsuneki, 1976. Kontyû, 44: 63-64. [Holotype: Male]. Alexander \& Schwarz, 1994, Univ. Kansas Sci. Bull., 55: 252 [in list]. syn. nov.

Nomada risiriensis Tsuneki, 1976. Kontyû, 44: 50-52. [Holotype: Male]; Alexander \& Schwarz, 1994, Univ. Kansas Sci. Bull., 55: 251 [in list]. syn. nov.

\section{Redescription.}

Female.

Color: Head reddish brown, the following portions are black: macula surrounding antennal sockets, transverse elliptical macula surrounding ocelli on vertex, broad line on genal area along preoccipital ridge extending from hypostoma up to vertex (usually these maculae connected at least partially). In specimens with developed black portions, maculae on face fused into one large macula. In specimens with less developed black portions, macula on antennal area smaller, supraclypeal area and frons before medial ocellus reddish brown. Antennal scape reddish brown with black line on lateral surface, FL1-4 reddish brown wholly, the following segments becoming blackish apically, frequently apical three or four segments black wholly.

Mesosoma black; the following portions are reddish brown; collar on the top but sometimes tinged with bright yellow, pronotal lobe, tegula, four longitudinal lines of size variable from well-separated to fused largely each other on scutum, axilla, scutellum except peripheral margin, large macula on the lateral side of mesopleuron, metanotum, a pair of large maculae on posterolateral corner propodeum, stretching into the propodeal triangle.

Metasoma reddish brown, T1 black on basal half, each following terga blackish basally and apically; the following portions are yellow: a complete band on $\mathrm{T} 2$ which strongly narrowed medially, sometimes notched at median portion above and beneath so that appears as largely fused two maculae, a pair of small round spots on T3; line of four maculae on T4, inner two of them transversely elliptical, close together on median T4, outer two small, round on lateral side of T4, large square maculae on T5 medially. Pygidial plate reddish brown.

Legs reddish brown; the following portions are black: fore coxa on anteroinner and upper portions, mid coxa posteriorly, hind coxa on anteroinner and posterior portions. In specimens with more developed black portions, all femora largely black basally.

Sculpture: Punctures on labrum small, moderately sparse. Those on clypeus small, shallow, very dense. Those on supraclypeal area larger and distinct.

Punctures on scutellum smaller, denser than scutum. Mesopleuron moderately areolate. Propodeum outside triangle areolate, much denser than on mesopleuron, except weakly rugose portion under spiracle. Propodeal triangle coarsely irregularly rugose on basal half and central portion, the remaining portion tessellate.

Terga faintly microsculptured, mat without punctules. Pygidial plate with punctures small, dense.

Vestiture: Vestiture on labrum, clypeus and clypeal area very fine, short, sparse, especially inconspicuous on clypeus. That on lower genal area near hypostoma plumose, evidently longer than on labrum.

Vestiture on scutum and scutellum brown, weakly plumose, more weakly plumose posteriorly, short, suberect. That on mesopleuron fine, weakly plumose, comparatively sparse. That on posterolateral corner of propodeum whitish, plumose, considerably sparse, evidently shorter on mesopleuron, frequently worn out and integument appeared nearly hairless.

Terga dense, short, appressed pubescence. Pseudopygidium rudimentary, restricted on apicomedian edge of T5. Pygidial plate covered with short, dense hairs.

Structure: Body length 9-11 mm. CD:UID:LID 


\section{0:48:44. OCD/LOD 1.1}

Interantennal elevation moderately raised, with low keeled carina. Inner eye margins weakly convergent below. Clypeus highly raised and produced anteriorly. Labrum 1.5 times as wide as long; distinct tooth in the center, not accompanied by carina on each side; apical portion below labral tooth distinctly produced anteriorly, not or weakly upcurved; apical margin not serrated. Mandible slender.

Preoccipital ridge rounded behind vertex, gradually angulated apically. Relative length of FL1-3 1:1.5:1.3-1.4, relative length to apical width of FL1 1.1 times, FL2 1.6- 1.7 times, FL3 1.5 times (FL3 1.3 times in original description).

Apical marginal area of pronotum tessellate with sparse, subobsolete punctures; submarginal area depressed, finely transversely wrinkled, transition from marginal to submarginal area distinctly step-like. Scutum relatively weakly raised, anterior margin gradually down-curved until meeting collar. Scutellum weakly

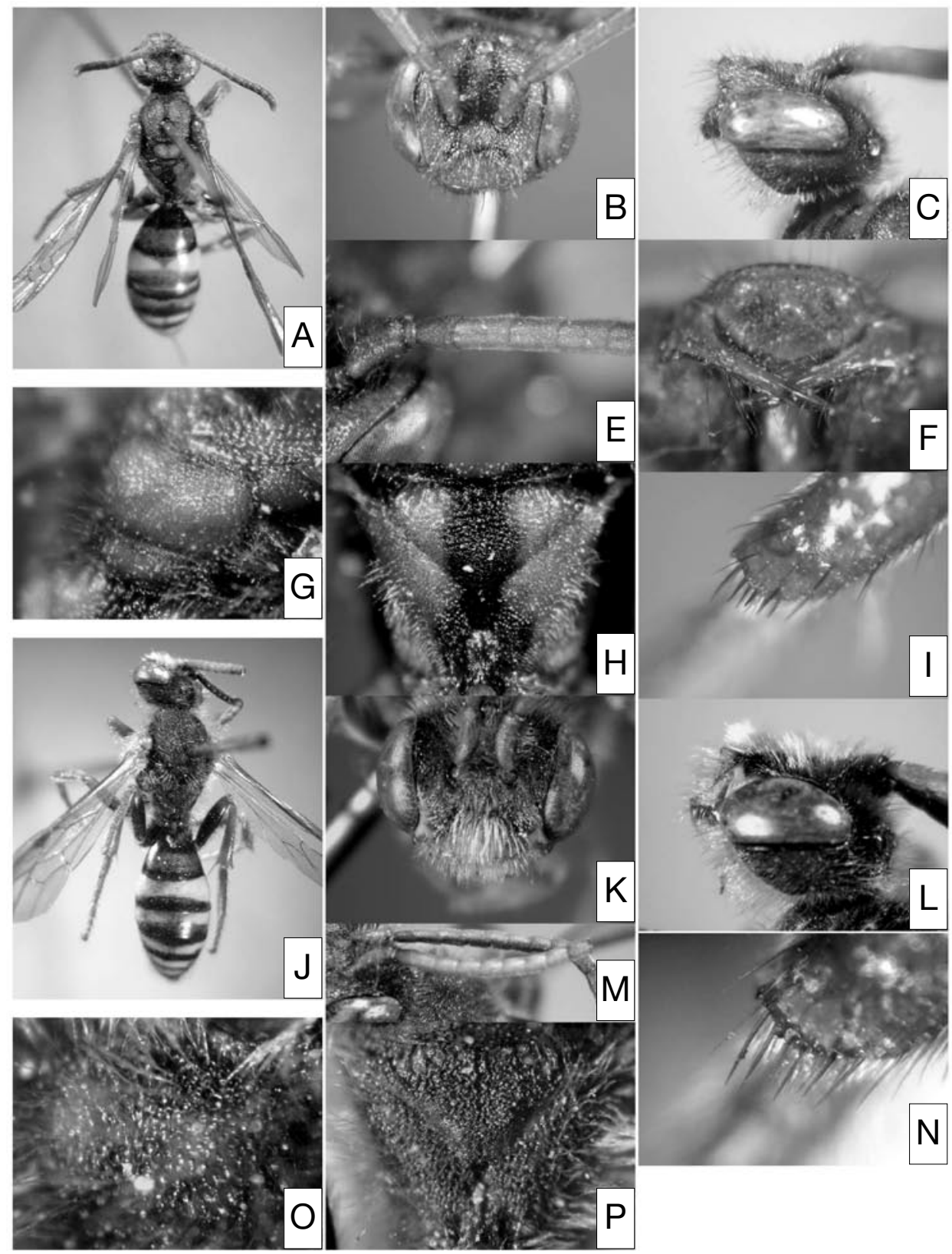

Fig. 27. Nomada fukuiana Tsuneki. Female: A-H. Male: I-O. A, I: habitus, dorsal view. B, C, J, K: head. D, L: antenna. E: Labrum. F, M: scutellum. G, N: propodeam triangle. H, O: apicomedian setae on hind tibia. 

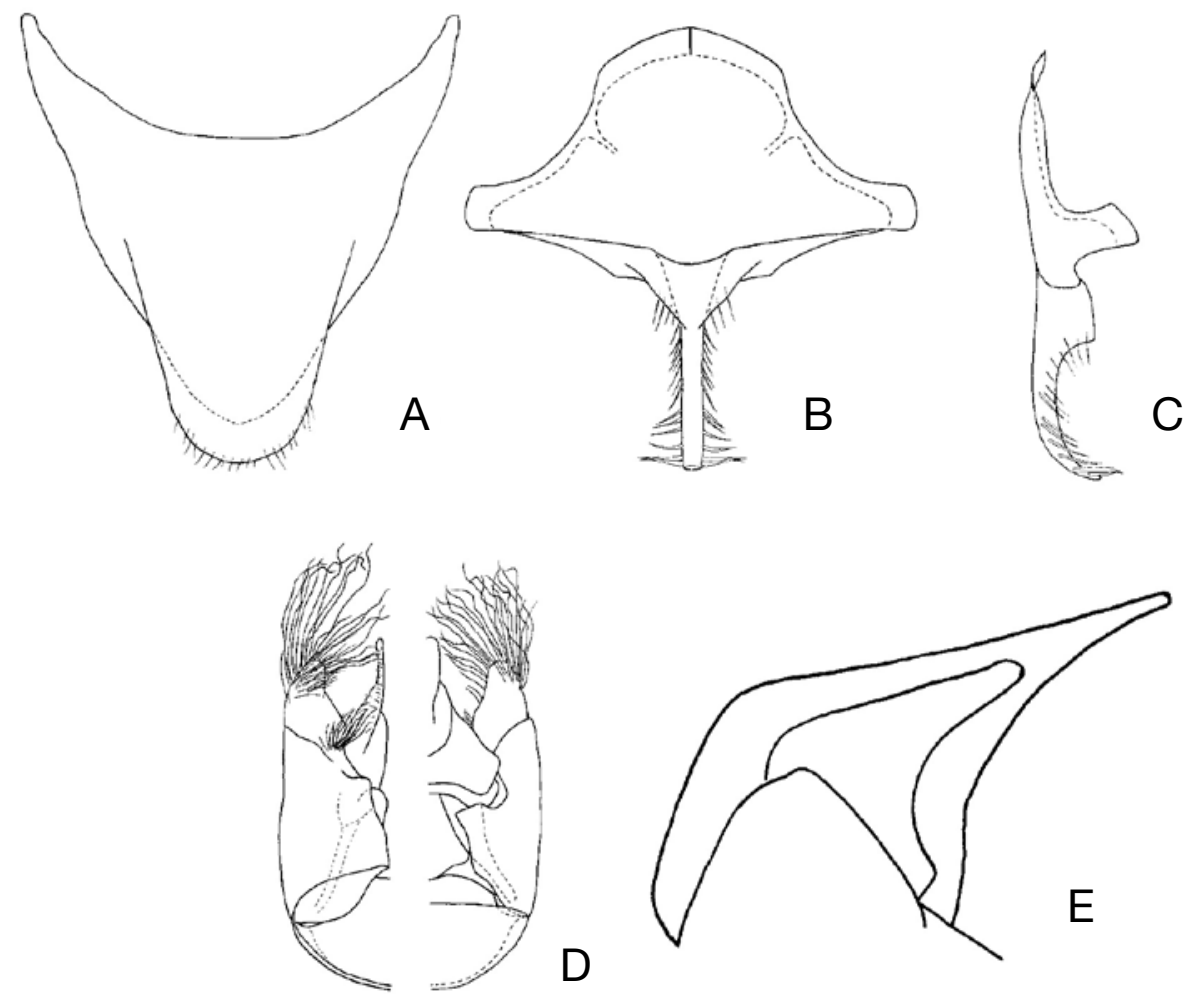

Fig. 28. Nomada fukuiana (male). A: 7th metasomal sternum, ventral view. B: 8th sternum, dorsal view. C: the same, lateral view. D: genital capsule (left, ventral view; right, dorsal view). E: penis valve and gonostylus, lateral view (vestiture omitted).

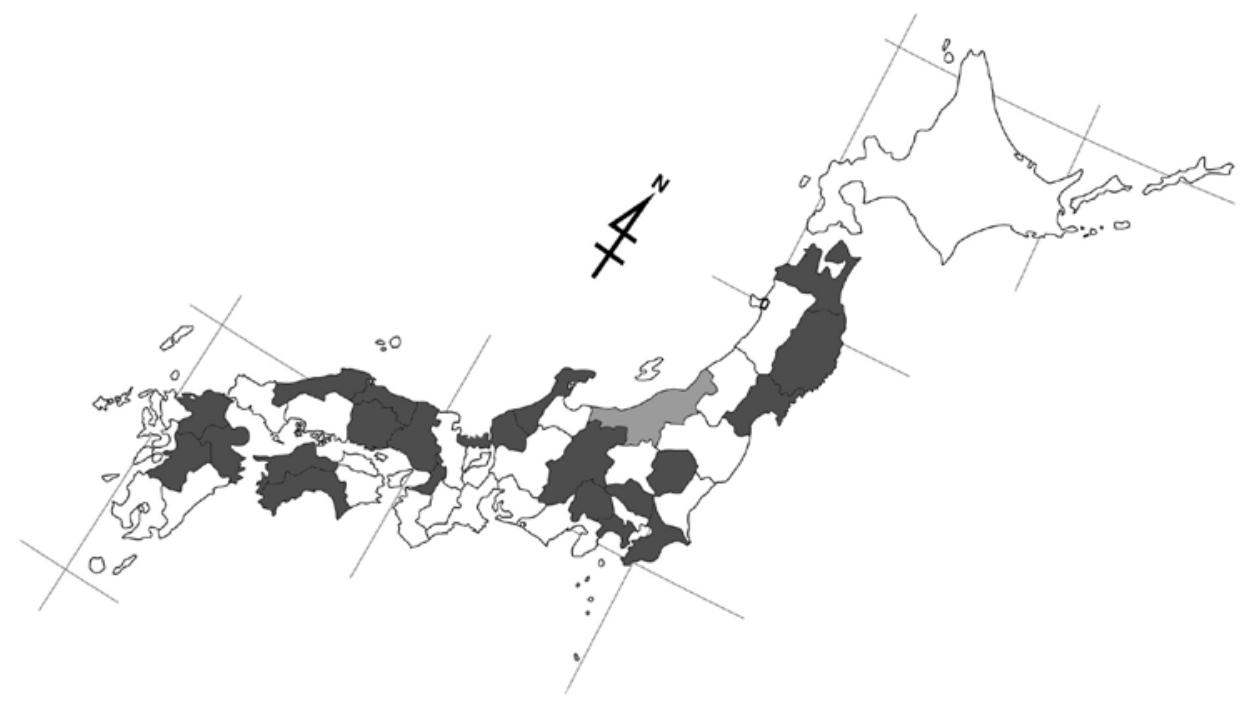

Fig. 29. Distribution of $N$. fukuiana on the Japanese mainlands. Densely shaded: prefectures with the specimens examined in the present study. Lightly shaded: prefectures with records in literature, but no specimens examined in the present study. 
raised, anterior face flat and much wider than posterior face, median furrow absent. Pygidial plate rounded at apical portion, weakly notched at apex.

Fore femur slender. Procoxa weakly produced apically, but not forming a spine. Apicomedian setae on hind tibia six to eight in number, dark brown to black, moderately long and straight, sometimes posteriormost seta slightly curved anteriorly, usually evenly spaced, sometimes a number of anterior setae closer together, gradually shorter anteriorly.

\section{Male.}

Color: Head largely black; the following portions are yellow: mandible with apical one-third reddish brown, labrum, malar area, lower inner eye margins extending up near or at level of lower margin of antennal socket. Apical portion of clypeus darkened yellow or reddish brown to rather blackish, the width variable ranging from apical one-third to narrowly apical margin. Scape reddish brown anteriorly, black posteriorly, flagellar segments black posteriorly, first to eighth segments reddish brown anteriorly, the following three last segments blackish or black wholly.

Mesosoma black; the following portions are reddish brown: collar on the top, a small vague spot on anterior portion of mesopleuron but sometimes lacking, two thin, short, longitudinal lines on scutum, two maculae on scutellum but sometimes lacking.

Metasoma black, T1 with reddish brown complete band; the following portions are yellow: complete band each on T2-6 (sometimes those on T2 and T3 narrowly in the middle), vague band or spot each on T2-6.

Legs largely reddish brown; in specimens with less developed black portions, the following portions are black: all coxae with apex tinge with reddish brown, all trochanters posteriorly, a small spot on posterior of fore and mid femur, macula on posterior of hind femur extending from base to the middle of femur. In specimens with developed black portions, the black is as follows: all trochanter except apical margin tinge with reddish brown, fore femur except upper and apical portions, mid and hind femora except apical annular portion reddish brown, a line each on all posterior of tibiae.

Sculpture: Punctures on clypeus distinct, otherwise as in female.

Vestiture: Vestiture on labrum, clypeus, supraclypeal area, frons, lower genal area near hypostoma pale brown, erect, densely plumose, roughly similar in length and density but somewhat denser on labrum.

Vestiture on scutum and scutellum similar to that on clypeus, somewhat more weakly plumose. That on mesopleuron whitish, strongly plumose, sparser than on scutum. That on posterolateral to dorsal surface of propodeum similar to that on mesopleuron, but color similar to that on scutum, not forming a hair patch.

Vestiture on ventral surfaces of fore and mid femora as long as the maximum width of each segment, that on ventral surface of hind femur moderately dense, strongly plumose, long, suberect, straight.

Structure: Body length 7-11 mm. CD:UID:LID 50:51:47. OCD/LOD 1.6.

The following aspects are different from female: interantennal elevation moderately raised, with highly raised keeled carina which lowered abruptly from level of anterior margin of antennal socket in profile; clypeus raised and produced as in female, apicolateral corner angulated to form a weak ridge; preoccipital ridge angulated behind vertex, otherwise rounded; scape somewhat wider than flagellar segments; relative length of FL1-3 1:1.5:1.3, relative length to apical width of FL1 equal, FL2 1.7 times, FL3 1.5 times, tyloidea on FL1, FL2 absent, those on FL3-6 distinctly delimited, weakly raised, oval, successively more rounded, those on the following segments slightly convex but well-defined depending on the perspective; scutellum usually weakly, roundly raised, median furrow absent, frequently considerably flat wholly; pygidial plate deeply, triangularly or roundly emarginated at apex; hind femur slender, basoventral flattened surface distinctly but not strongly depressed in posterior view; apicomedian setae on hind tibia four in number, paler and slenderer than in female, usually evenly spaced.

Male terminalia: 7th metasomal sternum as in Fig. 28-A. 8th as in Fig. 28-B, C. Gonostylus comparatively short; vestiture sparse, long, simple, sinuate apically; basoventral lobe weakly developed, with long, simple, sinuate vestiture. Penis valve produced posteriorly beyond gonostylus, apex extending much beyond apex of gonostylus in lateral view. Gonocoxite with wide dorsal invagination; inner dorsal lobe wider than long, with apex truncate.

Distribution. Japan (Honshu, Shikoku, Kyushu).

Specimens examined. Holotype (MNHAM), 우, attached with two labels as follows: "Washiga-take/ Fukui Jap./ 3. V. 1960/ K. Tsuneki (white rectangular and typed except the top and the third lines handwritten)", "Nomada/ fukuiana 우/ Tsuneki/ Holotypus (red rectangular with handwritten letters)".

Other specimens: We have examined about 20 females and 50 males. On the localities, see Fig. 29. Some of them are listed as follows: JAPAN [Honshu] Aomori: 10', Mt. Bonju (Namioka), 27. v. 1995 (M. Yamada). Iwate: 10', Sawauchi, 14. v. 1971 (T. Chiba, NIAES). 
Table 11. Seasonal change of number of the captured individual of N. fukuiana in Japan (Number of females indicates at the left of slash in cell, that of males at the right. E: early, M: mid, L: late).

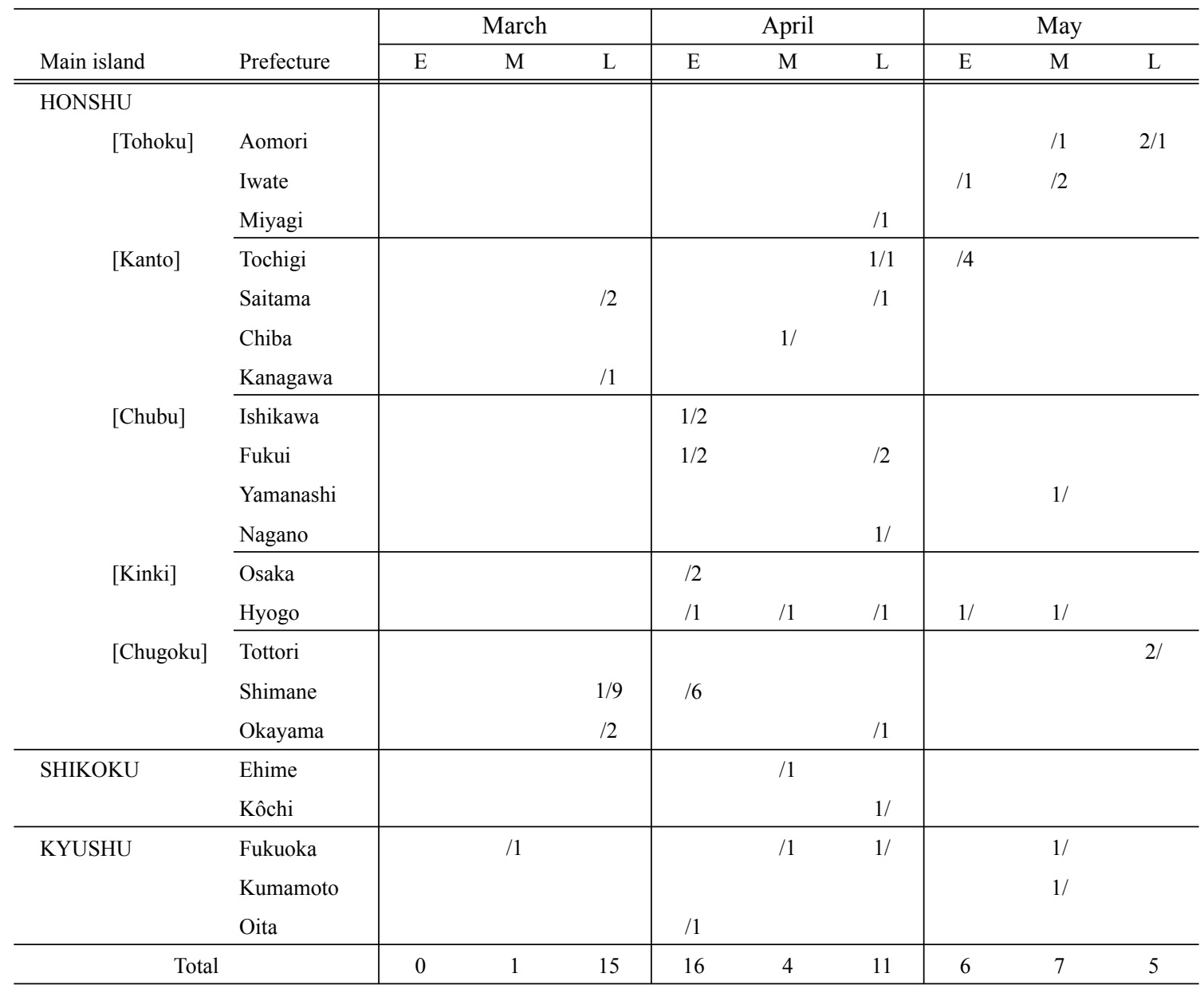

Saitama: $1 \sigma^{\top}$, Kanasana Shrine, Mt. Nambuontakesan, Kamikawa-machi, Kodama-gun, 27. iv. 1973 (K. Hara, T. Nambu Coll.). Chiba: 10', Namiki, Kouzaki, Katori gun, 19. iv. 1998 (H. Suda). Ishikawa: 1우2 점 Mt. Utatsu, Kanazawa C., 3. iv. 1974 (Y. Yoneda, ELKU). Nagano: 1우, Todai, Ina, 29. iv. 1963 (Y. Maeta). Osaka: 2ㅇ, Mt. Mino, Settsu, 6. iv. 1955 (K. Komatsu, ELKU). Hyogo: 10', Ryuzoji, 21. iv. 1952 (S. Momoi, SEHU). Tottori: 2우, Mt. Daisetsu, 23. v. 2002 (Y. Maeta). [Shikoku] Ehime: 10', Mt. Saragamine, 16. iv. 1952 (T. Edashige, ELKU). Kochi: 1우, Nakamura-shi, 27. iv. 1957 (Y. Hirashima, ELKU). [Kyushu] Fukuoka: 1우, Mt. Hikosan, 11. v. 1951 (Y. Hirashima, ELKU). Kumamoto: 1우, Mt. Shiratoriyama, 15. v. 1979 (K. Ohara, MNHAH). Oita: $10^{7}$, Mt. Hanamureyama, Shônai-machi, Oita-gun, 6. iv. 2006 (K. Mitai).

Biology. It is a univoltine species, collected from mid March to late May (Table 11). Floral associations are as follows: [Caprifoliaceae] Weigela hortensis.
[Compositae] Petasites japonicus. The host is unknown. Remarks. The female is very similar to Nomada panzeri orientis Tsuneki and $N$. towada Tsuneki in general appearance. The rudimentary pseudopygidium easily distinguishes $N$. fukuiana from $N$. panzeri whose pseudopygidium is much wider and prominently shining. It can be separated from $N$. towada as follows: the wholly black apical three flagellar segments in N. fukuiana, but not wholly black in N. towada; the clypeus in fukuiana raised higher than in $N$. towada; the pseudopygidium in $N$. fukuiana somewhat less rudimentary than in $N$. towada; in N. fukuiana the lateral face of the pronotum tessellate with sparse superimposed punctures on the anterior portion, and transverse-striate on the posterior portion, with a longitudinal distinct step between the two portions, due to the posterior portion abruptly recessed from the anterior, whereas in N. towada the pronotum without such a step or, if present, it extends very shortly from the dorsal of the pronotum; in $N$. fu- 
kuiana $\mathrm{T} 2$ with the largely fused two yellow maculae in a few specimens or a complete yellow band in most specimens, whereas in $N$. towada $\mathrm{T} 2$ with the two wellseparated or rarely partially fused yellow maculae.

Judged from the original description, the male assumed as N. panzeri orientis in Tsuneki (1973) is the male of this species. In addition, two male paratypes of Nomada panzeri orientis Tsuneki were examined and found to belong to $N$. fukuiana. The male is also similar superficially to Nomada harimensis Cockerell, but sepa- rated by the four, thin setae on hind tibia (ten in number in $N$. harimensis), and the complete yellow band on $\mathrm{T} 2$.

\section{Nomada fulvicornis jezoensis}

Matsumura, 1912

[Japanese name: Ezo-kimadara-hanabachi]

(Figs. 30-32; Table 12)

Nomada jezoensis Matsumura, 1912, Thous. Ins. Jap., Suppl. IV: 196-197 [Holotype: Female. Type local-

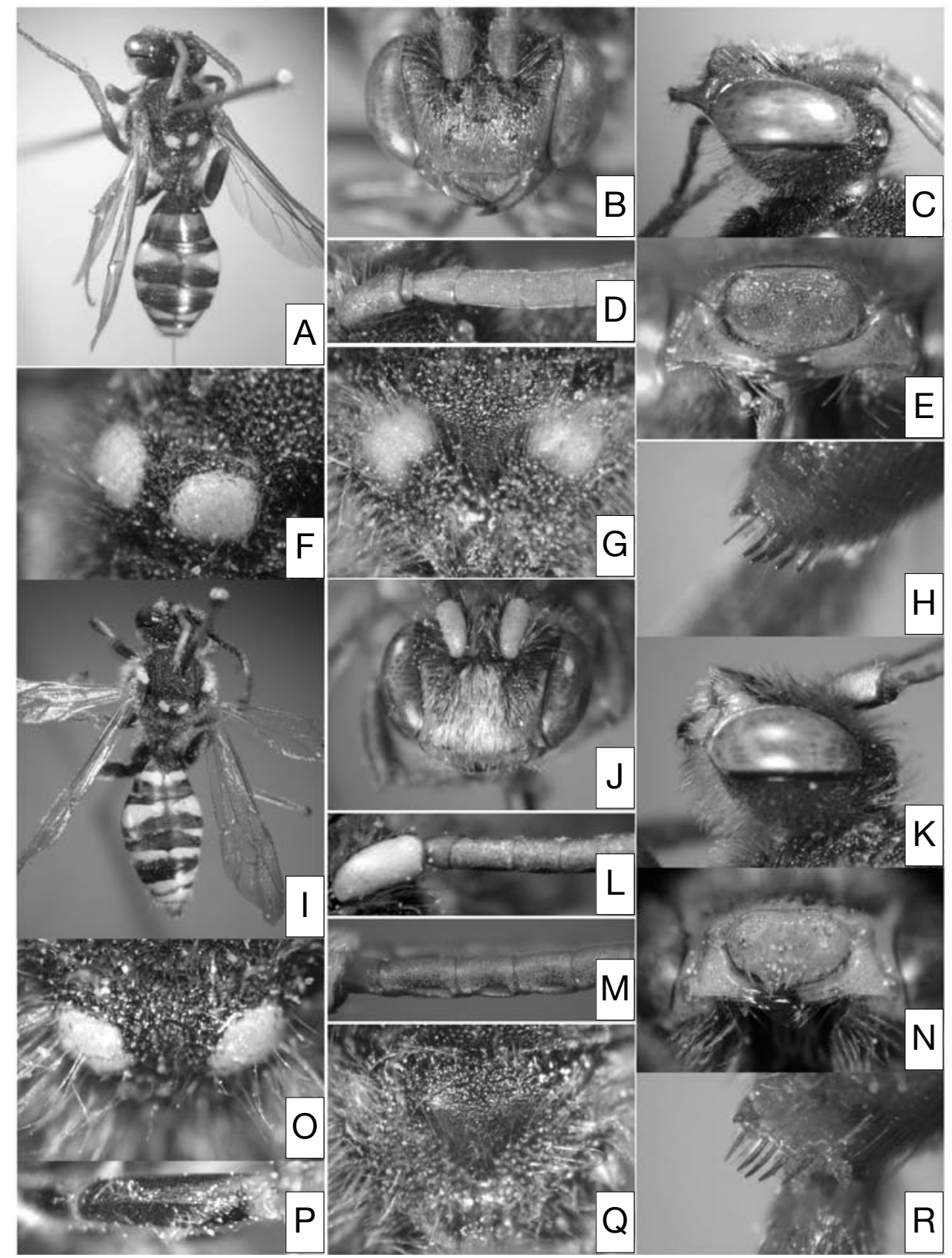

Fig. 30. Nomada fulvicornis jezoensis Matsumura. Female: A-H. Male: I-R. A, I: habitus, dorsal view. B, C, J, K: head. D, L, M: antenna. E, N: labrum. F, O: scutellum. G, Q: propodeal triangle. H, R: apicomedian setae on hind tibia. P: hind femur, ventral view. 
ity: Sapporo, Hokkaido, Japan].

Nomada lineola: Yasumatsu, 1938, Ins. Mats., 13: 39

[synonymization with Nomada lineola Panzer].

Nomada lineola jezoensis: Tsuneki, 1973, Etizenia, 66: 58-60 [redescription].

Nomada fulvicornis jezoensis: Alexander \& Schwarz, 1994, Univ. Kansas Sci. Bull., 55: 248 [in list].

\section{Redescription.}

\section{Female.}

Color: Head black, the following portions are reddish brown: mandible except apical one-fourth or onefifth dark red, labrum, clypeus, malar area, lower paraocular area extending up along inner eye margin to top of compound eye, line along lower outer eye margin extending up beyond midpoint of compound eye in profile. Antenna reddish brown wholly.

Mesosoma black; the following portions are reddish brown: tegula, two short thin lines near lateral margin of scutum, transversely elliptical macula on lateral surface of mesopleuron; the following portions are bright yellow: collar on the top, pronotal lobe, two maculae on scutellum, a pair of large maculae of color variable from bright yellow to reddish brown on dorsal surface of propodeum.

Metasoma largely black, T1 with brown band on apical half; the following portions are yellow: a pair of triangular maculae each on T2 and T3 (the latter smaller, intermacular area brown), complete or narrowly interrupted medially band on T4, large macula on T5 medially. Pygidial plate reddish brown.

Legs largely reddish brown; the following portions are blackish or black: all coxae except apices, hind trochanter basoventrally, fore and mid femora basoventrally, hind femur except dorsally and apicoventrally.

Sculpture: Punctures on labrum small, indistinct. Those on clypeus and supraclypeal area small, distinct, dense, those on the latter slightly deeper.

Mesoscutal line distinct, raised as low carina, from middle nearly to apical margin of scutum. Punctures on scutellum as on scutum. Mesopleuron deeply, coarsely areolate. Propodeum outside triangle areolate, more shallowly and densely than on mesopleuron. Propodeal triangle coarsely irregularly rugose on basal half and central portion, the remaining portion tessellate.

Terga faintly microsculptured, matt with dense punctules. Pygidial plate with punctures small, indistinct.

Vestiture: Vestiture on labrum moderately long on apical portion, nearly hairless on basal portion, weakly plumose, sparse. That on clypeus and supraclypeal area appressed, strongly plumose, but short, sparse. That on lower genal area near hypostoma much longer than on labrum, plumose.

Vestiture on scutum and scutellum fine, whitish, sparse, weakly plumose, erect. That on mesopleuron longer, more strongly plumose. That on posterolateral to dorsal surface of propodeum yellowish, plumose, erect or suberect, not forming a distinct patch.

Pseudopygidium well developed as normal in female Nomada. Pygidial plate covered with short, dense hairs.

Structure: Body length 9.5-11 mm. CD:UID:LID 50: 52:48. OCD/LOD 1.5.

Vertex between lateral ocelli and compound eye impressed, so that central area of vertex surrounded by ocelli concave. Interantennal elevation moderately raised. Inner eye margins strongly convergent below. Clypeus moderately raised and weakly produced anteriorly. Labrum 1.7-1.8 times as wide as long; labral tooth present at one-fourth from apex, not accompanied by carina: apical portion below labral tooth very weakly produced anteriorly, not upcurved; apical margin indistinctly serrated. Preoccipital ridge distinctly carinated. Relative length of FL1-3 1:1.5:1.2, relative length to apical width of FL1 1.2 times, FL2 1.7 times, FL3 1.3- 14 times.

Scutellum highly roundly raised, median furrow deep. Hypoepimeral area protuberant as low conicalshaped convexity. Posterior area around propodeal spiracle concave, with a carinated ridge above. Pygidial plate triangular at apical portion, weakly notched at apex.

Fore femur moderately, or more or less robust. Hind femur moderately built; boundary between anterior and posterior faces distinctly angulated from base of segment to near apex. Apicomedian setae of hind tibia six or seven in number, posteriormost seta thin, straight, short, acute at apex, pale brown, others thicker, slightly curved, flattened, bluntly pointed at apex, dark brown or black.

Male.

Color: Head and mesosoma black; the following portions are bright yellow: mandible except apical onethird dark reddish, labrum, clypeus on apical half, malar area, lower paraocular area extending up along inner eye margin to level of antennal sockets, short line along outer eye margin extending up from hypostoma, collar on the top, pronotal lobe, tegula, two maculae on scutellum. Scape bright yellow anteriorly, black posteriorly, flagellar segments pale reddish brown anteriorly, basal four or five segments black posteriorly, paler apically.

Metasoma largely dark brown to black: the follow- 

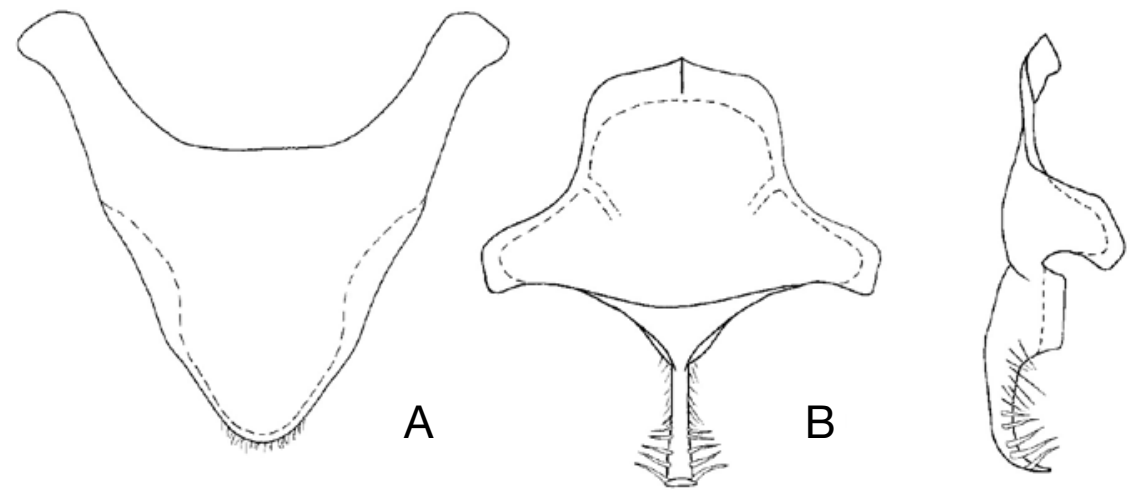

C
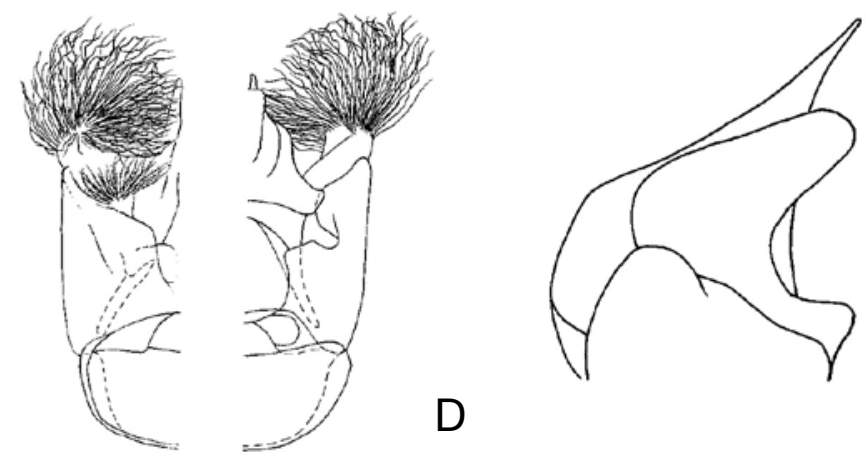

D

$E$

Fig. 31. Nomada fulvicornis jezoensis (male). A: 7th metasomal sternum, ventral view. B: 8th sternum, dorsal view. C: the same, lateral view. D: genital capsule (left, ventral view; right, dorsal view). E: penis valve and gonostylus, lateral view (vestiture omitted).

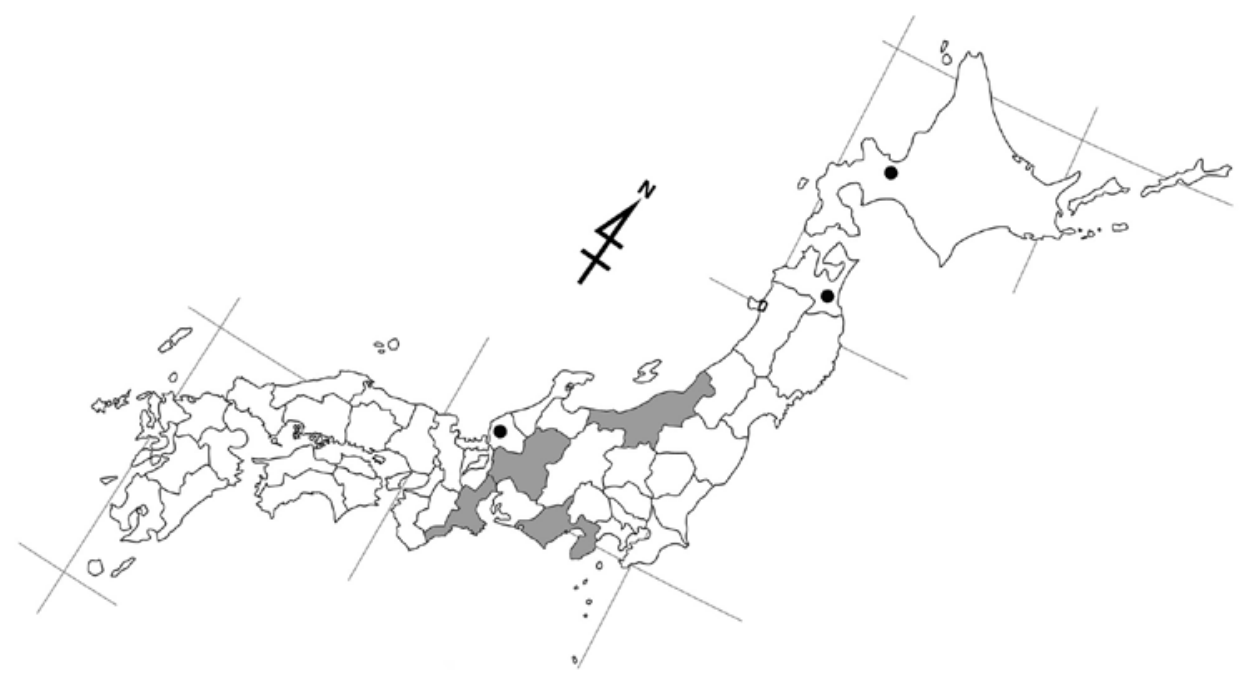

Fig. 32. Distribution of $N$. fulvicornis jezoensis on the Japanese mainlands. Dots: localities of the specimens examined in the present study. Shaded: prefectures with records in literature, but no specimens examined in the present study. 
ing portions are yellow: band on $\mathrm{T} 1$ but narrowly interrupted in the middle, a pair of large roughly triangular maculae on $\mathrm{T} 2$, complete band each on $\mathrm{T} 3$ and $\mathrm{T} 4$ but both sometimes interrupted narrowly in the middle, T5 largely, vague band each on S2-6, pygidial plate which darker apically.

Legs reddish brown; the following portions are blackish or black: all coxae, all trochanters ventrally, fore and mid femora ventrally and black portion wider basally, hind femur except upperside and basal annular portion.

Sculpture: Sculpture in generally finer than in female, pygidial plate covered by dense, small punctures, otherwise as in female.

Vestiture: Vestiture on labrum yellowish white, comparatively short, much shorter, sparser on basal portion, plumose. That on clypeus and clypeal area silverywhite, strongly plumose, appressed, dense as to obscure integument. That on lower genal area near hypostoma much longer than on labrum.

Vestiture on scutum and scutellum pale brown, long, weakly plumose, dense. That on mesopleuron much longer, whitish, plumose. That on posterolateral to dorsal surface of propodeum similar to that on mesopleuron, but sparser than in female.

Vestiture on ventral surface of fore femur somewhat shorter or as long as the maximum width of segment, that of mid femur shorter than the half of maximum width of segment. That on ventral surface of hind femur moderately dense, posteriorly directed suberect, straight.

Structure: Body length 10-12 mm. CD:UID:LID 50:48:48. OCD/LOD 2.0.

The following aspects are different from female: vertex between lateral ocelli and compound eye impressed, ocellar area convex; interantennal elevation moderately raised, with highly raised carina which semicircular in profile; raise of clypeus somewhat higher than in female; preoccipital ridge distinctly carinated, gradually becoming angulated apically; scape much wider than flagellar segments; relative length of FL1-3 1:2.1:1.5, relative length to apical width of FL1 0.8 times, FL2 1.8 times, FL3 1.3 times, tyloidea on FL1 recognized as weak convex, those on FL2 weakly raised, indistinctly delimited, broadly and long elliptical, occupying apical three-fourths of posterior surface of segment, those on FL3-7 successively shorter, more rounded, more higher, the highest on FL6 or FL7, those on the following segments much indistinct; scutellum as in female, but usually somewhat lower than in female; concavity above propodeal spiracle and raise of ridge above it less prominent than in female; pygidial plate widely triangularly or roundly emarginated at apex; hind femur moderately built; basoventral flattened surface wide, reaching to two-thirds of ventral side from base of segment, prominently depressed in posterior view; boundary between baso-ventral flattened surface and posterior surface sharply angulated; apicomedian setae on hind tibia somewhat thinner than in female, otherwise as in female.

Male terminalia: 7th metasomal sternum as in Fig. 31-A. 8th as in Fig. 31-B, C. Gonostylus thick, roughly cylindrical, broadly rounded at apex in lateral view; vestiture dense, long, simple, strongly sinuate; basoventral lobe developed with long, plumose vestiture. Penis valve produced posteriorly beyond gonostylus, apex not extending beyond apex of gonostylus in lateral view. Gonocoxite with deep dorsal invagination; inner dorsal lobe wide with apex truncate.

Distribution. Japan (Hokkaido, Honshu).

Specimens examined. JAPAN [Hokkaido] Botanical Garden, Sapporo, 10', 10. v. 1989, 10', 23. v. 1989, 1 ○', 16. v. 1989, 1우, 19. vi. 1989 (S. Sakagami, NIAES); University Campus of Hokkaido Univ., Sapporo, 1 o', 8. v. 1959, $10^{\text {' }, 13 . ~ v . ~} 1959$ (S. Sakagami, SEHU); Maruyama, Sapporo, 1우, 28. v. 1950, 1우, 25. v. 1950, 1 ○', 15. v. 1950, 1우, 10. vi. 1950, 3우, 1. vi. 1950, 2 우, 2. vi. 1950 (K. Kosugi, SEHU); 10', Sapporo, 27. v. 1955 (K. Kamijo, SEHU); Sapporo, 1우, 12. vi. 1912, 10. vi. 1916 (S. Matsumura, ELKU). [Honshu] Aomori: Towada, 1우 10', 30. v. 1959, 10', 24. v. 1959 (K. Shimoyama, APM). Fukui: Mt. Monjusan, 21, v. 1967 (T. Murota).

Biology. It is a univoltine species, collected from May to June (Table 12). Floral associations are as follows: [Compositae] Taraxacum officinale. The host is unknown. European nominotypical subspecies attacks Panurgus calcaratus (Scopoli).

Remarks. This species has a wide distribution covering nearly whole the Palearctic Region, and shows the wide morphological variation. This Japanese subspecies jezoensis differs from the nominotypical subspecies by the longer first and second flagellar segments: the relative length of the first and second flagellar segments are 1.2 times and 1.7 times in female, 0.8 times, 1.8 times in male from Hokkaido, Japan, whereas 1.0 times and 1.7 times in female, 0.8 times and 1.6 times in male from Kazakhstan. These differences, however, are subtle and there is a possibility that the antennal length changes clinally over a wide distribution of species and, therefore, Japanese race may not be recognized as a subspecific unit. At present, however, we have not examined ample materials, so that the treatment about Japanese 
Table 12. Seasonal change of number of the captured individual of $N$. fulvicornis jezoensis in Japan (Number of females indicates at the left of slash in cell, that of males at the right. E: early, M: mid, L: late).

\begin{tabular}{|c|c|c|c|c|c|c|c|}
\hline \multirow[b]{2}{*}{ Main island } & \multirow[b]{2}{*}{ Prefecture } & \multicolumn{3}{|c|}{ May } & \multicolumn{3}{|c|}{ June } \\
\hline & & $\mathrm{E}$ & $\mathrm{M}$ & $\mathrm{L}$ & $\mathrm{E}$ & $\mathrm{M}$ & $\mathrm{L}$ \\
\hline HOKKAIDO & & 12 & $3 / 4$ & $2 / 2$ & $7 /$ & $2 /$ & \\
\hline \multicolumn{8}{|l|}{ HONSHU } \\
\hline \multirow[t]{2}{*}{ [Chubu] } & Aomori & & & $2 / 1$ & & & \\
\hline & Fukui & & & $1 /$ & & & \\
\hline \multicolumn{2}{|l|}{ Total } & 2 & 7 & 8 & 7 & 2 & 0 \\
\hline
\end{tabular}

race should remain conservative.

This subspecies is similar to Nomada pyrifera Cockerell in both sexes, but can be easily separated from the latter by the second flagellar segments less than twice as long as apical width of the segment.

The record of this species from Kumamoto Pref. (Sugiura et al., 2004; identification by Mitai) was based on misidentification.

12. Nomada fusca Schwarz, 1986

[Japanese name: Fusage-kimadara-hanabachi] (Figs. 33, 34; Table 13)

Nomada fusca Schwarz, 1986, Entomofauna, 7: 434-437

[Holotype: Female. Type locality: Hattula, Finland].

\section{Redescription.}

Female.

Color: Head black, the following portions are dark reddish brown: mandible except apical one-fourth black, labrum, clypeus except upper margin, malar area, thin line along compound eye, usually the line widened mesally at top of compound eye. In two specimens, genal area wholly black. In one specimen, a vague small spot present on supraclypeal area. Antennae pale brown anteriorly and darker posteriorly.

Mesosoma black; the following portions are reddish brown; collar on the top, pronotal lobe, tegula, four vague, well-separated longitudinal lines on scutum but wholly black in two specimens, axilla, scutellum wholly or except peripheral margin, a transversely elliptical macula below scrobe. Usually two pairs of vague spot on dorsal surface of propodeum: one pair in triangle, the other on lower dorsal but wholly black in two specimens. In one specimen, a spot present on hypoepimeral area.

Metasoma dark reddish brown to black, T1 dark reddish brown on apical half, T2 black on basal and apical narrow margin, vague reddish brown band on $\mathrm{T} 3$ but sometimes lacking; the following portions are yellow: a pair of oval maculae on T2 with intermacular area reddish brown, complete band on $\mathrm{T} 4$, large rectangular macula on T5 medially. Pygidial plate blackish.

Legs largely black; the following portions are reddish brown: all coxae except basal and inner portions, fore and mid trochanters anteriorly, hind trochanter except ventrally, fore femur except dorsally and ventrally, mid and hind femora except dorsally and apicoventrally.

Sculpture: Punctures on labrum sparse, obliterated, interpunctural space polished and reflective. Those on clypeus and supraclypeal area gradually larger and more distinct, on supraclypeal area considerably coarse, deep.

Punctures on scutellum smaller and denser than those on scutum. Mesopleuron moderately areolate. Lateral and dorsal sides outside triangle on propodeum shallowly areolate, except tessellate portion with sparse punctures under spiracle. Propodeal triangle irregularly rugose at basal half and central portion, the remaining portion tessellate.

Terga faintly microsculptured without punctules.

Vestiture: Vestiture on labrum inconspicuous, fine, sparse very short except a few hairs on apical margin much longer. That on clypeus and supraclypeal area also very sparse, fine, very weakly plumose, appressed. That on lower genal area near hypostoma longer than on apical margin of labrum.

Vestiture on scutum and scutellum brown tinged with golden, short, suberect or appressed, simple or weakly plumose. That on mesopleuron pale brown, much longer, more strongly plumose. That on posterolateral corner of propodeum whitish, very short, suberect, moderately dense at lower portion, plumose, not forming hair patch. Pseudopygidium prominently developed, composed of long, only subtle scale-shaped, disheveled hairs. Pygidial plate covered with long, dense 
hairs which conceal integument under them.

Structure: Body length 9.5-11.5 mm. CD:UID:LID 50:48:48. OCD/LOD 1.6.

Interantennal elevation moderately raised. Inner eye margins nearly parallel. Clypeus moderately raised and produced anteriorly. Labrum 1.6 times as wide as long; labral tooth present slightly or evidently before the center, not accompanied by carina; apical portion below

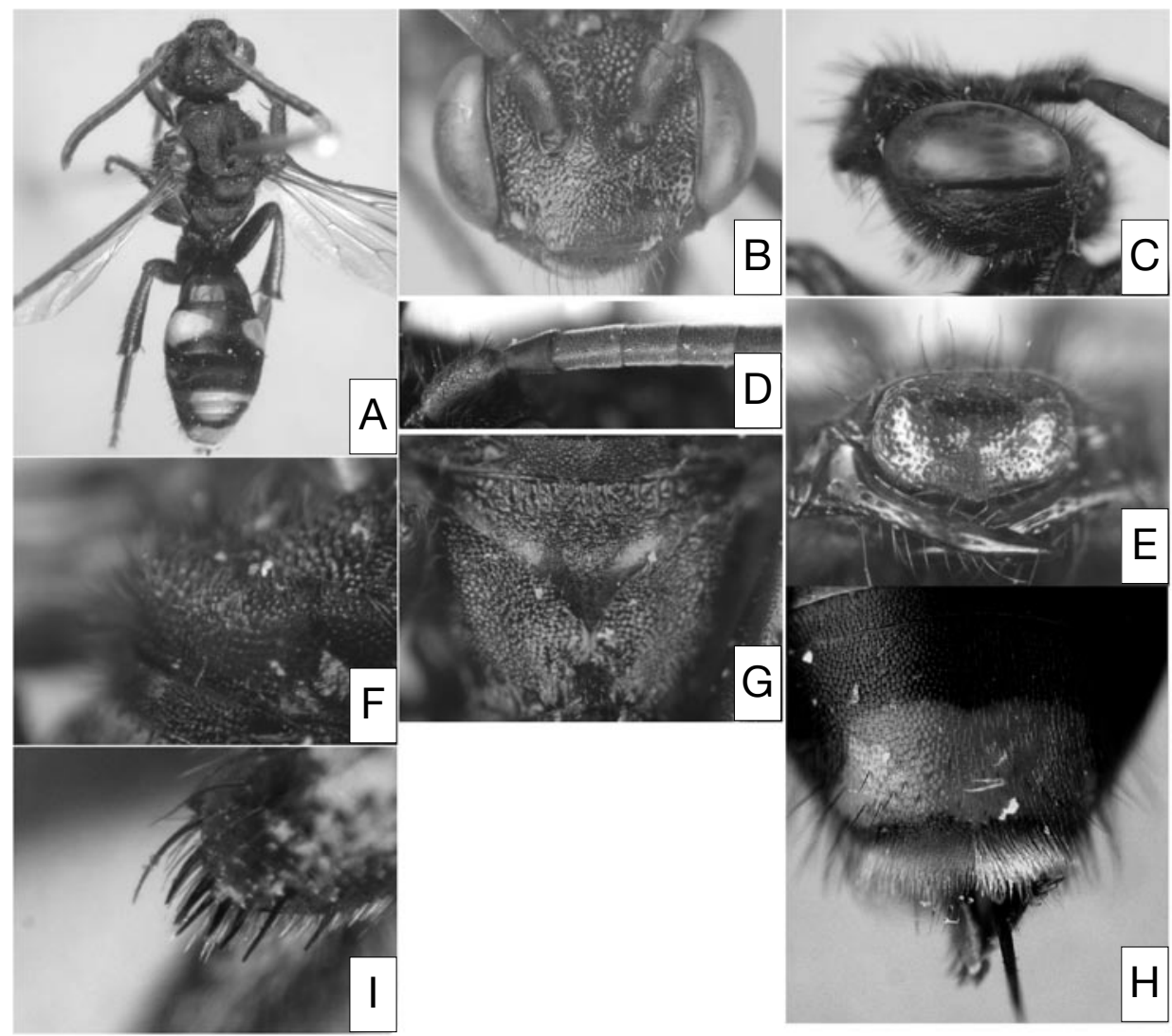

Fig. 33. Nomada fusca Schwarz (female). A: habitus, dorsal view. B, C: head. D: antenna.E: labrum. F: scutellum. G: propodeal triangle. H: pseudopygidium. I: apicomedian setae on hind tibia.

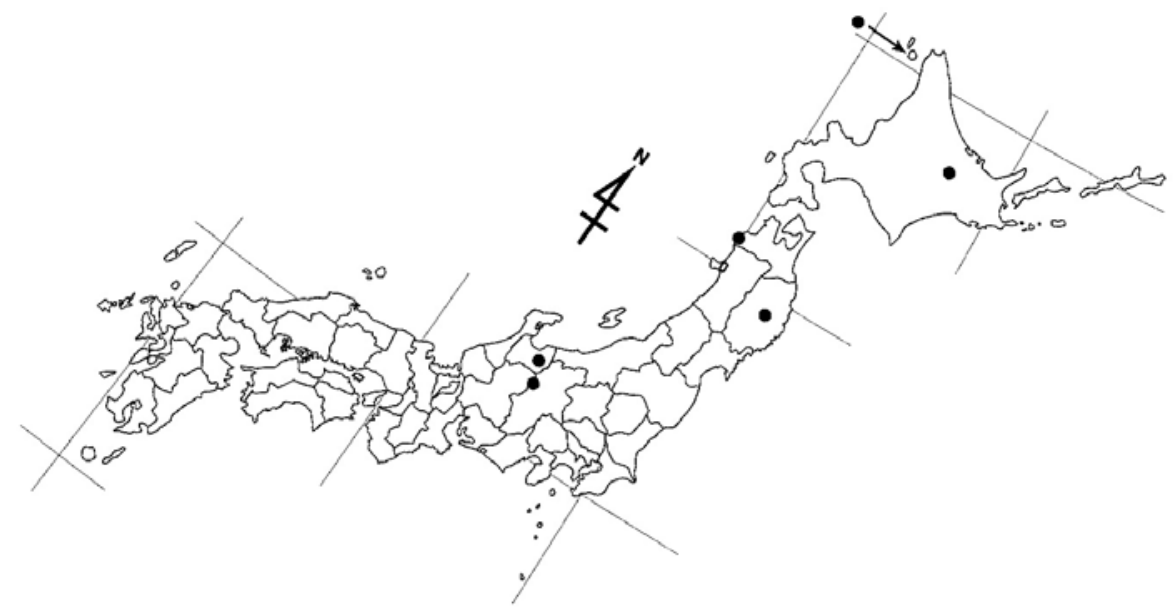

Fig. 34. Distribution of $N$. fusca on the Japanese mainlands.

Dots: localities of the specimens examined in the present study. 
Table 13. Seasonal change of number of the captured individual of $N$. fusca in Japan (Number of females indicates at the left of slash in cell, that of males at the right. E: early, M: mid, L: late).

\begin{tabular}{|c|c|c|c|c|}
\hline \multirow[b]{2}{*}{ Main island } & \multirow[b]{2}{*}{ Prefecture } & \multicolumn{3}{|c|}{ June } \\
\hline & & $\mathrm{E}$ & $\mathrm{M}$ & $\mathrm{L}$ \\
\hline "HOKKAIDO & & & $1 /$ & $1 /$ \\
\hline \multicolumn{5}{|l|}{ HONSHU } \\
\hline \multirow[t]{2}{*}{ [Tohoku] } & Aomori & & & 1/ \\
\hline & Iwate & & $1 /$ & \\
\hline [Chubu] & Nagano & & $2 /$ & \\
\hline \multicolumn{2}{|l|}{ Total } & 0 & 4 & 2 \\
\hline
\end{tabular}

labral tooth weakly produced anteriorly, not upcurved; apical margin indistinctly serrated. Mandible slender. Preoccipital ridge weakly angulated, not carinate. Relative length of FL1-3 1:1.5:1.3, relative length to apical width of FL1 equal, FL2 1.7 times, FL3 1.4 times.

Scutellum moderately or highly raised, anterior face nearly flat, median furrow moderately deep.

Fore femur moderately built. Apicomedian setae on hind tibia five or six in number, posteriormost seta thin, slightly curved downward, evidently longer than others, others robust, dark brown, usually irregularly spaced.

Pygidial plate moderately rounded at apical portion.

Distribution. Sweden, Finland, Estonia, western Russia, Japan (new record: Hokkaido, Honshu).

Specimens examined. JAPAN [Hokkaido] 1우, Forest Park, Kafukai, Rebun-chô, Rebun Is. Hokkaido, 25. vi. 2000 (M. Saito); 1오, Shekihoku Pass, Rubeshibechô, 19. vi. 2005 (Y. Maeta). [Honshu] Iwate: 1우, Mt. Kenashimoriyama, Morioka, 15. vi. 1991 (T. Chiba, NIAES). Toyama: 1우, lakeside of Lake Kurobe-ko, Tateyama-machi, 22. v. 1998 (H. Negoro, TSM); 1우, Tateyama-bijodaira, 6. vi. 1990 (H. Negoro, TSM). Nagano: 2우, Kamikochi, 18. vi. 1932 (K. Iwate, ELKU). FINLAND 10', det. M. Schwarz. SWEDEN 1우, det. M. Schwarz.

Biology. It is a rare species in Japan, collected from mid to late June (Table 13). The host and floral association are unknown.

Remarks. The female recorded by Tsuneki (1975) as summer form of Nomada osimana oirasensis from Aomori Pref. should be assigned to this species. It is similar to Nomada asozuana Tsuneki and Nomada leucophthalma (Kirby). It can be separated from N. asozuana by the combination of the following characters: the prominent pseudopygidium composed of very long, the weakly modified, disheveled hairs, the pygidial plate bearing the same hairs as pseudopygidium, the less strongly produced clypeus, the absence of hair patch of white appressed pubescence on the lateral side of T3-5. It is different from $N$. leucophthalma in the abovementioned hairs of pseudopygidium and on pygidial plate, whereas in N. leucophthalma the pseudopygidium is composed of not prominently long hairs, as normal as in female Nomada, and the pygidial plate is covered with thin, not compact hairs which do not obscure the integument under them.

13. Nomada guttulata Schenck, 1861

[Japanese name: Seiyô-kimadara-hanabachi] (Figs. 35-37; Table 14)

Nomada guttulata Schenck, 1861, Jahrb. Ver. Naturk. Nassau, 14: 391; Tsuneki, 1973, Etizenia, 66: 109-110 [redescription]; Alexander \& Schwarz, 1994, Univ. Kansas Sci. Bull., 55: 248 [in list].

Nomada mishimana Tsuneki 1976, Kontyû, 44: 154 (Holotype: Male); Alexander \& Schwarz, 1994, Univ. Kansas Sci. Bull., 55: 250 [in list]. syn. nov.

\section{Redescription. \\ Female.}

Color: Head reddish brown; the following portions black: macula just above antennal socket, line on subantennal suture to epistomal suture, transverse elliptical macula surrounding ocelli, line on genal area along preoccipital ridge extending from hypostoma up to level of top of compound eye in profile. Mandible reddish brown except apical one-third dark red. Antenna wholly pale reddish brown.

Mesosoma black; the following portions are reddish brown; collar on the top, pronotal lobe, tegula, four broad lines on scutum, sometimes fused partially, axilla, scutellum nearly wholly, mesopleuron except a black macula of variable size on ventral side and small vague blackish spot on hypoepimeral area, two pairs of large macula on propodeum, one pair of which on 
posterolateral corner, other pair on basolateral corner of propodeal triangle.

Metasoma largely reddish brown, T1 black on basal one-third or basal half; the following portions are yellow; a pair of round spots each on T2 and T3 (the latter much smaller), a pair of irregular spots on T4, large roughly square maculae on T5 medially, which divided by longitudinal thin black line in the middle. Pygidial plate reddish brown.
Legs largely brown to pale brown; the following portions are blackish or black: fore coxa basally, hind coxa posteriorly, small spot each on ventral surfaces of fore and mid femora.

Sculpture: Punctures on labrum distinct but shallow, moderately dense. Those on clypeus and supraclypeal area larger and dense, those on clypeus slightly smaller than on supraclypeal area.

Punctures on scutellum slightly sparser and larger or

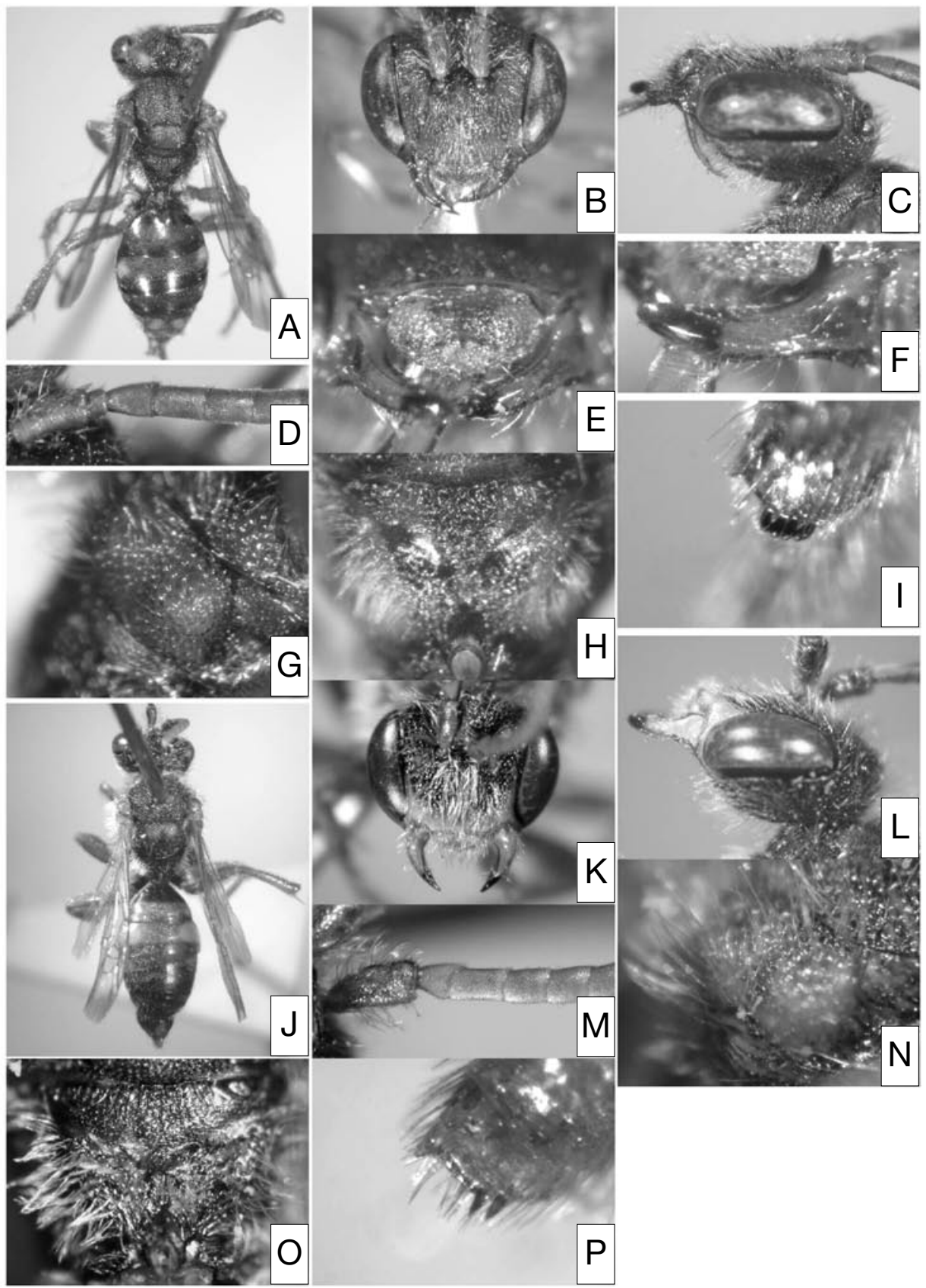

Fig. 35. Nomada guttulata Schenck. Female: A-I. Male: J-P. A, J: habitus, dorsal view. B, C, K, L: head. D, M: antenna. E: labrum. F: mandible. G, N: scutellum. H, O: propodeal triangle. I, P: apicomedian setae on hind tibia. 
as on scutum. Mesopleuron shallowly areolate. Propodeum outside triangle shallowly areolate, except weakly rugose portion with obliterated, sparse punctures under spiracle. Propodeal triangle irregularly rugose at basal half and central portion, longitudinal rugae prominent basolaterally, the remaining portion faintly tessellate or smooth.

Terga smooth with sparse punctules, on T1 much sparse, virtually impunctate mostly. Pygidial plate with punctures obliterated, sparse, the interpunctural space smooth and polished.

Vestiture: Vestiture on labrum pale brown, plumose, long on apical margin, otherwise much shorter. That on clypeus and supraclypeal area pale brown, short, strongly plumose, appressed. That on lower genal area near hypostoma as long as on apical portion of labrum, but much sparser.

Vestiture on scutum brown, short, thick, simple, that on scutellum darker and longer. That on mesopleuron whitish, strongly plumose, much longer than on scutum. That on posterolateral corner of propodeum long, strongly plumose, whitish, suberect, dense to form distinct patch.

Pseudopygidium small, composed of short, strongly translucent scale-shape hairs, thus apical margin of T5 can be seen through it. Pygidial plate covered with sparse short hairs.

Structure: Body length 6-6.5 mm. CD:UID:LID 50:50:40. OCD/LOD 2.0.

Interantennal elevation weakly raised, with highly raised keeled carina. Inner eye margins nearly straight, strongly convergent below. Clypeus weakly raised and produced anteriorly. Labrum 1.8 times as wide as long; labral tooth slightly before the center, not accompanied by carina; apical portion feebly produced anteriorly, not upcurved; apical margin serrated. Mandible comparatively short, blunt at apex. Preoccipital ridge carinate. Relative length of FL1-3 1:1.1-1.2:1.0-1.2, relative length to apical width of FL1 1.3 times, FL2 1.6 times, FL3 1.41.5 times.

Scutellum moderately raised, anterior face flat, median furrow shallow. Hypoepimeral area completely flat. Pygidial plate rounded at apical portion.

Fore femur moderately built. Hind femur moderately built; boundary between anterior and posterior faces distinctly angulated from base of segment to near apex. Apicomedian setae on hind tibia four or five in number, posteriormost seta short, needle-shaped, others black, considerably short, rounded wholly, close together.

Male.

Color: Head and mesosoma black; the following portions are yellow or brownish yellow: mandible except apical one-fourth, labrum, clypeus on apical onethird to apical half, malar area, lower paraocular area extending up along inner eye margin to level of antennal sockets, small spot along top of compound eye; the following portions are brown: collar on the top, pronotal lobe, macula on anterior portion of mesopleuron. Scutellum with two reddish brown maculae.

Metasoma pale brown, T1 black on basal half, T2 and $\mathrm{T} 3$ each with a pair of round vague maculae, these two pairs similar in shape, but former large than the latter.

Legs as in female.

Sculpture: Similar to that in female except as follows: punctures on clypeus somewhat deeper and more distinct than in female. Terga faintly microsculptured, with dense punctules.

Vestiture: Vestiture on labrum similar to female. That on clypeus and clypeal area silvery-white, appressed, evidently less plumose than on labrum, dense to obscure the surface. That on lower genal area near hypostoma whitish, much longer than on apical portion of labrum.

Vestiture on scutum and scutellum whitish, long, erect, dense. That on mesopleuron whitish, strongly plumose, longer than on scutum. That on posterolateral corner of propodeum similar to on scutum, not dense to form hair patch.

Vestiture on ventral surface of fore femur as long as the maximum width of segment, that of mid femur shorter than the maximum width of segment. That on ventral surface of hind femur moderately dense, short, suberect.

Structure: Body length 6-8 mm. CD:UID:LID 50:48:38. OCD/LOD 2.2.

The following aspects are different from female: preoccipital ridge angulated, but not carinated as in female; scape somewhat wider than flagellar segments; relative length of FL1-3 1:1.4- 1.5:1.0-1.1, relative length to apical width of FL1 equal, FL2 1.7-1.8 times, FL3 1.3 times, FL5- FL8 only slightly longer than wide, FL9 and FL10 as long as wide, ultimate segment twice as long as basal width, tyloidea present on FL3 and the following segments, each recognized as obscure convex; scutellum usually more roundly than in female, otherwise as in female; pygidial plate shallowly or scarcely emarginated at apex; hind femur robust, basoventral flattened surface indistinct, ventral margin of segment straight in posterior view, boundary between basoventral flattened surface and posterior surface of segment angulated; apicomedian setae on hind tibia four or five in number, 


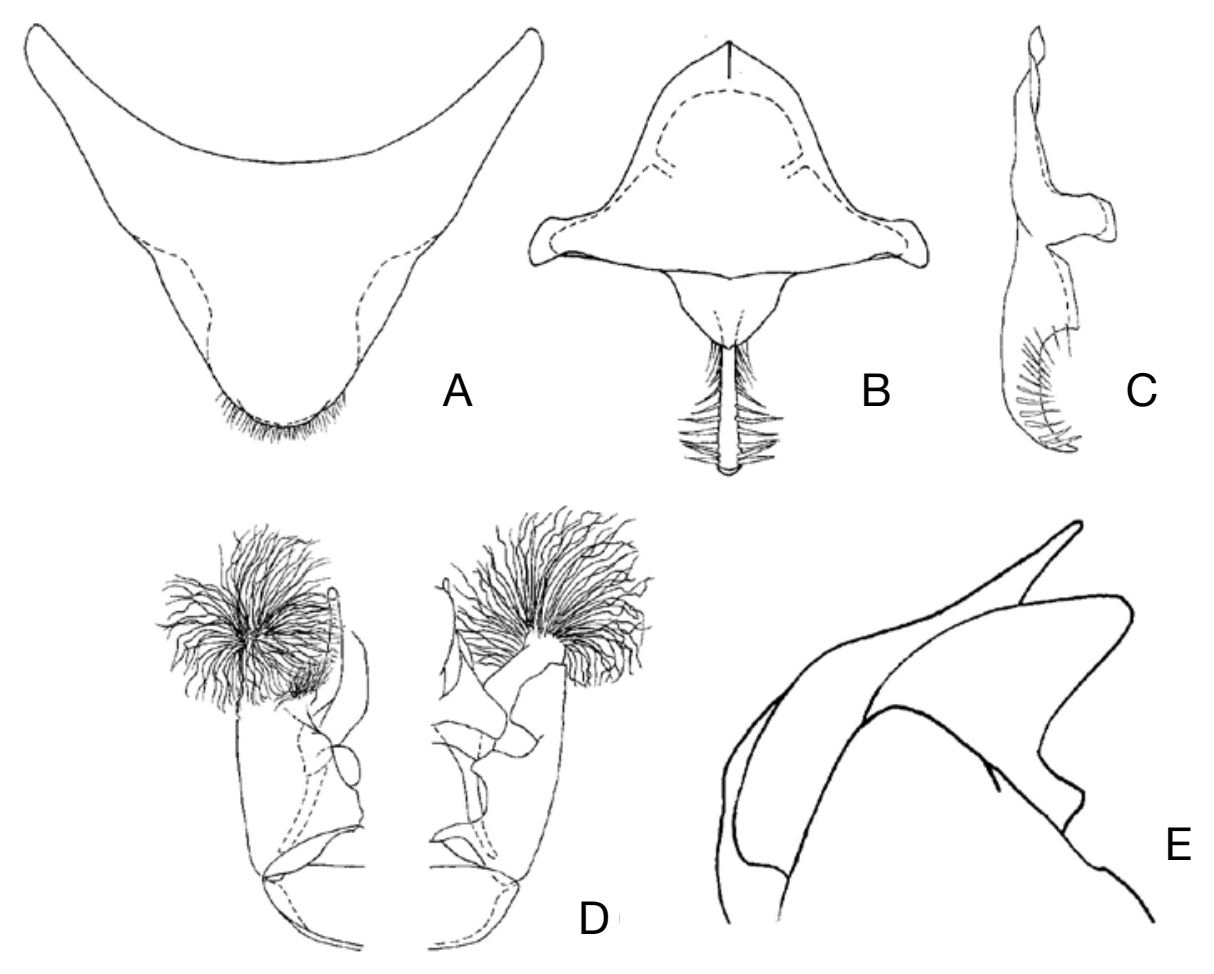

Fig. 36. Nomada guttulata (male). A: 7th metasomal sternum, ventral view. B: 8th sternum, dorsal view. C: the same, lateral view. D: genital capsule (left, ventral view; right, dorsal view). E: penis valve and gonostylus, lateral view (vestiture omitted).

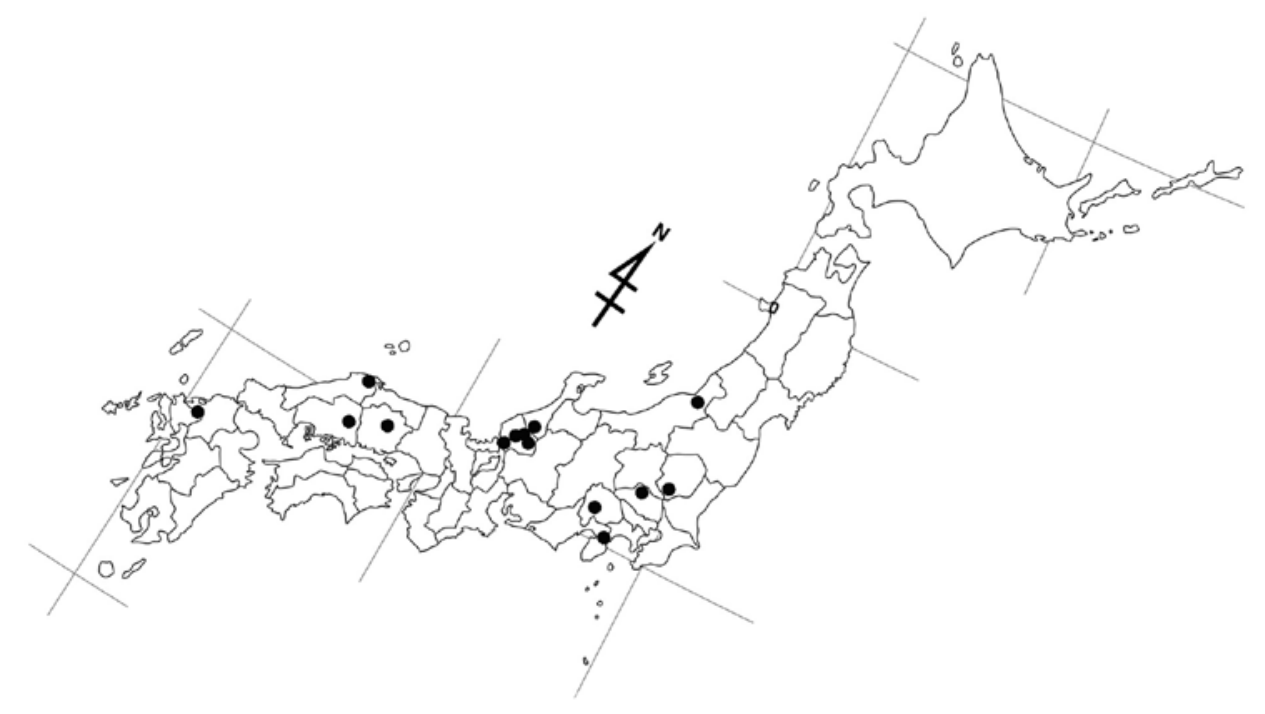

Fig. 37. Distribution of $N$. guttulata on the Japanese mainlands. Dots: localities of the specimens examined in the present study. 
Table 14. Seasonal change of number of the captured individual of N. guttulata in Japan (Number of females indicates at the left of slash in cell, that of males at the right. E: early, M: mid, L: late).

\begin{tabular}{|c|c|c|c|c|c|c|c|c|c|c|}
\hline \multirow[b]{2}{*}{ Main island } & \multirow[b]{2}{*}{ Prefecture } & \multicolumn{3}{|c|}{ April } & \multicolumn{3}{|c|}{ May } & \multicolumn{3}{|c|}{ August } \\
\hline & & $\mathrm{E}$ & $\mathrm{M}$ & $\mathrm{L}$ & $\mathrm{E}$ & $\mathrm{M}$ & $\mathrm{L}$ & $\mathrm{E}$ & M & $\mathrm{L}$ \\
\hline \multicolumn{11}{|l|}{ HONSHU } \\
\hline \multirow[t]{2}{*}{ [Kanto] } & Tochigi & & $1 / 1$ & & & & & & & \\
\hline & Saitama & & & $/ 1$ & & & & & & \\
\hline \multirow[t]{4}{*}{ [Chubu] } & Niigata & & & & $/ 1$ & & & & & \\
\hline & Ishikawa & & & $1 / 1$ & & & & & & \\
\hline & Fukui & & $1 /$ & $1 / 2$ & & & & & & $/ 1$ \\
\hline & Yamanashi & & & & $1 /$ & & & & & \\
\hline \multirow[t]{3}{*}{ [Chugoku] } & Shimane & & $1 / 4$ & $/ 1$ & & & & & & \\
\hline & Okayama & & & & $1 /$ & & & & & \\
\hline & Hiroshima & & & & & $1 /$ & & & & \\
\hline KYUSHU & Saga & $1 /$ & & & & & & & & \\
\hline \multicolumn{2}{|l|}{ Total } & 1 & 8 & 7 & 3 & 1 & 0 & 0 & 0 & 1 \\
\hline
\end{tabular}

posteriormost two thin, pale in color, difficult to discern among surrounding hairs, moderately long, others black and shorter.

Male terminalia: 7th metasomal sternum as in Fig. 36-A. 8th as in Fig. 36-B, C. Gonostylus short, thick; vestiture dense, long, strongly sinuate: basoventral lobe developed, with plumose, long, nearly straight vestiture. Penis valve slightly produced posteriorly beyond gonostylus, apex not extending beyond apex of gonostylus in lateral view. Gonocoxite with deep dorsal invagination; inner dorsal lobe as wide as long, with apex truncate.

Distribution. Palearctic Region; Japan (Honshu, Kyushu).

Specimens examined. We have examined nine females and 12 males as follows: JAPAN [Honshu] Tochigi: Iwafune, 10', 12. iv. 1981, 1우, 18. iv. 1982 (Y. Suzuki, K. Nakamura Coll.). Saitama: 10', Yorii, 26. iv. 1981 (T. Nambu). Niigata: 10', Kurokawa, 5. v. 1982 (K. Baba, TIM). Ishikawa: Shiramine, 10', 29. iv. 1985, 1우, 30. iv. 1985 (Y. Haneda). Fukui: 1오, Iwaya, 18. iv. 1960 (K. Tsuneki, MNHAH); 20', 26. iv. 1975 (H. Okuno, MNHAH); Shimo-uchinami, Ohno, 24. viii. 1975 (Y. Haneda); 1우, Ichijo-dani, 25. iv. 1976 (collector unknown, MNHAH). Yamanashi: 1우, Shimobe, 2. v. 1976 (O. Tadauchi, ELKU). Shimane: 1우4б', Mt. Dake, Matsue, 13. iv. 1986 (N. Sugiura); 10', Mt. Makuragi, 28. iv. 1992 (Y. Maeta). Okayama: 1우, Doi, Kagaminocho, Tomata-gun, 10. v. 2003 (M. Katô). Nagano, 1우, Jinseki-chô, Jinseki-gun, 17. v. 1996 (M. Saitô). [Kyushu] Saga: Kami-ozoegawa, Fuji, 5. iv. 2002 (O. Tadauchi, ELKU). KAZAKHSTAN 1 우 $1 \sigma^{\nearrow,}$ det. M. Schwarz.

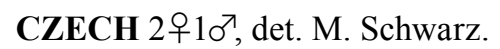

Biology. It is a rare species in Japan, collected from April to May, but one male specimen is collected in late August (Table 14). Floral associations are as follows: [Ranunculaceae] Ranunculus japonicus. [Rosaceae] Potentilla fragarioides var. major. [Compositae] Taraxacum albidum. The host is unknown in Japan. In Europe, Andrena florivaga Eversmann, A. pauxilla Stöeckhart, $A$. labiata Fabricius, and $A$. potentillae Panzer are known as the host (Celary, 1995).

Remarks. The female can be easily recognized from the congeners by the extremely short, rounded black apicomedian setae on hind tibia. The male is similar to Nomada nipponica Yasumatsu et Hirashima, but can be separated from it by the extremely short, rounded black apicomedian setae on hind tibia, and the short, not modified vestiture on ventral side of hind femur.

Compared with European individuals, the slightly shorter, closer together apicomedian setae on hind tibia, the lower clypeus in female, the FL1 and FL2 slightly longer, the apically blunt mandible in male. It should be treated as separated taxa from European N. guttulata if the same criteria applied in recognition at specific or subspecific level, as in Nomada alboguttata etizenensis which is recognized based on a few characters including the length of antenna. But at present we stand on the conservative view, namely Japanese individuals are assigned to $N$. guttulata, until ample materials from various localities are available for the study. 
14. Nomada hackoda Tsuneki, 1973

[Japanese name: Hakkô-kimadara-hanabachi]

(Figs. 38-40; Table 15)

Nomada hackoda Tsuneki, 1973, Etizenia, 66: 128-129

[Holotype: Male. Type locality: Towada, Aomori

Pref., Honshu, Japan]; Alexander \& Schwarz, 1994,

Univ. Kansas Sci. Bull., 55: 248 [in list].

Nomada calloptera (female): Tsuneki, 1973, Etizenia,
66: 62-66.

Nomada nurukawa Tsuneki, 1973, Etizenia, 66: 135-137

[Holotype: Male]; Alexander \& Schwarz, 1994, Univ. Kansas Sci. Bull., 55: 250 [in list]. syn. nov.

Nomada nurukawa var. Tsuneki, 1975, Kontyû, 43: 473-475 [Male]. syn. nov.

Nomada hakodatensis Tsuneki, 1976, Kontyû, 44: 52-54

[Holotype: Male]; Alexander \& Schwarz, 1994, Univ. Kansas Sci. Bull., 55: 248 [in list]. syn. nov.

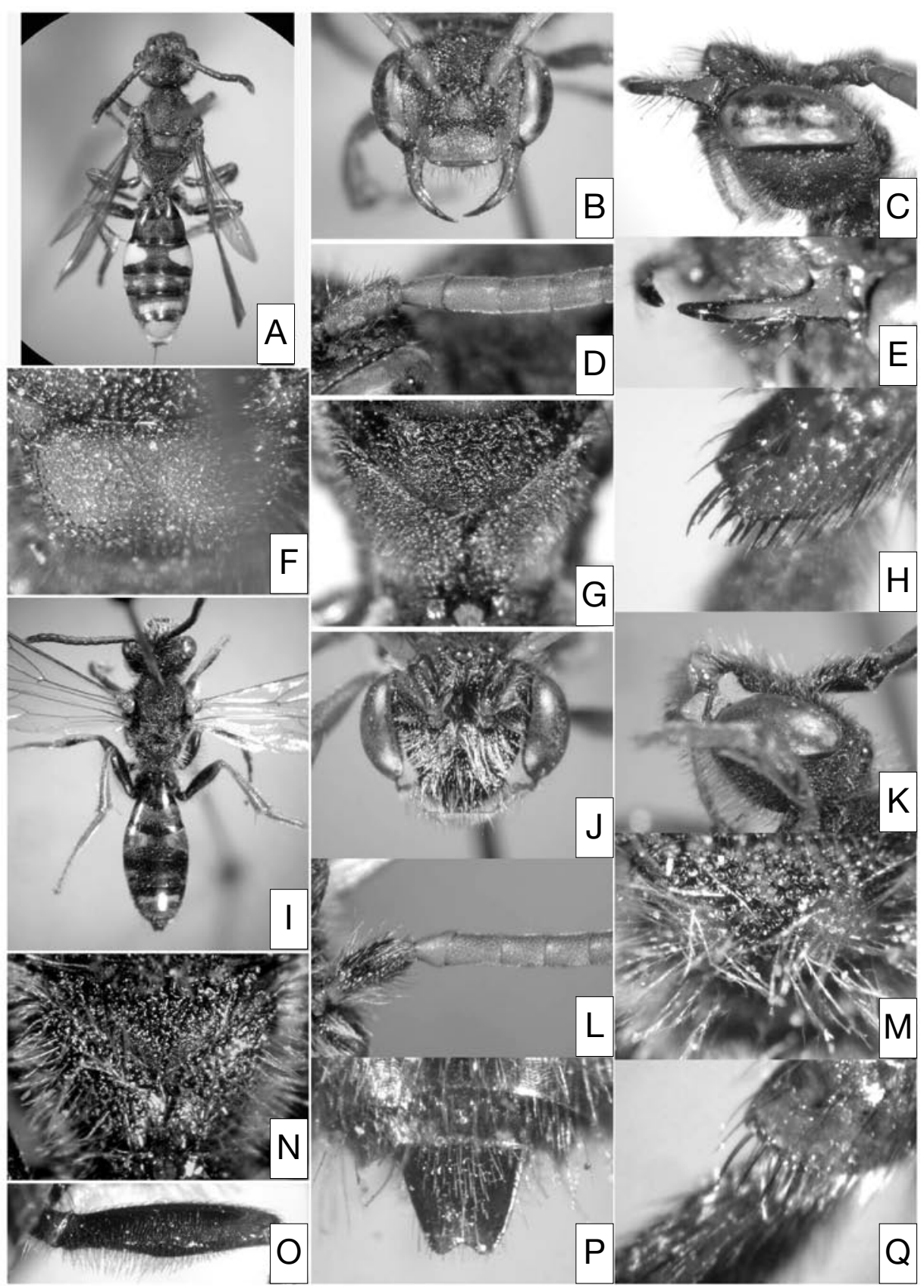

Fig. 38. Nomada hackoda Tsuneki. Female: A-H. Male: I-Q. A, I: habitus, dorsal view. B, C, J, K: head. D, L: antenna. E: mandible, F, M: scutellum. G, N: propodeal triangle. H, Q: apicomedian setae on hind tibia. O: hind femur, posterior view. P: pygidial plate. 
Nomada hanedai Tsuneki, 1976, Kontyû, 44: 58-59 [Holotype: Male]; Alexander \& Schwarz, 1994, Univ. Kansas Sci. Bull., 55: 248 [in list]. Syn. Nov.

\section{Redescription.}

\section{Female.}

Color: Head black; the following portions are dark reddish brown: mandible except apical one-fourth dark red, labrum, clypeus on apical two-thirds, malar area, supraclypeal area, lower paraocular area, line along compound eye which widened mesally at top of compound eye. Antenna reddish brown, darkened apically.

Mesosoma black; the following portions are reddish brown: collar on the top, pronotal lobe, tegula, axilla, four lines which fused at least partially on scutum, ventral and lower half of lateral portion of mesopleuron, sometimes small vague spot presents on hypoepimeral area, scutellum, sometimes two pairs of small macula on propodeum, one pair of them in propodeal triangle, the other pair on lateral side.

Metasoma reddish brown; the following portions are yellow: a pair of large oval maculae on T2, a line of four spots on T3, inner two of them smaller or sometimes lacking, narrowly interrupted medially band on $\mathrm{T} 4$, large macula largely occupying dorsal portion of T5. Each sternum irregularly black on basal portion. Pygidial plate reddish brown.

Legs largely black; the following portions are dark reddish brown: all coxa at apices, fore and mid trochanters anteriorly, all femora dorsally and apicoanteriorly, all tibiae dark brown anteriorly.

Sculpture: Punctures on labrum moderately large, indistinct, interpunctural space smooth. Those on clypeus and supraclypeal area distinct and larger.

Punctures on scutellum smaller and denser than on scutum. Mesopleuron moderately areolate. Propodeum outside triangle densely areolate, denser than on mesopleuron. Propodeal triangle irregularly coarsely rugose, the rugae highly raised and complicated as to show maze-like pattern, the remaining portion tessellate. Pygidial plate with small and dense punctures.

Vestiture: Vestiture on labrum brown tinged with golden, long and weakly plumose on apical margin otherwise much shorter and simple. That on clypeus and supraclypeal area brown tinge with golden, fine, weakly plumose, moderately long and dense. That on lower genal area near hypostoma evidently longer than on apical margin of labrum.

Vestiture on scutum and scutellum dark brown, short, erect or suberect, simple, moderately dense. That on mesopleuron pale brown to whitish, fine, longer than on scutum, weakly plumose, sparse. That on posterolateral to dorsal surface of propodeum outside triangle white or somewhat pale brown, short, plumose, about as long as on scutum, comparatively dense, not forming hair patch.

Pseudopygidium composing of whitish, fine, long, not modified hairs which similar to those on pygidial plate.

Structure: Body length 8.5-13 mm. CD:UID:LID 50:47:45. OCD/LOD 1.4.

Interantennal elevation weakly raised, with highly raised keeled carina. Inner eye margins weakly convergent below. Clypeus highly raised, strongly produced anteriorly. Labrum 1.6 times as wide as long; small tooth slightly before the center, not accompanied by carina; apical portion below labral tooth moderately produced anteriorly, not upcurved; apical margin not serrated. Mandible long and slender. Preoccipital ridge distinctly angulated. Relative length of FL1-3 1:1.4-1.5:1.2-1.3, FL1 1.1 times, FL2 1.7 times, FL3 1.5 times.

Scutellum moderately raised, anterior face flat, median furrow shallow. Posterior area around propodeal spiracle concave, with rounded ridge. Pygidial plate widely rounded at apical portion with a shallow notch at apex.

Fore femur moderately built. Apicomedian setae on hind tibia five to eight in number, robust, black, irregularly spaced, posteriormost seta slightly longer, others roughly same in length.

\section{Male.}

Color: Head and mesosoma largely black; the following portions reddish brown: middle part of mandible with apical one-fourth blackish, sometimes collar on the top, pronotal lobe, tegula, small vague spot on anterior portion of mesopleuron, large one macula or two separated maculae on scutellum. Yellow are as follows: clypeus on apical half but the width variable, sometimes upper margin of the yellow emaginated medially, or interrupted medially, malar area, lower paraocular area extending up along inner eye margin to level of antennal socket, spot along top of compound eye, basal half of mandible. Scape black wholly or reddish brown anteriorly, flagellar segments dark brown anteriorly and darkened apically, black posteriorly.

Metasoma black; the following portions reddish brown: band on T1, band between the yellow maculae on T3, pygidial plate; the following portions are yellow: a pair of large, transverse, oval maculae on T2, medially narrowly interrupted band on $\mathrm{T} 3$, complete band each on T4 and T5, large macula on T6 medially, widely 

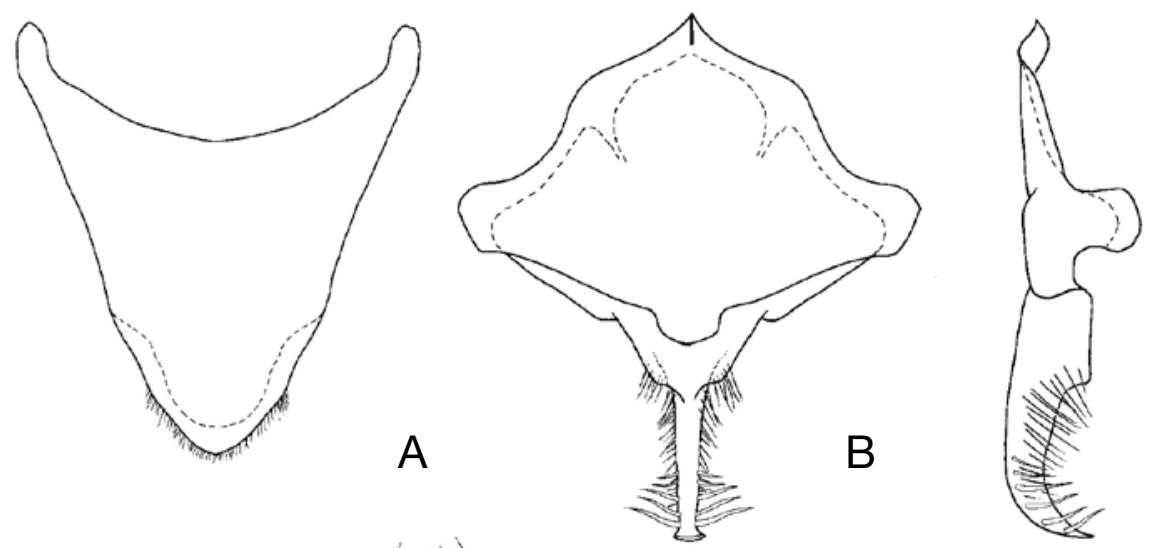

C
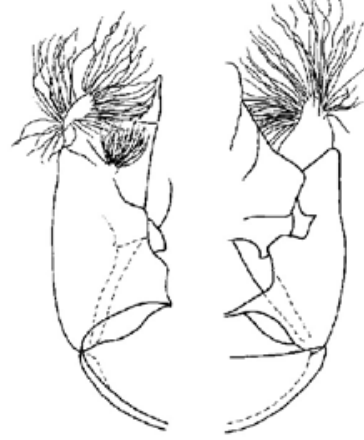

$\mathrm{D}$

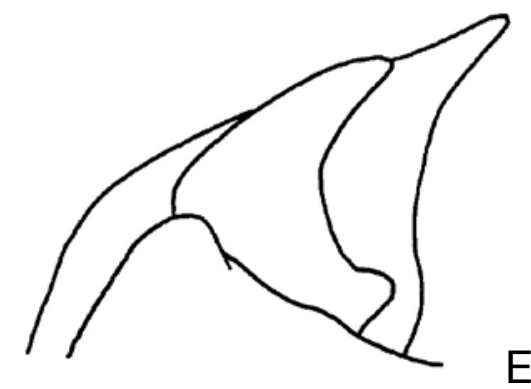

Fig. 39. Nomada hackoda (male). A: 7th metasomal sternum, ventral view. B: 8th sternum, dorsal view. C: the same, lateral view. D: genital capsule (left, ventral view; right, dorsal view). E: penis valve and gonostylus, lateral view (vestiture omitted).

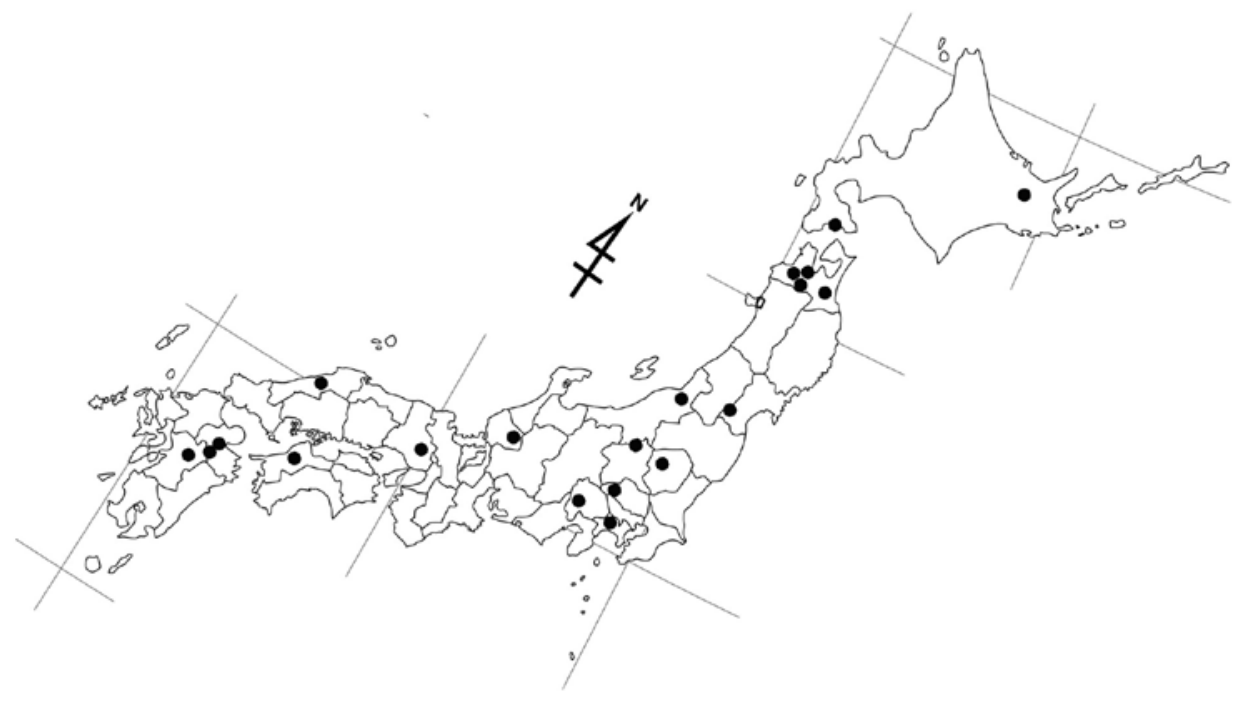

Fig. 40. Distribution of $N$. hackoda on the Japanese mainlands. Dots: localities of the specimens examined in the present study. 
separated two small spots on $\mathrm{S} 2$, a narrow band each on S3 and T4, small elliptical macula on S5, inverted triangular maculae on S6.

Legs also largely black; the following portions are dark reddish brown: all coxa apically, fore and mid trochanters apically, all femora dorsally and apicoanteriorly; all tibiae dark brown anteriorly. In the male, clypei are largely black in the specimens from Oita Pref., the northern part of Kyushu, whereas the specimens from Gumma Pref., the middle part of Honshu, and Aomori Pref., the northern part of Honshu have clypei with wider yellow portion.

Sculpture: As in female except as follows: punctures on scutum and scutellum more or less denser and deeper; propodeum outside triangle areolate all over, not densely as in female.

Vestiture: Vestiture on labrum whitish or pale brownish, erect, plumose, dense, long, evenly in density and length wholly. That on clypeus and supraclypeal area similar to that on labrum, but slightly longer, darker ventrally. That on genal area strongly plumose, longer than on labrum.

Vestiture on scutum and scutellum pale brown, long, erect, weakly plumose but slightly more strongly posterad. That on mesopleuron similar to that on scutum, but whitish, strongly plumose. That on posterolateral to dorsal surface of propodeum outside triangle similar to on mesopleuron, slightly denser, not forming hair patch.

Vestiture on ventral surfaces of fore and mid trochanters and femora slightly curved laterally, that of fore femur longer than the maximum width of segment, that of mid femur as long as the maximum width of segment. That on ventral surface of hind femur dense, erect, strongly plumose, straight.

Structure: Body length 8.5-13 mm. CD:UID:LID 50:57:46. OCD/LOD 1.7.

The following aspects are different from female: preoccipital ridge rounded behind vertex, angulated apically; scape wider than flagellar segments, but not prominent; relative length of FL1-3 1:1.7:15, relative length to apical width of FL1 1.1 times, FL2 1.7 times, FL3 1.5 times, tyloidea on FL2 distinctly delimited, broadly ridge-shaped, those on FL3 and FL4 higher raised, those on FL5 and the following segments not highly raised, occupying whole posterior surface of each segment, elliptical, becoming roughly rectangular apically seen in posterior view; scutellum weakly or moderately, roundly raised, median furrow shallow or scarcely discernible; posterior area around propodeal spiracle shallowly concave, without a distinct ridge; pygidial plate widely, triangular or roundly emarginated at apex; fore femur slender or moderately built; hind femur moderately built; basoventral flattened surface distinct, but not reaching to midpoint of segment, strongly de-

Table 15. Seasonal change of number of the captured individual of N. hackoda in Japan (Number of females indicates at the left of slash in cell, that of males at the right. E: early, M: mid, L: late).

\begin{tabular}{|c|c|c|c|c|c|c|c|c|c|c|c|c|c|c|c|c|}
\hline \multirow[b]{2}{*}{ Main island } & \multirow[b]{2}{*}{ Prefecture } & \multicolumn{3}{|c|}{ March } & \multicolumn{3}{|c|}{ April } & \multicolumn{3}{|c|}{ May } & \multicolumn{3}{|c|}{ June } & \multicolumn{3}{|c|}{ August } \\
\hline & & E & $\mathrm{M}$ & $\mathrm{L}$ & E & $\mathrm{M}$ & $\mathrm{L}$ & E & $\mathrm{M}$ & L & E & $\mathrm{M}$ & $\mathrm{L}$ & E & M & L \\
\hline HOKKAIDO & & & & & & & & $/ 1$ & & & & & & & & \\
\hline \multicolumn{17}{|l|}{ HONSHU } \\
\hline \multirow[t]{2}{*}{ [Tohoku] } & Aomori & & & & & & 12 & $/ 1$ & 12 & & 17 & $/ 1$ & & & & \\
\hline & Miyagi & & & & & & & & & 1/ & & & & & & \\
\hline \multirow[t]{4}{*}{ [Kanto] } & Tochigi & & & & & & & & $/ 1$ & & & & & & & \\
\hline & Gumma & & & & & & & & & & & $/ 1$ & & & & \\
\hline & Saitama & & & & & & & $1 /$ & $1 /$ & & & & & & & \\
\hline & Kanagawa & & & & $/ 1$ & & & & & & & & & & & \\
\hline \multirow[t]{2}{*}{ [Chubu] } & Niigata & & & & & & & & & & & & 1/ & & & \\
\hline & Fukui & & & & $1 /$ & & & & & & & & & & & 1/ \\
\hline [Kinki] & Hyogo & & & & $/ 1$ & & & & 1/ & & & & & & & \\
\hline [Chugoku] & Shimane & & & & & $/ 1$ & & & & & & & & & & \\
\hline SHIKOKU & Ehime & & & & & $/ 1$ & & & & & & & & & & \\
\hline \multirow[t]{2}{*}{ KYUSHU } & Kumamoto & & & $2 / 4$ & & & & & & & & & & & & \\
\hline & Oita & & & & & $1 / 1$ & $18 / 7$ & & 1/ & $1 /$ & & & & & & \\
\hline \multicolumn{2}{|c|}{ Total } & 0 & 0 & 6 & 3 & 4 & 27 & 3 & 6 & 2 & 7 & 2 & 1 & 0 & 0 & 1 \\
\hline
\end{tabular}


pressed in posterior view; apicomedian setae on hind tibia thinner and usually paler than in female, otherwise as in female.

Male terminalia: 7th metasomal sternum as in Fig. 39-A. 8th as in Fig. 39-B, C. Gonostylus comparatively short, weakly flattened apically; vestiture long, simple, sparse, each hair thick, weakly sinuate apically; basoventral lobe developed, with long, minutely plumose vestiture. Penis valve not produced posteriorly beyond gonostylus, apex extending much beyond apex of gonostylus in lateral view. Gonocoxite with deep dorsal invagination; inner dorsal lobe wider than long, with apex truncate.

Distribution. Japan (Hokkaido, Honshu, Shikoku, Kyushu).

Specimens examined. JAPAN [Hokkaido] 10', Kussaro-ko, Teshikaga, 6. v. 1984 (O. Tadauchi, ELKU). [Honshu] Aomori: 10', Okawara, 29. iv. 1960 (M. Yamada). Miyagi: 1우, Gaga, Mt. Zao, 24-25. v. 1958 (unknown collector, ELKU). Tochigi: 10', Ogurayama, Nikko, 18. v. 1980 (K. Nakamura). Gumma: 10', Mt. Tanigawa, 14. vi. 1952 (R. Ishikawa, ELKU). Saitama: 1우, Mitsumine, 5. v. 1971 (T. Nambu). Kanagawa: 10', Mt. Bukka, Aikogum, 6. iv. 1955 (H. Nagase). Niigata: 1 우, Mt. Ninouji, 27. vi. 1965 (M. Schwarz Coll.). Fukui: 1우, Echi, Takehara, 6. iv. 1959 (T. Tano). Yamanashi: 1 우, Yashajin, Ashiyasu-mura, Nakakoma-gun, collecting data unknown. Hyogo: 10', Sasayama (Tamba), 3. iv. 1952 (S. Taniguchi, ELKU). Shimane: 10', Sanbe, 12. iv. 1982 (H. Shimizu, Y. Haneda Coll.). [Shikoku] Ehime: 1 ऽ', Mt. Saragamine, 16. iv. 1952 (R. Ishikawa, ELKU). [Kyushu] Kumamoto: 2우6ð', Kugino, Aso, 28. iii. 1960 (Y. Miyatake, ELKU). Oita: 19우3ð', Mt. Kuroiwayama, Kokonoe-machi, Kusu-gun, 28. iv. 2006 (K. Mitai).

Biology. It is a univoltine species, collected from March to June, with one female collected in late August (Table 15). Floral associations are as follows: [Rosaceae] Spiraea thunbergii. [Ericaceae] Pieris japonica. [Ericaceae] Rhododendron kiusianum. [Compositae] Petasites japonicus, Petasites japonicus var. giganteus. The host is unknown.

Remarks. Mr. Haneda (1994) was the first to cast doubt on the combination of sexes of Nomada calloptera Smith in Tsuneki (1973). The circumstantial evidences as co-occurrence of sexes indicate that the female which Tsuneki supposed as female of $N$. calloptera is the female of $N$. hackoda, and that Nomada rengnio Tsuneki is the true female of $N$. calloptera. Nomada hackoda can be separated from $N$. calloptera by the greatly anteriorly produced clypeus in both sex and the female pseudopygidium composed of not modified hairs. Nomada maculifrons Smith and this species share the greatly anteriorly produced clypeus in both sexes, but $N$. hackoda differs from the latter by the densely punctate labrum and scutellum in female, the straight apicomedian setae on hind tibia in female, the pseudopygidium composed of not modified hairs in female, the not conical-shaped tyloidea on the flagellar segments in male, and the densely punctate scutellum in male.

15. Nomada hakonensis Cockerell, 1911 [Japanese name: Higenaga-kimadara-hanabachi] (Figs. 41-43; Table 16)

Nomada hakonensis Cockerell, 1911a, Proc. U. S. Nat. Mus., 39: 647 [Holotype: Male. Type locality: Hakone, Honshu, Japan] ; Hirashima, 1965, Icon. Ins. Jap., Col. Nat. ed., Vol. III: 309, pl. 155; Tsuneki, 1973, Etizenia, 66: 104-106 [redescription]; Alexander \& Schwarz, 1994, Univ. Kansas Sci. Bull., 55: 248 [in list].

Nomada murotai Tsuneki, 1973, Etizenia, 66: 110-112 [Holotype: Female]; Alexander \& Schwarz, 1994, Univ. Kansas Sci. Bull., 55: 250 [in list]. syn. nov.

\section{Redescription. \\ Female.}

Color: Head reddish brown; the following portions are black: large macula above antennal socket encompassing ocelli, line on subantennal to epistomal sutures, broad line on genal area along preoccipital ridge extending from hypostoma up to vertex (these two maculae connected at vertex). Sometimes also clypeus on basal half and supraclypeal area black. Antenna pale brown, darker posteriorly.

Mesosoma black; the following portions are reddish brown: collar largely, anterior margin of pronotum, pronotal lobe, tegula, four longitudinal lines on scutum which sometimes largely fused and scutum nearly wholly reddish brown except narrow median black line, axilla, scutellum, large maculae almost occupying lateral surface of mesopleuron, propodeum except medial line and anterior margin.

Metasoma reddish brown, T1 black on basal half, T3-5 distinctly black each on basal margin, T2 with a pair of round yellow maculae laterally, T5 with a large vague yellow macula medially. Pygidial plate brown or dark brown.

Legs largely pale brown, all femora each with darkened maculae ventrally, these maculae variable in size, sometimes lacking.

Sculpture: Punctures on labrum small and distinct, 


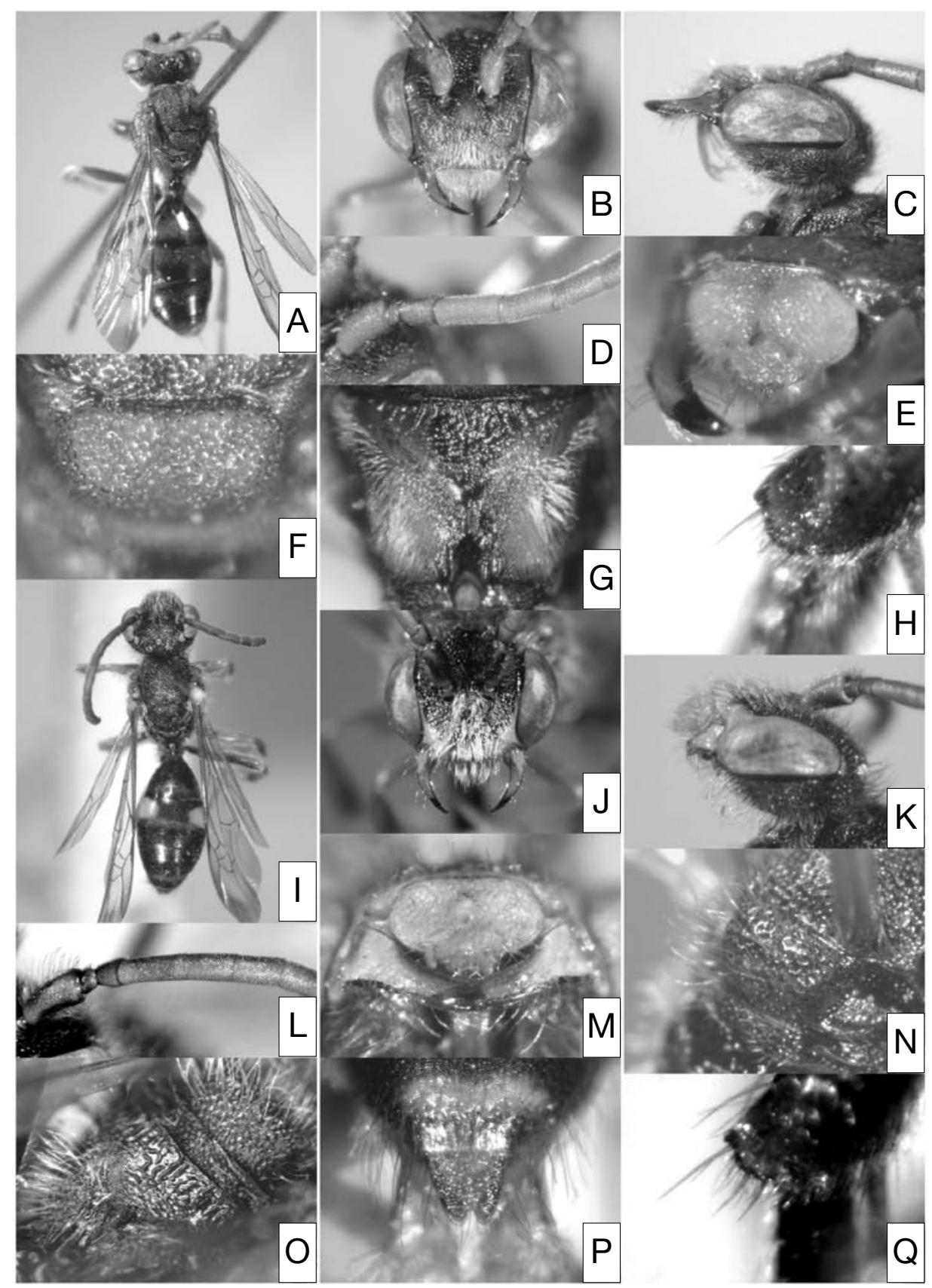

Fig. 41. Nomada hakonensis Cockerell. Female: A-H. Male: I-Q. A, I: habitus, dorsal view. B, C, J, K: head. D, L: antenna. E, M: labrum. F, N: scutellum. G, O: propodeal triangle. H, Q: apicomedian setae on hind tibia. P: pygidial plate.

very dense. Those on clypeus and supraclypeal area larger.

Punctures on scutellum sparer or as on scutum. Mesopleuron shallowly areolate. Propodeum outside triangle shallowly areolate. Propodeal triangle rugose basally and centrally, usually longitudinal rugae prominent, interspaces of rugae smooth and shiny or sometimes closely irregularly rugose without shiny interspaces on the basomedially, the remaining portion faintly tessellate to shiny smooth.

Terga faintly microsculptured without punctules. Pygidial plate with weak, sparse punctures.

Vestiture: Vestiture on labrum white, strongly plumose, dense. That on clypeus and supraclypeal area as on labrum, but appressed. That on lower genal area near hypostoma plumose, erect, somewhat longer than on la- 

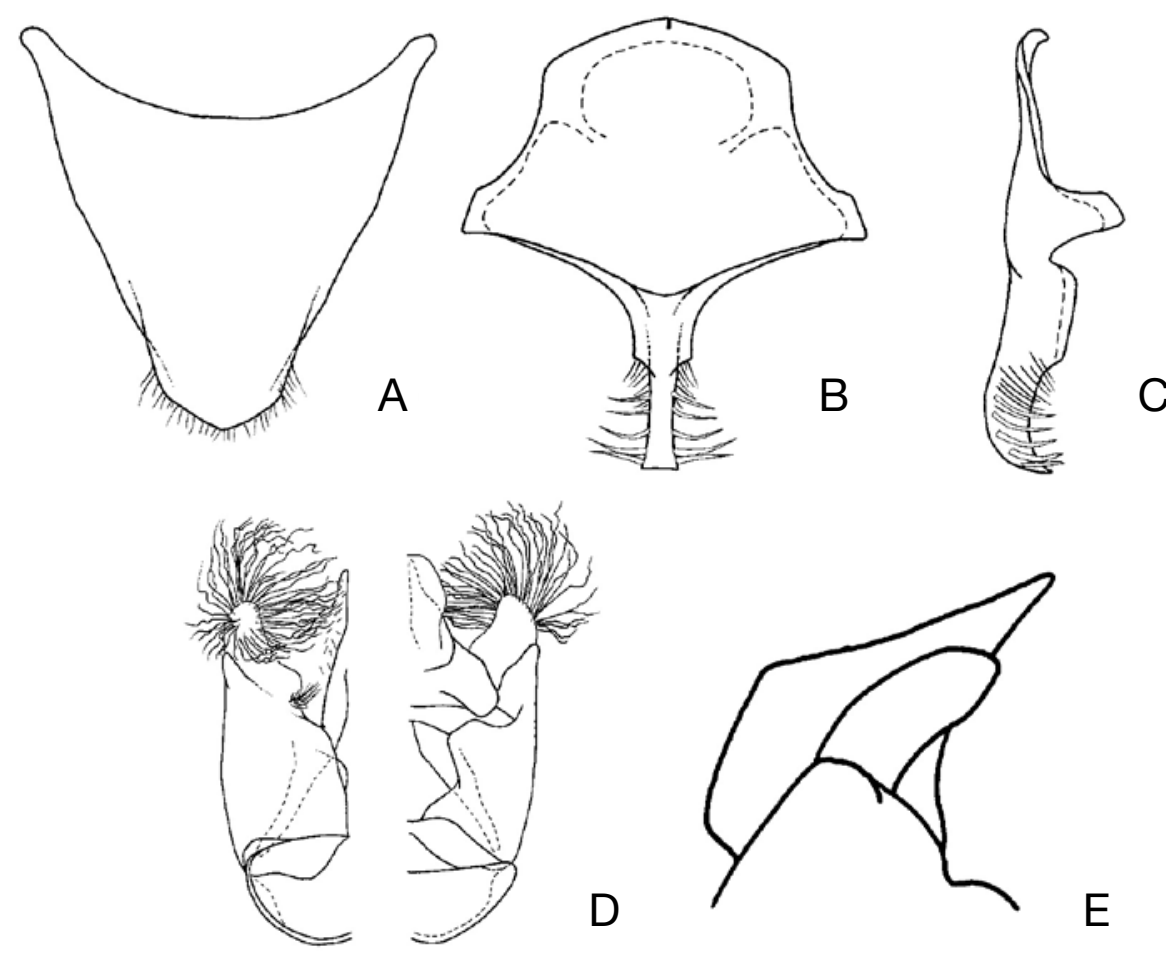

Fig. 42. Nomada hakonensis (male). A: 7th metasomal sternum, ventral view. B: 8th sternum, dorsal view. C: the same, lateral view. D: genital capsule (left, ventral view; right, dorsal view). E: penis valve and gonostylus, lateral view (vestiture omitted).

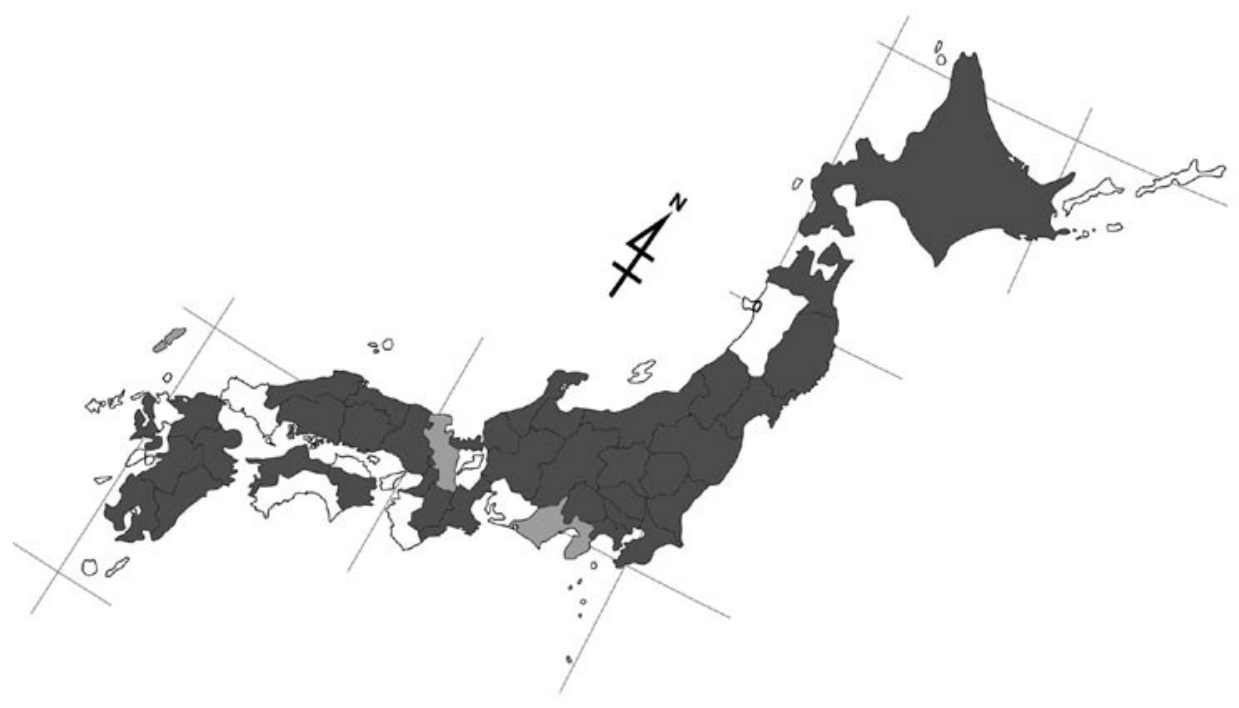

Fig. 43. Distribution of $N$. hakonensis on the Japanese mainlands. Densely shaded: prefectures with the specimens examined in the present study. Lightly shaded: prefectures with records in literature, but no specimens examined in the present study. 
brum.

Vestiture on scutum and scutellum inconspicuous, short, brown to dark brown. That on mesopleuron whitish, strongly plumose, long. That on posterolateral corner of propodeum whitish, short, strongly plumose, appressed, dense, forming hair patch.

Vestiture on terga very sparse, especially T1 and 2 nearly hairless. Pseudopygidium small, silvery-shining, composed of broadly flattened, scale-like hairs. Pygidial plate covered with fine, sparse hairs.

Structure: Body length 5-6.5 mm ("4.7 mm-7.2 mm" in redescription by Tsuneki [1973]). CD:UID:LID 50:50:45. OCD/LOD 1.8 .

Interantennal elevation weakly raised. Inner eye margins moderately convergent below. Clypeus weakly raised and moderately produced anteriorly. Labrum 1.6 times as wide as long; three distinct labral teeth arranged in low triangle, medial tooth located slightly before or at the center, not accompanied by carina; the apical portion below labral tooth weakly produced anteriorly, not upcurved; the apical margin indistinctly serrated. Preoccipital ridge rounded. Scape slightly wider than flagellar segments. Relative length of FL1-3 1:1.8:1.5, relative length to apical width of FL1 1.2 times, FL2 2.4-2.6 times, FL3 2.0 times.

Scutellum weakly to moderately raised, anterior surface flat, median furrow very shallow or scarcely discernible. Pygidial plate triangular at apical portion.

Fore femur considerably slender. Apicomedian setae on hind tibia three in number, well-separated, posteriormost seta evidently longer than other two, all thin, difficult to discern among surrounding hairs.

\section{Male.}

Color: Head and mesosoma largely black; the following portions are yellow: mandible except apical onefourth, labrum but sometimes darkened, clypeus on apical band ranging from very narrow to occupying apical half, malar area, lower paraocular area extending up along the inner eye margin to level of antennal socket, spot tinged with brown along top of compound eye, spot on anterior surface of mesopleuron but frequently lacking. Pronotal lobe brown. Scutellum wholly black or with dark red two maculae.

Metasoma largely dark brown to black; T1 with apical half pale brown to brown containing two black spots, $\mathrm{T} 2$ and T3 each with a pair of round yellow maculae (that on T3 much smaller, intermacular space pale brown to dark brown), $\mathrm{T} 4$ and $\mathrm{T} 5$ each with indistinct dark brown band, T6 with a brown to dark brown, transverse elliptical macula.

Legs pale brown; the following portions are black: all coxae except narrow apical portion, fore trochanter dorsally, mid and hind trochanters dorsally and ventrally but sometimes wholly black except narrow anterior surface, fore and mid femora ventrally, hind femur except dorsally.

Sculpture: As in female.

Vestiture: Vestiture on labrum pale brown, plumose, long on apical margin, otherwise much shorter, dense to obscure the integument. That on clypeus and supraclypeal area similar to that on labrum, appressed. That on lower genal area near hypostoma longer than on labrum.

Vestiture on scutum and scutellum brown, moderately long, slightly longer on scutellum. That on mesopleuron white, plumose, much longer than on scutum. That on posterolateral to dorsal surface of propodeum outside triangle sparse, plumose, slightly shorter than that on mesopleuron, white to pale brown, not forming hair patch.

Vestiture on ventral surfaces of fore and mid femora somewhat shorter than the maximum width of each segment. That on ventral surface of hind femur moderately dense, suberect, short.

Structure: Body length 4.5-7 mm. CD:UID:LID 50:48:41. OCD/LOD 1.8.

The following aspects are different from female: interantennal carina weakly raised as in female, but top of carina horizontally straight in profile, and somewhat abruptly lowered anteriorly from level of anterior margin of antennal socket; relative length of FL1-3 1:2.7:2.0, relative length to apical width of FL1 0.8 times, FL2 2.4-2.5 times, FL3 1.7-1.8 times, tyloidea weakly developed only on FL4-5, very narrowly ridge-shaped in posterior view, weakly raised in lateral view; pygidial plate with triangular or deeply U-shaped emargination at apex; fore femur slender, slightly wider than in female; hind femur slender; basoventral flattened surface indistinct, ventral margin of segment straight in posterior view; apicomedian setae on hind tibia as in female.

Male terminalia: 7th metasomal sternum as in Fig. 42-A. 8th as in Fig. 42-B, C. Gonostylus cylindrical; vestiture long, simple, somewhat sparse, sinuate; basoventral lobe absent, but moderately long simple vestiture on the corresponding portion. Penis valve produced posteriorly beyond gonostylus, apex extending beyond apex of gonostylus in lateral view. Gonocoxite with deep and narrow dorsal invagination; inner dorsal lobe as wide as long, with apex truncate.

Distribution. Japan (Hokkaido, Honshu, Shikoku, Kyushu, Tsushima Is.); South Korea (new record).

Specimens examined. We have examined about 330 
Table 16. Seasonal change of number of the captured individual of N. hakonensis in Japan (Number of females indicates at the left of slash in cell, that of males at the right. E: early, M: mid, L: late).

\begin{tabular}{|c|c|c|c|c|c|c|c|c|c|c|c|c|c|c|c|c|}
\hline \multirow[b]{2}{*}{ Main island } & \multirow[b]{2}{*}{ Prefecture } & \multicolumn{3}{|c|}{ March } & \multicolumn{3}{|c|}{ April } & \multicolumn{3}{|c|}{ May } & \multicolumn{3}{|c|}{ June } & \multicolumn{3}{|c|}{ July } \\
\hline & & $\mathrm{E}$ & M & $\mathrm{L}$ & $\mathrm{E}$ & $\mathrm{M}$ & $\mathrm{L}$ & $\mathrm{E}$ & $\mathrm{M}$ & $\mathrm{L}$ & $\mathrm{E}$ & $\mathrm{M}$ & $\mathrm{L}$ & $\mathrm{E}$ & $\mathrm{M}$ & $\mathrm{L}$ \\
\hline HOKKAIDO & & & & & & & & $/ 1$ & $7 /$ & 7/ & 4/ & $1 /$ & & & & \\
\hline \multicolumn{17}{|l|}{ HONSHU } \\
\hline \multirow[t]{5}{*}{ [Tohoku] } & Aomori & & & & & & $1 / 7$ & $3 / 8$ & $3 / 4$ & $11 / 2$ & 12 & $2 /$ & & & & \\
\hline & Iwate & & & & & & 12 & $1 / 3$ & $1 / 1$ & 1/ & & 12 & & & & \\
\hline & Miyagi & & & & & $/ 1$ & 13 & $4 / 9$ & 13 & & & & & & & \\
\hline & Yamagata & & & & & & & & & $1 /$ & & & & & & \\
\hline & Fukushima & & & & & & & & 1/ & $2 /$ & & & & & & \\
\hline \multirow{6}{*}{ [Kanto] } & Tochigi & & & & 13 & $3 / 14$ & $6 / 11$ & $4 / 9$ & $3 /$ & $/ 4$ & & & & & & \\
\hline & Gumma & & & & & & $/ 1$ & & & & & & & & & \\
\hline & Saitama & & & $/ 1$ & 1/ & $11 / 18$ & $9 / 1$ & $3 / 1$ & $2 /$ & & & & & & & \\
\hline & Chiba & & & & $1 / 1$ & $/ 1$ & $3 / 2$ & 1/ & & & & & & & & \\
\hline & Tokyo & & & & 15 & $2 / 4$ & & $1 / 1$ & & & & & & & & \\
\hline & Kanagawa & & & & $/ 1$ & & $/ 1$ & 1/ & & & & & & & & \\
\hline \multirow[t]{7}{*}{ [Chubu] } & Niigata & & & & & & & & & 1/ & & & & & & \\
\hline & Toyama & & & & & $/ 1$ & & & & & & & & & & \\
\hline & Ishikawa & & & & & $/ 1$ & $/ 1$ & $8 / 84$ & $1 / 1$ & & & & & & & \\
\hline & Fukui & & & & 13 & $2 / 1$ & $7 / 84$ & $48 / 93$ & $17 / 8$ & $17 / 5$ & $/ 1$ & & & & & \\
\hline & Yamanashi & & & & & $/ 1$ & 1/ & $2 / 2$ & & & & & & & & \\
\hline & Nagano & & & & & & & $/ 1$ & $3 /$ & $3 / 1$ & & & & & & \\
\hline & Gifu & & & & & & & & $/ 1$ & & & & & & & \\
\hline \multirow[t]{4}{*}{ [Kinki] } & Mie & & & & & 12 & 12 & & & & & & & & $/ 1$ & \\
\hline & Osaka & & & $/ 1$ & & $/ 1$ & & & & & & & & & & \\
\hline & Hyogo & & & & & & $1 / 1$ & $1 /$ & & & & & & & & \\
\hline & Nara & & & & $2 / 2$ & & & & & & & & & & & \\
\hline \multirow[t]{4}{*}{ [Chugoku] } & Tottori & & & & & & 1/ & & & & & & & & & \\
\hline & Shimane & & & & & & & 1/ & & & & & & & & \\
\hline & Okayama & & & & & & 16 & & & & & & & & & \\
\hline & Hiroshima & & & & & & $4 / 6$ & & & & & & & & & \\
\hline \multirow[t]{2}{*}{ SHIKOKU } & Tokushima & & & & & $/ 1$ & & & & & & & & & & \\
\hline & Ehime & & & & & $/ 1$ & & & & & & & & & & \\
\hline \multirow[t]{6}{*}{ KYUSHU } & Fukuoka & & 12 & $3 / 9$ & $20 / 61$ & $16 / 10$ & $19 / 3$ & $8 / 1$ & $10 /$ & & & & & & & \\
\hline & Nagasaki & & & & & & & $/ 1$ & & & & & & & & \\
\hline & Kumamoto & & & $5 / 41$ & & 14 & $1 / 1$ & & $/ 1$ & & & & & & & \\
\hline & Oita & & & & 17 & 1/ & $1 / 4$ & & $3 /$ & & & & & & & \\
\hline & Miyazaki & & & & $1 /$ & $11 / 8$ & $2 / 1$ & $/ 1$ & & & & & & & & \\
\hline & Kagoshima & & & $1 /$ & & & & & & & & & & & & \\
\hline \multicolumn{2}{|c|}{ Total } & 0 & 2 & 61 & 107 & 115 & 193 & 311 & 70 & 55 & 7 & 5 & 0 & 0 & 1 & 0 \\
\hline
\end{tabular}

females and 600 males. On the localities, see Fig. 43. Some of them are listed as follows: JAPAN [Honshu] Iwate: $3 \sigma^{7}$, Morioka, 9. v. 1971 (T. Chiba, NIAES). Yamagata: 1우, 27. v. 1976 (O. Tadauchi, ELKU). Fu- kushima: 2우, Nakayama, Koriyama, 23. v. 1975 (O. Tadauchi, ELKU). 1우1ర', Ogawa, Kitaibaraki-shi, 9-23. iv. 2002 (malaise trap. H. Goto, FFPRI). Gumma: 10', Kamihino, Fujioka, 27. iv. 2001 (T. Nambu, ELKU). 
Nagano: 3우, Oyanohara, Otari, 15. v. 1976 (O. Tadauchi, ELKU). Gifu: 10', Nonomata, Shôkawa-mura, Ônogun, 14. v. 2004 (T. Sugimoto, ELKU). Hyogo: 10", Sasayama (Tamba), 26. iv. 1953 (S. Taniguchi, ELKU). Nara: 2우2ᄋ', Nara, 10. iv. 1952 (R. Ishikawa, NSMT). Tottori: 1우, Chizu, Mt. Nagi, 26. iv. 1976 (O. Tadauchi, ELKU). [Shikoku] Tokushima: 10', Ichiu, 17. iv. 1976 (O. Tadauchi, ELKU). Ehime: 10', Mt. Saragamine, 16. iv. 1952 (R. Ishikawa, ELKU). [Kyushu] Nagasaki: 10', Yoshida, Mine, Tsushima, 4. v. 1986 (O. Tadauchi, ELKU). Kumamoto: 1우, Kugino, Aso Nat. Park, 28. iii. 1960 (T. Kawarabata, ELKU). Oita: 70', Mt. Hanamureyama, Shônai-machi, Oita-gun, 6. iv. 2006 (K. Mitai). Miyazaki: 11우7ð', Ebino Highland, Ebino-shi $\cdot$ Kobayashishi, 14. iv. 2003 (K. Mitai). SOUTH KOREA, 20', Sam Jeon-Li, Ma Cheong-Meon, Hamyang-Gun, Kyeon Sang Nam-Do, 11. v. 1991 (O. Tadauchi, ELKU).

Biology. It is a common, univoltine species in Japan, inhabits from low land to mountainous region. The collecting records are from mid March to mid July, with most records from April to May (Table 16). Floral associations are as follows: [Ranunculaceae] Ranunculus japonicus. [Cruciferae] Brassica rapa, Capsella bursapastoris. [Rosaceae] Potentilla fragarioides var. major. [Aceraceae] Acer palmatum. [Violaceae] Viola grypoceras. [Diapensiaceae] Shortia uniflora var. kantoensis. [Compositae] Taraxacum officinale, Taraxacum platycarpum. The host is unknown.

Remarks. It is similar superficially to Nomada flavoguttata (Kirby) and N. montverna Tsuneki, but easily separated from the latter by the longer second flagellar segment in both sexes. Nomada murotai Tsuneki, 1973 was described based on one female specimen and no additional specimens have been recorded since then. According our examination, although the holotype has the relatively shorter antennal segments for females of $N$. hakonensis, it is otherwise structurally identical with $N$. hakonensis.

16. Nomada harimensis Cockerell, 1914 [Japanese name: Harima-kimadara-hanabachi] (Figs.44-46; Table 17)

Nomada harimensis Cockerell, 1914, Ann. Mag. Nat. Hist. Lond., (8)13: 425 [Holotype: Male. Type locality: Hyogo, Honshu, Japan]; Tsuneki, 1973, Etizenia, 66: 80-83 [redescription]; Alexander \& Schwarz, 1994, Univ. Kansas Sci. Bull., 55: 248 [in list].

Nomada orientalis Yasumatsu et Hirashima, 1953, Kontyû, 20: 29-31 [Holotype: Female], synonymized by Tsuneki, 1973: 80-83.

\section{Redescription. \\ Female.}

Color: Head reddish brown, sometimes tinged with yellow on lower paraocular area and lower inner eye margin; the following portions are black: large macula on antennal area, usually supraclypeal area reddish brown, transverse elliptical macula on ocellar area (these two maculae nearly always fused partially, but always reddish brown spot just before median ocellus), clypeus on narrow basal margin, broad line on gena along preoccipital ridge extending from hypostoma up to the level of top of compound eye in profile. Mandible reddish brown except apical one-third dark red. Antenna brown wholly, or scape black posteriorly, flagellar segments reddish brown anteriorly, darker apically and posteriorly.

Mesosoma black; the following portions are reddish brown or frequently strongly darker: collar on the top, pronotal lobe, anterior margin of pronotum but sometimes lacking, usually well-separated four lines on scutum, tegulae, axillae, scutellum wholly or except peripheral margin, mesopleuron except the peripheral margin and small black spot on ventral side, sometimes a small black spot on mesopleuran scrobe, two vague spots on metanotum but frequently wholly black, dorsal surface of propodeum except longitudinal medial portion black.

Metasoma largely reddish brown. T1 black on basal one-third or half. The following portions are yellow: a pair of oval maculae each on T2 and T3 (the latter much smaller, sometimes becoming small spots), a pair of vague spots on $\mathrm{T} 4$ but frequently lacking, a roughly rectangular, large macula on T5. Pygidial plate reddish brown. Sterna largely reddish brown. Apical margin of each S1-4 blackish. S4 and S5 each with a pair of yellow spots on anterolateral margin. Pygidial plate reddish brown.

Legs largely black; the following portions are reddish brown: anterodorsal portions of all femora, on fore femur the brown reaching to the apical two-thirds of dorsal surface of the segment, the brown portions successively narrower on mid- and hind femora, all tibiae largely anteriorly, sometimes the black reduced to small spot on fore tibia.

Sculpture: Punctures on labrum dense, shallow. Those on clypeus and supraclypeal area smaller, more distinct. Those on scutellum somewhat denser or as on scutum. Mesopleuron moderately areolate. Lateral and dorsal sides outside the triangle densely areolate except rugose portion under the spiracle. Propodeal triangle irregularly rugose on basal half and central portion, the 
remaining portion tessellate or nearly smooth. Terga faintly microsculptured, with moderately dense punctules. Pygidial plate with obliterated punctures.

Vestiture: Vestiture on labrum brown tinged with golden, moderately dense, plumose, long on apical margin, otherwise much shorter. That on clypeus and supraclypeal area as on labrum but appressed or suberect, dense so as to obscure the integument. That on lower genal area near hypostoma as on labrum.
Vestiture on scutum and scutellum brown to blackish, erect, moderately dense, weakly plumose. That on mesopleuron plumose, whitish, much longer than those on scutum. That on posterolateral to dorsal surface of propodeum outside triangle whitish or brownish, denser, shorter and more strongly plumose than that on mesopleuron, forming a somewhat loose hair patch, integument can be seen clearly in some direction. Pseudopygidium short longitudinally. Pygidial plate covered

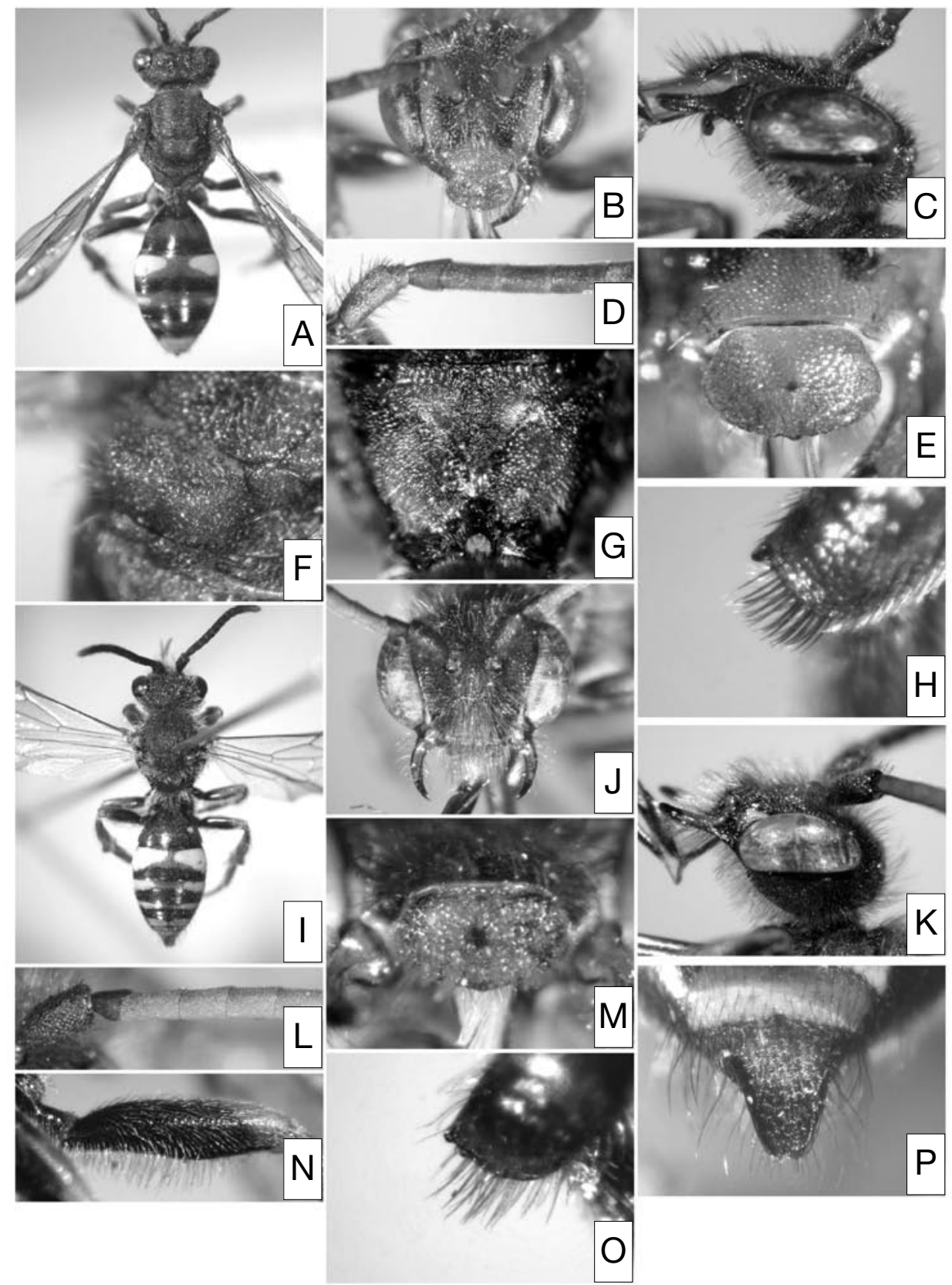

Fig. 44. Nomada harimensis Cockerell. Female: A-H. Male: I-P. A, I: habitus, dorsal view. B, C, J, K: head. D, L: antenna. E, M: labrum. F: scutellum. G: propodeal triangle. H, O: apicomedian setae on hind tibia. N: hind femur, anterior view. P: pygidial plate. 
with sparse, fine, short hairs.

Structure: Body length 6.5-9.5 mm. CD: UID: LID 50:47:40. OCD/LOD 1.7.

Interantennal elevation moderately raised. Inner eye margins moderately convergent below. Clypeus highly raised and produced anteriorly. Labrum 1.5 times as wide as long, with a distinct labral tooth in the middle, not accompanied by a carina on each side; apical portion below labral tooth moderately produced anteriorly, weakly upcurved; apical margin distinctly serrated. Preoccipital ridge angulate gradually rounded apically. Relative length of FL1-3 1:1.7-1.8:1.5, relative length to apical width of FL1 equal times, FL2 1.9-2.0 times, FL3 1.6-1.7 times.

Scutellum highly raised; anterior surface flat; median furrow wide and deep. Pygidial plate triangular at apical portion.

Fore femur slender or moderately built. Apicomedian setae on hind tibia about 25 in number, dark brown or black, thin, all similar in shape but slightly shorter apically, close together, difficult to discern individually.

Male.

Color: Head and mesosoma black; yellow portion confined to malar area, or more extended up along the inner eye margin but not reaching to the level of antennal sockets. The yellow darker downward, frequently becoming dark brown at malar area, sometimes the yellow extending beyond malar space into basodorsal portion of mandible. Mandibles usually black basally, dark brown medially, dark red at apical one-third. Scape wholly dark brown, flagellar segments dark brown anteriorly, black posteriorly, frequently apical four or five segments wholly black. Pronotal lobe and tegula brown to dark brown.

Metasoma black; the following portions are brown to dark brown: a band on $\mathrm{T} 1$, the band containing a pair of black spots laterally, sometimes also containing a din yellow mark in the band, intermacular space on T2-4; the following portions are yellow: a pair of yellow maculae each on T2-4 (the maculae on T2 oval-shaped, close so as to nearly touch each other, further apart each other and thinner successively on T3 and T4), a band on $\mathrm{T} 5$, which sometimes interrupted medially, a large macula on T6. In the melanic specimens, terga deeper black except the yellow maculae. Sterna 2-3 each with a variously developed yellow band, sometimes reduced to vague spots or lacking.

Coxae and trochanters of all legs black wholly, all femora also largely black except each dorsoanterior portion brown, the brown on fore femur reaching the apical two-thirds of dorsal surface of the segment, successive- ly narrower on mid-, and hind femur; all tibiae largely black posteriorly, otherwise brown, sometimes the black on fore tibia reduced to small spot.

Vestiture: That on labrum, clypeus and supraclypeal area pale brown, strongly plumose, erect on labrum, appressed on clypeus and supraclypeal area, dense as to completely conceal the integument of clypeus. That on lower genal area near hypostoma less plumose, as long as or somewhat longer than on labrum.

Vestiture on scutum and scutellum pale brown, long, fine, erect, weakly plumose. That on mesopleuron whitish, slightly longer, somewhat more strongly plumose. That on posterolateral to dorsal surface of propodeum outside triangle similar to that on scutum, not forming a hair patch.

Vestiture on ventral surfaces of fore- and mid femora slightly longer than the maximum width of each segment. That on ventral surface of hind femur with long, strongly plumose, moderately dense.

Sculpture: As in female.

Structure: Body length 7-9 mm. CD:UID:LID 50:50:41. OCD/LOD 2.0.

The following aspects are different from female: labrum 1.3-1.4 times as wide as long, otherwise similar in shape to that of female; scape evidently wider than the flagellar segments; relative length of FL1-3 1:1.7:1.5, relative length to apical width of FL1 0.9-1.0 times, FL2 1.8 times, FL3 1.6 times, tyloidea absent on FL1, that on FL2 feebly linear, those on FL3-7 distinctly delimited, elliptical, but not highly raised, those on FL8-9 indistinctly delimited, rounded ridge-shaped, that on ultimate segment scarcely discernible; preoccipital ridge gently rounded; scutellum moderately, roundly raised; median furrow very shallow or scarcely discernible; fore femur as in female, but slightly wider; apicomedian setae on hind tibiae about ten in number, evidently thinner than in female, otherwise as in female; hind femur slender; basoventral flattened surface wide, extended toward the apex slightly beyond the midpoint of the segment, markedly depressed in posterior view; pygidial plate shallowly emarginated at apex .

Male terminalia: 7th metasomal sternum as in Fig. 45-A. 8th as in Fig. 45-B, C. Gonostylus thick, short, inner basal portion somewhat angulate, shelf-like; vestiture long, simple, strongly sinuate; basoventral lobe developed, with plumose, long vestiture. Penis valve produced posteriorly beyond gonostylus, apex extending much beyond apex of gonostylus in lateral view. Gonocoxite with deep dorsal invagination; inner dorsal lobe slightly longer than wide, with apex truncate.

Distribution. Japan (Hokkaido, Honshu, Shikoku, 

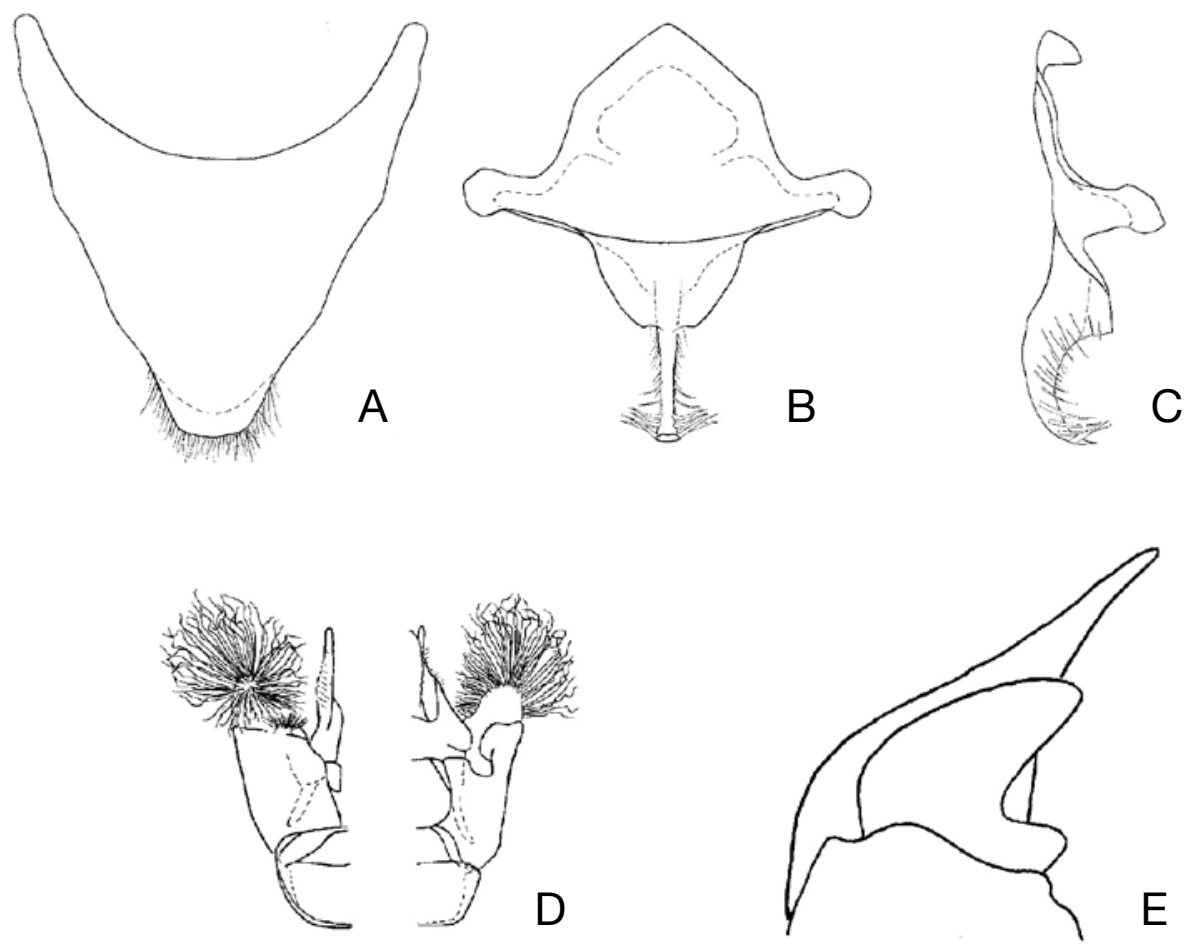

Fig. 45. Nomada harimensis (male). A: 7th metasomal sternum, ventral view. B: 8th sternum, dorsal view. C: the same, lateral view. D: genital capsule (left, ventral view; right, dorsal view). E: penis valve and gonostylus, lateral view (vestiture omitted).

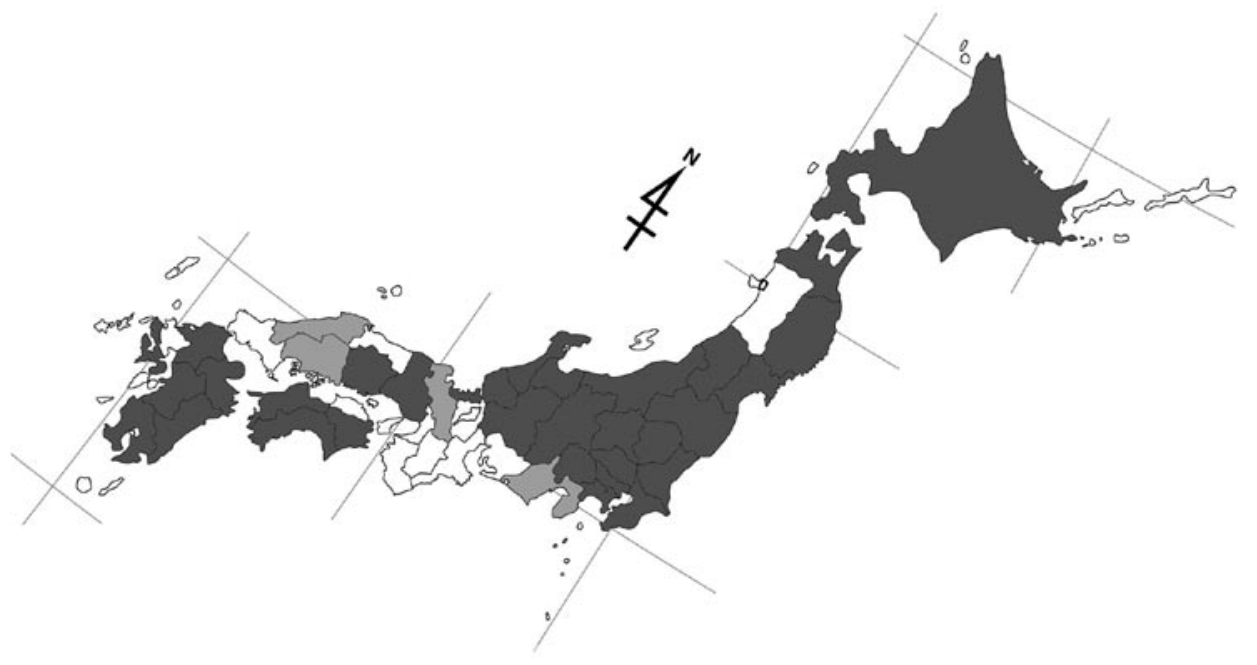

Fig. 46. Distribution of $N$. harimensis on the Japanese mainlands. Densely shaded: prefectures with the specimens examined in the present study. Lightly shaded: prefectures with records in literature, but no specimens examined in the present study. 
Table 17. Seasonal change of number of the captured individual of $N$. harimensis in Japan (Number of females indicates at the left of slash in cell, that of males at the right. E: early, M: mid, L: late).

\begin{tabular}{|c|c|c|c|c|c|c|c|c|c|c|}
\hline \multirow[b]{2}{*}{ Main island } & \multirow[b]{2}{*}{ Prefecture } & \multicolumn{3}{|c|}{ March } & \multicolumn{3}{|c|}{ April } & \multicolumn{3}{|c|}{ May } \\
\hline & & $E$ & $\mathrm{M}$ & $\mathrm{L}$ & $\mathrm{E}$ & $\mathrm{M}$ & $\mathrm{L}$ & $\bar{E}$ & $\mathrm{M}$ & $\mathrm{L}$ \\
\hline HOKKAIDO & & & & & & & $1 / 1$ & $/ 1$ & $1 /$ & $1 /$ \\
\hline HONSHU & Aomori & & & & & $3 / 20$ & $2 / 6$ & $1 / 2$ & $2 / 1$ & $3 / 1$ \\
\hline \multirow[t]{4}{*}{ [Tohoku] } & Iwate & & & & & $1 / 1$ & $1 / 3$ & $2 /$ & $2 / 1$ & $1 / 1$ \\
\hline & Miyagi & & & $2 /$ & 9/ & $5 /$ & $13 /$ & $4 /$ & $1 /$ & $2 /$ \\
\hline & Yamagata & & & & & & & & & $1 /$ \\
\hline & Fukushima & & & & & & & & & $1 /$ \\
\hline \multirow[t]{7}{*}{ [Kanto] } & Ibaraki & & & & & $1 /$ & $1 /$ & & & \\
\hline & Tochigi & & & 13 & $/ 6$ & $9 / 7$ & $3 /$ & $2 /$ & $4 /$ & 6 \\
\hline & Gumma & & & & $1 /$ & & & $2 / 2$ & & \\
\hline & Saitama & & & 14 & $3 / 1$ & $3 / 1$ & $1 / 2$ & $2 / 1$ & $/ 1$ & \\
\hline & Chiba & & & $/ 1$ & $2 / 4$ & $1 / 1$ & 1/ & $3 /$ & & \\
\hline & Tokyo & & $1 / 3$ & 12 & $1 / 7$ & & & & & \\
\hline & Kanagawa & & & 13 & $4 / 2$ & & $1 /$ & & & $/ 1$ \\
\hline \multirow[t]{7}{*}{ [Chubu] } & Niigata & & & & 1 & $1 / 2$ & $1 / 1$ & $1 / 1$ & & $4 / 1$ \\
\hline & Toyama & & & & & $1 /$ & 1/ & & & \\
\hline & Ishikawa & & & & $1 / 7$ & $/ 1$ & 2/ & & & \\
\hline & Fukui & & $4 / 4$ & $8 / 4$ & $7 / 6$ & $1 / 5$ & $16 / 27$ & $9 / 8$ & $9 / 3$ & $2 / 1$ \\
\hline & Yamanashi & & & & $/ 1$ & & & & & \\
\hline & Nagano & & & & & $/ 1$ & & $1 / 2$ & $2 /$ & $4 /$ \\
\hline & Gifu & & & & & & & $1 /$ & & \\
\hline \multirow[t]{2}{*}{ [Kinki] } & Osaka & & & $3 / 7$ & 15 & & & & $1 /$ & \\
\hline & Hyogo & & & & & & & $/ 1$ & & \\
\hline [Chugoku] & Okayama & & & & & & 12 & & & \\
\hline \multirow[t]{3}{*}{ SHIKOKU } & Tokushima & & & & & $2 /$ & & & & \\
\hline & Ehime & & & & $/ 2$ & $2 / 4$ & & & & \\
\hline & Kochi & & & & & & $4 /$ & & & \\
\hline \multirow[t]{6}{*}{ KYUSHU } & Fukuoka & $/ 1$ & $5 / 14$ & $6 / 12$ & $24 / 13$ & $18 / 6$ & 6/ & $2 / 1$ & 4/ & \\
\hline & Nagasaki & & & & $1 /$ & & & & & \\
\hline & Kumamoto & & & $1 / 3$ & $1 / 1$ & & & & & \\
\hline & Oita & & $/ 1$ & & $10 / 7$ & & $2 / 1$ & & $1 /$ & \\
\hline & Miyazaki & & & & & $5 / 1$ & & $2 /$ & & \\
\hline & Kagoshima & $/ 1$ & & & & & & & $1 /$ & \\
\hline \multicolumn{2}{|l|}{ Total } & 2 & 32 & 59 & 127 & 103 & 99 & 51 & 34 & 30 \\
\hline
\end{tabular}

Kyushu); South Korea.

Specimens examined. Holotype (USNM), male, attached with three labels as follows: "Harima/ 7. IV. 1912 [white rectangle with handwritten letters]", "Type/ No. 18383/ U. S. N. M. [red rectangle and typed except for the numerals handwritten]", "Nomada/ harimensis/ Ckll. TYPE [white rectangle with handwritten letters]". This type lacks the metasoma.
Other specimens: We have examined about 300 females and 250 males. On the localities, see Fig. 47. Some of them are listed as follows: JAPAN [Honshu] Iwate: $10^{\top}$, Oshida, 25. iv. 1976 (T. Chiba, NIAES). Fukushima: 1우, Nakayama, Koriyama, 23. v. 1975 (O. Tadauchi, ELKU). Gunma: 1우, Okutone, 2. iv. 1984 (H. Nagase). [Shikoku] Tokushima: 1오, Ichiu, 17. iv. 1976 (O. Tadauchi, ELKU). Ehime: 1우, Ochiai, Kuma-machi, 15. 
iv. 1976 (O. Tadauchi, ELKU). Kochi: 2우, Nakamurashi, 27. iv. 1957 (Y. Hirashima, ELKU). [Kyushu] Nagasaki: 1우, Mt. Hachiro-dake, Nagasaki City, 4. iv. 1953 (H. Kamiya, ELKU). Miyazaki: Ebino Highland, Ebino-shi, 9. v. 2005 (K. Mitai). SOUTH KOREA, 1우, Suigen, 6. v. 1924 (K. Sato, ELKU).

Biology. This species is common and abundant in Japan, and flies from early March to end of May in Japan (Table 17). The activity peaks from late May to April. Maeta et al. (1996) reported Andrena ruficurus rabicurus Hirashima as host of $N$. harimensis in Miyagi Pref., Honshu in Japan, in which paper a hibernating adult of $N$. harimensis had been found in host cell. Andrena ruficurus rabicurus, however, is not distributed in Kyushu, whereas $N$. harimensis is common in Kyushu as well as in Honshu. This fact suggests that $N$. harimensis attacks nests of multiple Andrena species. Floral associations are as follows: [Salicaceae] Salix gracilistyla. [Cruciferae] Brassica rapa var. amplexcaulis. [Rosaceae] Potentilla fragarioides var. major, Potentilla freyniana, Rubus hirsutus. [Aceraceae] Acer sieboldianum. [Scrophulariaceae] Veronica persica. [Compositae] Petasites japonicus, Petasites japonicus var. giganteus.

Remarks. The female is similar to Nomada amurensis Radoszkowsky and N. pacifica Tsuneki, and the male is similar to $N$. fukuiana Tsuneki, but both sexes can be easily separated from them by the apicomedian setae on hind tibia, which are thin, close together more than ten in number. These setae of $N$. pacifica might give the similar appearance with that of $N$. harimensis to eyes of unfamiliar observer. In that case the structure of mandible is helpful in separating these two species in both sexes. In $N$. harimensis, the mandible is acute at apex as normal in Nomada, whereas in N. pacifica the mandible not acute but truncate or feebly incised at truncate apex.

17. Nomada icazti Tsuneki, 1976

[Japanese name: Ikazuchi-kimadara-hanabachi]

(Figs. 47-49; Table 18)

Nomada icazti Tsuneki, 1976, Kontyû, 44: 59-61 [Holotype: Female. Type locality: Sunayama Hills, Fukui Pref., Honshu, Japan]; Alexander \& Schwarz, 1994, Univ. Kansas Sci. Bull., 55: 248 [in list].

Nomada wakasana Tsuneki, Kontyû, 44: 56-58 [Holotype: Male]. syn. nov.

\section{Redescription.}

\section{Female.}

Color: Head reddish brown, tinged with yellow on basal half of labrum, lower paraocular area, line along outer eye margin; the following portions are black: macula just above antennal socket, transverse elliptical macula surrounding ocelli, line on genal area along preoccipital ridge from hypostoma up to vertex (these maculae always separated), line on subantennal suture. Mandible reddish brown except apical one-third dark red. Antenna wholly pale reddish brown, sometimes flagellar segments somewhat darker posteriorly.

Mesosoma black; the following portions are reddish brown: collar on the top, anterior margin of pronotum, pronotal lobe, tegula, four well-separated longitudinal lines on scutum, axilla, scutellum nearly wholly or except peripheral margin, mesopleuron nearly wholly except the black on ventral portion, a pair of large maculae on propodeum which expanded anteriorly to occupy posterior half of lateral side, posteriorly into basolateral corner of triangle, containing a pair of longitudinal zigzag bright yellow maculae on the dorsal. The brown portion on mesopleuron contains transversely elliptical yellow macula.

Metasoma pale reddish brown, T1 blackish brown on basal one-third or basal half; the following portions are yellow: a pair of maculae each on T2-T4 (that on T2 oval, those on T3 and T4 smaller, round or elliptical), large macula on T5 medially, S2-5 largely. Pygidial plate pale brown.

Legs largely pale reddish brown; the following portions are black or blackish: fore coxa on upper and inner narrow margin, mid and hind coxae posteriorly, all femora anteriorly and posteriorly; sometimes a black line present on posterior of each femur medially.

Sculpture: Punctures on labrum weak, indistinct or sometimes distinct. Those on clypeus and supraclypeal area smaller and denser.

Punctures on scutellum as on scutum. Mesopleuron densely areolate. Lateral and dorsal sides outside triangle of propodeum densely areolate, much denser and more distinctly than on mesopleuron. Propodeal triangle irregularly rugose on basal half and central portion, rugae highly raised, complicated as to show maze-like pattern, the remaining portion tessellate.

Terga faintly microsculptured, virtually impunctate. Pygidial plate with weak, moderately dense punctures, impunctate margin wide and polished.

Vestiture: Vestiture on labrum plumose, relatively dense. That on clypeus and supraclypeal area appressed, plumose, moderately dense. That on lower genal area nearly hypostoma slightly longer than on apical margin of labrum.

Vestiture on scutum and scutellum brown to dark brown, very short, simple, suberect. That on meso- 

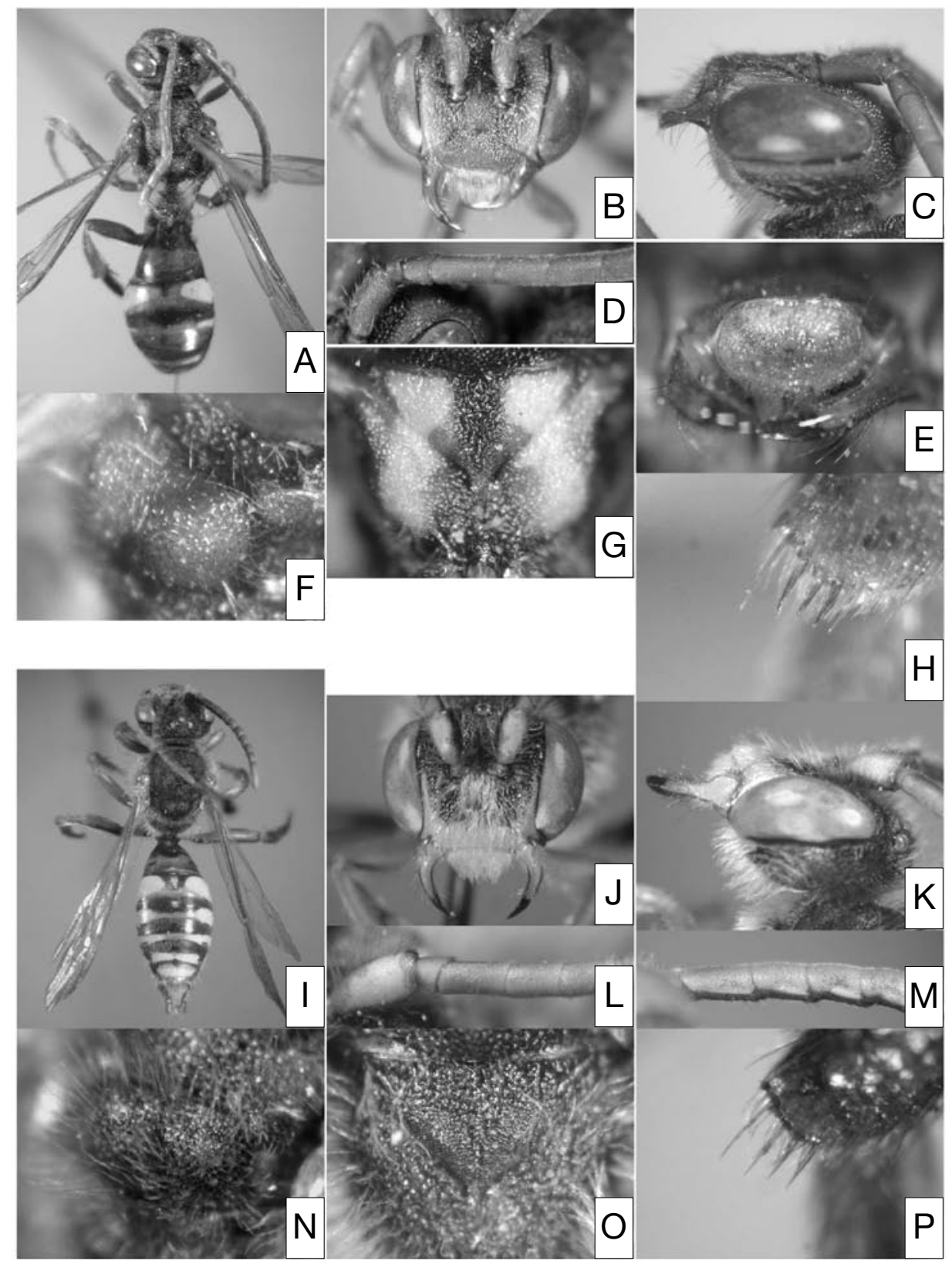

Fig. 47. Nomada icazti Tsuneki. Female: A-H. Male: I-P. A, I: habitus, dorsal view. B, C, J, K: head. D, L, M: antenna. E: labrum. F, N: scutellum. G, O: propodeal triangle. H, P: apicomedian setae on hind tibia.

pleuron white, plumose, more or less sparse, evidently longer than on scutum. That on posterolateral surface of propodeum whitish, short, plumose, suberect, not dense to form hair patch.

Pseudopygidium well developed as normal in female Nomada. Pygidial plate covered with fine, short hairs.

Structure: Body length 7-9 mm. CD:UID:LID 50:46:41. OCD/LOD 1.6.

Interantennal elevation weakly or moderately raised, with highly raised keeled carina. Inner eye margins con- vergent below. Clypeus weakly or moderately raised and weakly produced anteriorly. Labrum 1.5 times as wide as long; labral tooth present at or slightly before the center, accompanied by indistinct carina which runs nearly horizontally on each side, sometimes these carinae hard to distinguish from surrounding plumose hairs; apical portion triangularly produced anteriorly, moderately upcurved; apical margin distinctly serrated with triangular protuberance medially. Mandible slender. Preoccipital ridge rounded. Relative length of FL1-3 1:2.3-2.4:2.0 

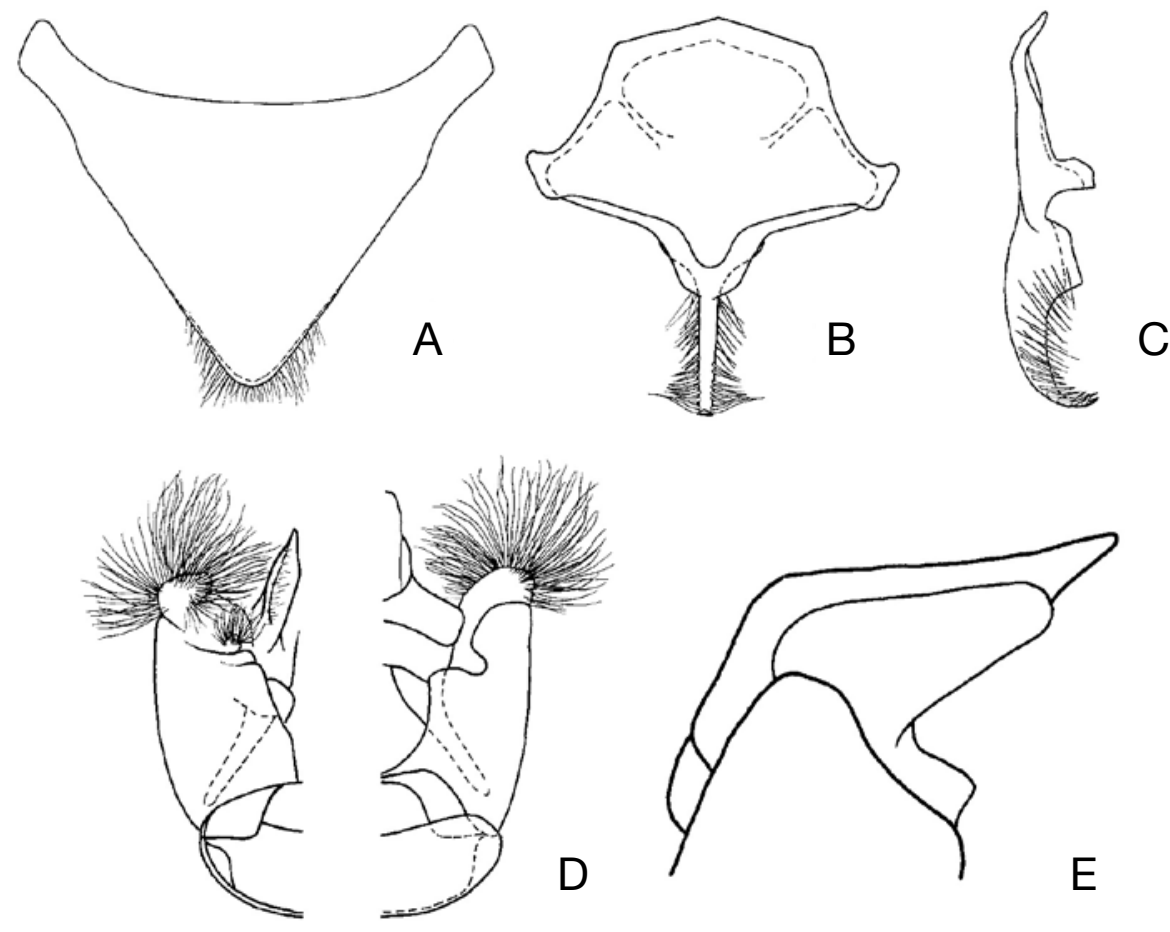

Fig. 48. Nomada icazti (male). A: 7th metasomal sternum, ventral view. B: 8th sternum, dorsal view. C: the same, lateral view. D: genital capsule (left, ventral view; right, dorsal view). E: penis valve and gonostylus, lateral view (vestiture omitted).

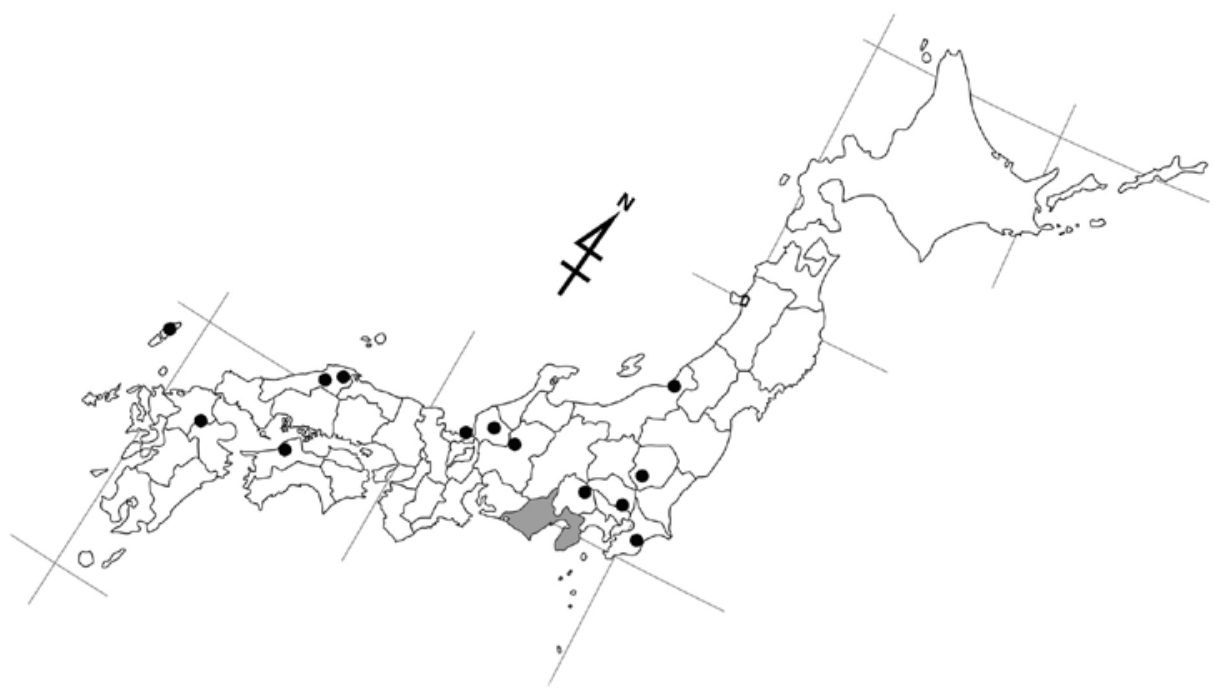

Fig. 49. Distribution of $N$. icazti on the Japanese mainlands. Dots: localities of the specimens examined in the present study. Shaded: prefectures with records in literature, but not specimens examined in the present study. 
(1:2:1.5 in original description), relative length to apical width of FL1 0.9 times, FL2 2.2-2.3 times, FL3 1.8-1.9 times, each of the following segments longer than 1.5 times.

Scutum moderately raised as normal in Nomada ("mesoscutum suddenly raised at the anterior margin" in original description). Scutellum moderately roundly raised, median furrow deep. Pygidial plate triangular at apical portion, shallowly notched at apex.

Fore femur slender. Apicomedian setae on hind tibia four in number, posteriormost seta long, thin, pale brown, others slightly shorter, robust, acute at apex, dark brown, evenly spaced.

Male.

Color: Head largely black; the following portions are bright yellow: mandible except apical one-third black, labrum, clypeus on apical half to apical two-thirds, malar area, lower paraocular area extending up along inner eye margin to level of antennal socket, line on genal area extending up shortly from hypostoma along lower outer eye margin in profile. Scape bright yellow anteriorly, black posteriorly, flagellar segments brown anteriorly or dark brown basally, paler apically, black posteriorly.

Mesosoma black except as follows: pronotal lobe pale brown, transversely elliptical bright yellow macula on dorsal surface of mesopleuron extending from anterior margin near to posterior margin of mesopleuron.

Metasoma dark brown, T1 pale brown on apical half, containing a pair of blackish spots in brown portion; the following portions are yellow: a pair of maculae each on T2 and T3 (the former round, larger, the latter elliptical, smaller), complete band each on $\mathrm{T} 4$ and $\mathrm{T} 5$, transverse elliptical macula on T6, medially upcurved band each on S2-6. In melanic specimens, yellow portions greatly reduced, each band interrupted widely in the middle, other portions outside yellow portions deeply black.

Legs pale to reddish brown, with lower posterior half of fore coxa bright yellow which is the same color as macula on mesopleuron); the following portions are black: fore and mid femora ventrally, hind femur except dorsally and apically; hind tibia darkened posteriorly. The black portions of femora variable in size ranging from restricted on basal narrow portion to reaching near to apex of segments.

Sculpture: As in female.

Vestiture: Vestiture on labrum white, longer on apical margin otherwise slightly shorter, strongly plumose, dense. That on clypeus and supraclypeal area similar to that on labrum, but appressed, obscuring the integument. That on lower genal area nearly hypostoma slight- ly longer than on apical margin of labrum.

Vestiture on scutum and scutellum pale brown, erect, weakly plumose, dense. That on mesopleuron whitish, strongly plumose, evidently longer than on scutum. That on posterolateral to dorsal surface of propodeum similar to that on scutum, but slightly longer and more strongly plumose, not forming hair patch.

Vestiture on ventral surface of fore femur longer than the maximum width of segment, that of mid femur shorter than the maximum width of segment. That on ventral surface of hind femur fine, sparse, erect, moderately long, straight.

Structure: Body length 7.5-10.5 mm. CD:UID:LID 50:49:42. OCD/LOD 1.7-1.8.

The following aspects are different from female: interantennal carina somewhat abruptly lowered anteriorly from level of anterior margin of antennal socket in profile; scape much wider than flagellar segments; relative length of FL1-3 1:2.7-2.8:2.1 (1:2:1.5 in original description of Nomada wakasana Tsuneki $=N$. icazt $i$ by Tsuneki [1973]), relative length to apical width of FL1 0.6 times, FL2 2.1 times, FL3 1.6 times, each of the following segments ranging from 1.4 to 1.6 times, tyloidea on FL1 absent, that on FL2 narrowly, highly raised, ridge-shaped occupying the apical one-third of posterior surface of the segment, those on the following segments slightly wider, not highly raised, occupying the apical half of posterior surface of each segment; scutellum moderately, roundly raised, median furrow usually shallow, sometimes narrow, very deep; pygidial plate with apex rounded, more or less deeply emarginated medially; hind femur slender; basoventral flattened surface narrow, shallowly depressed in posterior view; apicomedian setae on hind tibia much thinner and paler than in female, otherwise as in female.

Male terminalia: 7th metasomal sternum as in Fig. 48-A. 8th as in Fig. 48-B, C. Gonostylus thick, weakly curved mesad; vestiture very fine, simple, slightly sinuate apically; basoventral lobe weakly developed, with vestiture as on gonostylus. Penis valve produced posteriorly beyond gonostylus, apex extending beyond apex of gonostylus in lateral view. Gonocoxite with narrow dorsal invagination; inner dorsal lobe wider than long, with apex roundly triangular.

Distribution. Japan (Honshu, Shikoku, Kyushu, Tsushima Is.); South Korea (new record).

Specimens examined. Holotype (MNHAH), 우, attached with two labels as follows: "Sunayama, Ohno/ Fukui, Japan/ 1. V. 1968/ Y. HANEDA [white rectangle with handwritten letters. "Sunayama" written in Japanese]", "Nomada/ icazti 우/ Tsuneki/ Holotype [orange 
rectangle with handwritten letters]".

Other specimens: JAPAN [Honshu] Tochigi: Iwafune, Shimotsuga, 10', 11. iv. 1982, 2우, 18. iv. 1982 (Y. Suzuki, K. Nakamura Coll.). Saitama: Heirinji, Niizamachi, 2우10', 6. v. 1958, 3우, 9. v. 1958 (R. I., ELKU). Chiba: 1우, Mt. Guntarisan, Ichinomiya-machi, Chôsei-gun, 13. iv. 2002 (K. Kubo, H. Nagase Coll.). Niigata: 1우, Senami, 1. v. 1984 (K. Baba, ELKU). Fukui: 70', Shinjo-Mihama, 30. iv. 1978 (H. Kurokawa);

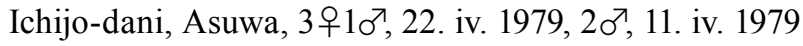
(Y. Haneda); 3우40 ', Ichijodani, 29. iv. 1980 (T. Tano); Asakura, Fukui-shi, 10', 19. iv. 1980, 4우, 11. v. 1980 (C. Nozaka); 2o', Kanamata-cho, Fukui-shi, 23. iv. 2006 (K. Mitai). Yamanashi: $2 \sigma^{\top}$, Nishizawakeikoku, Mitomi Vil., 28. v. 1980 (H. Suda). Gifu: 1우, Shirotori-chô, Gujô-gun, 14. v. 2004 (T. Sugimoto, ELKU). Shimane: 10', Inbe, 18. iv. 1982 (H. Shimizu, EBSU); $3 \sigma^{\top}$, Mt. Makuragi, 26. iv. 1982 (Y. Ono, EBSU); 2우, Nishikawatsu, Matsue City, 27. iv. 1983 (Y. Sasaki, EBSU); 1우, Mt. Sambe, 25. iv. 1992 (Y. Maeta). [Shikoku] Ehime: 10', Sugitake nr: Matsuyama, 19. iv. 1953 (T. Mohri, ELKU). [Kyushu] Fukuoka: 1우, Mt. Hikosan, 6. v. 1951 (Y. Hirashima, ELKU). Nagasaki: 10', Hitakatsu-Nishidomari, Gongenyama, Tsushima Is. ., 12. iv. 1941 (T. Shirozu, ELKU); 10', Izumi, Kamitsushima, Tsushima Is. 2. v. 1986 (O. Tadauchi, ELKU). SOUTH KOREA, 1우, Sam Jeon-Li, Ma Cheong-Myon, Hamyang-Gun, Kyon Sang Nam-Do, 1. v. 1992 (O. Tadauchi, ELKU).

Biology. It is a univoltine species, collected from mid April to May (Table 18). Floral associations are as follows: [Cruciferae] Brassica rapa. [Rosaceae] Rubus palmatus var. coptophyllus. The host is unknown.

Remarks. Tsuneki (1976) described Nomada wakasana and $N$. icazti in the same paper, based on one male and one female, respectively. Although these two "species" are rare (a total of 53 specimens examined in the present study), there were some occasions on which they are collected simultaneously. Therefore, it is concluded that they are conspecific. The same conclusion had been already pointed out by Haneda (1985).

In the case of female, the combination of the short first flagellar segment and the characteristic maculation on propodeum distinguish it from other similar species, for example Nomada fervens Smith, $N$. pyrifera Cockerell, and $N$. hakonensis Cockerell. The male is similar to males of $N$. fervens and $N$. amurensis Radoszkowsky of the first generation in the similar body color and the long second flagellar segment, but differs from them in the short first flagellar segments and the long apicomedian seta on hind tibia. It is also similar superficially to the male of $N$. panzeri orientis Tsuneki, but can be easily recognized by the long second flagellar segment. Other characters helpful in recognizing the male is the bright yellow maculae on dorsal side of mesopleuron, which, together with yellow macula on the anterior of fore coxa, gives appearance of a transversely long, yellow line crossing the lateral side of thorax.

Table 18. Seasonal change of number of the captured individual of N. icazti in Japan (Number of females indicates at the left of slash in cell, that of males at the right. E: early, M: mid, L: late).

\begin{tabular}{|c|c|c|c|c|c|c|c|}
\hline \multirow[b]{2}{*}{ Main island } & \multirow[b]{2}{*}{ Prefecture } & \multicolumn{3}{|c|}{ April } & \multicolumn{3}{|c|}{ May } \\
\hline & & $\mathrm{E}$ & $\mathrm{M}$ & $\mathrm{L}$ & $\mathrm{E}$ & $\mathrm{M}$ & $\mathrm{L}$ \\
\hline \multicolumn{8}{|l|}{ HONSHU } \\
\hline \multirow[t]{3}{*}{ [Kanto] } & Tochigi & & $2 / 1$ & & & & \\
\hline & Saitama & & & & $5 / 1$ & & \\
\hline & Chiba & & $1 /$ & & & & \\
\hline \multirow[t]{4}{*}{ [Chubu] } & Niigata & & & & $1 /$ & & \\
\hline & Fukui & & $/ 4$ & $6 / 14$ & & $4 /$ & \\
\hline & Yamanashi & & & & & & 12 \\
\hline & Gifu & & & & & $1 /$ & \\
\hline [Chugoku] & Shimane & & $/ 1$ & $3 / 3$ & & & \\
\hline SHIKOKU & Ehime & & $/ 1$ & & & & \\
\hline \multirow[t]{2}{*}{ KYUSHU } & Fukuoka & & & & $1 /$ & & \\
\hline & Nagasaki & & $/ 1$ & & $/ 1$ & & \\
\hline \multicolumn{2}{|l|}{ Total } & 0 & 11 & 26 & 9 & 5 & 2 \\
\hline
\end{tabular}


18. Nomada kaguya Hirashima, 1953

[Japanese name: Kaguya-kimadara-hanabachi]

(Figs. 50-52; Table 19)

Nomada kaguya Hirashima, 1953, Trans. Shikoku Ent. Soc., 3: 135-136 [Holotype: Female. Type locality: Omogo Valley, Ehime Pref., Shikoku, Japan]; Tsune- ki, 1973, Etizenia, 66: 107-109 [Redescription]; Alexander \& Schwarz, 1994, Univ. Kansas Sci. Bull., 55: 249 [in list].

\section{Redescription.}

Female.

Color: Head black, the following portions are yellow

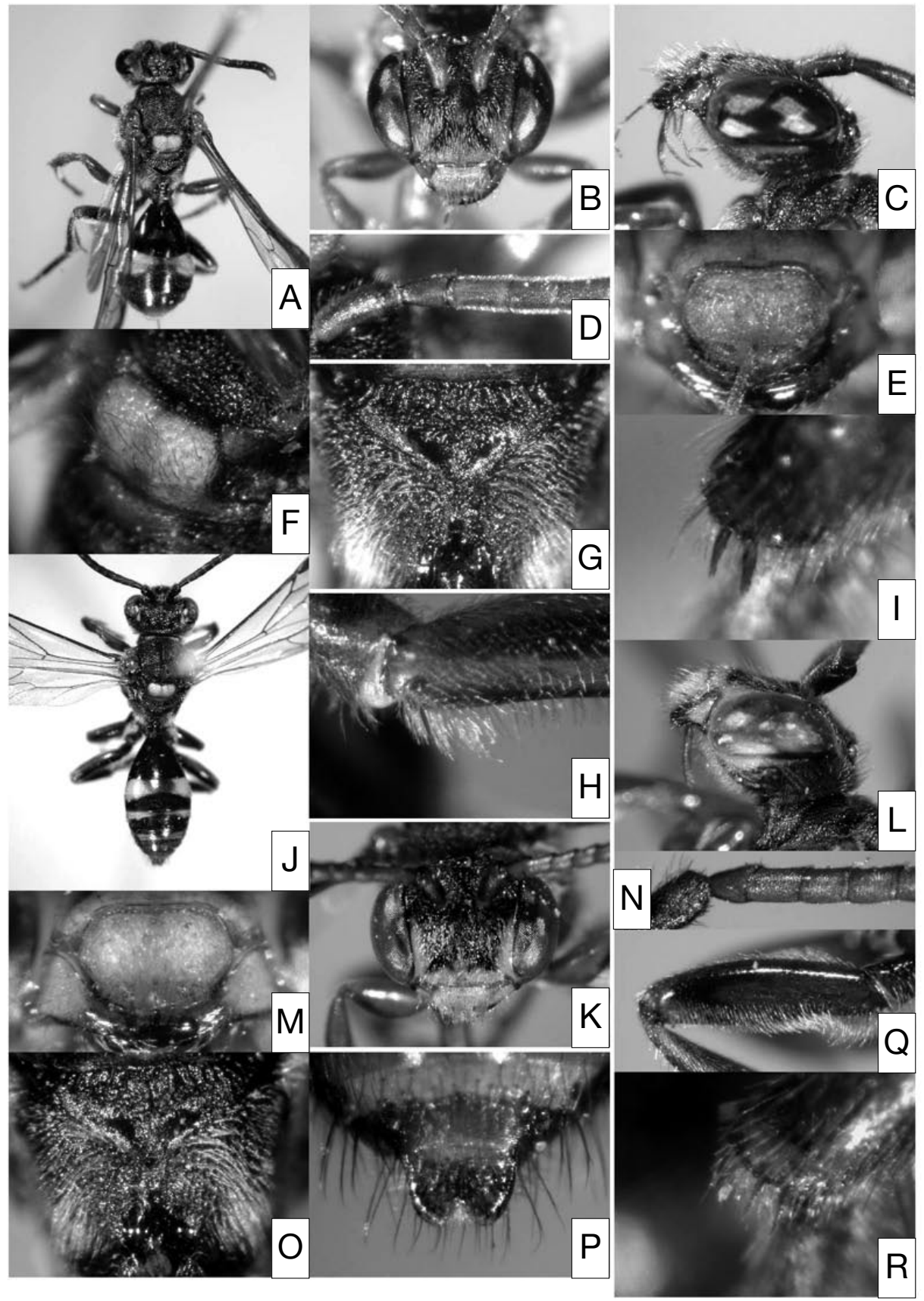

Fig. 50. Nomada kaguya Hirashima. Female: A-I. Male: J-R. A, J: habitus, dorsal view. B, C, K, L: head. D, N: antenna. E, M: labrum. F: scutellum. G, O, : propodeal triangle. H, Q: hind femur (H: anterior view; Q: posterior view). I. R: apicomedian setae on hind tibia. P: pygidial plate. 

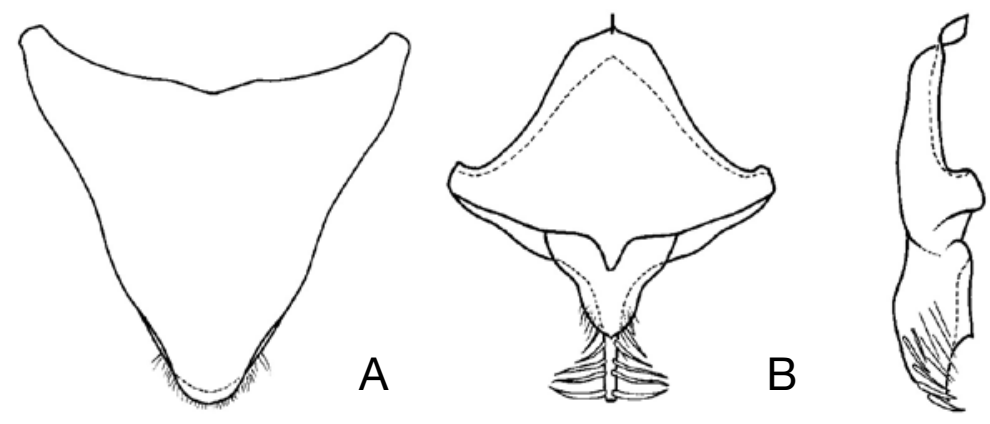

C
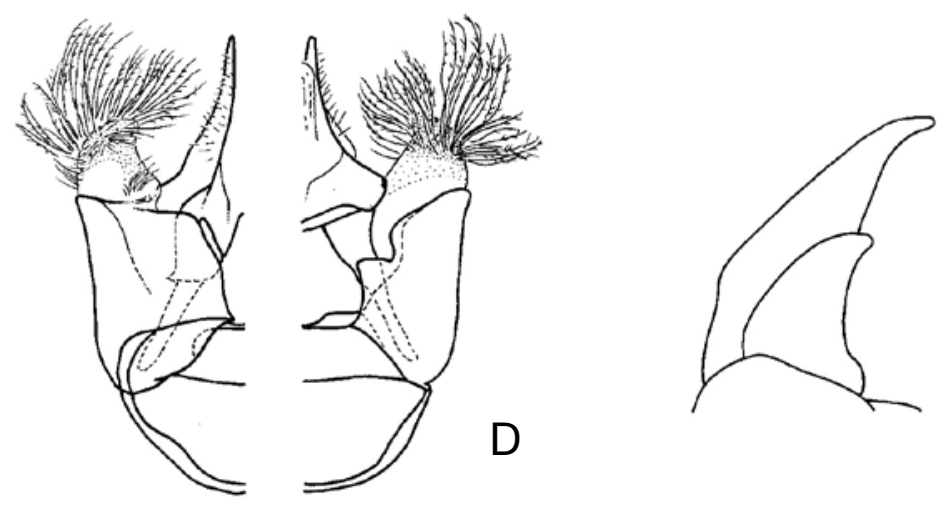

E

Fig. 51. Nomada kaguya (male). A: 7th metasomal sternum, ventral view. B: 8 th sternum, dorsal view. C: the same, lateral view. D: genital capsule (left, ventral view; right, dorsal view). E: penis valve and gonostylus, lateral view (vestiture omitted).

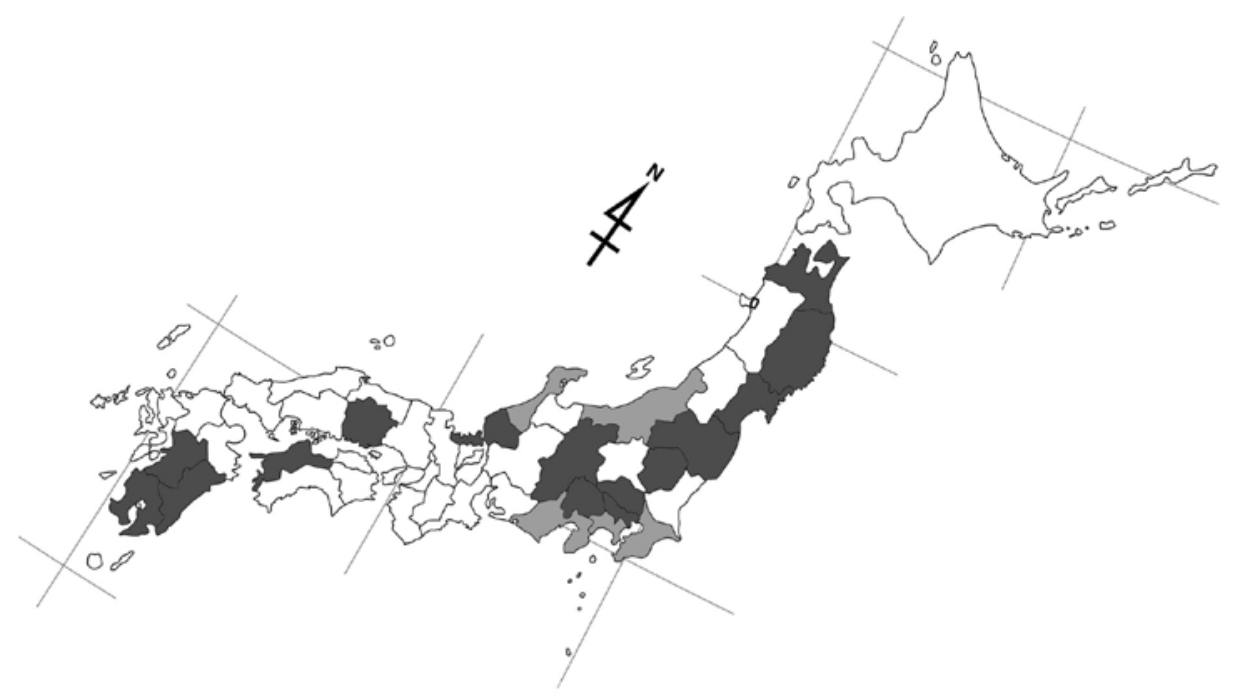

Fig. 52. Distribution of $N$. kaguya on the Japanese mainlands. Densely shaded: prefectures with the specimens in the present study. Lightly shaded: prefectures with records in literature, but no specimens examined in the present study. 
or yellow tinged with brown: mandible except apical one-fourth dark red or black, labrum, clypeus on apical half but sometimes nearly wholly yellowish brown except narrow margin along the epistomal suture, supraclypeal area but sometimes wholly black, malar area, lower paraocular area extending up along inner eye margin to top of compound eye, line on genal area extending along outer eye margin from hypostoma up to near vertex. The yellow along inner and outer eye margins not connected at vertex. Scape pale reddish brown with a black line on posterior surface, flagellar segments reddish brown anteriorly, darker posteriorly and much darker apically, except ultimate segment wholly reddish brown.

Mesosoma black; the following portions are yellow or yellowish brown: collar on the top, pronotal lobe, line along each lateral margin of scutum, tegula, axilla, scutellum (always wholly bright yellow), transverse macula on lateral surface of mesopleuron, which usually bright yellow medially, gradually tinged with brown peripherally, metanotum. Sometimes reddish brown spot present above hypoepimeral area.

Metasoma largely dark brown, T1 medially with vague pale brown macula which sometimes developed to band; the following portions are yellow: a pair of oval maculae each on T2 and T3 (the latter smaller, intermacular area on T2 pale brown) square macula T5 medially.

Legs pale brown to brown; the following portions are black or blackish: fore coxa basally, fore trochanter dorsally, fore femur basoventrally, mid coxa except narrowly apically, mid trochanter anteriorly and dorsally, mid femur basally, hind coxa except narrowly apically, hind trochanter anteriorly and dorsally, hind femur posteriorly except apical and basal narrow portions and anteriorly except basal half.

Sculpture: Punctures on labrum dense, distinct. Those on clypeus and supraclypeal area as on labrum.

Punctures on scutellum slightly shallower and sparser than on scutum. Mesopleuron deeply areolate. Lateral and dorsal sides outside triangle on propodeum areolate, evidently more weakly than on mesopleuron. Propodeal triangle coarsely irregularly rugose on basal half and central portion, rugae prominent highly raised, the remaining portion tessellate or smooth. Pygidial plate with punctures obliterated, sparse, interpunctural space slightly imbricate.

T1 polished, impunctate, the following terga faintly microsculptured, virtually impunctate.

Vestiture: Vestiture on labrum yellowish, plumose, long on apical margin, otherwise much shorter. That on clypeus and supraclypeal area appressed, short, finely plumose, sparser than those on labrum, integument of clypeus clearly can be seen. That on lower genal area near hypostoma much shorter than on labrum.

Vestiture on scutum and scutellum brown, sparse, simple very short, slightly longer on scutellum. That on mesopleuron weakly plumose, whitish, moderately dense, suberect or nearly appressed. That on posterolateral to dorsal surface of propodeum outside triangle, whitish, somewhat tinged with golden, suberect to appressed, strongly plumose, more or less dense but integument can be seen.

T1 hairless, the following terga with sparse, minute pubescence; T3 laterally with a loose patch of appressed, plumose, white hairs, a similar patch discernible on T4 laterally, but much smaller, largely hidden under translucent margin of T3. Pseudopygidium small, composed of not strongly modified hairs. Pygidial plate covered by fine, sparse hairs.

Fore coxa covered with appressed, plumose, white hairs on anterior portion. Vestiture on basal ventral surface somewhat longer and denser than the remaining portion, suberect, posteriorly directed.

Structure: Body length 7-7.5 mm, $4.5 \mathrm{~mm}$ in one extraordinarily small specimen. CD:UID:LID 50:48:42. OCD/LOD 1.1 .

Interantennal elevation moderately raised. Inner eye margins moderately convergent below. Clypeus weakly raised and produced anteriorly. Labrum 1.5 times as wide as long; three distinct teeth arranged in a line on subapical margin, median tooth conical, other two flat, triangular; apical portion not upcurved; apical margin not serrated. Mandible comparatively wide, blunt at apex. Preoccipital ridge rounded behind vertex, angulated or carinated apically. Relative length of FL1-3 1:1.3:1.1, relative length to apical width of FL1 1.4-1.5 times, FL2 2.0 -2.1 times, FL3 1.7 times, each of the following segments more than 1.5 times.

Scutellum moderately roundly raised, median furrow very shallow. Mesopleuron distinctly roundly concave around scrobe, evidentely, but not strongly convex just above this concavity. Pygidial plate yellowish brown, lateral margin obtusely angulated, widely emarginated or truncate at apex.

Fore femur moderately built. Apicomedian setae on hind tibia three to five in number, all the same in length, relatively short, posteriormost seta slender, pale brown, difficult to discern among surrounding hairs, frequently lacking probably because of drop-out, others somewhat flattened, acute at apex, dark brown.

Male.

Color: Head and mesosoma similar to those in fe- 
Table 19. Seasonal change of number of the captured individual of N. kaguya in Japan (Number of females indicates at the left of slash in cell, that of males at the right. E: early, M: mid, L: late).

\begin{tabular}{|c|c|c|c|c|c|c|c|c|c|c|}
\hline \multirow[b]{2}{*}{ Main island } & \multirow[b]{2}{*}{ Prefecture } & \multicolumn{3}{|c|}{ August } & \multicolumn{3}{|c|}{ September } & \multicolumn{3}{|c|}{ October } \\
\hline & & $E$ & $M$ & $\mathrm{~L}$ & $\mathrm{E}$ & $\mathrm{M}$ & $\mathrm{L}$ & $E$ & M & $\mathrm{L}$ \\
\hline \multicolumn{11}{|l|}{ ב HONSHU } \\
\hline \multirow[t]{4}{*}{ [Tohoku] } & Aomori & & & $/ 1$ & & & & & & \\
\hline & Iwate & & & $1 / 4$ & & & & & & \\
\hline & Miyagi & & & $/ 1$ & & & & & & \\
\hline & Fukushima & & $/ 1$ & $1 /$ & & & & & & \\
\hline \multirow[t]{3}{*}{ [Kanto] } & Tochigi & & & & $2 /$ & 13 & $2 /$ & & & $1 /$ \\
\hline & Saitama & & $/ 2$ & & $/ 1$ & $2 / 5$ & & & & \\
\hline & Tokyo & & & & & & $1 /$ & & & \\
\hline \multirow[t]{3}{*}{ [Chubu] } & Fukui & & & $1 / 3$ & & & $1 / 1$ & & & \\
\hline & Yamanashi & & $1 / 4$ & $2 / 3$ & $2 / 1$ & $1 /$ & $2 /$ & & & \\
\hline & Nagano & & $/ 1$ & & & $/ 1$ & & & & \\
\hline [Chugoku] & Okayama & & & & $3 / 1$ & & & & & \\
\hline SHIKOKU & Ehime & & & & $1 /$ & & & & & \\
\hline \multirow[t]{3}{*}{ KYUSHU } & Kumamoto & & & & $1 /$ & $2 / 3$ & $1 /$ & & & \\
\hline & Miyazaki & 12 & & & 15 & $2 /$ & & & & \\
\hline & Kagoshima & & & & & & & $/ 1$ & & \\
\hline \multicolumn{2}{|l|}{ Total } & 2 & 9 & 17 & 17 & 19 & 8 & 1 & 0 & 1 \\
\hline
\end{tabular}

male except as follows: yellow portion on head brighter, supraclypeal area always black, antenna black posteriorly, scutum black wholly, spot on anterior surface of mesopleuron smaller or lacking.

T1 and T2 similar to female, T3 and T4 each with a brownish yellow band, sometimes narrowly interrupted in the middle, T5 with transverse elliptical macula.

Legs as in female, but black portions more developed, sometimes posterior surface of hind coxa to tibia black wholly.

Sculpture: Punctures on clypeus larger and sparser than on labrum, separated by a puncture diameter apart in places, larger and sparser than on female, otherwise as in female.

Vestiture: Vestiture on face finer, less plumose, otherwise as in female. Vestiture on mesopleuron evidentely whitish and that on propodeum sparser than on female, otherwise on mesosoma as in female. That on propodeum evidently sparser than in female, otherwise as in female. Loose hair patch each on lateral portion of T2-4, composed of more strongly plumose than in female.

Vestiture on ventral surfaces of fore- and mid femora sparse, much shorter than the maximum width of each segment. That on ventral surface of hind femur long plumose, that on basal portion of flattened surface appressed basally, then upcurved and erect, apically curved toward apex of segment, that on apical portion of flattened surface appressed toward base of segment, hairs on posterior margin of flattened surface erect.

Structure: Body length 7-8 mm. CD:UID:LID 50:50:40. OCD/LOD 1.5.

The following aspects are different from female: preoccipital ridge rounded behind vertex, angulated apically; scape somewhat wider than flagellar segments; relative length of FL1-3 1:1.5:1.3, relative length to apical width of FL1 equal, FL2 1.7 times, FL3 1.5 times; pygidial plate weakly tapering toward apex, sometimes lateral margins nearly parallel, the apex wide, deeply, triangularly emarginated.

Fore femur robust, dilated medially. Hind femur slender; basoventral flattened surface narrow, not reaching to midpoint of segment, evidently depressed in posterior view. Apicomedian setae on hind tibia three or four in number, much slenderer and paler than in female, otherwise as in female.

Male terminalia: 7th metasomal sternum as in Fig. 51-A. 8th as in Fig. 51-B, C. Gonostylus thick, short; vestiture long, strongly plumose, moderately dense, basoventral lobe absent, but moderately long simple vestiture on the corresponding portion. Penis valve strongly produced posteriorly beyond gonostylus, apex 
not extending beyond apex of gonostylus in lateral view. Gonocoxite with shallow dorsal invagination; inner dorsal lobe produced triangularly.

Distribution. Japan (Honshu, Shikoku, Kyushu).

Specimens examined. Holotype (ELKU), 우, attached with two labels as follows: "[Shikoku]/ Omogo/ (Iyo)/ 7. ix. 1951/ Y. Hirashima (white rectangle and typed)", "Holotype/ Nomada kaguya/ Hirashima, 1953 (pale orange rectangular with handwritten letters)".

Other specimens: We have examined about $30 \mathrm{fe}-$ males and 45 males. On the localities, see Fig. 52. Some of them are listed as follows: JAPAN [Honshu] Miyagi: 107, Aone-onsen, 25. viii. 1970 (T. Nambu). [Kyushu] Miyazaki: Ebino Highland, Ebino-shi/Kobayashi-shi, 2 우, 16. ix. 2003, $2 \sigma^{\nearrow, ~ 5 . ~ v i i i . ~ 2004, ~} 5 \sigma^{\nearrow}$, 3. ix. 2004 (K. Mitai).

Biology. It is a univoltine species, collected from early August to late October (Table 19). Floral associations are as follows: [Compositae] Kalimeris pinnatifida, Kalimeris yomena, Picris hieracioides var. glabrescens, Stenactis annuus.

Suda (1980) reported the frequent co-occurrence of Nomada kaguya and Lipotrichus yasumatsui (Hirashima) (cited as Rhopalomelissa yasumatsui) and the observation of the former entering into the nests of the latter in Yamanashi Pref., Honshu. This host association is proven by Maeta et al (1996) who excavated the nests of L. yasumatsui in Iwate Pref., Honshu and gathered the prepupae, which were identified as N. kaguya after eclosion.

Remarks. This species can be easily recognized from other summer-to-autumn congeners by the wholly bright yellow scutellum in both sexes. It is similar to Nomada aswensis Tsuneki in the wholly yellow scutellum and the propodeum with the dense vestiture, but differs from it by the normally needle-shaped apicomedian setae on hind tibia (flattened, slender leaf-shaped in $N$. aswensis) and the different flight season (active in spring in N. aswensis).

19. Nomada kinosukei Tsuneki, 1973

[Japanese name: Kinosuke-kimadara-hanabachi] (Figs. 53-55; Table 20)

Nomada kinosukei Tsuneki, 1973, Etizenia, 66: 107-109 [Holotype: Female. Koike, Fukui Pref., Honshu, Japan]; Alexander \& Schwarz, 1994, Univ. Kansas Sci. Bull., 55: 249 [in list].

Redescription. (male new to science) Female.
Color: Head black, the following portions are pale brown: mandible with one-fifth dark red, labrum, clypeus, supraclypeal area, malar area, lower paraocular area extending up narrowly along inner eye margin to level of antenna sockets, spot along top of compound eye, line along outer eye margin extending up beyond midpoint of compound eye in profile. Antenna yellowish brown anteriorly, scape and basal half of flagellum darker, paler apically.

Mesosoma black; the following portions are yellow or yellowish brown: collar on the top, pronotal lobe, line each along lateral margin of scutum, axilla, scutellum largely except median furrow black (usually these maculae on dorsal portion of mesosoma bright yellow), large maculae on lateral surface of mesopleuron, metanotum. Posterolateral corner of propodeum tinged with vague reddish brown.

Metasoma largely brown to dark brown, T1 black on basal half, basal half of T2 brown with a pair of vague yellow spots laterally, T3 and T4 dark brown each with a pair of subobsolete spots laterally, T5 with square dark yellow macula medially.

Legs yellowish brown, tinged with yellow on apical margin of all coxae; the following portions are blackish: fore trochanter posteriorly, fore femur apicoventrally, fore tibia posteriorly, mid femur except narrowly both apically and basally, mid tibia posteriorly, hind trochanter posteriorly, hind femur and tibia except apical annular portion of tibia.

Sculpture: Punctures on labrum dense, small, indistinct. Those on clypeus and supraclypeal area distinct, larger than on labrum, slightly deeper on supraclypeal area.

Punctures on scutellum as on scutum. Mesopleuron areolate shallowly, much wider and somewhat deeper on hypoepimeral area. Lateral and dorsal sides outside triangle of propodeum densely areolate, denser than on mesopleuron, except sparsely rugose portion under spiracle. Propodeal triangle irregularly rugose on basal half and central portion, the remaining portion tessellate. Pygidial plate with punctures considerably sparse, the interpunctural space smooth.

All terga nearly smooth, polished, without punctures.

Vestiture: Vestiture on labrum short, plumose, longer on apical portion, pale brown, not intermixed with simple blackish bristles. That on clypeus and supraclypeal area appressed, short, plumose, pale brown, sparser than those on labrum, surface of clypeus clearly can be seen. That on lower genal area near hypostoma short, as long as or slightly shorter than on labrum, weakly plumose. 
Vestiture on scutum and scutellum sparse, simple, dark brown tinged with golden, suberect on scutum, erect on scutellum. That on mesopleuron as long as on scutellum, strongly plumose, whitish. That on posterolateral surface of propodeum outside triangle short, partially dense, and plumose.

T1 hairless, the following terga with minute, considerably sparse pubescence. Pseudopygidium well developed composed of greatly modified scale-like hairs.
Pygidial plate covered with sparse, brown hairs.

Structure: Body length $5 \mathrm{~mm}$. CD:UID:LID 50:50:43. OCD/LOD 1.2.

Interantennal elevation moderately raised, with highly raised keeled carina. Inner eye margins strongly convergent below. Clypeus weakly raised and produced. Labrum 1.6 times as wide as long; labral tooth present slightly before the middle, accompanied by longitudinal and obliquely transverse carinae; apical portion not

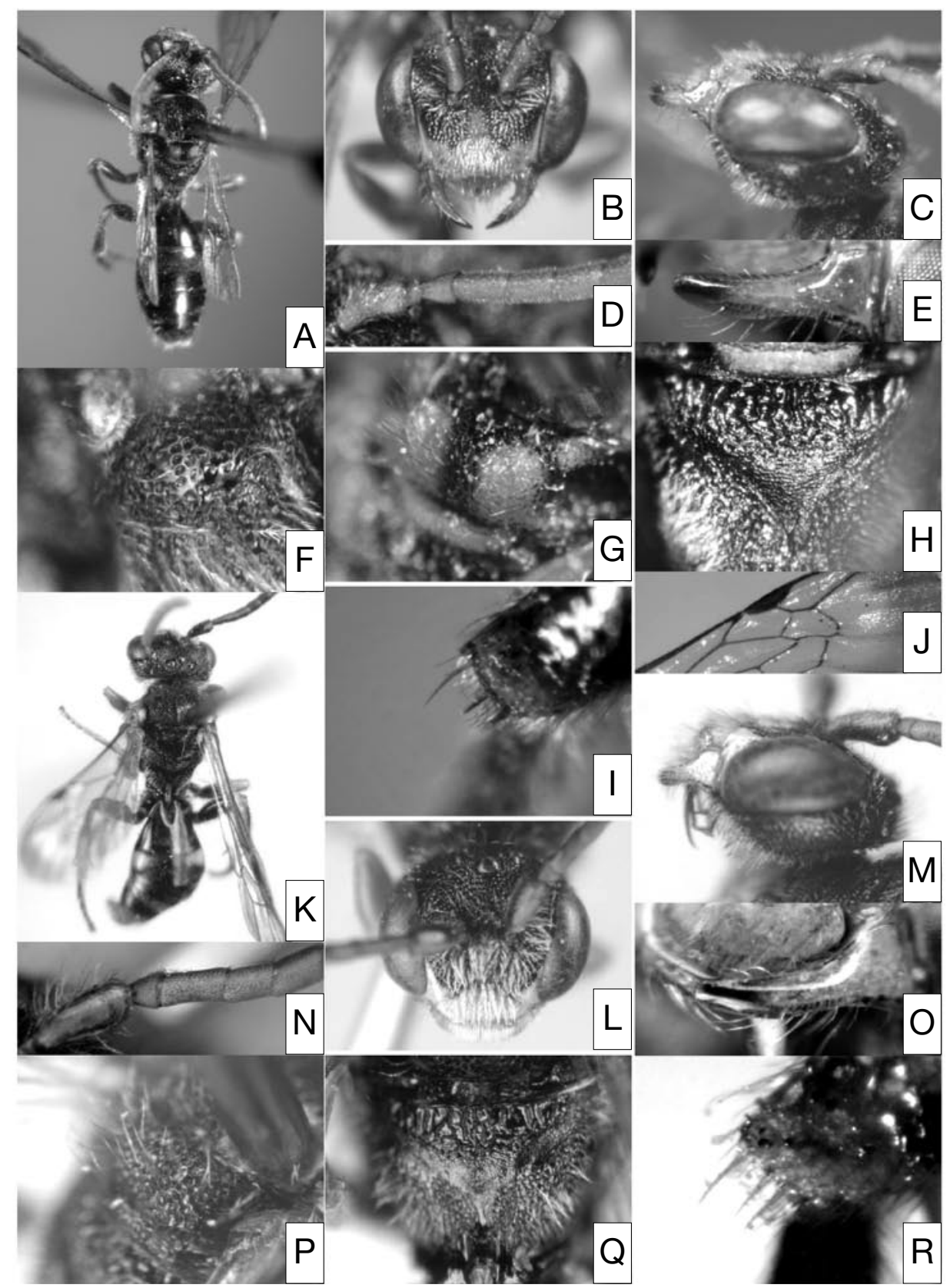

Fig. 53. Nomada kinosukei Tsuneki. Female: A-J. Male: K-R. A, K: habitus, dorsal view. B, C, L, M: head. D, N: antenna. E, O: mandible. F: hypoepimeral area. G, P: scutellum. H, Q: propodeal triangle. I, R: apicomedian setae on hind tibia. J: submarginal cells in fore wing. 

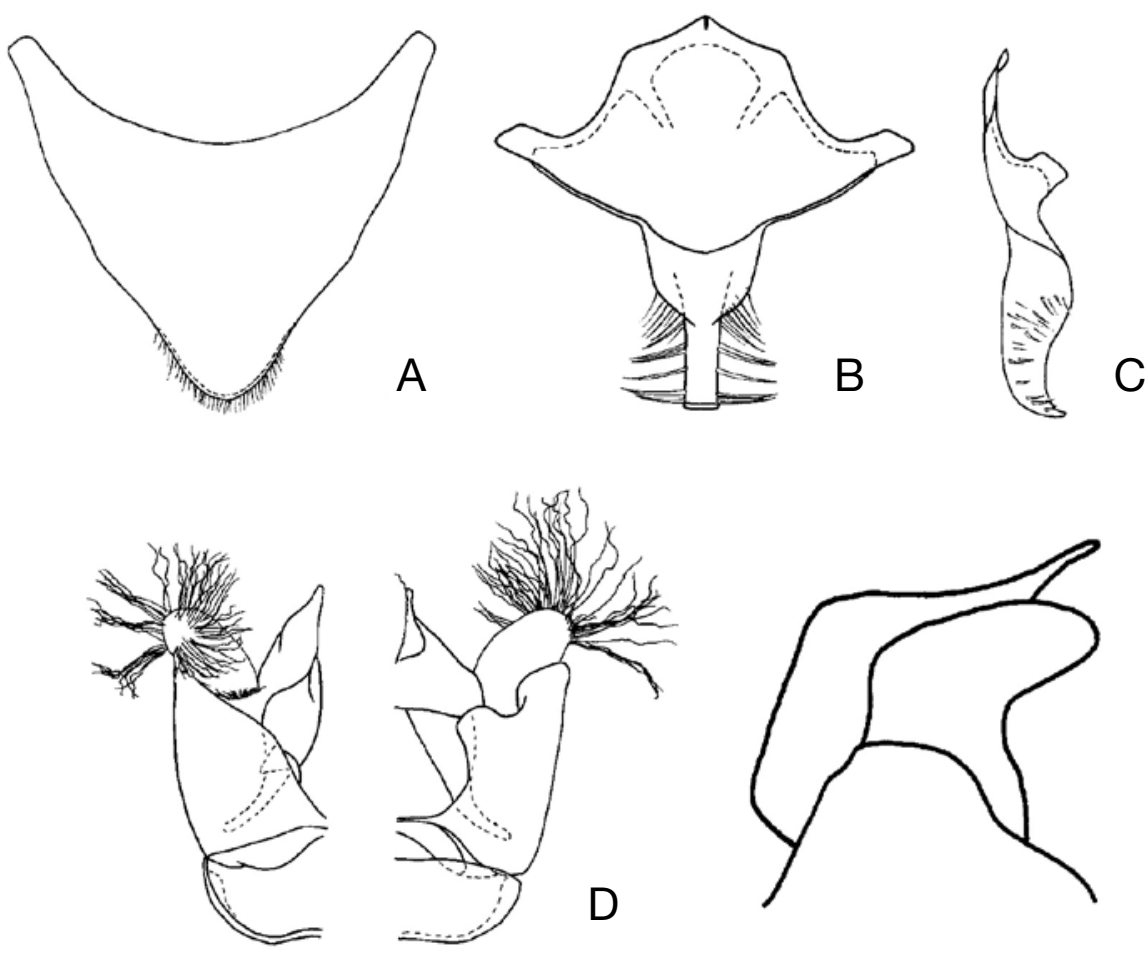

$E$

Fig. 54. Nomada kinosukei (male). A: 7th metasomal sternum, ventral view. B: 8th sternum, dorsal view. C: the same, lateral view. D: genital capsule (left, ventral view; right, dorsal view). E: penis valve and gonostylus, lateral view (vestiture omitted).

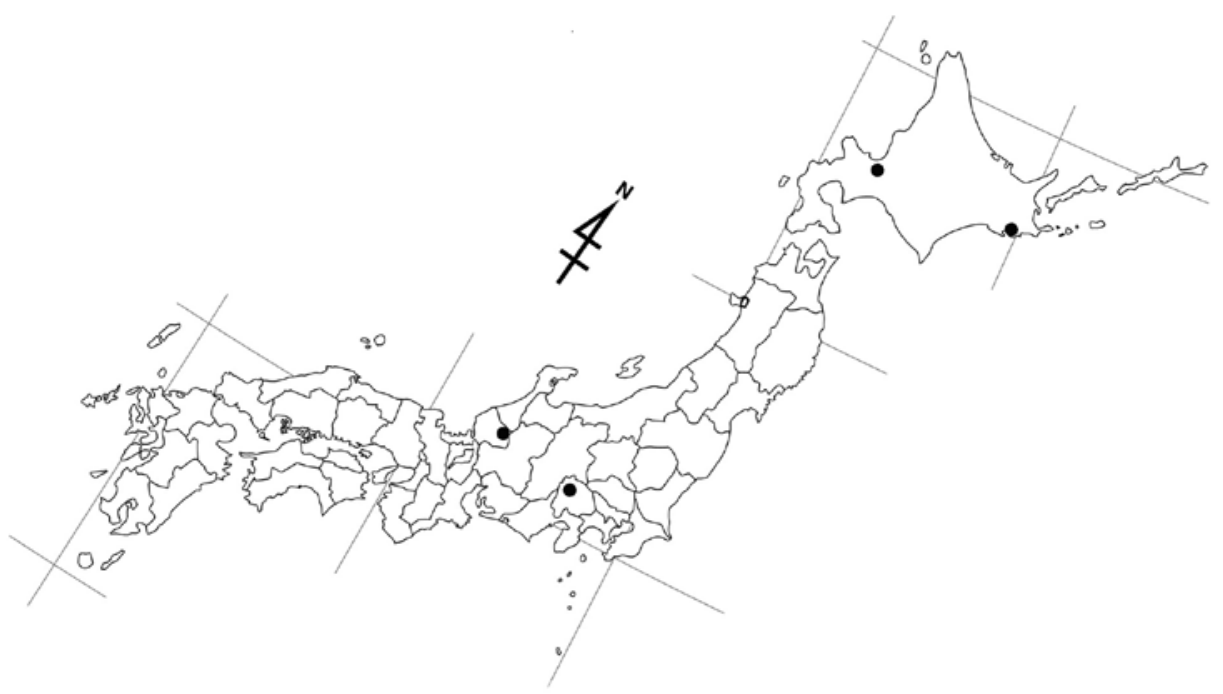

Fig. 55. Distribution of $N$. kinosukei on the Japanese mainlands. Dots: localities of the specimens examined in the present study. 
upcurved; apical margin nor serrated. Mandible comparatively wide, blunt at apex. Preoccipital ridge angulated. Relative length of FL1-3 1:1.5:1.3, relative length to apical width of FL1 1.1 times, FL2 1.8 times, FL3 1.6 times.

Scutellum moderately roundly raised, median furrow very shallow. Pygidial plate pale brown, narrowly triangular at apical portion.

Fore femur moderately built. Apicomedian setae on hind tibia three or four in number, pale brown, straight, evenly spaced, posteriormost seta longer, others slightly thicker.

Fore wing with two submarginal cells of roughly equal size.

Male.

Color: Head black; the following portions are yellow: mandible except apical two-fifths blackish, labrum, clypeus except upper margin, malar area, lower paraocular area extending up along inner eye margin, not reaching to level of lower margin of antennal socket, very small spot along top of compound eye. Antenna brown anteriorly, dark brown posteriorly.

Mesosoma black with pronotal lobe and tegula yellowish brown.

Metasoma black, each tergum paler apically, T2 and $\mathrm{T} 3$ each with a pair of vague yellow spots, that on T3 partially hidden under the preceding terga, $\mathrm{T} 5$ with a large vague yellowish brown macula. All coxae black except apical margin paler, fore femur and tibia yellowish brown except ventral surface black, mid femur black except apical annular portion and posterior surface yellowish brown, mid tibia yellowish brown except ventral surface dark brown, hind femur dark brown except apical annular portion and apical dorsal surface yellowish brown.

Sculpture: As in female except pygidial plate covered by large, obliterated punctures.

Vestiture: Vestiture on labrum yellowish, strongly plumose, dense, longer on apical portion. That on clypeus and supraclypeal area similar to that on labrum, but appressed, obscuring the integument. That on lower genal area near hypostoma as long as on labrum. That on scutum as long as on vertex, simple, posteriorly directed.

Vestiture on scutellum evidently longer than that on vertex, weakly plumose, erect. That on mesopleuron strongly plumose, slightly longer than on scutellum, whitish, moderately dense. That on posterolateral to dorsal surface of propodeum outside triangle whitish, plumose, much shorter than on scutellum, sparse, not forming hair patch.
Metasoma as in female

Vestiture on ventral surface of all femora very short, much shorter than half of maximum width of each segment, that on hind femur weakly plumose, appressed, directed posteriorly. That on ventral surface of hind femur sparse, fine, suberect short.

Structure: Body length $5 \mathrm{~mm}$. CD:UID:LID 50:50:49. OCD/LOD 1.5.

The following aspects are different from female: interantennal carina raised higher than female, lowered abruptly anteriorly from level of anterior margin of antennal socket in profile; labrum nearly flat, 1.6 times as wide as long; three teeth in a lower triangle, median tooth conical, located in the center, other two flat, triangular; apical portion not upcurved; apical margin not serrated; preoccipital ridge angulated; scape evidently wider than flagellar segments; relative length of FL1-3 1:2.1:1.7, relative length to apical width of FL1 0.7 times, FL2 1.8 times, FL3 1.4-1.5 times; pygidial plate shallowly emarginated at apex; hind femur slender; basoventral flattened surface indistinct, ventral margin of segment straight in posterior view; apicomedian setae on hind tibia somewhat slenderer than in female, otherwise as in female.

Male terminalia: 7th metasomal sternum as in Fig. 54-A. 8th as in Fig. 54-B, C. Gonostylus thick, short, rounded at apex; vestiture long, simple, moderately dense, strongly sinuate; basoventral lobe absent, but moderately long simple vestiture on the corresponding portion. Penis valve produced posteriorly beyond gonostylus, apex greatly narrowed apically, not extending beyond apex of gonostylus in lateral view. Gonocoxite with moderately deep dorsal invagination; inner dorsal lobe as wide as long, with apex truncate.

Distribution. Japan (Hokkaido, Honshu).

Specimens examined. Holotype (MNHAH), 우, attached with two labels as follows: "Koike/ Fukui, Japan/ 17. VIII. 1972/ K. Tsuneki (white rectangle and typed except "Koike" handwritten in Japanese and collecting date also handwritten)", "Nomada/ kinosukei/ Tsuneki 우/ HOLOTYPE (red rectangle with handwritten letters)".

Other specimens: JAPAN [Hokkaido] 1우, Akkeshi, 15. vii. 1967 (Matsumura, MNHAH); Moiwa, 3. vii. 1972 (Kawano, MNHAH). [Honshu] Fukui: Arashi, Ohno, 10', 23. viii. 1974 (Y. Haneda), 1우, 23. viii. 1976 (T. Tano), 1우10', 27. viii. 1976 (Y. Haneda). Yamanashi: 1우, 9-10. ix. 1975 (J. Emoto, MNHAH).

Biology. It is an extremely rare species, collected from early July to early September (Table 20). The host and floral association are unknown. 
Table 20. Seasonal change of number of the captured individual of $N$. kinosukei in Japan (Number of females indicates at the left of slash in cell, that of males at the right. E: early, M: mid, L: late).

\begin{tabular}{|c|c|c|c|c|c|c|c|c|c|c|}
\hline \multirow[b]{2}{*}{ Main island } & \multirow[b]{2}{*}{ Prefecture } & \multicolumn{3}{|c|}{ July } & \multicolumn{3}{|c|}{ August } & \multicolumn{3}{|c|}{ September } \\
\hline & & $\mathrm{E}$ & $\mathrm{M}$ & $\mathrm{L}$ & $\mathrm{E}$ & $\mathrm{M}$ & $\mathrm{L}$ & $\mathrm{E}$ & M & L \\
\hline HOKKAIDO & & $1 /$ & $1 /$ & & & & & & & \\
\hline \multicolumn{11}{|l|}{ HONSHU } \\
\hline [Chubu] & Fukui & & & & & & $2 / 2$ & & & \\
\hline & Yamanashi & & & & & & & $1 /$ & & \\
\hline Total & & 1 & 1 & 0 & 0 & 0 & 4 & 1 & 0 & 0 \\
\hline
\end{tabular}

Remarks. This species, like Nomada koikensis Tsuneki, is characteristic in the two submarginal cells in fore wing. It can be separated from N. koikensis by the large yellow or orange maculae on scutum, scutellum and metanotum in female, the loose hair patch on propodeum in female, the 13-segmented antenna in male. It is also similar to the first generation of Nomada flavoguttata (Kirby), but differs from it in having the two submarginal cells in the fore wing, and the sparser and more widened punctures on the hypoepimeral area than on the neighboring areas.

The record of this species from Tochigi Pref. (Ikudome, 2002) was based on misidentification.

20. Nomada leucophthalma (Kirby, 1802) [Japanese name: Kuro-kimadara-hanabachi]

(Figs. 56, 57; Table 21)

Apis leucophthalma Kirby, 1802, Monographia Apum Angliae, 2: 197 [Holotype: Male. Type locality: Barham, Kent, England].

Nomada leucophthalma : Alexander \& Schwarz, 1994, Univ. Kansas Sci. Bull., 55: 249 [in list].

Nomada kuro Tsuneki, 1986, Spec. Publ. Hym. Assoc., (32): 52 [Holotype: Female]; Alexander \& Schwarz, 1994, Univ. Kansas Sci. Bull., 55: 249 [in list]. syn. nov.

Nomada muinensis Tsuneki, 1986, Spec. Publ. Hym. Assoc., (32): 53-54 [Holotype: Male]; Alexander \& Schwarz, 1994, Univ. Kansas Sci. Bull., 55: 250 [in list]. syn. nov.

\section{Redescription.}

\section{Female.}

Color: Head largely black, the following portions are reddish brown: mandible except apical one-fourth or one-fifth dark red, labrum, clypeus on apical two-thirds to apical half, malar area, thin line along compound eye, the line expands mesally at top of compound eye but sometimes thinner or interrupted at midpoints of inner and outer eye margins. Sometimes a vague reddish brown spot present on supraclypeal area. Antennae wholly pale brown or darker posteriorly.

Mesosoma black; the following portions are reddish brown: anterior margin of pronotum, collar on the top, pronotal lobe, tegula, axilla, usually four well-separated longitudinal lines on scutum, scutellum wholly, a spot on hypoepimeral area but rarely lacking, a large macula below mesopleuran scrobe (these two maculae on mesopleuron not connected, rarely greatly smaller), two pairs of macula on dorsal surface of propodeum. Maculae on propodeum variable in size: one pair in triangle, the other on lower dorsal; rarely wholly black, or rarely they fused into a pair of large maculae occupying dorsal surface nearly wholly. The black lines on scutum sometimes greatly thinner but rarely widely developed and fused into a pair of large maculae.

Metasoma reddish brown to blackish, T1 black on basal half and narrow apical margin, T2 black on basal narrow margin; the following portions are yellow: a pair of triangular maculae on T2, a pair of small spots on T3 but sometimes lacking, yellow band on T4 (sometimes narrowly interrupted medially, roughly square macula on T5 medially. Each sternum irregularly black on basal margin.

Legs largely reddish brown; the following portions are black: all coxae basally and posteriorly, all femora on narrowly annular portions and hind femur posteriorly. Sometimes the black on basal femora wider, occupying basal one third of segment.

Sculpture: Punctures on labrum small and indistinct, sparse, the interpunctural area polished. Those on clypeus and supraclypeal area larger and more distinct, on clypeus becoming indistinct apically.

Punctures on scutellum smaller and denser than those on scutum. Mesopleuron moderately areolate. Lateral and dorsal sides outside triangle of propodeum densely areolate, denser than on mesopleuron wholly or 
except rugose portion under spiracle. Propodeal triangle roundly convex medially, irregularly coarsely rugose largely except tessellate portion along apicolateral margin of triangle.

Terga faintly microsculptured, with dense and indistinct punctules. Pygidial plate with small, dense punctures, impunctate margin narrow.

Vestiture: Vestiture on labrum, clypeus and supra- clypeal area inconspicuous, very short, sparse; that on apical margin of labrum longer; that on clypeus and clypeal area appressed. That on lower genal area near hypostoma much longer than on apical margin of labrum, moderately dense.

Vestiture on scutum and scutellum pale brown tinged with golden, short, erect or suberect, minutely plumose or simple. That on mesopleuron whitish, much

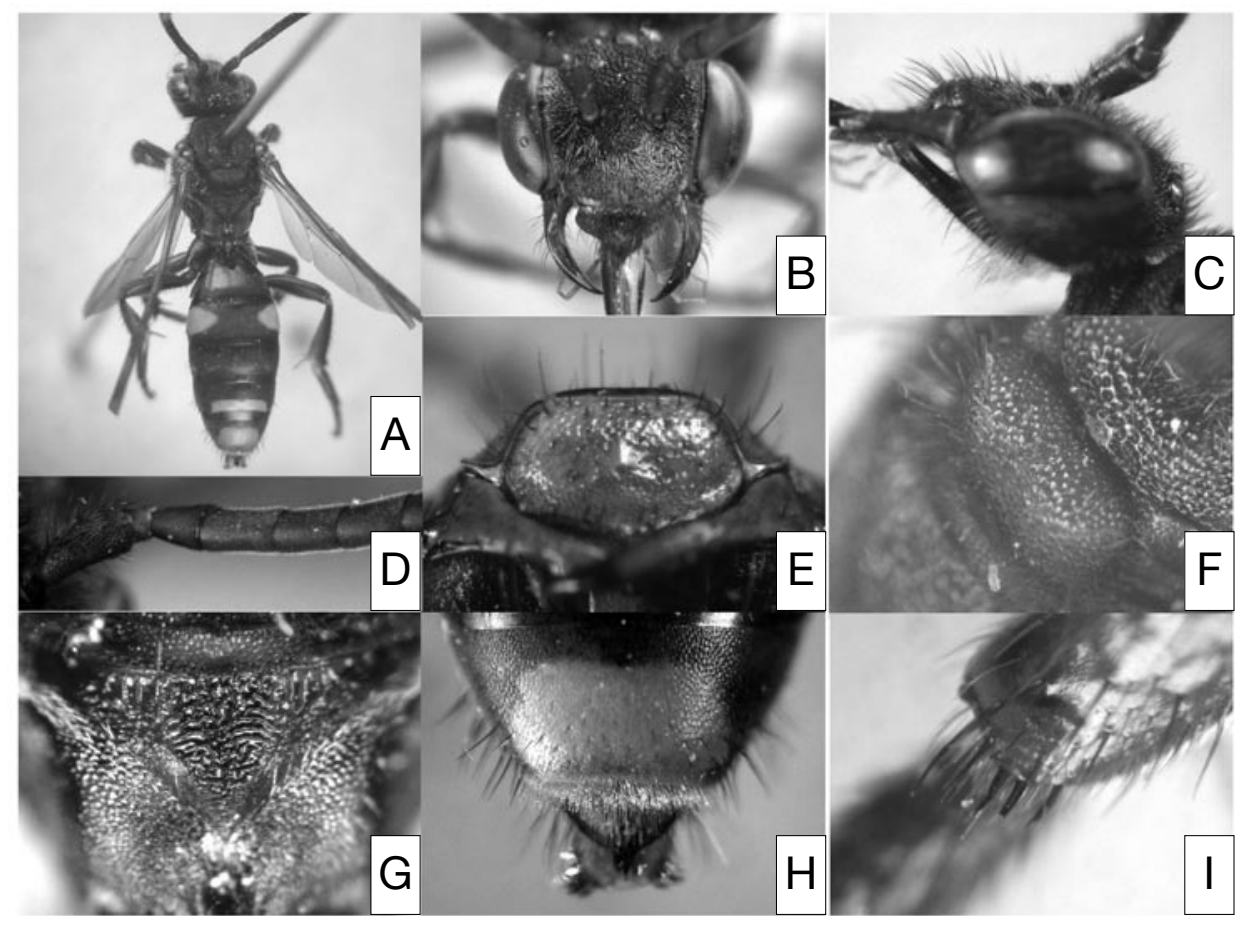

Fig. 56. Nomada leucophthalma (Kirby) (female). A: habitus, dorsal view. B, C: head. D: antenna. E: labrum. F: scutellum. G: propodeal triangle. H: pseudopygidium. I: apicomedian setae on hind tibia.

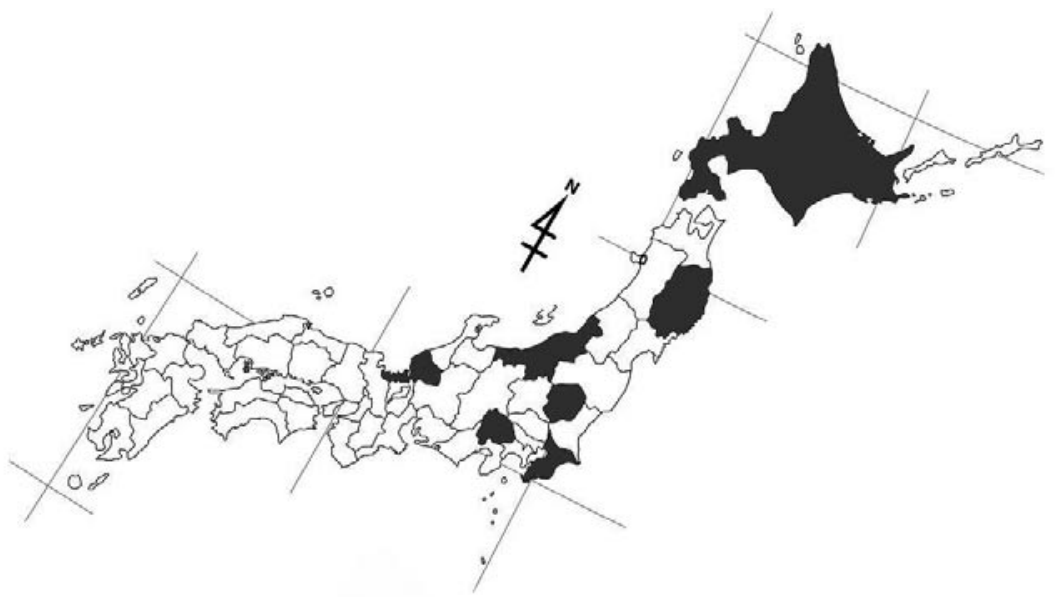

Fig. 57. Distribution of $N$. leucophthalma on the Japanese mainlands. Shaded: prefectures with the specimens examined in the present study. 
Table 21 . Seasonal change of number of the captured individual of $N$. leucophthalma in Japan (Number of females indicates at the left of slash in cell, that of males at the right. E: early, M: mid, L: late).

\begin{tabular}{|c|c|c|c|c|c|c|c|c|c|c|c|c|c|}
\hline \multirow[b]{2}{*}{ Main island } & \multirow[b]{2}{*}{ Prefecture } & \multicolumn{3}{|c|}{ April } & \multicolumn{3}{|c|}{ May } & \multicolumn{3}{|c|}{ June } & \multicolumn{3}{|c|}{ July } \\
\hline & & $\mathrm{E}$ & $\mathrm{M}$ & $\mathrm{L}$ & $\mathrm{E}$ & $\mathrm{M}$ & $\mathrm{L}$ & $\mathrm{E}$ & $\mathrm{M}$ & $\mathrm{L}$ & $\mathrm{E}$ & $\mathrm{M}$ & $\mathrm{L}$ \\
\hline HOKKAIDO & & $1 /$ & & & & $5 /$ & $2 /$ & $2 /$ & $4 /$ & $3 /$ & $5 /$ & $32 /$ & \\
\hline $\begin{array}{l}\text { HONSHU } \\
\qquad[\text { Tohoku }]\end{array}$ & Iwate & & & & & & 1/ & & & & & & \\
\hline [Kanto] & $\begin{array}{l}\text { Tochigi } \\
\text { Chiba }\end{array}$ & & & 1/ & & & $2 /$ & $\begin{array}{l}3 / \\
1 /\end{array}$ & & & & & \\
\hline [Chubu] & $\begin{array}{l}\text { Niigata } \\
\text { Fukui } \\
\text { Yamanashi }\end{array}$ & & & $1 /$ & $1 /$ & $1 /$ & $5 /$ & & & $1 /$ & & & \\
\hline KYUSHU & Fukuoka & 1 & 0 & 2 & 1 & 6 & 10 & & & & & & \\
\hline Total & & & & & & & & 6 & 4 & 4 & 5 & 32 & 0 \\
\hline
\end{tabular}

longer, strongly plumose. That on posterolateral to dorsal surface of propodeum outside triangle inconspicuous, frequently confined narrowly on lower posterolateral corner, very short, moderately dense, weakly plumose, white.

Terga sparsely hairy, sometimes T1 virtually hairless. Pseudopygidium well developed as normal in female Nomada. Pygidial plate covered thin, short, not dense hairs.

Structure: Body length 8-11.5 mm. CD:UID:LID 50:50:47. OCD/LOD 1.6.

Interantennal elevation weakly or moderately raised. Inner eye margins nearly parallel. Clypeus moderately raised and produced anteriorly. Labrum 1.6 times as wide as long; labral tooth present slightly or evidently before the center, not accompanied by carina; apical portion weakly produced anteriorly, not upcurved; apical margin indistinctly serrated only medially. Mandible slender. Preoccipital ridge weakly angulated, not carinate. Relative length of FL1-3 1:1.5:1.3, relative length to apical width of FL1 equal, FL2 1.7 times, FL3 1.4 times.

Scutellum moderately raised, anterior face nearly flat, median furrow moderately deep. Pygidial plate reddish brown, apical margin widely rounded, usually with a shallow notch at apex.

Fore femur moderately built. Apicomedian setae on hind tibia five or six in number (eight in one specimen), posteriormost seta slender, slightly curved downward, evidently longer than others, others robust, dark brown, usually irregularly spaced.

Male. Not recorded from Japan.

Distribution. Northern and central Europe; Japan (new record: Hokkaido, Honshu, Kyushu).

Specimens examined. JAPAN [Hokkaido] 32우,
Lake Shikaribetsu, Shikaoi-chô, 3, vii. 2006 (Y. Maeta). [Honshu] Iwate: 1오, Nishiyama, 30. v. 1971 (T. Chiba, EIAES). Chiba: Sakahata, Kimitsu City, 2. vi. 1996 (H. Suda). [Kyushu] Fukuoka: 1오, Mt. Hikosan, 9. v. 1951 (Y. Hirashima, ELKU). CZECH 2우20', det. M. Schwarz.

Biology. It is a univoltine species, collected from early April to early July (Table 21). Floral associations are as follows: [Salicaceae] Salix taraikensis. [Compositae] Chrysanthemum leucanthemum. The host is unknown.

Remarks. The female is similar to Nomada asozuana Tsuneki and N. fusca Schwarz. It can be differentiated from them in the combination of the following characters: the not strongly produced clypeus (as in N. fusca), the absence of hair patch of white appressed pubescence on the lateral side of T3-5, the well-developed pseudopygidium (but not prominently and not disheveled appearance as in $N$. fusca), the pygidial plate covered with thin, short, not dense hair.

The record of this species from Oita Pref. (Yamazaki and Kato, 2003) was based on misidentification.

21. Nomada maculifrons Smith, 1869

[Japanese name: Kaomon-kimadara-hanabachi] (Figs. 58-60; Table 22)

Nomada maculifrons Smith, 1869, Entomologist, 4: 206 [Holotype: Female. Type locality: Japan]; Hirashima, 1965, Icon. Ins. Jap., Col. Nat. ed., Vol. III: 309, pl. 155; Tsuneki, 1973, Etizenia, 66: 52-56 [redescription; first description of male]; Alexander \& Schwarz, 1994, Univ. Kansas Sci. Bull., 55: 249 [in list]. 


\section{Redescription.}

Female.

Color: Head largely reddish brown, the brown somewhat paler on lower face and tinged with yellow or distinctly yellow along lower inner eye margin; the following portions are black: macula surrounding antennal socket except supraclypeal area always reddish brown, transverse elliptical macula surrounding ocelli (these maculae above frequently fused partially, but always reddish brown spot present just before the median ocel- lus), line on epistomal suture, broad line on genal area along preoccipital ridge extending from hypostoma up to level of top of compound eye in profile. Mandible reddish brown except apical one-third dark red. Antenna pale brown anteriorly, darker apically and posteriorly, sometimes wholly black posteriorly.

Mesosoma black; the following portions are reddish brown: collar on the top, pronotal lobe, four longitudinal lines on scutum but sometimes largely fused into two broad lines, axillae, scutellum wholly, mesopleuron

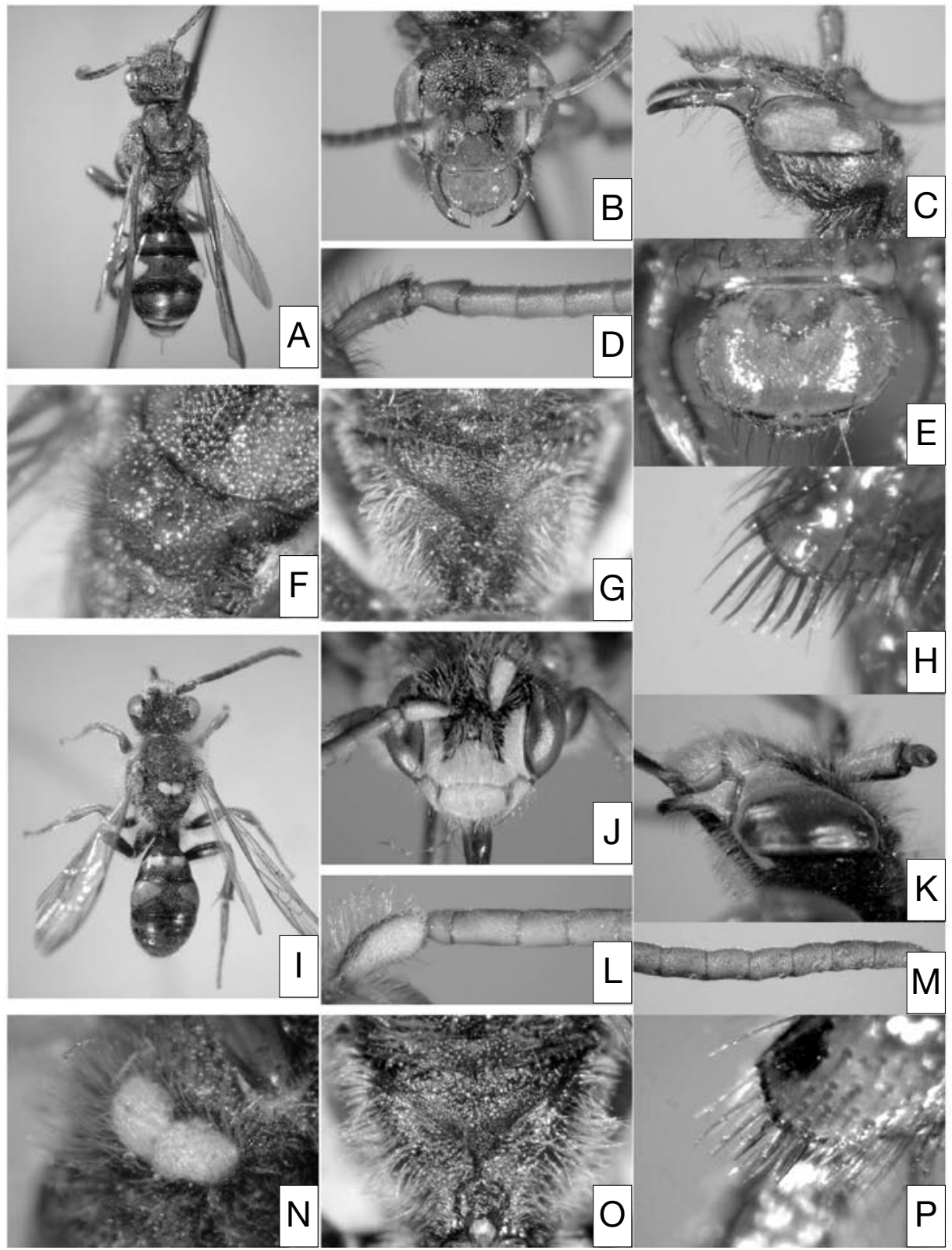

Fig. 58. Nomada maculifrons Smith. Female: A-H. Male: I-P. A, I: habitus, dorsal view. B, C, J, K: head. D, L, M: antenna. E: labrum. F, N: scutellum. G, O: propodeal triangle. H, P: apicomedian setae on hind tibia. 
nearly wholly except a black macula of variable size on ventral side, a spot on the metanotum but sometimes lacking, a pair of large maculae on posterolateral corner of propodeum, which frequently divided into smaller four maculae by black line on lateral boarder of propodeal triangle.

Metasoma largely brown, T1 black on basal half, other following terga strongly blackish; the following portions are yellow: a pair of oval maculae on T2, a pair of spots on the lateral side of T3, dark yellow band narrowly interrupted medially or rarely complete on $\mathrm{T} 4$, roughly rectangular macula $\mathrm{T} 5$ medially, vague spot or band each on S4 and S5.

Legs largely reddish brown; the following portions are black or blackish: fore coxa narrowly basally and posteriorly, mid coxa except apex, fore hind coxae narrowly basally and posteriorly, all femora basally except dorsally and apico- to medioventrally, sometimes all femora wholly blackish anteriorly and posteriorly.

Sculpture: Punctures on labrum, clypeus and supraclypeal area small, indistinct, obliterated in places; interpunctural space on medial portion of labrum and lower paraocular area wide, smooth and polished.

Punctures on scutum comparatively sparse, especially on posterior portion where punctures about puncture diameter apart in places. Those on scutellum sparser than on scutum, usually anterior flattened surface widely impunctate. Mesopleuron shallowly areolate. Propodeum outside triangle shallowly areolate. Propodeal triangle irregularly coarsely rugose basally and medially, the remaining portion tessellate.

Terga faintly microsculptured, with moderately dense punctules. Pygidial plate with small, shallow, dense punctures, impunctate margin wide.

Vestiture: Vestiture on labrum pale brown, simple and short, sparse, except weakly plumose and much longer on apical margin. That on clypeus and supraclypeal area inconspicuous, short, fine, appressed. That on lower genal area near hypostoma longer than on labrum, sparse.

Vestiture on scutum and scutellum brown tinged with golden, short but slightly longer on scutellum, simple, appressed, on anterior and medial portion directed posteriorly, but on posterior portion erect, or directed anteriorly. That on mesopleuron pale brown or whitish, fine, plumose, much longer than on scutum. That on posterolateral to dorsal surface of propodeum outside triangle brown tinged with golden, strongly plumose, erect, long, moderately dense, not forming hair patch. Pseudopygidium short in transverse length composed of brown, scale-like hairs. Pygidial plate covered with short, dense hairs.

All femora with sparsely, but evenly dense, long, curved apically, simple hairs except each posterior surface without such vestiture.

Structure: Body length 7-10 mm. CD:UID:LID 50:47:45. OCD/LOD 1.6.

Interantennal elevation weakly raised, with low keeled carina. Inner eye margins nearly parallel. Clypeus highly raised, strongly produced anteriorly. Labrum 1.4 times as wide as long; three distinct teeth present on subapical margin, arranged in a line, median tooth larger and conical, other two smaller, flat triangular; apical portion below one-third from apex strongly upcurved, apical margin not serrated. Mandible slender and long, abruptly narrowed at one-third from apex. Preoccipital ridge gently angulated behind vertex, becoming highly raised carina apically. Hypostomal carina highly raised. Scape somewhat narrower than flagellar segments. Relative length of FL1-3 1:1.6:1.3, relative length to apical width of FL1 nearly equal, FL2 1.7-1.8 times, FL3 1.5.-1.6 times.

Scutellum moderately raised, anterior face flat, median furrow narrow, usually deep. Posterior area around propodeal spiracle shallowly but widely concave, without ridge above. Pygidial plate brown, apical margin widely rounded, usually with a small notch at apex.

Fore and mid femora not robust, but rather cylindrical, less compressed anteroposteriorly than typical form in female Nomada. Hind femur slender, cylindrical, widely and shallowly depressed on basoventral surface, but without distinct basoventral flattened surface.

Apicomedian setae on hind tibia five to seven in number, or sometimes more (nine as the maximum in examined specimens), long, bluntly pointed at apex, dark brown to black, posteriormost seta the longest, gradually shorter and more strongly curved anteriorly, anterior two or three setae more or less flattened, sometimes strongly so.

Male.

Color: Head black; the following portions are yellow: mandible except apical one-third dark red, labrum, clypeus on apical half, malar area, lower paraocular area extending up along inner eye margin to level of antennal socket (yellow portion on lower paraocular area not variable in shape, but the yellow on clypeus sometimes narrower in small individuals). Scape yellow anteriorly, black posteriorly, flagellar segments brown anteriorly, black posteriorly but paler apically.

Mesosoma black; the following portions are yellow: collar on the top, macula on anterior surface of mesopleuron, its size variable independently of body size, 

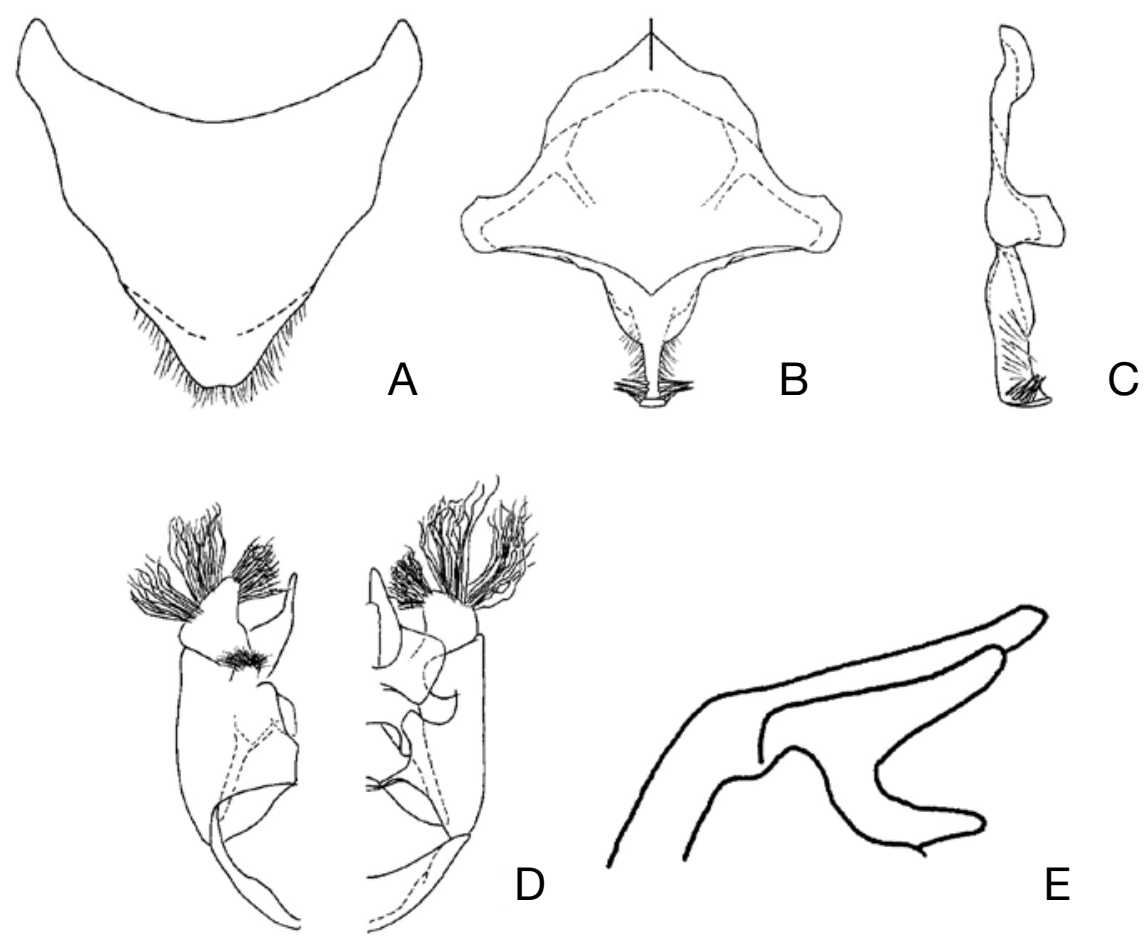

Fig. 59. Nomada maculifrons (male). A: 7th metasomal sternum, ventral view. B: 8th sternum, dorsal view. C: the same, lateral view. D: genital capsule (left, ventral view; right, dorsal view). E: penis valve and gonostylus, lateral view (vestiture omitted).

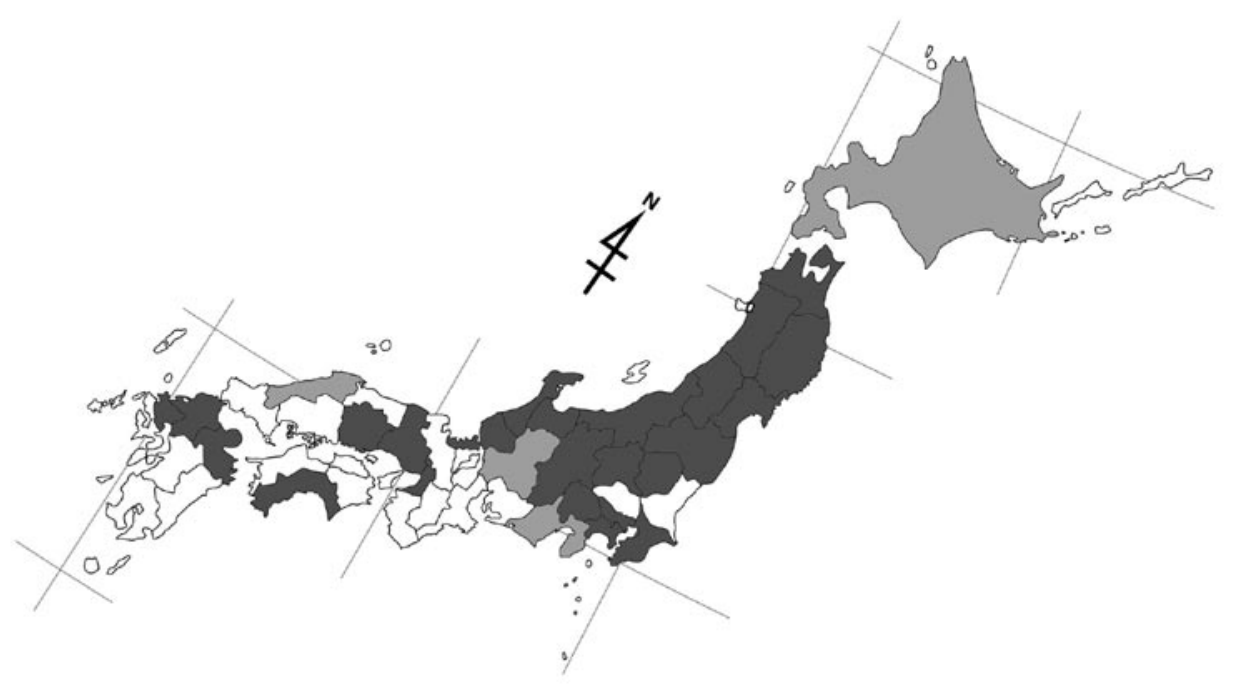

Fig. 60. Distribution of $N$. maculifrons on the Japanese mainlands. Densely shaded: prefectures with the specimens examined in the present study. Lightly shaded: prefectures with records in literature, but no specimens examined in the present study. 
ranging from round, small spot to transversely elliptical larger macula. Pronotal lobe yellow to brown. Tegula brown. Scutellum wholly black or with a pair of reddish brown or yellow spots. Larger male individuals frequently have scutellum with yellow color, smaller males have scutellum with reddish brown spots or without any spot.

Metasoma brown to black, T1 black on basal half, apical half of $\mathrm{T} 1$ containing a pair of irregularly transversely elliptical yellow maculae which frequently reduced to small vague spots or lacking, and a pair of small black spots below the yellow macula; the following portions are yellow: a pair of maculae each on T2 and T3 (the former oval and larger, the latter transversely elliptical, smaller, intermacular area brown), four spots arranged in a line on T4, macula each on T5 and T6 (the former transversely elliptical, the latter nearly rectangular), band or spot each on S2-6.

Legs brown; the following portions are black: all coxae except each apical margins brown, inner margin of fore coxa bright yellow, all trochanters posteriorly or sometimes hind trochanter wholly black, fore and mid femora ventrally, spot on each ventral surface of fore and mid tibiae, hind femur except dorsally.

Large-sized male individuals frequently have the scutellum with yellow color. Smaller male individuals have the scutellum with reddish brown spots or without any spot.

Sculpture: Punctures on head and mesosoma denser than in female, those on scutum and scutellum continuous, otherwise as in female.

Vestiture: Vestiture on labrum white, longer on apical margin of labrum otherwise slightly shorter, strongly plumose, erect, dense. That on clypeus and supraclypeal area similar to those on labrum but appressed, somewhat sparser. Those on lower genal area near hypostoma evidently longer than on labrum.

Vestiture on scutum and scutellum pale brown, erect, weakly plumose, long, somewhat darker on the peripheral portion. That on mesopleuron whitish, strongly plumose, whitish, evidently longer than on scutum. That on propodeum outside triangle similar in shape and density to on scutum, but slightly longer and more strongly plumose.

Vestiture on ventral surfaces of fore and mid femora longer or as long as the maximum width of each segment. That on ventral surface of hind femur with fine, sparse, short hairs.

Structure: Body length 7-10.5 mm. CD:UID:LID 50:49:44. OCD/LOD 1.7.

The following aspects are different from female: interantennal carina raised moderately or highly, higher than in female, lowered abruptly anteriorly from level of anterior margin of antennal socket in profile; labrum 1.5 times as wide as long, similar in shape to that of female except apical reflection weaker and teeth much smaller, especially lateral two teeth less distinct; scape as wide as flagellar segments; relative length of FL1-3 1:3.0-3.2:2.2-2.3, relative length to apical width of FL1 0.6 times, FL2 2.2-2.3 times, FL3 1.7 times, tyloidea on FL2 very narrowly ridge-shaped, extending from apical margin of FL2 near to basal margin, those on the following four segments gradually shorter, broader, those on last five segments becoming conical tubercle, but less distinct on ultimate segment; collar carinated medially, not emarginated medially; scutellum as in female, but median furrow shallower; area around propodeal spiracle not concave, without ridge; pygidial plate triangularly emarginated at apex; fore femur slender; hind femur slender, basoventral flattened surface wide, reaching to two-thirds of ventral side from base of segment, distinctly but not deeply depressed in posterior view. Apicomedian setae on hind tibia much slenderer and paler than in female, difficult to discern among surrounding long hairs, otherwise as in female.

Male terminalia: 7th metasomal sternum as in Fig. 59-A. 8th as in Fig. 59-B, C. Gonostylus roughly cylindrical, slender in lateral view; vestiture present on apical portion and lateral sides, that on apical portion not long, plumose, that on lateral sides longer, simple, weakly sinuate apically; basoventral lobe developed with plumose, long vestiture. Penis valve produced posteriorly beyond gonostylus, apex extending beyond apex of gonostylus in lateral view. Gonocoxite with deep and wide dorsal invagination; inner dorsal lobe longer than wide, with apex truncate.

Distribution. Japan (Hokkaido, Honshu, Shikoku, Kyushu); South Korea.

Specimens examined. Holotype (BMNH), 우, attached with four labels as follows: "Type/ H. T. (circular and typed, the edge colored red)", "B. M. TYPE/ HYM/ 17. B. 529 (white rectangular and typed except the bottom line handwritten)", "Japan (blue circular with handwritten letters)", "Nomada/ maculifrons/ Smith (blue rectangular with handwritten letters)".

Other specimens: We have examined about 100 females and 230 males. On the localities, see Fig. 60. Some of them are listed as follows: JAPAN [Honshu] Iwate: 10', Morioka, 9. v. 1971 (T. Chiba, NIAES). Akita: 10', Gasyodake, Hachimantai, 7. vi. 1992 (T. Chiba, NIAES). Yamagata: 1웅', Oguni, 27. v. 1976 (O. Tadauchi, ELKU). Fukushima: 3 우, Sawa (Iwashiro), 24. v. 1946 (Y. Kurosawa, ELKU). Gumma: 10', Tumago- 
Table 22. Seasonal change of number of the captured individual of $N$. maculifrons in Japan (Number of females indicates at the left of slash in cell, that of males at the right. E: early, M: mid, L: late).

\begin{tabular}{|c|c|c|c|c|c|c|c|c|c|c|c|c|c|c|c|c|}
\hline \multirow[b]{2}{*}{ Main island } & \multirow[b]{2}{*}{ Prefecture } & \multicolumn{3}{|c|}{ March } & \multicolumn{3}{|c|}{ April } & \multicolumn{3}{|c|}{ May } & \multicolumn{3}{|c|}{ June } & \multicolumn{3}{|c|}{ October } \\
\hline & & $\mathrm{E}$ & $\mathrm{M}$ & $\mathrm{L}$ & $\mathrm{E}$ & $\mathrm{M}$ & $\mathrm{L}$ & $\mathrm{E}$ & $\mathrm{M}$ & $\mathrm{L}$ & $\mathrm{E}$ & $\mathrm{M}$ & $\mathrm{L}$ & $\mathrm{E}$ & $\mathrm{M}$ & $\mathrm{L}$ \\
\hline \multicolumn{17}{|l|}{ HONSHU } \\
\hline \multirow[t]{6}{*}{ [Tohoku] } & Aomori & & & & & & & & $3 / 5$ & $18 / 23$ & $2 / 8$ & $3 / 6$ & $2 /$ & & & \\
\hline & Iwate & & & & & & & $/ 1$ & & $1 / 1$ & $1 /$ & & & & & \\
\hline & Miyagi & & & & & & & & & $2 /$ & & & & & & \\
\hline & Akita & & & & & & & & & & $/ 1$ & & & & & \\
\hline & Yamagata & & & & & & & & & $1 / 1$ & & $1 /$ & & & & \\
\hline & Fukushima & & & & & & & & & $3 / 2$ & & & & & & \\
\hline \multirow[t]{6}{*}{ [Kanto] } & Tochigi & & & & & $4 / 4$ & $1 / 4$ & $1 / 2$ & $3 /$ & $2 / 1$ & $/ 1$ & & & & & \\
\hline & Gumma & & & & & & & & & $/ 1$ & & & & & & \\
\hline & Saitama & & & $/ 1$ & $1 /$ & & & & & & & & & & & \\
\hline & Chiba & & & 2/ & $1 / 1$ & & & & & & & & & & & \\
\hline & Tokyo & & & 1/ & & & & & & & & & & & & \\
\hline & Kanagawa & & & 12 & & & & & $/ 1$ & & & & & & & \\
\hline \multirow[t]{6}{*}{ [Chubu] } & Niigata & & & & & & $/ 6$ & 16 & $1 / 6$ & $3 / 5$ & & & $/ 1$ & & & \\
\hline & Toyama & & & & & & & & 12 & $1 / 1$ & $1 / 2$ & & & & & \\
\hline & Ishikawa & & & & & & & & $/ 1$ & & & & & & & \\
\hline & Fukui & & & & 12 & & $/ 1$ & 121 & $5 / 27$ & $11 / 57$ & $10 / 7$ & $4 / 1$ & & $/ 2$ & & \\
\hline & Yamanashi & & & & & & & & $3 / 3$ & 15 & & & & & & \\
\hline & Nagano & & & & & & & & & & $1 /$ & & & & & \\
\hline \multirow[t]{2}{*}{ [Kinki] } & Osaka & & & & & & & $/ 2$ & & & & & & & & \\
\hline & Hyogo & & & & & & & & $/ 1$ & & & & & & & \\
\hline [Chugoku] & Okayama & & & & & & & & & & $1 / 2$ & & & & & \\
\hline SHIKOKU & Kochi & & & & & $/ 1$ & & & & & & & & & & \\
\hline \multirow[t]{3}{*}{ KYUSHU } & Fukuoka & & & & $/ 1$ & 12 & $1 / 1$ & $1 / 4$ & $1 /$ & & & & & & & \\
\hline & Saga & & & & & & & & & & & $/ 1$ & & & & \\
\hline & Oita & & & & & & & & $/ 1$ & & & & & & & \\
\hline \multicolumn{2}{|c|}{ Total } & 0 & 0 & 6 & 6 & 11 & 14 & 38 & 60 & 139 & 37 & 16 & 3 & 2 & 0 & 0 \\
\hline
\end{tabular}

imura, 22. v. 2002 (H. Nagase). Tokyo: 1우, Toyama, 30. iii. 1948 (R. Ishikawa, ELKU). Nagano: 1우, Nagano, 9. vi. 1948 (K. Kamijo, SUHU). Osaka: 2б', Mt. Mito, Settsu, 5. v. 1955 (K. Komatsu, ELKU). Hyogo: 10', Sasayama (Tamba), 15. v. 1953 (S. Taniguchi, ELKU). Okayama: 12우 ð7, Ondarako, Kamisai, 8. vi. 1975 (T. Kondo, ELKU). [Shikoku] Kochi: Tanono, Taishomachi, 16. iv. 1976 (O. Tadauchi, ELKU). [Kyushu] Fukuoka: 1우, Narutakeyama (Chikuzen), 22. iv. 1951 (Y. Hirashima, ELKU). Saga: 10', Hokuzan Dam, Ozeki, 16. vi. 1973 (J. Emoto, ELKU). Oita: 10', Kuju, 11. v. 1978 (Collector unknown, ELKU). SOUTH KOREA, $4{ }^{\nearrow}$, Kawang Nung, Pochon-Gun, Kyongi-Do, 23. iv. 1992 (O. Tadauchi, ELKU).

Biology. It is a univoltine species, collected from late March to late June, with most records in May (Table 22). Two male individuals are collected in early October in Fukui Pref., Honshu. These specimens are regarded not as the first generation but as the untimely occurred adults because they are very few, compared with the number of individuals collected in spring, and because no differences between individuals collected in spring and in October. Floral associations are as follows: [Rosaceae] Potentilla fragarioides var. major, Prunus grayana, Rubus crataegifolius, Rubus oldhamii. [Malvaceae] Althaea rosea. [Caprifoliaceae] Weigela coraeensis, Weigela hortensis. The host is unknown.

Remarks. The Korean individuals of $N$. maculifrons tend to show differences from the Japanese ones as follows: the punctures on the clypeus and the dorsal sur- 
face of the mesosoma in female are more distinct and the clypei in male are not so highly raised and so greatly produced anteriorly as those in the Japanese male. Although these differences are usually fairly clear, the intermediates sometimes do occur. We, therefore, do not regard them as distinct taxa. This species is not rare, but not abundant in Japan. In South Korea, it seems to be abundant because this species makes up more than half of approximately 450 Korean Nomada specimens deposited in ELKU.

The female is similar to Nomada hackoda Tsuneki in having the greatly produced clypeus, but differs from it by the nearly impunctate labrum, the labral tooth which is located near at apical margin, and the longer, slightly curved, blunt apically setae on hind tibia. The male can be easily separated from the Japanese congeners by the broad, bright yellow line along inner eye margin on face and the conical-shaped tyloidea on the flagellar segments.

22. Nomada montverna Tsuneki, 1973

[Japanese name: Miyama-kimadara-hanabachi] (Figs. 61-63; Table 23)

Nomada montverna Tsuneki, 1973, Etizenia, 66: 97-100 [Holotype: Male. Type locality: Taniyama, Fukui Pref., Honshu, Japan]; Alexander \& Schwarz, 1994, Univ. Kansas Sci. Bull., 55: 250 [in list].

Redescription. (female new to science)

It is closely similar in structure to Nomada flavoguttata (Kirby), so that only diagnostic characters are described below.

\section{Female.}

Wintering generation.

Color: Similar to wintering generation of Nomada flavoguttata (Kirby) except supraclypeal area always black (nearly always tinged reddish brown in wintering generation of $N$. flavoguttata), lower dorsal surface of propodeum with or without a pair of small red or reddish brown maculae, and propodeal triangle wholly black (propodeum with a pair of large reddish brown maculae spreading into the triangle, very rarely wholly black in wintering generation of $N$. flavoguttata).

Sculpture: Head and mesosoma more deeply punctate than in wintering generation of $N$. flavoguttata, especially on lateral side of mesopleuron.

Vestiture: As to wintering generation of N. flavoguttata.

Structure: Body length 5-6.5 mm. CD:UID:LID 50:50:40-45. OCD/LOD 1.2-1.4. Mandible more strongly curved than in $N$. flavoguttata in both generations.

First generation.

Color: As in first generation of N. flavoguttata.

Sculpture: Punctures markedly deeper than in first generations of $N$. montverna itself and $N$. flavoguttata.

Vestiture: Vestiture sparser, shorter, less plumose than in conspecific wintering generation, as in first generation of $N$. flavoguttata.

Structure: Mesosoma somewhat robuster than in conspecific wintering generation and $N$. flavoguttata in both generations.

Male.

Wintering generation.

Color: Scutellum wholly black (nearly always with yellow to reddish brown maculae in wintering generation of $N$. flavoguttata).

Sculpture: Head and mesosoma more deeply punctate than in wintering generation of $N$. flavoguttata, especially on lateral side of mesopleuron, but the difference between two species not markedly as in female.

Vestiture: As in wintering generation of $N$. flavoguttata.

Structure: As in wintering generation of N. flavoguttata.

First generation.

Color: As in first generation of N. flavoguttata.

Sculpture: Punctures evidently deeper than in first generations of $N$. montverna itself and $N$. flavoguttata, but the difference between two generations and between two species not markedly as in female.

Vestiture: Vestiture sparser, shorter, less plumose than in conspecific wintering generation, as in first generation of $N$. flavoguttata.

Structure: Body length 4.5-6 mm. CD:UID:LID 50: 52: 38-42. OCD/LOD 1.4-1.5. Structure as in first generation of $N$. flavoguttata.

Male terminalia: 7th metasomal sternum as in Fig. 62-A. 8th as in Fig. 62-B, C. Gonostylus short; vestiture long, comparatively sparse, simple, sinuate apically; basoventral lobe absent, but very long, simple, weakly sinuate vestiture on the corresponding portion. Penis valve produced posteriorly beyond gonostylus, apex slightly extending beyond apex of gonostylus in lateral view. Gonocoxite with shallow dorsal invagination; inner dorsal lobe wider than long, with apex truncate.

Distribution. Japan (Hokkaido, Honshu, Kyushu).

Specimens examined. Holotype (MNHAH), o', attached with two labels as follows: "Koike/ Fukui, Japan/ 2. vi. 1957/ K. Tsuneki (white rectangular and typed)", "Nomada/ montverna/ TSUNEKI/ HOLOTYPE (red rectangular with handwritten letters)". 
Other specimens: We have examined about 350 females and 170 males. On the localities, see Fig. 63. Some of them are listed as follows: JAPAN [Hokkaido] 107, Akagawa, Hakodate, 13. v. 1960 (M. Mumakata, ELKU). [Honshu] Iwate: 4ð', Shimo-ohkuzu, Morioka C., 4. v. 1991 (T. Chiba, NIAES). Akita: Hokotate, Mt. Chokai, 25. v. 1975 (O.Tadauchi, ELKU). Chiba: 10', Honda, Midori, Chiba City, 11. vi. 1995 (H. Suda). Tokyo: 1우, Jindaiji, 1. vi. 19?? (T. Nambu). Kanagawa: 10', Yokosuka-shi, Hirasaku 4-chôme, 21. v. 2002 (H. Na- gase). Yamanashi: 1우, Akiyama, Minamitusurugun, 20. vi. 1978 (H. Suda). Mie: Yoccaichi C. Isaka, 20. v. 1987 (A. Kawazoe, ELKU). Hyogo: 1우, Mt. Futatabi, Kobe, 5. iv. 1991 (N. Sugiura). Hiroshima: 2우10 , Imanishi, Saijo-machi, 25, iv. 1976 (O. Tadauchi, ELKU). [Kyushu] Fukuoka: 24우14 $\sigma^{7}$, Kyushu University Forest, Sasaguri-machi, Kasuya-gun, 15. iii. 2006 (K. Mitai). Kumamoto: 10', Tatsuda-Yama, Kumamoto City, 31. iii. 2006 (N. Sugiura). Oita: 5우, Mt. Hanamureyama, Shônai-machi, Oita-gun, 28. iv. 2006 (K. Mitai). Ka-

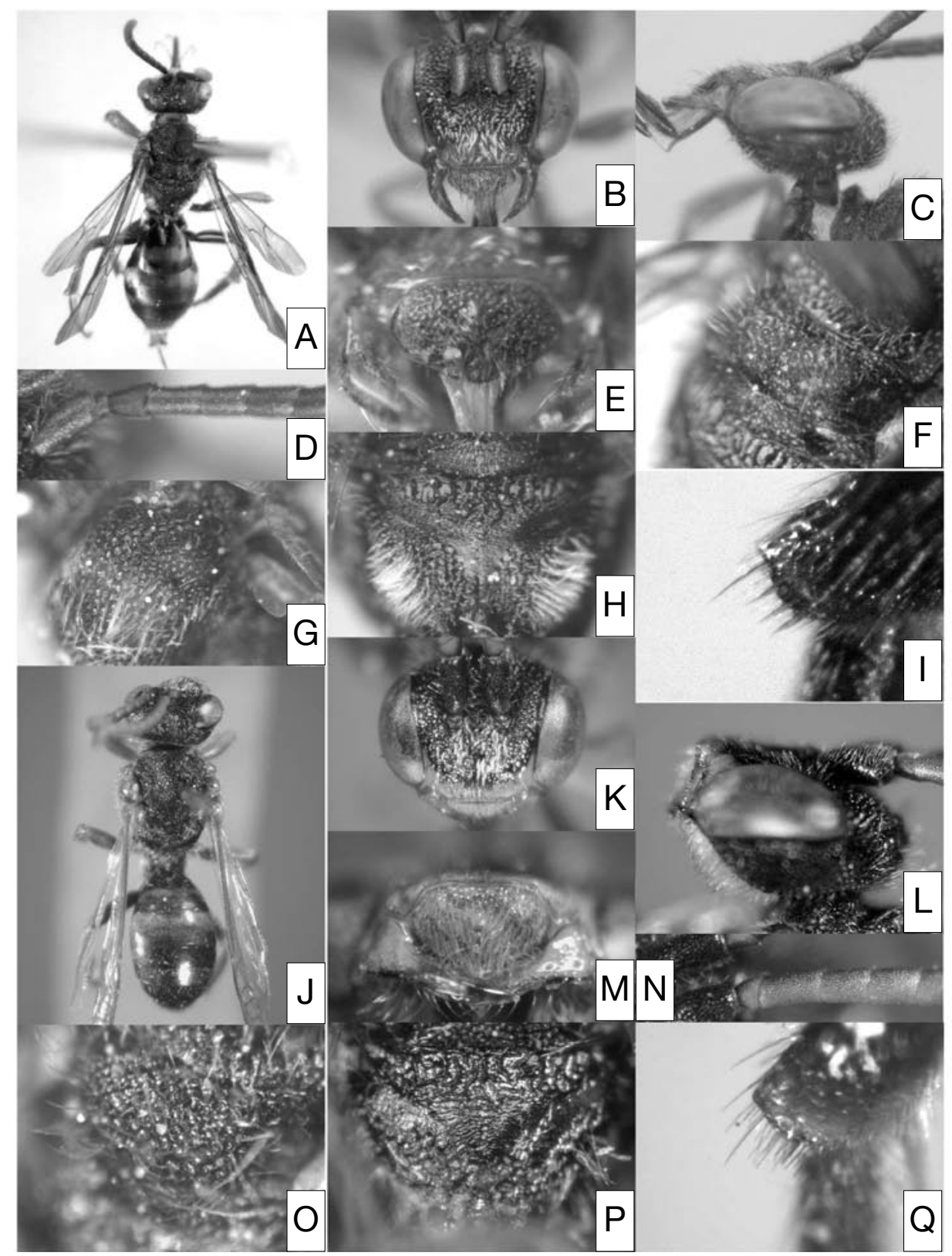

Fig. 61. Nomada montverna Tsuneki. Female: A-I. Male: J-Q. A, J: habitus, dorsal view. B, C, K, L: head. D, N: antenna. E, M: labrum. F, O: scutellum. G: mesopleuron. H, P: propodeal triangle. I, Q: apicomedian setae on hind tibia. 

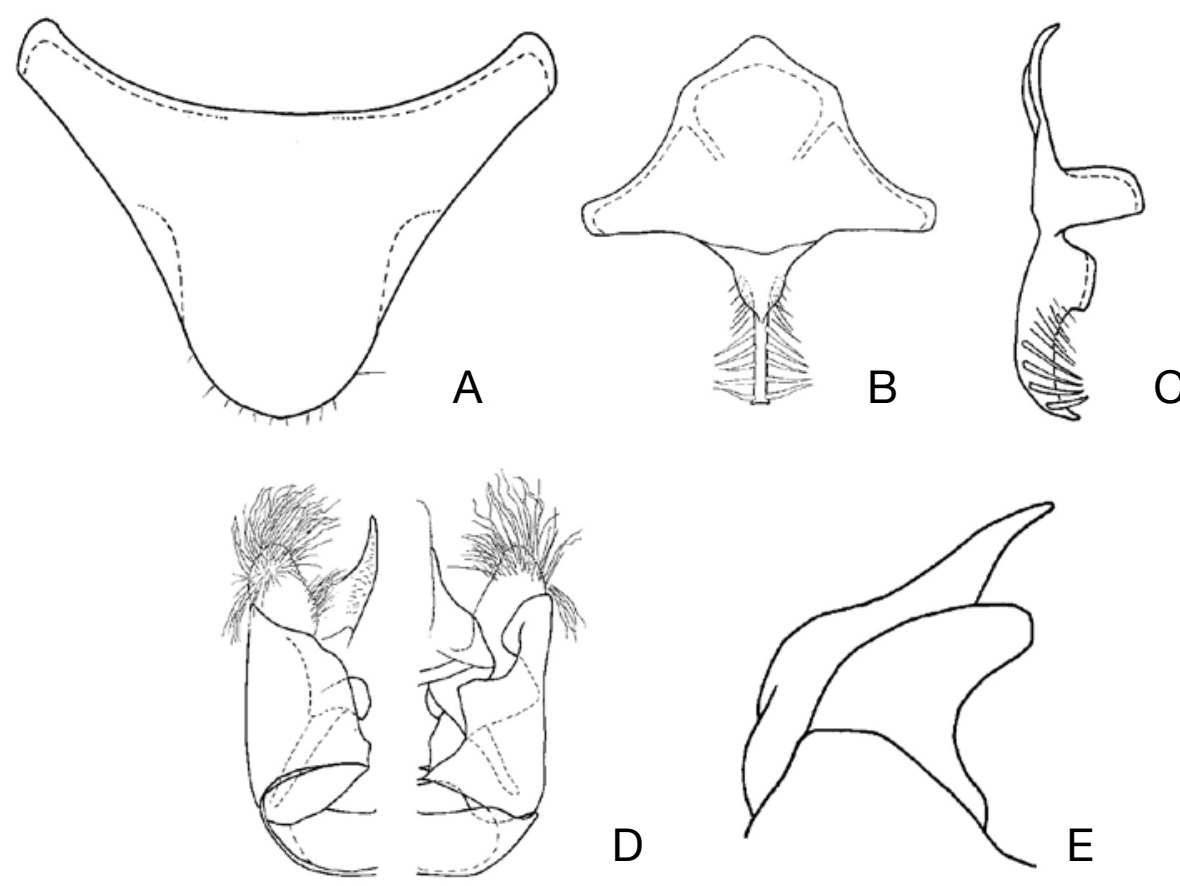

D

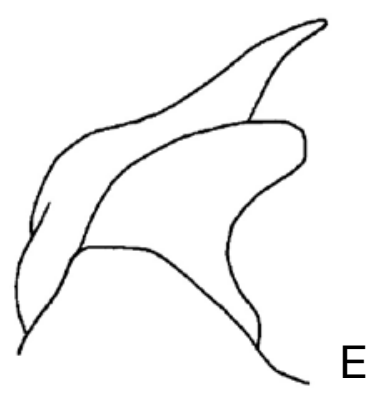

Fig. 62. Nomada montverna (male). A: 7th metasomal sternum, ventral view. B: 8th sternum, dorsal view. C: the same, lateral view. D: genital capsule (left, ventral view; right, dorsal view). E: penis valve and gonostylus, lateral view (vestiture omitted).

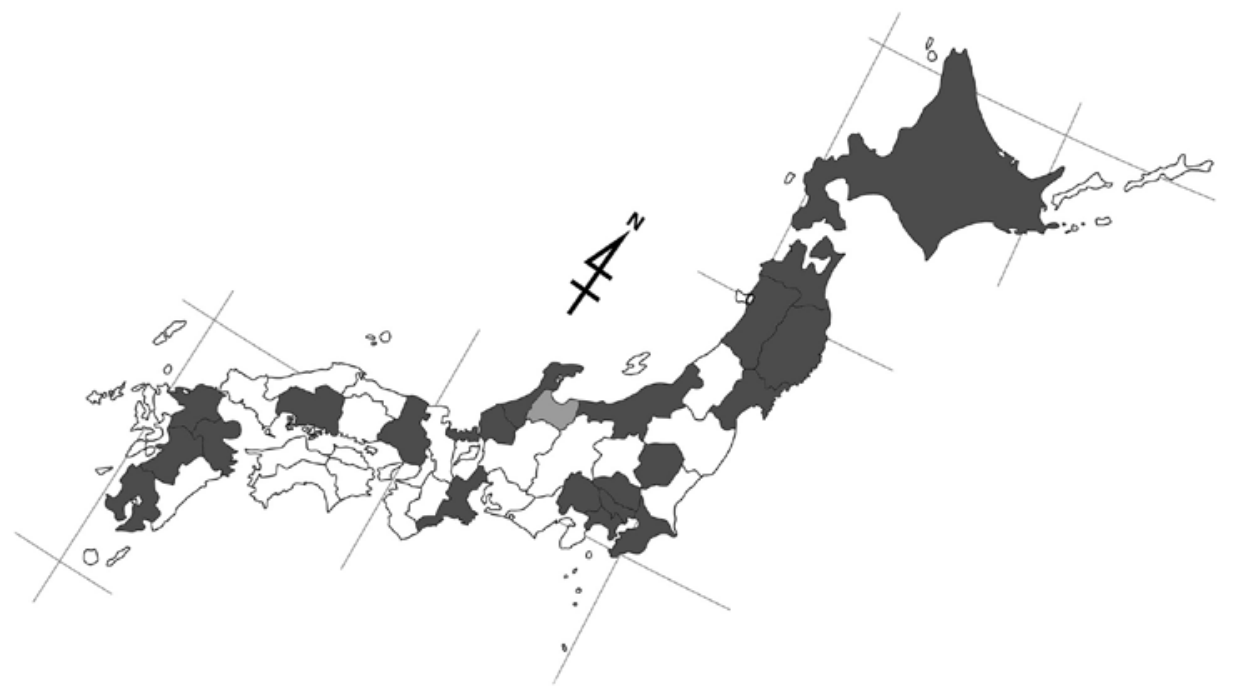

Fig. 63. Distribution of $N$. montverna on the Japanese mainlands. Densely shaded: prefectures with the specimens examined in the present study. Lightly shaded: prefectures with records in literature, but no specimens examined in the present study. 
Table 23. Seasonal change of number of the captured individual of $N$. montverna in Japan (Number of females indicates at the left of slash in cell, that of males at the right. E: early, M: mid, L: late).

\begin{tabular}{|c|c|c|c|c|c|c|c|c|c|c|c|c|c|c|c|c|c|c|c|c|c|c|}
\hline \multirow[b]{2}{*}{ Main island } & \multirow[b]{2}{*}{ Prefecture } & \multicolumn{3}{|c|}{ March } & \multicolumn{3}{|c|}{ April } & \multicolumn{3}{|c|}{ May } & \multicolumn{3}{|c|}{ June } & \multicolumn{3}{|c|}{ July } & \multicolumn{3}{|c|}{ August } & \multicolumn{3}{|c|}{ October } \\
\hline & & $E$ & $M$ & $\mathrm{~L}$ & $\mathrm{E}$ & $\mathrm{M}$ & $\mathrm{L}$ & $\mathrm{E}$ & $M$ & $\mathrm{~L}$ & $\mathrm{E}$ & $\mathrm{M}$ & $\mathrm{L}$ & $\mathrm{E}$ & $\mathrm{M}$ & $\mathrm{L}$ & $E$ & $M$ & $\mathrm{~L}$ & $\mathrm{E}$ & $M$ & $\mathrm{~L}$ \\
\hline HOKKAIDO & & & & & & & & & $/ 1$ & & $1 /$ & & & & 12 & & & $/ 1$ & & & & \\
\hline $\begin{array}{l}\text { HONSHU } \\
\text { [Tohoku] }\end{array}$ & $\begin{array}{l}\text { Aomori } \\
\text { Iwate } \\
\text { Miyagi } \\
\text { Akita }\end{array}$ & & & & & & $\begin{array}{c}2 / 5 \\
/ 1\end{array}$ & $\begin{array}{l}1 / 2 \\
1 / 8\end{array}$ & $1 / 4$ & $\begin{array}{l}1 / \\
/ 1\end{array}$ & $1 / 1$ & $3 /$ & 1/ & & $\begin{array}{l}1 / \\
/ 1\end{array}$ & $2 /$ & $/ 1$ & & & & & \\
\hline [Kanto] & $\begin{array}{l}\text { Tochigi } \\
\text { Saitama } \\
\text { Chiba } \\
\text { Tokyo } \\
\text { Kanagawa }\end{array}$ & & & $\begin{array}{l}/ 7 \\
1 /\end{array}$ & $\begin{array}{l}1 / 1 \\
13 / 1 \\
\\
\\
\\
/ 1\end{array}$ & $\begin{array}{r}13 \\
07 /\end{array}$ & $\begin{array}{c}4 / 2 \\
1 / \\
3 /\end{array}$ & $3 / 6$ & $/ 1$ & $\begin{array}{l}/ 1 \\
/ 1\end{array}$ & 1/ & $\begin{array}{l}2 / 1 \\
/ 2\end{array}$ & & 1/ & & & & & & & & \\
\hline [Chubu] & $\begin{array}{l}\text { Niigata } \\
\text { Ishikawa } \\
\text { Fukui } \\
\text { Yamanashi }\end{array}$ & & & & & $2 /$ & $\begin{array}{c}1 / 1 \\
/ 2\end{array}$ & $\begin{array}{l}6 / 5 \\
1 / \\
\end{array}$ & $5 / 2$ & $9 / 3$ & $14 / 1$ & $\begin{array}{l}1 / \\
1 /\end{array}$ & $\begin{array}{l}1 / \\
/ 1\end{array}$ & 1/ & $2 / 2$ & $\begin{array}{l}1 / \\
1 / 4\end{array}$ & $2 / 1$ & $/ 1$ & $\begin{array}{l}1 / 1 \\
2 /\end{array}$ & 1/ & & \\
\hline [Kinki] & $\begin{array}{l}\text { Mie } \\
\text { Hyogo }\end{array}$ & & & & 1/ & & $1 /$ & $1 /$ & $1 /$ & & & & & & & & & & & & & \\
\hline [Chugoku] & Hiroshima & & & & & $1 /$ & $2 / 1$ & & & & & & & & & & & & & & & \\
\hline KYUSHU & $\begin{array}{l}\text { Fukuoka } \\
\text { Kumamoto } \\
\text { Oita } \\
\text { Kagoshima }\end{array}$ & & $45 / 518$ & $\begin{array}{c}81 / 11 \\
1 / 1\end{array}$ & $31 /$ & $41 / 2$ & 7/1 & & $/ 1$ & $\begin{array}{l}2 / \\
4 / 8 \\
\end{array}$ & $\begin{array}{c}11 / 2 \\
1 / \\
\end{array}$ & & & & & & & & & & & \\
\hline Tot & & 0 & 96 & 102 & 58 & 56 & 35 & 34 & 16 & 30 & 33 & 10 & 3 & 2 & 8 & 8 & 4 & 2 & 4 & 1 & 0 & 0 \\
\hline
\end{tabular}

goshima: $5{ }^{\nearrow}$, Sata (Osumi), Magome-Hetsuka, 24. v. 1952 (Esaki and Hirashima, EKLU)

Biology. It is a bivoltine, common species. The wintering generation is collected from mid March to June (Table 23). The first generation is collected from late May to October. The active periods of wintering and first generations are partially overlapped from May to June, but they never concur in the same place.

Remarks. The records of this species in literature are scarce, compared with the abundant records of the related species, Nomada flavoguttata (Kirby). The scarcity, however, seems to be the artifact due to the difficulty of identification. Actually, it is as common as $N$. flavoguttata, at least in Kyushu, Japan. The recognition of Nomada montverna as good species is confirmed in the present study and the diagnostic characters from $N$. flavoguttata are as follows: the more strongly curved mandible, the deeper dorsal invagination in gonocoxite, the penis valve which produced posteriorly beyond the gonostylus in lateral view, the deeper punctures on body, especially on scutum and lateral surface of mesopleuron. The last character is diagnostically the most useful, but difficult to describe or illustrate. Both species are bivoltine, the integuments of the first generations are more deeply punctate than in the wintering generation, so that the first generation of $N$. flavoguttata is similar to the wintering generation of $N$. montverna, rather than to the conspecific wintering generation.

The color characters are also useful in separating them. In the case of female of the wintering generation as follows: the supraclypeal area is wholly black in $N$. montverna whereas more or less a reddish brown spot presents on it in N. flavoguttata; the reddish brown maculae on dorsal surface of propodeum are small, always outside the triangle, and frequently lacking in $N$. montverna, whereas the reddish brown maculae are larger, nearly always expanding into the triangle in $N$. flavoguttata. In the case of male of the wintering generation, 
the scutellum is always wholly black in N. montverna whereas the bright yellow to dark reddish brown maculae nearly always present on scutellum in N. flavoguttata but very rarely wholly black. In the case of the first generation, the colorations of two species are similar to each other and not diagnostically useful, although the differences of the depth of punctation on body are so prominent to easily separate them.
23. Nomada pacifica Tsuneki, 1973

[Japanese name: Hiroha-kimadara-hanabachi]

(Figs. 64-66; Table 24)

Nomada pacifica Tsuneki, 1973, Etizenia, 66: 97-100

[Holotype: Female. Type locality: Koike, Fukui Pref., Honshu, Japan]; Alexander \& Schwarz, 1994, Univ. Kansas Sci. Bull., 55: 250 [in list].

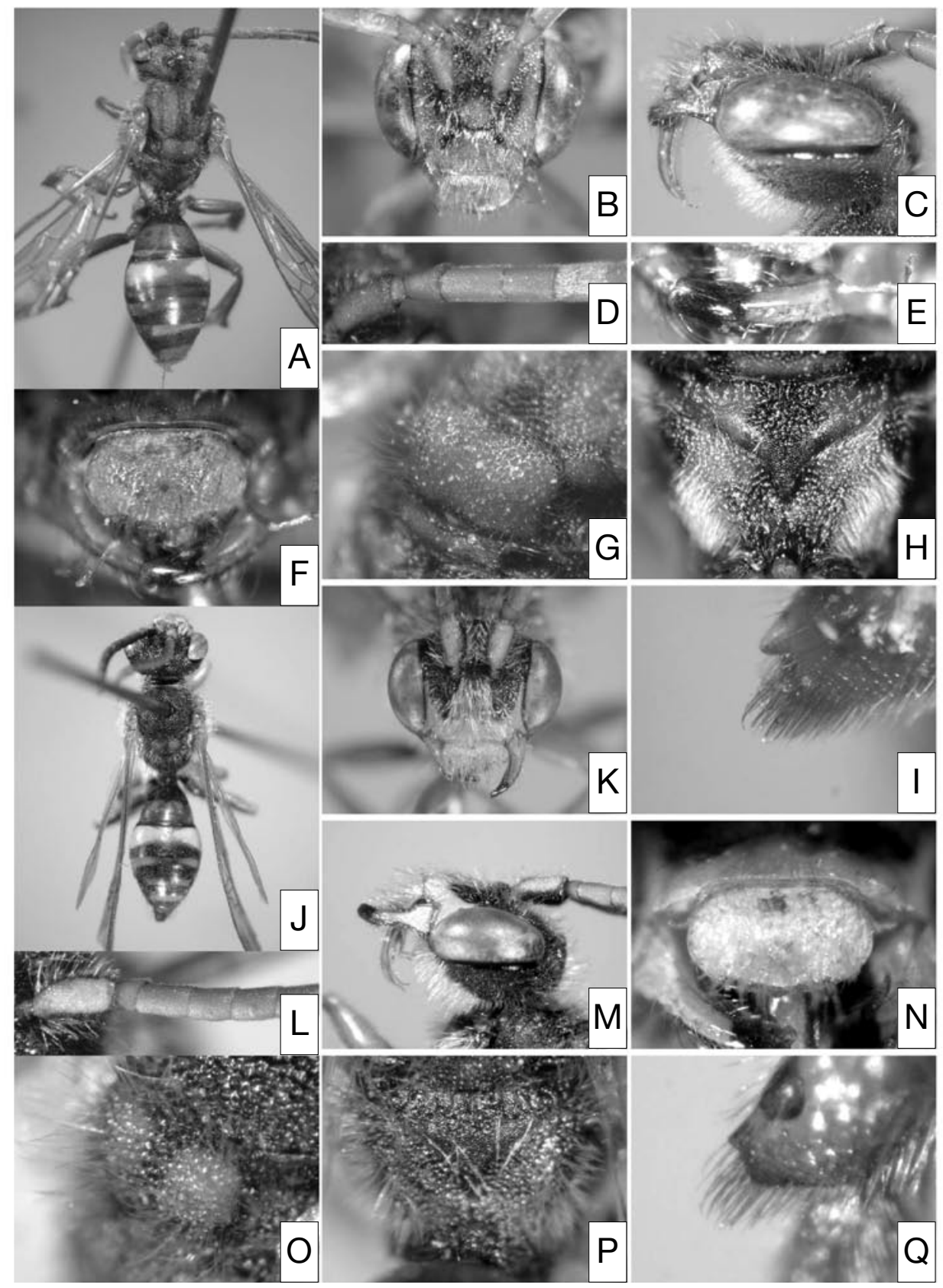

Fig. 64. Nomada pacifica Tsuneki. Female: A-I. Male: J-Q. A, J: habitus, dorsal view. B, C, K, M: head. D, L: antenna. E: mandible. F, N: labrum. G, O: scutellum. H, P: propodeal triangle. I, Q: apicomedian setae on hind tibia. 


\section{Redescription.}

Female.

Color: Head reddish brown, tinged with yellow on lower paraocular area and lower inner eye margin; the following portions are black: macula on antennal area except supraclypeal area reddish brown, transverse elliptical macula surrounding ocelli with a reddish brown spot frequently just before the median ocellus (these two maculae frequently fused partially), line on epistomal suture, broad line on genal area along preoccipital ridge extending from hypostoma up to level of top of compound eye in profile. Mandible reddish brown except apical one-third dark red. Antenna reddish brown or pale brown anteriorly, darker posteriorly, sometimes wholly pale brown.

Mesosoma black; the following portions are reddish brown: collar on the top, pronotal lobe, anterior margin of pronotum, longitudinal lines on scutum which variable from four, well-separated thin lines to two broad lines occupying scutum nearly wholly except medial longitudinal black line, tegulae, axillae, scutellum, mesopleuron except small black spot on scrobe and black macula of variable size on ventral side, sometimes the black on peripheral margin of mesopleuron conspicuously wider, metanotum, a pair of large maculae on posterolateral corner of propodeum which are frequently divided into four or six, small spots on each side.

Metasoma largely reddish brown; T1 black on basal half, T2 and T3 narrowly black basally; the following portions are yellow: a pair of oval or narrowly elliptical maculae each on T2 and T3 (the latter smaller, frequently reduced to transverse small maculae, sometimes lacking), narrowly medially interrupted or sometimes complete band on $\mathrm{T} 4$, roughly rectangular macula on $\mathrm{T} 5$ medially. S3-5 each with yellow band or macula of variable size, sometimes lacking.

Legs largely reddish brown; the following portions are black or blackish: fore and hind coxae dorsoanteriorly and posteriorly, mid coxa except apex, all femora basoventrally. The latter black extends from base near to apex on posterior surface of segment.

Sculpture: Punctures on labrum, clypeus and supraclypeal area successively more distinct and larger.

Punctures on scutellum as on scutum. Mesopleuron densely areolate. Lateral and dorsal sides outside triangle of propodeum densely areolate, denser than on mesopleuron. Propodeal triangle irregularly rugose on basal half, the rugae highly raised, the remaining portion more or less tessellate.

Terga faintly microsculptured with moderately dense punctules. Pygidial plate with obliterated, sparse punc- tures.

Vestiture: Vestiture on labrum pale brown, long and weakly plumose on apical margin, otherwise much shorter and simple. That on clypeus and supraclypeal area whitish or pale brown, plumose, appressed, sparse. That on lower genal area near hypostoma as long as on apical margin of labrum.

Vestiture on scutum and scutellum fine, moderately long, sparse. That on mesopleuron plumose whitish, more strongly plumose and much longer than on scutum. That on posterolateral to dorsal surface of propodeum outside triangle whitish, strongly plumose, moderately long, suberect, variable in density, sometimes forming loose hair patch, sometimes not so.

Pseudopygidium well developed as normal in female Nomada. Pygidial plate covered with fine, short hairs.

Structure: Body length 6-9 mm. CD:UID:LID 50:45:43. OCD/LOD 1.6.

Interantennal elevation moderately raised, with highly raised keeled carina. Inner eye margins weakly convergent below. Clypeus weakly or moderately raised and weakly produced anteriorly. Labrum 1.5-1.6 times as wide as long; labral tooth present slightly above or at the center, accompanied by indistinct carina on each side; apical portion below labral tooth weakly produced anteriorly, nearly straight, not upcurved; the apical margin indistinctly serrated. Mandible widely truncate or rounded at apex, rarely shallowly notched at truncate apex. Preoccipital ridge gently angulated behind vertex, becoming somewhat more strongly so apically. Relative length of FL1-3 1:1.8:1.5, relative length to apical width of FL1 nearly equal, FL2 1.8 times, FL3 1.5 times.

Scutellum moderately or highly raised, anterior surface flat, median furrow wide and moderately deep. Pygidial plate triangular at apical portion, without or with shallow emargination at apex.

Fore femur slender or moderately built. Apicomedian setae on hind tibia usually four to five in number (according to the original description by Tsuneki (1973), "usually seven to nine, sometimes four to six"), straight but sometimes slightly curved downward, black, intermixed with thick, straight, numerous, pale brown to golden hairs, these dense setae and hairs together forming a triangular brush-like tuft, so as to difficult to discern individually; apical process on tibial margin prominently produced and triangle-shaped.

Male.

Color: Head black; the following portions are yellow: mandible except apical one-third dark reddish or black, labrum, clypeus on apical half but gradually darkened upwards, changing to black at upper margin of 

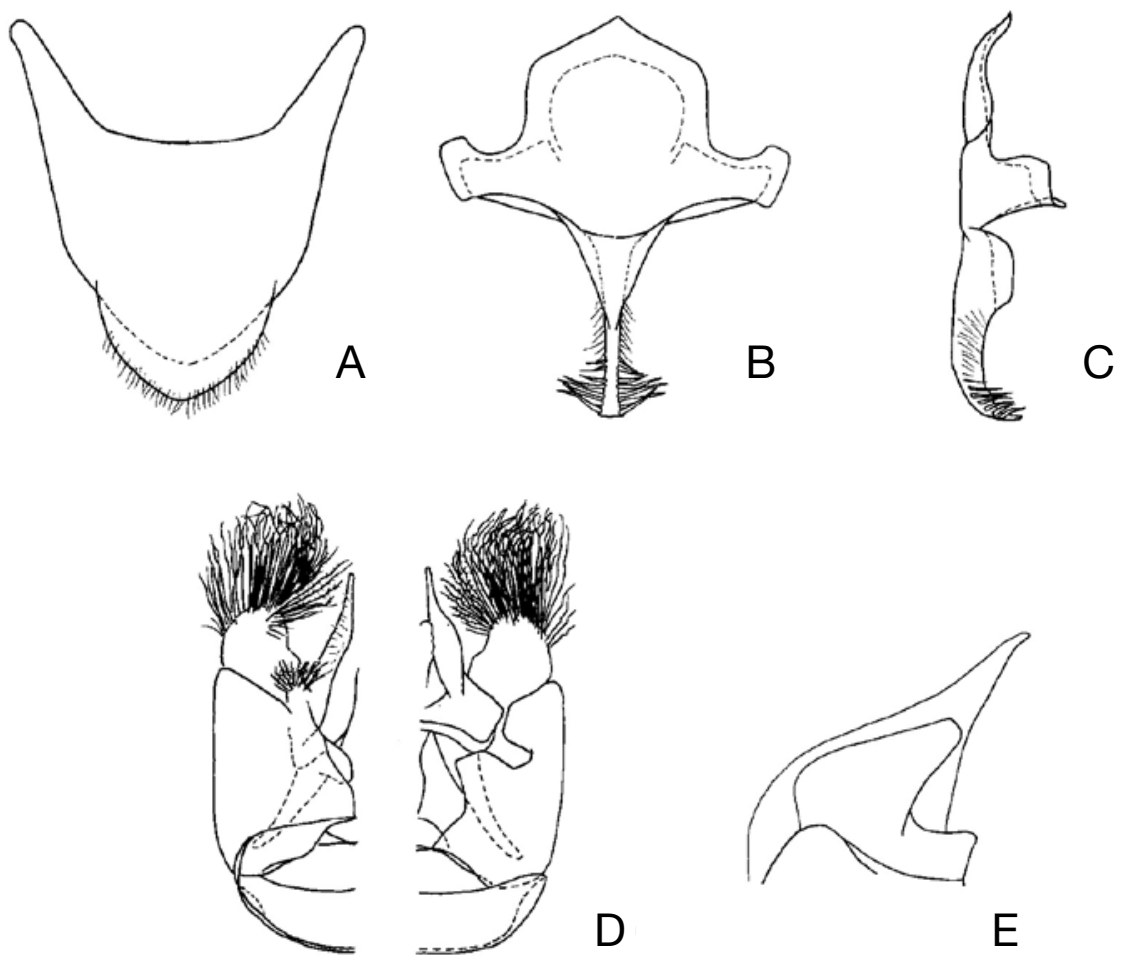

D

Fig. 65. Nomada pacifica (male). A: 7th metasomal sternum, ventral view. B: 8th sternum, dorsal view. C: the same, lateral view. D: genital capsule (left, ventral view; right, dorsal view). E: penis valve and gonostylus, lateral view (vestiture omitted).

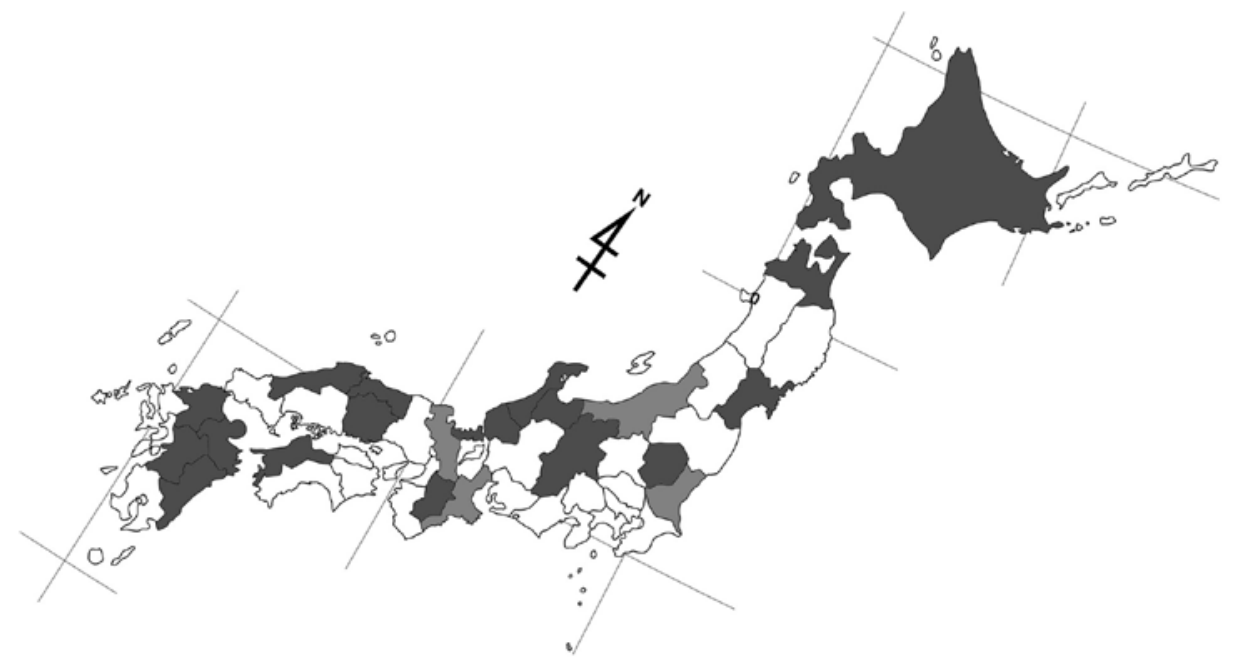

Fig. 66. Distribution of N. pacifica on the Japanese mainlands. Densely shaded: prefectures with the specimens examined in the present study. Lightly shaded: prefectures with records in literature, but no specimens examined in the present study. 
clypeus, malar area, lower paraocular area extending up along inner eye margin to level of lower margin of antennal socket. Scape broadly yellow to narrowly brown anteriorly, black posteriorly, flagellar segments brown anteriorly, black posteriorly.

Mesosoma black; the following portions are yellow or reddish brown: collar on the top, pronotal lobe, macula on anterior portion of mesopleuron with usually distinctly yellow portion in the middle of macula. Tegula brown or reddish brown. Scutellum reddish brown wholly. Rarely a pair of vague reddish brown spots present on lower dorsal portion of propodeum.

Metasoma brown to dark brown, T1 black on basal half; the following portions are yellow: a pair of yellow maculae on $\mathrm{T} 2$ which are transversely elliptical and nearly touching at the middle, or oval and well-separated, a pair of transversely elliptical maculae on T3, band each on T4 and T5 (the band contains a brown spot on each side, the spots sometimes so large that bands broken into a short band and two spots), large macula on T5, small spot on S1 medially, broad band containing a pair of brown maculae laterally on S2-5, those maculae frequently widened, so that bands on S4 and S5 reduced to small spots.

Legs brown; the following portions are black: all coxae except apical margins brown or yellowish brown, small spot on each trochanter posteriorly, fore and mid femora basoventrally, hind femur basoventrally and posteriorly, the black on basoventral surface extends gradually narrowing toward the apex of the segment; apicodorsal surfaces of all tibia tinged with yellow.

Sculpture: As in female, except dorsal surface of propodeum outside triangle weaker than in female.

Vestiture: Vestiture on labrum whitish, dense, long, plumose, evenly in density and length wholly. That on clypeus and supraclypeal area similar to that on labrum but appressed, as to obscure integument. That on lower genal area near hypostoma similar to that on labrum, but slightly longer.

Vestiture on scutum and scutellum pale brown, weakly plumose, erect, long, on scutellum slightly longer. That on mesopleuron whitish, longer and more strongly plumose than on scutum. That on posterolateral to dorsal portion of propodeum outside triangle similar to that on scutum, not forming hair patch.

Vestiture on ventral surface of fore femur as long as the maximum width of segment, that on mid femur somewhat shorter. That on ventral surface of hind femur sparse, short, suberect.

Structure: Body length 7-10.5 mm. CD:UID:LID 50:49:42. OCD/LOD 1.8 .
The following aspects are different from female: interantennal carina semicircular or abruptly lowered anteriorly from level of anterior margin of antennal socket in profile; scape evidently wider than flagellar segments; relative length of FL1-3 1:2.0:1.6, relative length to apical width of FL1 0.8 times ("longer than broad at apex" in original description), FL2 1.6-.17 times, FL3 1.3 times, tyloidea on FL1 recognized as obscure convex, those on FL2-10 sharply delimited, broad oval, that on ultimate segment elliptical, but indistinct; scutellum weakly or moderately, roundly raised, median furrow shallow, sometimes moderately deep; pygidial plate shallowly emarginated at apex; fore femur moderately built; hind femur moderately built; basoventral flattened surface reaching to midpoint of segment, shallowly depressed in posterior view.

Male terminalia: 7th metasomal sternum as in Fig. 65-A. 8th as in Fig. 65-B, C. Gonostylus thick, short; vestiture long, dense, sinuate apically, plumose on apical portion of gonostylus, otherwise simple; basoventral lobe developed, with plumose, long vestiture. Penis valve produced posteriorly beyond gonostylus, apex extending much beyond apex of gonostylus in lateral view. Gonocoxite with deep dorsal invagination; inner dorsal lobe as wide as long, with apex truncate.

Distribution. Japan (Hokkaido, Honshu, Shikoku, Kyushu); South Korea (new record).

Specimens examined. Holotype (MNHAH), 우, attached two labels as follows: "Taniyama/ Fukui, Japan/ 3. v. 1972/ K. Tsuneki (white rectangular and typed)", "Nomada/ pacifica 우/ Tsuneki/ Holotype (red rectangular with handwritten letters)".

Other specimens: We have examined 63 females and 100 males. On the localities, see Fig. 66. Some of them are listed as follows: JAPAN [Hokkaido] 1우, Lake Kanayama, Minamifurano-cho, Kamikawa, 16. vi. 2005 (Y. Maeta). [Honshu] Nagano: 3우, Kijimadaira, 24. v. 1976 (O. Tadauchi, ELKU). Nara: 20', Nara-park, 10. iv. 1952 (R. Ishikawa, ELKU). [Shikoku] Ehime: 10', Omogo, Iyo, 26. iv. 1953 (T. Edashige, ELKU). [Kyushu] Fukuoka: 8우30', Mt. Hikosan, 9. v. 1951 (Y. Hirashima, ELKU). Kumamoto: 1우, Tatsuda-Yama, Kumamoto City, 26. iv. 2005 (N. Sugiura). Oita: 9우, Mt. Sensuisan, Kokonoe-machi, Kusu-gun, 16. v. 2005 (K. Mitai). Miyazaki: 10', Tabuse, Nishimera, 5. iv. 1976 (O. Tadauchi, ELKU). SOUTH KOREA, ð’, Mt. Nogodan, San Nae Myon, Nam Weon-Gun, Cheon La Nam-Do, 13. v. 1991 (O. Tadauchi, ELKU).

Biology. It is a univoltine species, collected from late March to mid June, with most records in April and May (Table 24). One female specimen is collected in late July 
Table 24. Seasonal change of number of the captured individual of $N$. pacifica in Japan (Number of females indicates at the left of slash in cell, that of males at the right. E: early, M: mid, L: late).

\begin{tabular}{|c|c|c|c|c|c|c|c|c|c|c|c|c|c|c|c|c|}
\hline \multirow[b]{2}{*}{ Main island } & \multirow[b]{2}{*}{ Prefecture } & \multicolumn{3}{|c|}{ March } & \multicolumn{3}{|c|}{ April } & \multicolumn{3}{|c|}{ May } & \multicolumn{3}{|c|}{ June } & \multicolumn{3}{|c|}{ July } \\
\hline & & $E$ & $\mathrm{M}$ & $\mathrm{L}$ & $\mathrm{E}$ & $\mathrm{M}$ & $\mathrm{L}$ & $\mathrm{E}$ & $\mathrm{M}$ & $\mathrm{L}$ & $\mathrm{E}$ & $\mathrm{M}$ & $\mathrm{L}$ & $\mathrm{E}$ & $M$ & $\mathrm{~L}$ \\
\hline HOKKAIDO & & & & & & & & 14 & $1 /$ & $2 / 3$ & & $1 /$ & & & & $1 /$ \\
\hline \multicolumn{17}{|l|}{ HONSHU } \\
\hline \multirow[t]{2}{*}{ [Tohoku] } & Aomori & & & & & & & & & 13 & $/ 1$ & & & & & \\
\hline & Miyagi & & & & & & 13 & $/ 1$ & & & & & & & & \\
\hline [Kanto] & Tochigi & & & & & & & $/ 1$ & & & & & & & & \\
\hline \multirow[t]{3}{*}{ [Chubu] } & Ishikawa & & & & & & & 12 & & & & & & & & \\
\hline & Fukui & & & & $1 / 21$ & $2 / 2$ & $7 / 15$ & $5 / 8$ & $2 / 10$ & $2 / 1$ & & & & & & \\
\hline & Nagano & & & & & & & & & $3 /$ & & & & & & \\
\hline \multirow{3}{*}{$\begin{array}{l}\text { [Kinki] } \\
\text { [Chugoku] }\end{array}$} & Nara & & & & 13 & & & & & & & & & & & \\
\hline & Tottori & & & & & & & $/ 1$ & & & & & & & & \\
\hline & Shimane & & & & & 1/ & $/ 1$ & & & & & & & & & \\
\hline SHIKOKU & Ehime & & & & & & $/ 1$ & & & & & & & & & \\
\hline \multirow[t]{4}{*}{ KYUSHU } & Fukuoka & & & & & $/ 1$ & & $10 / 7$ & $7 / 1$ & & & & & & & \\
\hline & Kumamoto & & & $/ 1$ & & & $1 /$ & & & & & & & & & \\
\hline & Oita & & & & & & $1 / 1$ & & 9/ & $3 /$ & & & & & & \\
\hline & Miyazaki & & & & $/ 1$ & & & & & & & & & & & \\
\hline \multicolumn{2}{|c|}{ Total } & 0 & 0 & 1 & 26 & 6 & 30 & 39 & 30 & 17 & 1 & 1 & 0 & 0 & 0 & 1 \\
\hline
\end{tabular}

in Hokkaido. The specimen is regarded not as the first generation but as the untimely occurred adult because it is only one, and no differences among individuals collected in spring and in July.

Floral associations are as follows: [Salicaceae] Salix hultenii var. angustifolia, Salix petsusu, Salix sachalinensis. [Rosaceae] Potentilla fragarioides var. major. [Compositae] Petasites japonicus, Taraxacum officinale. The host is unknown.

Remarks. This species can be easily separated in both sexes from the Japanese congeners in the widely truncate mandible and the characteristic apicomedian setae on the hind tibia. However, the recognition as a good species is problematic, considering the relevance to Nomada ruficornis (Linnaeus) which is distributed in Europe. According to our examination, N. pacifica differs from $N$. ruficornis in having the widely truncate mandible in both sexes (deeply emarginated in truncate mandible so that bidentate in N. ruficornis), the strongly produced apical margin of the hind tibia in female, the more highly raised tyloidea on the male antenna, the yellow or reddish brown scutellum in male. The latter three distinctions seem not to be decisive because such characters are easy to vary intraspecifically in Nomada species. Although the first character state is stable gen- erally in the specimens from Japan, the specimens from South Korea have the feebly or distinctly apically emarginated mandibles, so that sometimes it is difficult to assign them to $N$. pacifica or $N$. ruficornis. In the present study, we stand on the conservative view, namely that $N$. pacifica is a good species. However, abundant materials from various localities from Japan to Europe are needed to examine in order to evaluate their independency as a good species.

24. Nomada panzeri orientis Tsuneki, 1973 [Japanese name: Mizuho-kimadara-hanabachi] (Figs. 67-69; Table 25)

Nomada panzeri orientis Tsuneki, 1973, Etizenia, 66: 68-72 [Holotype: Female. Type locality: Sanjuhassa, Fukui Pref., Honshu, Japan]; Alexander \& Schwarz, 1994, Univ. Kansas Sci. Bull., 55: 251 [in list].

Nomada sabanensis (male) Tsuneki, 1973, Etizenia, 66: 60-62.

Nomada floricola Tsuneki, 1973, Etizenia, 66: 78-79 [Holotype: Female]; Alexander \& Schwarz, 1994, Univ. Kansas Sci. Bull., 55: 247 [in list]. syn. nov.

Nomada nunobensis Tsuneki, 1986, Spec. Pub. Jap. Hym. Assoc., 32: 50 [Holotype: Female]; Alexander 
\& Schwarz, 1994, Univ. Kansas Sci. Bull., 55: 253 [in list]. syn. nov.

\section{Redescription.}

\section{Female.}

Color: Head largely reddish brown; the following portions are black: macula on antennal area except supraclypeal area reddish brown, line on subantennal suture to epistomal suture which usually ending at the anterior tentorial pit, transverse elliptical macula surrounding ocelli on vertex (rarely two maculae above connecting partially), broad line on genal area along preoccipital ridge from hypostoma up to level of top of compound eye in profile. Mandible reddish brown except apical one-third dark red. Antenna pale reddish brown wholly with thin black line on posterior surface of scape, or whole posterior surface of antenna darkened.

Mesosoma black; the following portions are reddish

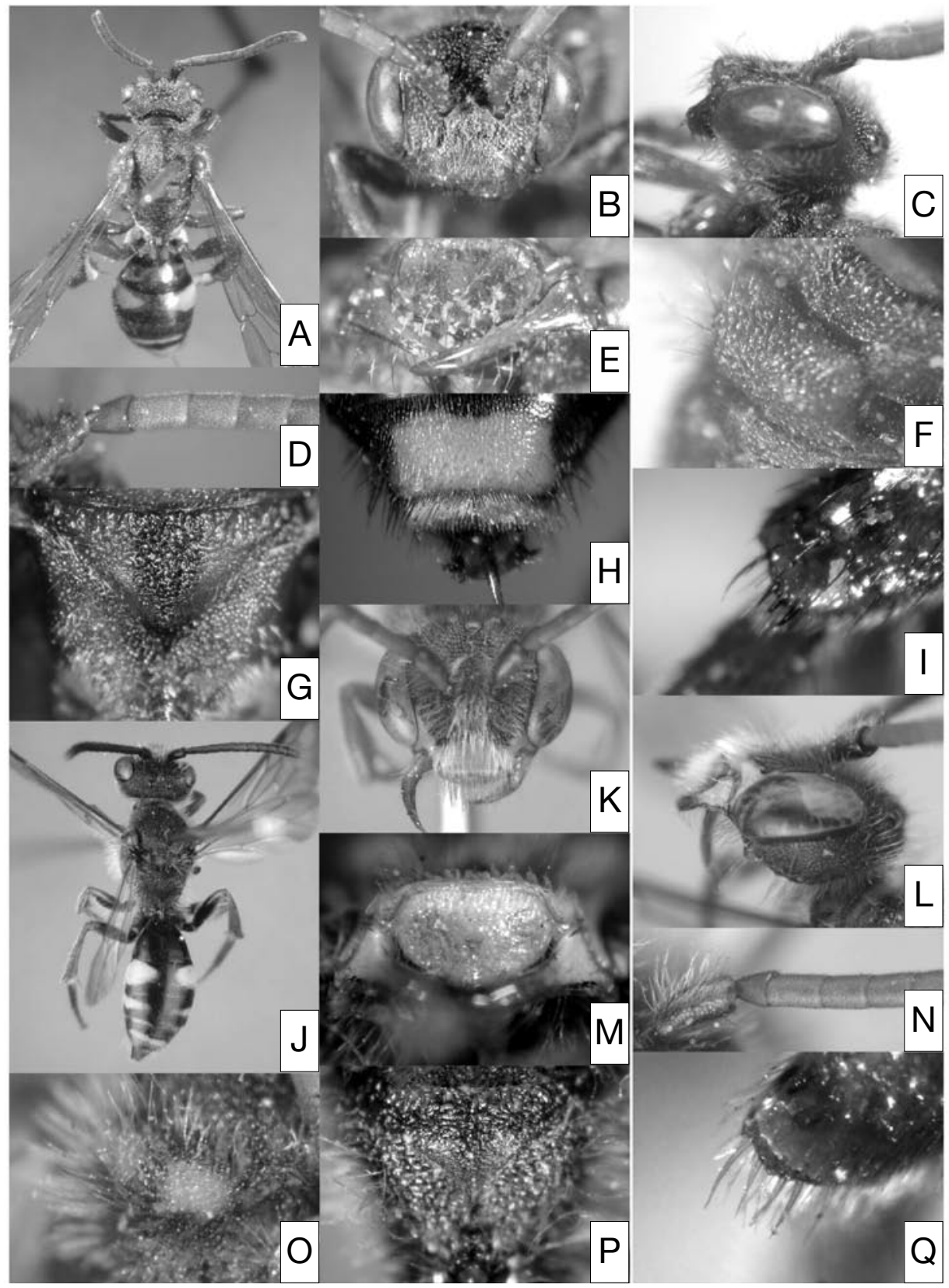

Fig. 67. Nomada panzeri orientis Tsuneki. Female: A-I. Male: J-Q. A, J: habitus, dorsal view. B, C, K, L: head. D, N: antenna. E, M: labrum. F, O: scutellum. G, P: propodeal triangle. H: pseudopygidium. I, Q: apicomedian setae on hind tibia. 
brown: collar, anterior margin of pronotum but sometimes apicolateral portion black, four broad longitudinal lines on scutum which usually fused partially, sometimes wholly fused to become a pair of large maculae, tegula, axilla, scutellum, mesopleuron except black peripheral portion and a black macula of variable size on ventral side, a pair of large maculae on posterolateral corner of propodeum which expanded anteriorly to reach to propodeal spiracle, posteriorly leaving longitudinal medial black line.

Metasoma largely reddish brown, T1 black on basal half; the following portions are yellow: a pair of oval maculae on T2, obliterated small spot on lateral side of T3, a pair of small transverse maculae on T4, large macula on T5, a pair of spots each on S3 and S4, two or four irregular spots on S5. The latter spots are frequently lacking.

Legs reddish brown; the following portions are black: all coxae posteriorly, basal maculae on all femo$\mathrm{ra}$, the black portions on anterior and posterior surface extend and become narrower apically. In specimens with less developed black portions, the black on fore and mid femora restricted to on narrow posterior portion.

Sculpture: Punctures on labrum small, indistinct. Those on clypeus slightly larger, more distinct, but shallower apically. Those on supraclypeal area further distinct.

Punctures on scutellum as on scutum. Mesopleuron moderately areolate. Lateral and dorsal sides outside triangle of propodeum areolate, more densely than on mesopleuron. Propodeal triangle irregularly rugose, the rugae usually not highly raised, but sometimes do and complicated as to show maze-like pattern, the remaining portion tessellate.

Terga faintly microsculptured with moderately dense, weak punctules. Pygidial plate with punctures small, shallow, dense.

Vestiture: Vestiture on labrum pale brown, long and weakly plumose on apical margin. That on clypeus sparse, short, appressed, very strongly plumose. That on lower genal area near hypostoma pale brown, moderately dense, as long as on apical portion of labrum.

Vestiture on scutum inconspicuous, dark brown tinged with golden, short, simple, suberect, sparse. That on mesopleuron whitish, fine, plumose, much longer than on scutum, sparse. That on posterolateral surface of propodeum white, very short, plumose, not dense to form hair patch.

Terga with very sparse inconspicuous pubescence, T1 frequently virtually hairless. Pseudopygidium long in longitudinally length, strongly yellowish shining, composed of strongly modified elongated scale-like hairs. Pygidial plate covered with fine, short hairs.

Structure: Body length 6-9 mm. CD:UID:LID 50:48:44. OCD/LOD 1.4.

Interantennal elevation moderately raised. Inner eye margins evidently convergent below. Clypeus weakly raised and produced anteriorly. Labrum 1.5- 1.6 times as wide as long; labral tooth present at the center, accompanied by serrated carina on each side; apical portion below labral tooth triangularly produced anteriorly, weakly upcurved; apical margin serrated with a triangular protuberance medially or sometimes without a distinct protuberance. Mandible slender. Preoccipital ridge rounded behind vertex, angulated or carinated apically. Relative length of FL1-3 1:1.7:1.4, relative length to apical width of FL1 1.0 times, FL2 1.8 times, FL3 1.4-1.5 times.

Scutellum moderately highly and roundly raised, median furrow wide and moderately deep. Hypoepimeral area completely flat. Posterior area around propodeal spiracle shallow concave, without ridge above it. Pygidial plate brown, apical margin rounded, with shallow notch at apex.

Fore femur slender. Apicomedian setae on hind tibia five to eight in number, moderately robust, brown to black, irregularly spaced, posteriormost seta slightly longer or as long as others which are roughly the same in length.

\section{Male.}

Color: Head black; the following portions are yellow: mandible except apical one-third blackish, clypeus on apical half to two-thirds, malar space, lower paraocular area extending up narrowly along inner eye margin usually to level of antennal socket. Scape wholly black or anteriorly with brown portion which variously developed.

Mesosoma black except as follows; tegula reddish brown, scutellum with a pair of reddish brown maculae of variable size, usually well-separated two maculae, sometimes too small to discern, sometimes fused into an elliptical large macula, transverse small yellow macula on anterior portion of mesopleuron.

Metasoma dark brown to black, usually intermacular space less dark, sometimes T1 pale brown on apical half; the following portions are yellow: a pair of oval or triangular maculae each on $\mathrm{T} 2$ and $\mathrm{T} 3$ (the latter much smaller), elliptical macula each on T4 and T5 (that on T3 narrowly interrupted), large macula on T6 medially, medially upcurved band each on S2-5 which are frequently interrupted variously among individuals, S6 antero- 

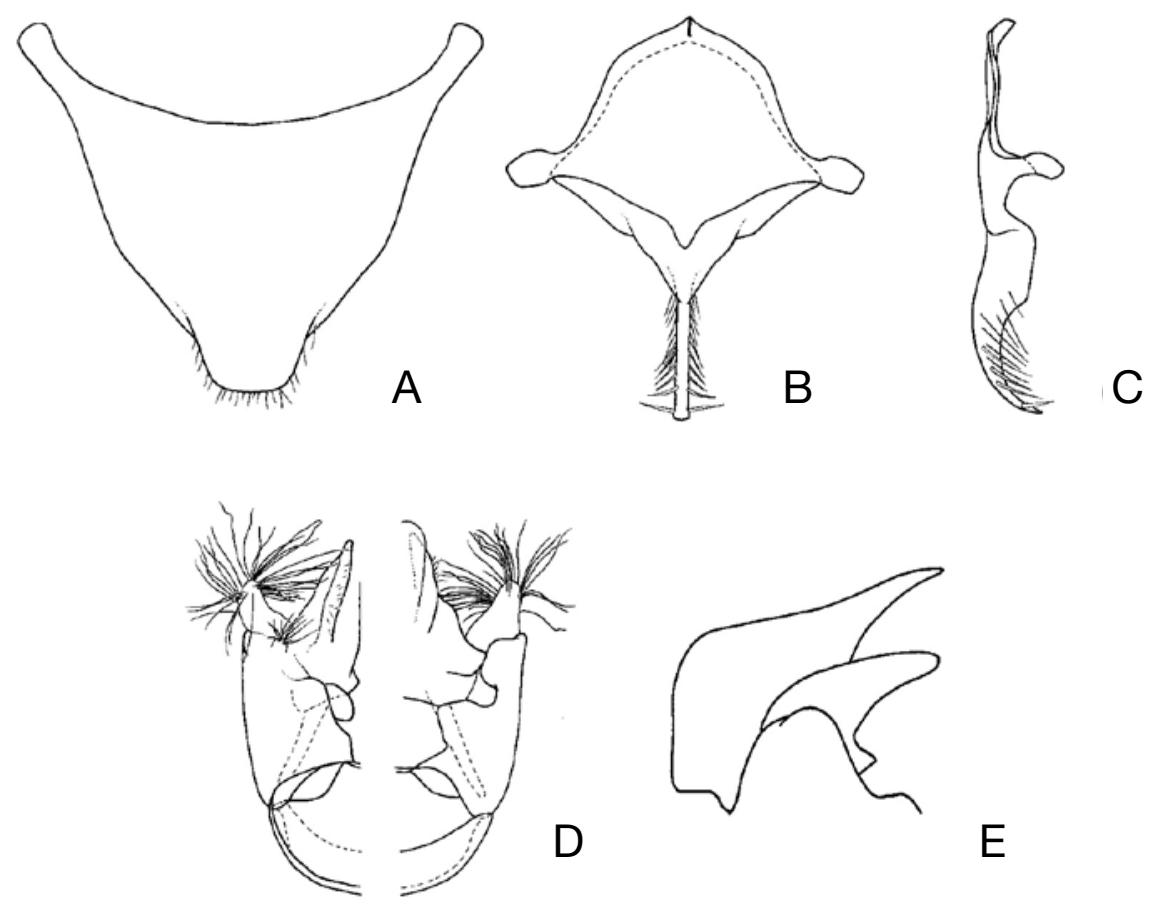

D

$E$

Fig. 68. Nomada panzeri orientis (male). A: 7th metasomal sternum, ventral view. B: 8th sternum, dorsal view. C: the same, lateral view. D: genital capsule (left, ventral view; right, dorsal view). E: penis valve and gonostylus, lateral view (vestiture omitted).

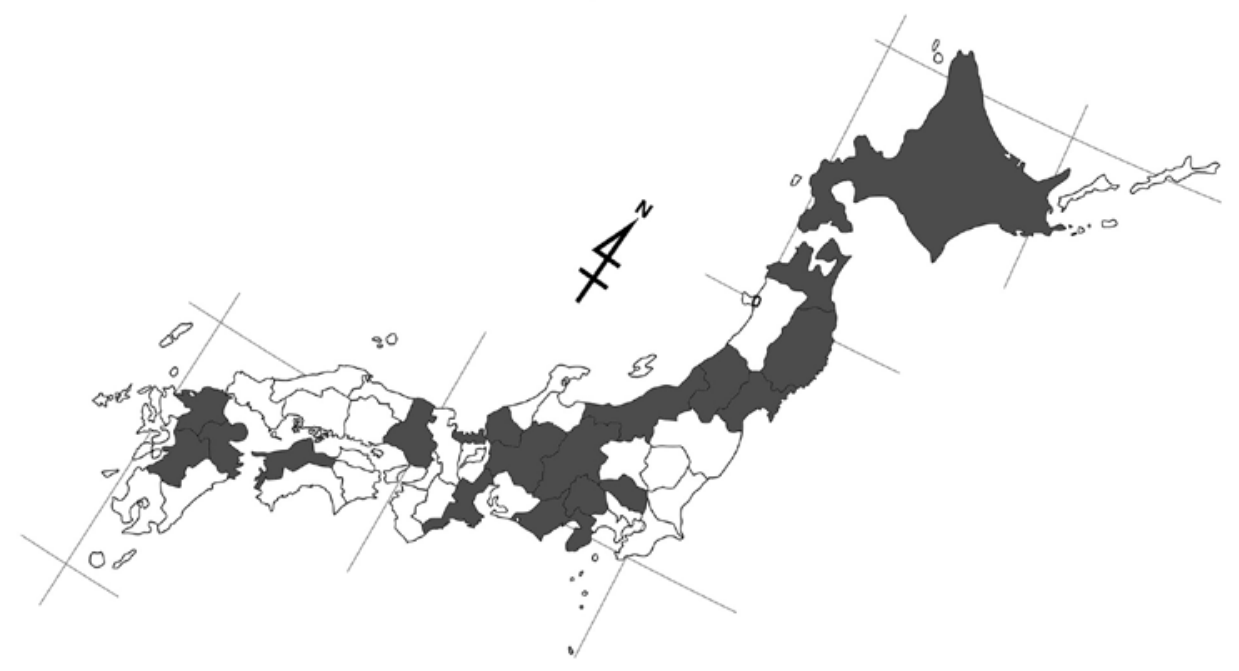

Fig. 69. Distribution of N. panzeri orientis on the Japanese mainlands. Shaded: prefectures with the specimens examened in the present study. 
medially.

Legs largely pale brown; the following portions are black: all coxae posteriorly, short line on each basoventral surface of fore and mid femora, hind femur basoventrally and posteriorly.

Sculpture: Sculpture on mesopleuron denser than in female, otherwise as in female.

Vestiture: Vestiture on labrum pale brown, evenly longer, somewhat longer on apical margin, plumose. That on clypeus and supraclypeal area white, strongly plumose, appressed, dense as to obscure integument. That on lower genal area near as long as on labrum.

Vestiture on scutum and scutellum whitish, fine, very long, weakly plumose. That on mesopleuron similar in density and length to that on scutum, strongly plumose. That on posterolateral to dorsal surface of propodeum outside triangle similar to that on scutum, not forming hair patch.

Vestiture on ventral surfaces of fore and mid femora evidently longer than the maximum width of each segment. That on ventral surface of hind femur with fine, short, erect, straight hairs.

Structure: Body length 6-9 mm. CD:UID:LID 50:50:40. OCD/LOD 1.8.

The following aspects are different from female: interantennal elevation and carina on it weakly raised, the carina abruptly lowered anteriorly from level of anterior margin of antennal socket in profile; preoccipital ridge rounded behind vertex, slightly angulated apically; scape slightly wider than flagellar segments; relative length of FL1-3 1:1.7:1.4, relative length to apical width FL1 0.9 times, FL2 1.7-1.8 times, FL3 1.3-1.4 times, tyloidea on FL1 absent, those on FL2 and FL3 oval, weakly raised, those on the following segments recognized as obscure convex; scutellum weakly, roundly raised, median furrow shallow; posterior area around propodeal spiracle flat or feebly concave, without a ridge; pygidial plate narrowly, deeply emarginated at apex; hind femur slender; basoventral flattened surface indistinct, not reaching to midpoint of segment, shallowly depressed in posterior view; apicomedian setae on hind tibia slenderer and usually paler than in female, difficult to discern

Table 25. Seasonal change of number of the captured individual of $N$. panzeri orientis in Japan (Number of females indicates at the left of slash in cell, that of males at the right. E: early, M: mid, L: late).

\begin{tabular}{|c|c|c|c|c|c|c|c|c|c|c|c|c|c|}
\hline \multirow[b]{2}{*}{ Main island } & \multirow[b]{2}{*}{ Prefecture } & \multicolumn{3}{|c|}{ March } & \multicolumn{3}{|c|}{ April } & \multicolumn{3}{|c|}{ May } & \multicolumn{3}{|c|}{ June } \\
\hline & & $E$ & $M$ & $\mathrm{~L}$ & $\mathrm{E}$ & $M$ & $\mathrm{~L}$ & $E$ & $\mathrm{M}$ & $\mathrm{L}$ & $E$ & $\mathrm{M}$ & $\mathrm{L}$ \\
\hline HOKKAIDO & & & & & & & $3 / 2$ & $4 / 7$ & $5 /$ & $4 / 1$ & $2 / 1$ & & \\
\hline \multirow{5}{*}{$\begin{array}{l}\text { HONSHU } \\
\qquad \text { [Tohoku] }\end{array}$} & & & & & & & & & & & & & \\
\hline & Aomori & & & & & & $/ 2$ & $/ 1$ & $/ 1$ & $3 / 1$ & & & \\
\hline & Iwate & & & & & & $/ 1$ & 12 & & $2 /$ & $1 /$ & & \\
\hline & Miyagi & & & & & & & $1 / 2$ & & & & & \\
\hline & Yamagata & & & & & & & & & $1 /$ & & & \\
\hline [Kanto] & Saitama & & & & & $1 /$ & & & & & & & \\
\hline [Chubu] & Niigata & & & \multirow{6}{*}{$/ 1$} & $/ 1$ & $/ 1$ & & & $/ 1$ & $1 /$ & & & \\
\hline & Fukui & & & & $/ 1$ & & 13 & $2 / 3$ & $5 / 6$ & & $2 /$ & & \\
\hline & Yamanashi & & & & & & & $/ 1$ & & & & & \\
\hline & Nagano & & & & $/ 2$ & 13 & 15 & $/ 4$ & $1 / 1$ & $3 /$ & & & \\
\hline & Gifu & & & & & & & $1 /$ & & & & & \\
\hline & Shizuoka & & & & & & & $/ 1$ & & & & & \\
\hline \multirow[t]{2}{*}{ [Kinki] } & Mie & & & & & & $1 /$ & & & & & & \\
\hline & Hyogo & & & & $/ 3$ & & & & & & & & \\
\hline [Chugoku] & Yamaguchi & & & & $/ 1$ & & & & & & & & \\
\hline SHIKOKU & Ehime & & & & & $/ 1$ & & & & & & & \\
\hline KYUSHU & Fukuoka & & & \multirow{3}{*}{$/ 1$} & $7 / 1$ & $7 /$ & $1 / 2$ & $1 /$ & & & & & \\
\hline & Kumamoto & & & & $/ 1$ & & & & & & & & \\
\hline & Oita & & & & $/ 1$ & & & & & & & & \\
\hline \multicolumn{2}{|l|}{ Total } & 0 & 0 & 2 & 19 & 13 & 20 & 30 & 20 & 16 & 6 & 0 & 0 \\
\hline
\end{tabular}


among surrounding hairs, otherwise as in female.

Male terminalia: 7th metasomal sternum as in Fig. 68-A. 8th as in Fig. 68-B, C. Gonostylus comparatively slender, roughly cylindrical; vestiture long, simple, very sparse, feebly sinuate apically; basoventral lobe developed, with sparse, simple, long vestiture. Penis valve produced posteriorly much beyond gonostylus, apex not extending beyond apex of gonostylus in lateral view. Gonocoxite with deep dorsal invagination; inner dorsal lobe wider than long, with apex truncate.

Distribution. Japan (Hokkaido, Honshu, Shikoku, Kyushu); South Korea (new record).

Specimens examined. Holotype (MNHAH), 우, Sanjuhassa, Fukui Pref. Honshu, Japan. 3. May.1956 (K. Tsuneki).

Other specimens: We have examined about $60 \mathrm{fe}-$ males and 90 males. On the localities, see Fig. 70. Some of them are listed as follows: JAPAN [Hokkaido] 1우 4 ऽ', Botanical garden, Sapporo, 4. v. 1964 (S. Sakagami, MNHAH). [Honshu] Aomori: 2오, Moya, Aomori, 30. v. 1975 (O. Tadauchi, ELKU). Iwate: $20^{\nearrow}$, Morioka, 9. v. 1971 (T. Chiba, NIAES). Yamagata: 1우, Tochiuda, Maruyama, 26. v. 1975 (O. Tadauchi, ELKU). Saitama: Yamazaki, Sakurasawa, Yorii, 16. iv. 1997 (T. Nambu). Niigata: Kurokawa, 10', 10. iv. 1985, 10', 19. iv. 1986 (K. Baba, ELKU). Fukui: $3 \sigma^{\nearrow}$, Mt. Somayama, 26. iv. 2006 (K. Mitai). Yamanashi: 10', Mt. Ohdeyama, Yamanakako Vil., 9. v. 1988 (H. Suda). Nagano: 20', Minamiminowa, Ina, 7. iv. 1961 (Y. Maeta). Gifu: 1 우, Hatahoko, Mt. Norikura, 8. v. 1976 (O. Tadauchi, ELKU). Shizuoka: 1б', Mt. Amagi, Izu, 7. v. 1975 (T. Nambu, MNHAH). Mie: 1우, Kan-onji-chô, Tsu-shi, 25. iv. 1936 (Collector unknown, ELKU). Hyogo: 20', Kiyoshikojin, Kishoshi, Maitani, Takarazuka-shi, 7. iv. 1955 (T. Kifune, ELKU). Yamaguchi: 20', Hagi, 5. iv. 19?? (Collector unknown, ELKU). [Shikoku] Ehime: 10', Ochiai, Kuma-machi, 15. iv. 1976 (O. Tadauchi, ELKU). [Kyushu] Fukuoka: 7우, Adachi Park, Kokurakita-ku, Kitakyushu-shi, 3. iv. 2006 (K. Mitai). Kumamoto: 1 ऽ, Tatsuda-Yama, Kumamoto City, 31. iii. 2006 (N. Sugiura). Oita: $1 \sigma^{\nearrow}$, Mt. Hanamureyama, Shônai-machi, Oita-gun, 6. iv. 2006 (K. Mitai). SOUTH KOREA, $1 \sigma^{\top}$, Mt. Hokkan, 19. iv. 1942 (K. Tsuneki, MNHAH); 1우10', Kawang Nung, Pochon-Gun, Kyongi-Do, 23. iv. 1992 (O. Tadauchi, ELKU).

Biology. It is a univoltine species, collected from late March to early June, with most records in April and May (Table 25). Floral associations are as follows: [Salicaceae] Salix future. [Cruciferae] Rorippa indica. [Hamamelidaceae] Corylopsis spicata. [Rosaceae] Potentilla fragarioides var. major, Rubus oldhamii. [Compositae]
Petasites japonicus, Taraxacum officinale. [Liliaceae] Gagea lutea. The host is unknown.

Remarks. The identification of this subspecies is considerably confused with the related species, therefore, all records in literature are excluded from Fig. 69. The male described as the male of Nomada sabaensis Tsuneki in Tsuneki (1973) corresponds to the true male of this subspecies. The females in paratype series of this subspecies contain $N$. fukuiana Tsuneki.

The female is similar to Nomada towada Tsuneki, N. fukuiana Tsuneki, N. leucophthalma (Kirby) and $N$. fusca Schwarz, but easily recognized from them by the highly reflective pseudopygidium composed of the short, greatly modified scale-like setae. This character state applies to the separation from the nominotypical subspecies panzeri.

The recognition of the male is not fully resolved. The males of the relative species, $N$. leucophthalma and $N$. fusca are unknown in Japan. In Europe, males of $P$. panzeri, leucophthalma, fusca are structurally unrecognizable, but can be separated only by the coloration (M. Schwarz, personal communication). Possibly this distinction based on their colorations can not be applied to individuals from Japan, so that the male specimens identified as $N$. panzeri orientis by us are likely to contain multiple species. Another problem is about the distinction from the male of $N$. towada. Nomada panzeri orientis and $N$. towada are good species respectively on the grounds of the above-mentioned, clear difference between females, and between male genitalia. In addition, it seems reasonable that the combinations of sexes is true, judging from the frequent co-occurrence of sexes of each species. However, N. panzeri and $N$. towada differ only by the coloration on face, except the differences of the genitalia, and sometimes the intermediate occurs, in such case it is difficult to identify them external-morphologically.

25. Nomada pyrifera Cockerell, 1918

[Japanese name: Nashimon-kimadara-hanabachi] (Figs. 70-72; Table 26)

Nomada pyrifera Cockerell, 1918, Ann. Mag. Nat. Hist. London, 9 (2): 480-481 [Holotype: Female. Type locality: "presumably Tokyo"]; Tsuneki, 1973, Etizenia, 66: 60-62 [redescription]; Alexander \& Schwarz, 1994, Univ. Kansas Sci. Bull., 55: 251 [in list].

\section{Redescription.}

Female.

Color: Head largely reddish brown, usually tinged 
with yellow on lower face, sometimes clypeus and supraclypeal area distinctly yellow, but sometimes only apical portion of clypeus tinged with yellow; the following portions are yellow: labrum except apical portion tinged with brown, malar area below paraocular ridge; the following portions are black: spot on anterior tentorial pit, macula just above antennal socket, transverse elliptical macula surrounding ocelli (two maculae above fused partially), line on genal area along preoccipital ridge from hypostoma up to level of top of compound eye in profile. Mandible reddish brown except apical one-third dark red or black. Antenna wholly pale reddish brown.

Mesosoma black; the following portions are reddish brown: collar on the top which usually tinged with yellow, anterior margin of pronotum, pronotal lobe, tegula, four but sometimes fused partially, longitudinal lines on scutum, axilla, scutellum, mesopleuron except narrowly peripheral margin and macula of variable size on ventral
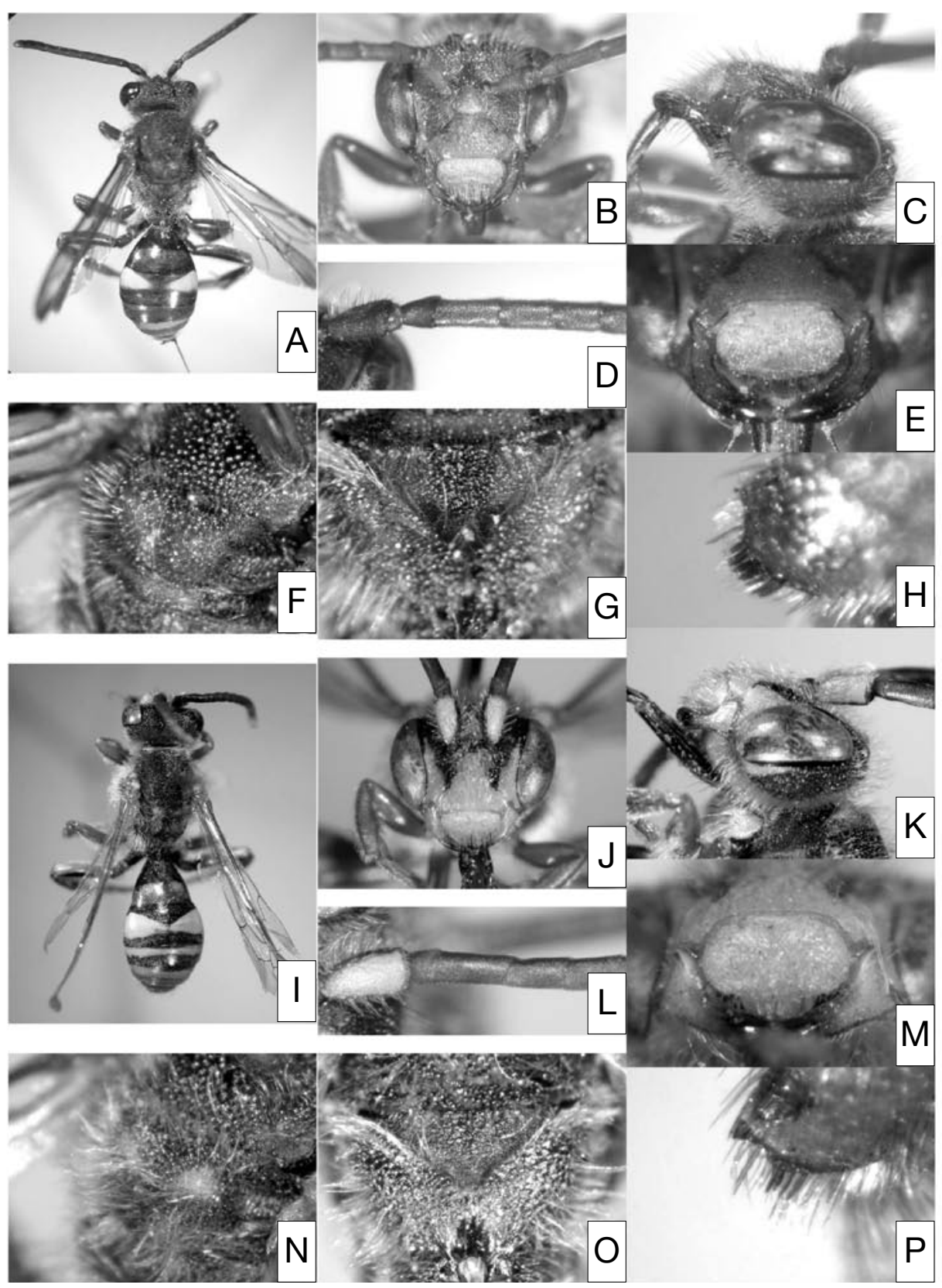

Fig. 70. Nomada pyrifera Cockerell. Female: A-H. Male: I-P. A, I: habitus, dorsal view. B, C, J, K: head. D, L: antenna. E, M: labrum. F, N: scutellum. G, O: propodeal triangle. H, P: apicomedian setae on hind tibia. 
side, metanotum, a pair of large maculae on posterolateral corner of propodeum which expanded anteriorly to reach to propodeal spiracle, posteriorly into basolateral corner of triangle.

Metasoma largely reddish brown, T1 black on basal half; the following portions are yellow: a pair of large maculae on T2, complete band on T4 (usually constant in width, but sometimes narrowed or narrowly interrupted by a brown spots each on lateral side of T4), T5 nearly wholly, S1-4 largely yellow except apical translucent margin.

Legs largely reddish brown; the following portions are black: fore coxa basally and all coxae posteriorly, line on posterior surface of hind femur.

Sculpture: Punctures on labrum small, shallow, dense. Those on clypeus small intermixed with larger ones. Those on supraclypeal area larger.

Punctures on scutellum as on scutum. Mesopleuron distinctly areolate. Lateral and dorsal sides outside triangle of propodeum densely areolate, denser than on mesopleuron, sometimes dorsal surface outside triangle sparse, shallow. Propodeal triangle irregularly coarsely rugose basally and centrally, interspaces among rugae and the remaining portion distinctly tessellate, the tessellation strong centrally as to show transversely striate rugae.

Terga faintly microsculptured, with moderately dense punctules except T1 impunctate. Pygidial plate with large, comparatively dense punctures, impunctate margin wide.

Vestiture: Vestiture on labrum pale brown, weakly plumose, erect, short. That on clypeus and supraclypeal area as on labrum, but sparser and appressed. That on lower genal area near hypostoma somewhat longer on hairs on apical margin of labrum.

Vestiture on scutum and scutellum pale brown, erect, weakly plumose, on scutellum slightly longer than on scutum. That on mesopleuron plumose whitish, erect, as dense as on scutum. That on posterolateral to dorsal surface of propodeum outside triangle as on mesopleuron, considerably hairy but not forming distinct hair patch. Pygidial plate covered with sparse long hairs.

Vestiture on terga very sparse, especially T1 nearly hairless. Pseudopygidium small.

Structure: Body length 9-11 mm. CD:UID:LID 50:50:45. OCD/LOD 1.9.

Interantennal elevation moderately or highly raised. Inner eye margins moderately convergent below. Clypeus moderately raised and produced anteriorly. Labrum 1.5-1.6 times as wide as long; labral tooth present evi- dently before the center, not accompanied by carina; apical portion below labral tooth not produced anteriorly, not upcurved; apical margin not serrated. Preoccipital ridge rounded behind vertex, gradually angulated and carinated apically. Relative length of FL1-3 1:2.2:1.7, relative length to apical width of FL1 equal times, FL2 2.2-2.3 times, FL3 1.8 times, each of the following segments more than 1.5 times.

Collar carinate on top with a shallow excavation in the middle. Scutellum highly raised, median furrow deep, convexities roughly triangular conical. Metapleuron distinctly convex on upper portion. Posterior area around propodeal spiracle concave, with a ridge. Pygidial plate brown, triangular at apical portion.

Fore femur moderately built. Apicomedian setae on hind tibia 10-13 in number, posteriormost seta pale brown, slightly longer and slenderer than others, acute at apex, others close together, difficult to discern individually, located a little apart from posteriormost seta, dark brown, somewhat flattened, blunt at apex.

\section{Male.}

Color: Head black; the following portions are yellow: mandible except apical one-third dark reddish, labrum, clypeus, supraclypeal area, lower paraocular extending up along inner eye margin to level of upper antennal socket, line along outer eye margin extending from hypostoma to level of lower antennal socket in profile. Vague reddish spot present along top of compound eye but sometimes lacking. Scape yellow anteriorly, flagellar segments reddish brown anteriorly, scape and flagellar segments black posteriorly.

Mesosoma black; the following portions are yellow: collar on the top, pronotal lobe, two maculae on scutellum (usually peripheral margin of the maculae tinged with brown), a vague yellow spot on metanotum but frequently lacking, macula on anterior portion of mesopleuron; the following portions are reddish brown: vague small spot on hypoepimeral area, a pair of spots on dorsolateral corner of propodeum. The latter spot sometimes enlarged and distinctly yellow.

Metasoma black except as follows: T1 pale brown on apical half containing a pair of vague round yellow spots, complete yellow band each on T2 -5 (that on T2 narrowed greatly in the middle), T6 and T2-6 nearly wholly yellow, pygidial plate largely yellow basally.

Legs pale brown to brown, successively darker in fore leg to hind leg, fore coxa anteriorly and mid coxae apicoanteriorly yellow, upper portions of fore and mid trochanter tinged with yellow; the following portions are black: fore coxa posteriorly, mid coxa nearly wholly, hind coxa posteriorly, mid femur basoventrally, hind fe- 

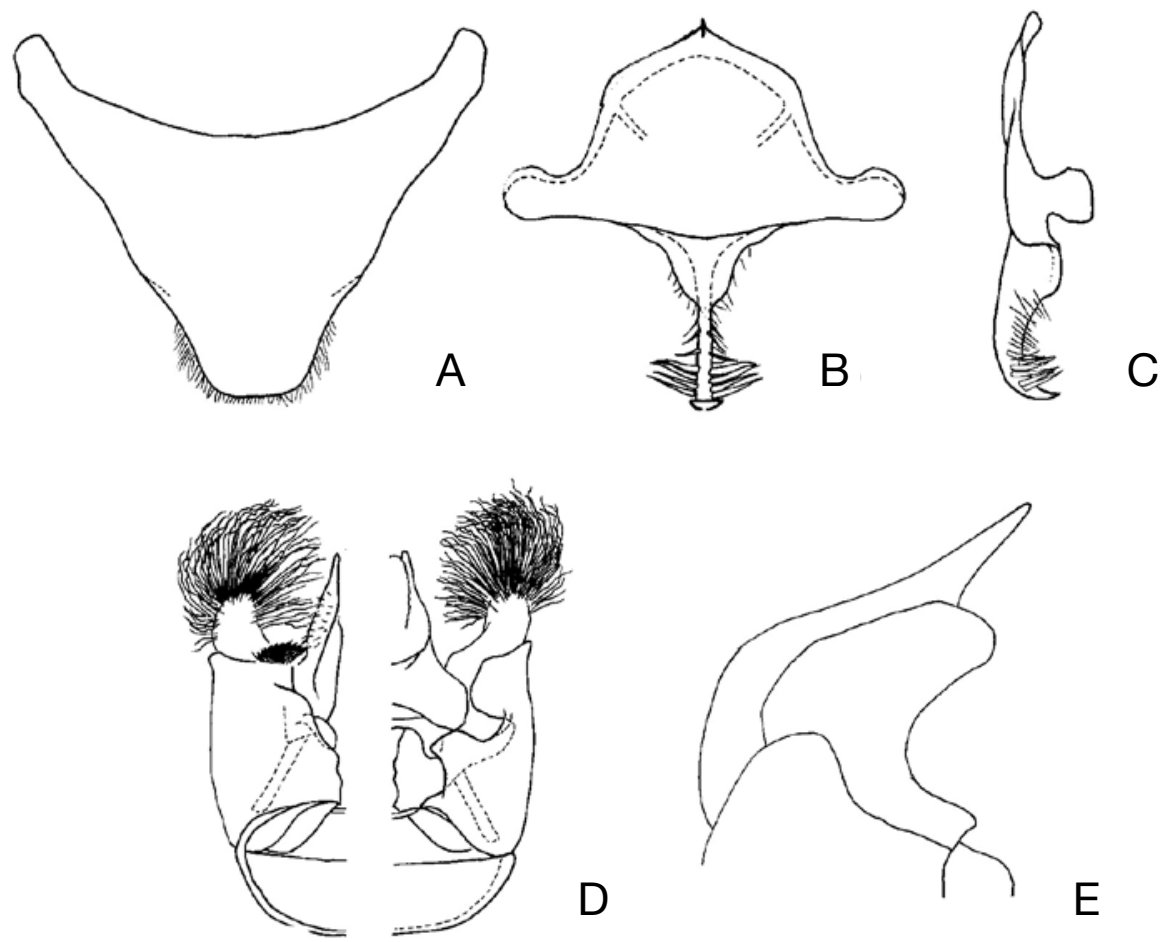

$E$

Fig. 71. Nomada pyrifera (male). A: 7th metasomal sternum, ventral view. B: 8th sternum, dorsal view. C: the same, lateral view. D: genital capsule (left, ventral view; right, dorsal view). E: penis valve and gonostylus, lateral view (vestiture omitted).

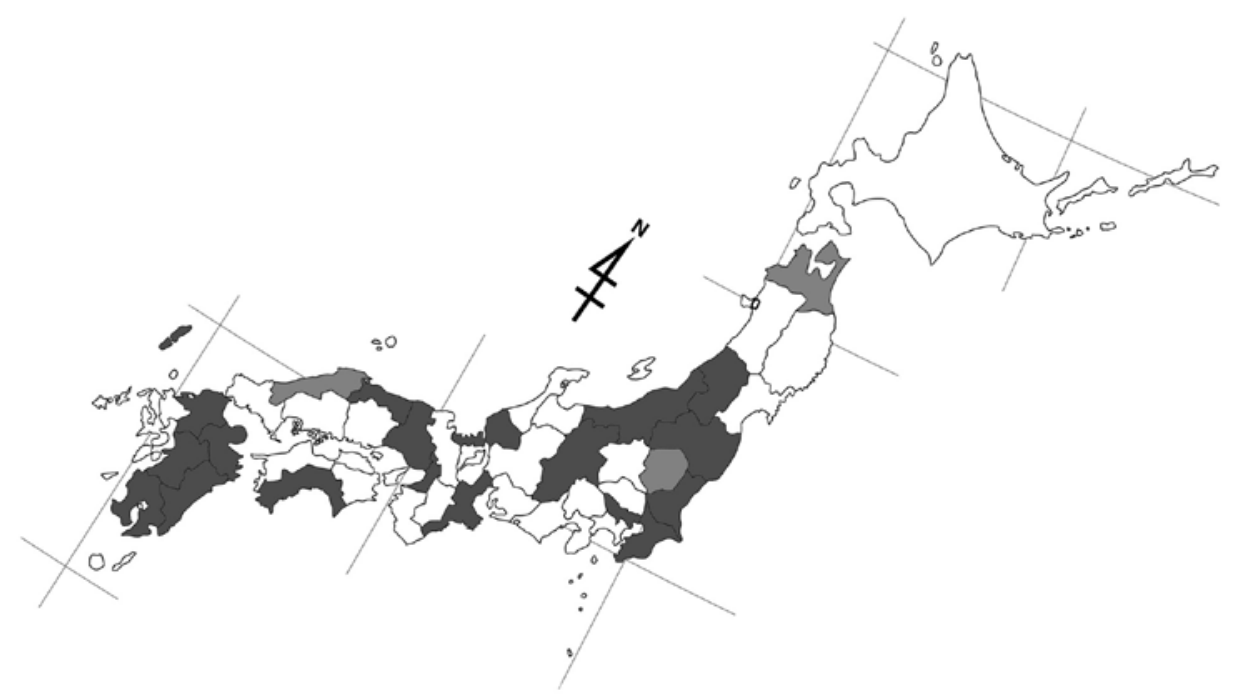

Fig. 72. Distribution of $N$. pyrifera on the Japanese mainlands. Densely shaded: prefectures with the specimens examined in the present study. Lightly shaded: prefectures with records in literature, but no specimens examined in the present study. 
Table 26. Seasonal change of number of the captured individual of $N$. pyrifera in Japan (Number of females indicates at the left of slash in cell, that of males at the right. E: early, M: mid, L: late).

\begin{tabular}{|c|c|c|c|c|c|c|c|c|c|c|c|c|c|}
\hline \multirow[b]{2}{*}{ Main island } & \multirow[b]{2}{*}{ Prefecture } & \multicolumn{3}{|c|}{ March } & \multicolumn{3}{|c|}{ April } & \multicolumn{3}{|c|}{ May } & \multicolumn{3}{|c|}{ June } \\
\hline & & $E$ & M & $\mathrm{L}$ & E & $\mathrm{M}$ & $\mathrm{L}$ & $E$ & $\mathrm{M}$ & $\mathrm{L}$ & $E$ & $\mathrm{M}$ & $\mathrm{L}$ \\
\hline \multicolumn{14}{|l|}{ HONSHU } \\
\hline \multirow[t]{2}{*}{ [Tohoku] } & Yamagata & & & & & & & $1 /$ & $1 /$ & $/ 1$ & & & \\
\hline & Fukushima & & & & & & & & & $/ 1$ & & & \\
\hline \multirow[t]{2}{*}{ [Kanto] } & Ibaraki & & & & & & & & $1 /$ & & & & \\
\hline & Chiba & & & & & 1/ & & & & & & & \\
\hline \multirow[t]{2}{*}{ [Chubu] } & Niigata & & & & & & $1 /$ & & $1 /$ & $1 /$ & & $/ 1$ & \\
\hline & Nagano & & & & & 1/ & & & & $3 /$ & & & \\
\hline \multirow[t]{3}{*}{ [Kinki] } & Mie & & & & & & $1 /$ & & & & & & \\
\hline & Osaka & & & & & $/ 1$ & & & & & & & \\
\hline & Hyogo & & & & $2 / 1$ & & & & & & & & \\
\hline [Chugoku] & Tottori & & & & & & $1 /$ & & & & & & \\
\hline SHIKOKU & Kochi & & & & & & $1 /$ & & & & & & \\
\hline \multirow[t]{6}{*}{ KYUSHU } & Fukuoka & & $/ 1$ & 15 & $11 / 18$ & $21 / 5$ & $3 / 1$ & $3 /$ & & & & & \\
\hline & Nagasaki & & & $/ 1$ & & & & & & & & & \\
\hline & Kumamoto & & & $/ 1$ & 13 & & 4/ & $1 /$ & $/ 1$ & & & & \\
\hline & Oita & & & & $4 / 65$ & & $18 / 4$ & & & & & & \\
\hline & Miyazaki & & & & 12 & $1 /$ & & & & & & & \\
\hline & Kagoshima & & & & & & & $1 /$ & & & & & \\
\hline \multicolumn{2}{|l|}{ Total } & 0 & 1 & 7 & 106 & 30 & 34 & 6 & 4 & 6 & 0 & 1 & 0 \\
\hline
\end{tabular}

mur posteriorly.

Sculpture: As in female.

Vestiture: Vestiture on labrum, yellowish erect, strongly plumose, dense. That on clypeus and supraclypeal area similar to that on labrum but silvery-shining, appressed, dense to obscure integument. That on lower genal area near hypostoma yellowish, longer than on labrum.

Vestiture on mesosoma similar to that in female but denser and more strongly plumose. That on posterolateral to dorsal surface of propodeum similar to on mesopleuron, not forming hair patch. Metasoma as in female.

Vestiture on ventral surfaces of coxae to femora of all legs long, strongly plumose, that on ventral surfaces of fore and mid femora curled on apical portion of each hairs, as long as the maximum width of each segment. That on ventral surface of hind femur sparse, short, appressed.

Structure: Body length 9-11 mm. CD:UID:LID 50:50:41. OCD/LOD 1.5.

The following aspects are different from female: interantennal carina highly raised and abruptly lowered anteriorly from level of anterior margin of antennal socket in profile; clypeus highly raised, more prominent than in female; preoccipital ridge rounded wholly; scape much wider than flagellar segments; relative length of FL1-3 1: 2.7: 2.2, relative length to apical width of FL1 0.7-0.8 times, FL2 2.5 times, FL3 1.8- 1.9 times, each of the following segments more than 1.5 times, tyloidea on FL1 absent, FL2 and FL3 ridge-shaped (the former much narrower as to be difficult to define), those on FL4-6 distinctly delimited, elliptical, not highly raised, those on the following segments narrower, together forming a weak ridge; scutellum highly raised, but evidently lower than in female, anterior face flat and much narrower than posterior face, median furrow wide, moderately deep; posterior area around propodeal spiracle shallowly concave, without a distinct ridge; pygidial plate usually shallowly emarginated at apex; hind femur moderately built; basoventral flattened surface wide, reaching to midpoint of segment, shallowly depressed in posterior view; boundary between basoventral flattened surface and posterior surface of the segment sharply angulated; posteriormost seta in apicomedian setae on hind tibia shorter and paler than in female, others six to eight in number, otherwise as in female. 
Male terminalia: 7th metasomal sternum as in Fig. 71-A. 8th as in Fig. 71-B, C. Gonostylus thick, rounded apically; vestiture long, simple, dense, sinuate apically; basoventral lobe developed, with plumose, dense, long vestiture. Penis valve produced posteriorly beyond gonostylus, apex extending slightly beyond apex of gonostylus in lateral view. Gonocoxite with deep dorsal invagination; inner dorsal lobe as wide as long, with apex truncate.

Distribution. Japan (Honshu, Shikoku, Kyushu).

Specimens examined. Holotype (USNM), 우, attached with four labels as follows: "Type No./ 23181/ U. S. N. M. (red rectangular and typed except the numerals handwritten)", “Ôkubo/ 5. V. '28 (white rectangular with handwritten letters. "28" may corresponds to Meiji 28 = 1895)", "No. 134 (white rectangular and typed)", "Nomada/ pyrifera/ CKLL. TYPE (white rectangular with handwritten letters)".

Other specimens: We have examined 83 females and 120 males. On the localities, see Fig. 72. Some of them are listed as follows: JAPAN [Honshu] Yamagata: 1우, Yamagata City, 3. v. 1930 (K. Hasegawa, ELKU). Fukushima: 10', Nakayama, Koriyama, 23. v. 1975 (O. Tadauchi, ELKU). Ibaraki: 1우, Furuyado-Yoshida, Mito-shi, 19. v. 1935 (T. Tani, NSMT). Nagano: 3우, Kijimadaira, 24. v. 1976 (O. Tadauchi, ELKU). Hyogo: 1 ○', Tamba, Sasayama, 7. iv. 1955 (S. Taniguchi, ELKU). Tottori: 1우, Masumizu, Mt. Daisen, 26. iv. 1975 (O. Tadauchi, ELKU). [Shikoku] Kochi: 1우, Nakamurashi, 27. iv. 1957 (Y. Hirashima, ELKU). [Kyushu] Oita: 4우65 ð7, Mt. Hanamureyama, Shônai-machi, Oita-gun, 6. iv. 2006 (K. Mitai). Nagasaki: 1ð', Kashi, Mitsushima, Tsushima Is., 30. iv. 1986 (O. Tadauchi, ELKU). Miyazaki: 10', Miyakonojo, 5. iv. 1949 (Y. Hirashima, ELKU). Kagoshima: 1우, Kurino, 5. v. 1955 (K. Sakamoto, H. Nagase Coll.).

Biology. It is a univoltine species, collected from late March to early June (Table 26). Floral association is as follows: [Rosaceae] Rubus hirsutus. The host is unknown.

Remarks. It is, like Nomada hakonensis Cockerell, characteristic in having the long second flagellar segment: $2.2-2.3$ times as long as the apical width of the segment in female, 2.5 times in male, but can be separated in both sexes from $N$. hakonensis by the much larger body, the labral tooth which is located near at apical margin (located at the middle in $N$. hakonensis), and the highly raised scutellum.
26. Nomada sabaensis Tsuneki, 1973

[Japanese name: Sabae-kimadara-hanabachi]

(Figs. 73, 74; Table 27)

Nomada sabaensis Tsuneki, 1973, Etizenia, 66: 112-115

[Holotype: Female. Type locality: Sabae, Fukui Pref., Honshu, Japan]; Alexander \& Schwarz, 1994, Univ. Kansas Sci. Bull., 55: 251 [in list].

\section{Redescription.}

Female.

Color: Head reddish brown, tinged with yellow on lower paraocular area; the following portions are black: macula on antennal area except supraclypeal area always reddish brown, transverse elliptical macula surrounding ocelli, line on epistomal suture, line on genal area along preoccipital ridge from hypostoma up to level of top of compound eye in profile; three maculae above well-separated in examined three specimens. Mandible reddish brown except apical one-third dark red. Antenna wholly pale reddish brown.

Mesosoma black; the following portions are reddish brown: collar on the top, anterior margin of pronotum, pronotal lobe, tegula, axilla, four broad, fused partially, longitudinal lines on scutum, scutellum, mesopleuron except narrow peripheral margin and macula on ventral side, a pair of large maculae on posterolateral corner of propodeum. The latter propodeal macula expanded anteriorly to reach to propodeal spiracle, posteriorly into basolateral corner of triangle.

Metasoma largely reddish brown, T1 black on basal half; the following portions are yellow: a pair of maculae each on T2 and T3 (the latter much smaller), a pair of close together, elliptical maculae on T4, large square macula on T5 medially, broad band each on S3-5.

Sculpture: Punctures on labrum moderately dense but indistinct. Those on clypeus dense and small, but larger laterally. Those on supraclypeal area similar to those on lateral area of clypeus.

Punctures on scutellum as on scutum. Mesopleuron shallowly areolate. Lateral and dorsal sides outside triangle of propodeum densely areolate, denser than on mesopleuron, on dorsal portion more weakly. Propodeal triangle irregularly rugose on basal one-third or slightly wider, the remaining portion distinctly tessellate.

T1 impunctate and smooth, the following terga faintly microsculptured with moderately dense punctules. Pygidial plate with obliterated, sparse punctures.

Vestiture: Vestiture on labrum whitish, plumose, long on apical margin, otherwise much shorter. That on clypeus and supraclypeal area whitish, finely plumose, 
short, appressed, sparser than on labrum. That on lower genal area near hypostoma as long as on apical margin of labrum.

Vestiture on scutum and scutellum pale brown, simple, appressed, very sparse and short, on scutellum somewhat longer than on scutum. That on mesopleuron whitish, plumose, as long as on scutellum. That on posterolateral corner of propodeum outside triangle white, long, strongly plumose; that at lower corner denser, forming loose hair patch.

Pseudopygidium small. Pygidial plate covered with sparse, short hairs.

Structure: Body length 7-8 mm. CD:UID:LID 50:48:44. OCD/LOD 1.5 .

Interantennal elevation weakly or moderately raised. Inner eye margins nearly parallel. Clypeus weakly

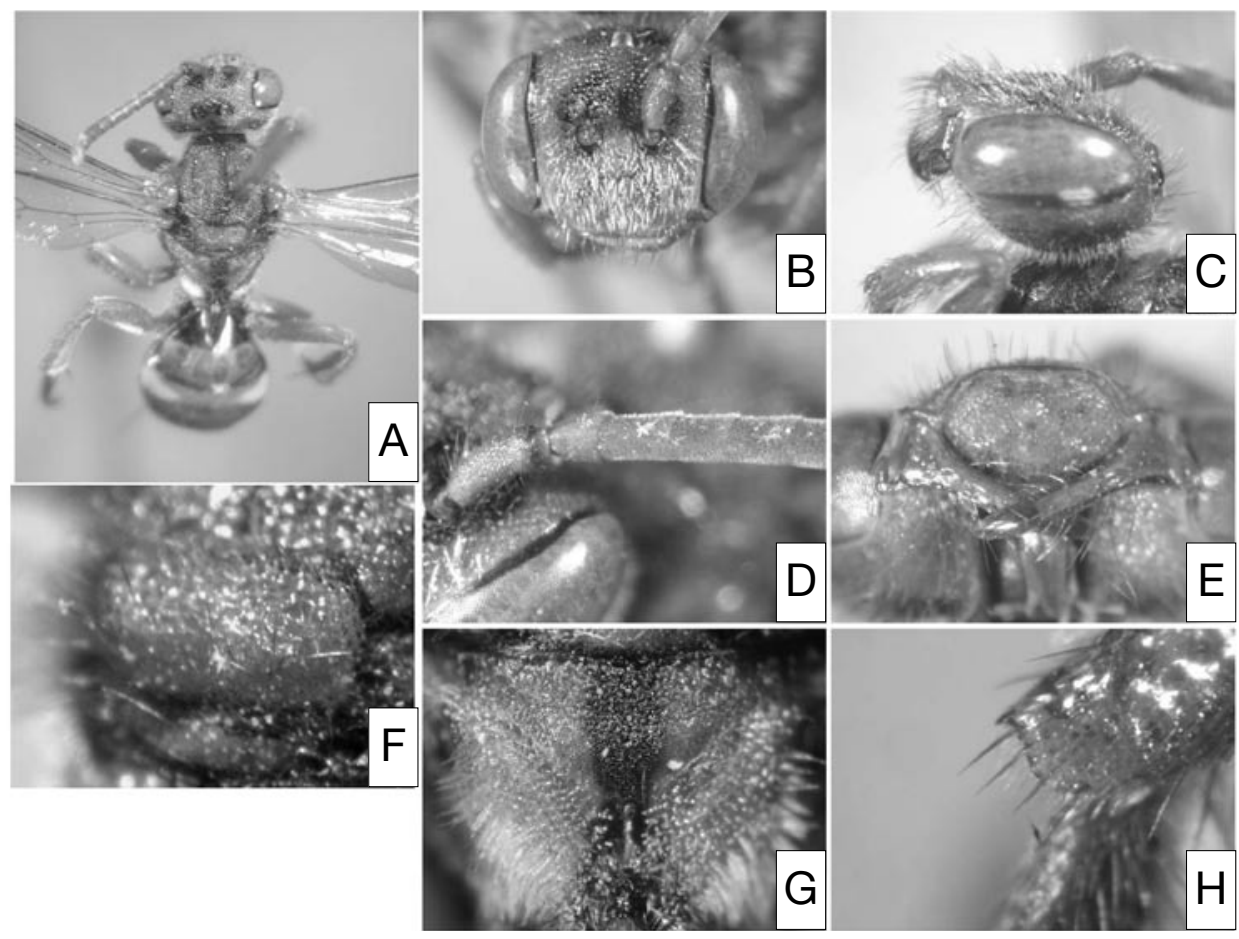

Fig. 73. Nomada sabaensis Tsuneki (Female). A: habitus, dorsal view. B, C, : head. D: antenna. E: labrum. F: scutellum. G: propodeal triangle. H: apicomedian setae on hind tibia.

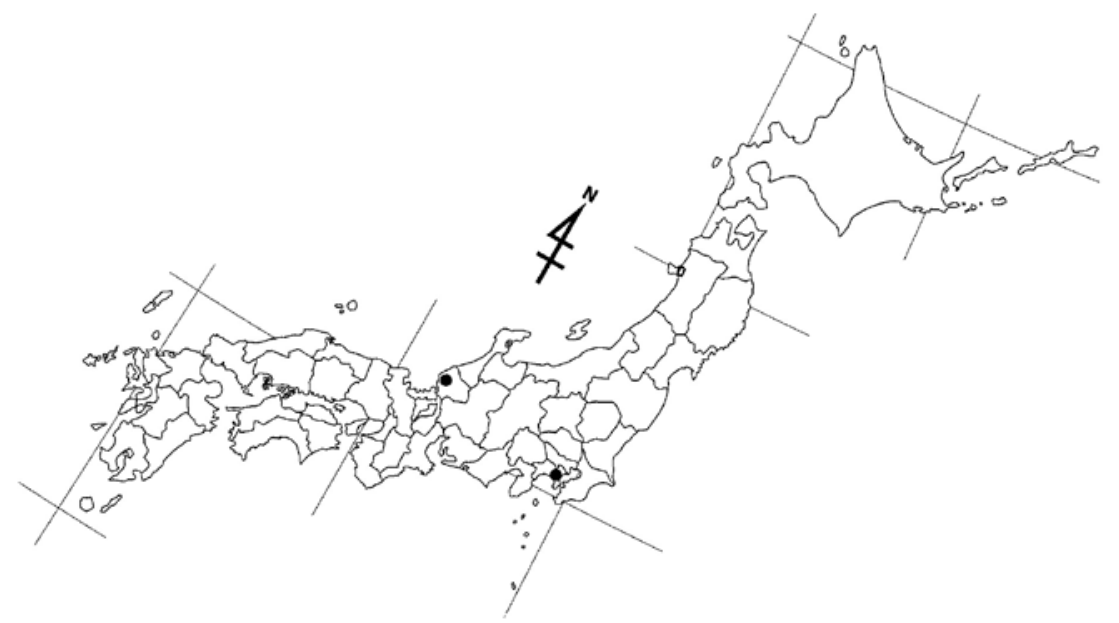

Fig. 74. Distribution of N. sabaensis on the Japanese mainlands. Dots: localities of the specimens examined in the present study. 
Table 27. Seasonal change of number of the captured individual of $N$. sabaensis in Japan (Number of females indicates at the left of slash in cell, that of males at the right. E: early, M: mid, L: late).

\begin{tabular}{|c|c|c|c|c|}
\hline \multirow[b]{2}{*}{ Main island } & \multirow[b]{2}{*}{ Prefecture } & \multicolumn{3}{|c|}{ April } \\
\hline & & $\mathrm{E}$ & $\mathrm{M}$ & $\mathrm{L}$ \\
\hline \multicolumn{5}{|l|}{ HONSHU } \\
\hline & Kanagawa & & 2/ & \\
\hline & Fukui & & 1/ & \\
\hline \multicolumn{2}{|c|}{ Total } & 0 & 3 & 0 \\
\hline
\end{tabular}

raised and produced anteriorly. Labrum 1.5 times as wide as long; labral tooth present in the center, accompanied by indistinct carina on each side; apical portion below labral tooth weakly produced anteriorly, not upcurved; apical margin not serrated with distinct triangular protuberance medially. Mandible slender. Preoccipital ridge distinctly angulated. Relative length of FL1-3 1:1.5:1.2, relative length to apical width of FL1 equal, FL2 1.5 times, FL3 1.2 times.

Scutellum moderately raised, anterior surface nearly flat, median furrow feeble. Hypoepimeral area completely flat. Pygidial plate reddish brown, triangular at apical portion. The description above is based not observation of full pygidial plate because pygidial plate of all examined specimens partially hidden by $\mathrm{T} 5$.

Fore and mid femora moderately or, more or less robust. Apicomedian setae on hind tibia four in number, moderately long, evenly well-spaced, thin, pale brown.

Male. Unknown.

Distribution. Japan (Honshu).

Specimens examined. Holotype (MNHAH), 우, attached with two labels as follows: "Sabae, Fukui Pr./ Japan/ 16. IV. 1956/ K. Tsuneki (white rectangular and typed)", "Nomada/ sabaensis/ Tsuneki 우/ HOLOTYPE (red rectangular with handwritten letters)".

Other specimens: JAPAN [Honshu] Kanagawa: 2 오, Chuorinkan, Yamato, Koza, 17. iv. 1958 (Collector unknown, ELKU). The identification of this species was considerably confused with the related species, therefore, all records of $N$. sabaensis in literature are excluded from Fig. 74.

Biology. All three specimens examined in the present study are collected in mid April (Table 27). The host and floral association are unknown.

Remarks. The male described by Tsuneki (1973) corresponds actually to male of $N$. panzeri orientis Tsuneki. The true male of $N$. sabaensis is unknown. The female is similar to Nomada calloptera Cockerell, but can be separated by the smaller body, the gently punctate scutellum, and the widely spaced, thin apicomedian setae on hind tibia.

\section{Nomada shirakii}

Yasumatsu et Hirashima, 1951

[Japanese name: Shiraki-kimadara-hanabachi]

(Figs. 75-77; Table 28)

Nomada shirakii Yasumatsu et Hirashima, 1951, Trans. Shikoku Ent. Soc., 2: 55-56 [Holotype: Male. Type locality: Takamiya, Fukuoka Pref., Kyushu, Japan]; Tsuneki, 1973, Etizenia, 66: 51-52 [redescription]; Alexander \& Schwarz, 1994, Univ. Kansas Sci. Bull., 55: 244 [in list].

Nomada iwakiyamana Tsuneki, 1986, Spec. Publ. Hym. Assoc., (32): 50-51 (Holotype: Female). syn. nov. Nomada kotomaria Tsuneki, 1986, Spec. Publ. Hym. Assoc., (32): 51-52 (Holotype: Female). syn. nov.

Nomada uzenis Tsuneki, 1986, Spec. Publ. Hym. Assoc., (32): 49 (Holotype: Female). syn. nov.

\section{Redescription.}

Female.

Color: Head reddish brown, frequently tinged with yellow on paraocular area and lower inner eye margin; the following portions are black: macula surrounding antennal socket, transverse elliptical macula surrounding ocelli on vertex (two above maculae usually connected at least partially, supraclypeal area frequently reddish brown), broad line on genal area along preoccipital ridge, this black line on genal area usually narrowly separated from black on vertex. But in specimens with widened black macula, these black maculae all widely connected. Mandible reddish brown except apical onefourth dark red. Antenna reddish brown or pale brown anteriorly, darker apically and posteriorly

Mesosoma black; the following portions are reddish brown: collar on the top, pronotal lobe, tegula, axilla, four longitudinal lines on scutum which always wellseparated, sometimes completely lacking, scutellum, large macula on lateral side of mesopleuron which fre- 
quently divided into a spot on hypoepimeral area and a large macula below scrobe, metanotum, two pairs of macula on propodeum (one pair in propodeal triangle, the other on posterolateral corner of propodeum).

Metasoma largely brown to reddish brown; the following portions are yellow: a pair of round or oval maculae each on T2 and T3 (the latter much smaller, sometimes lacking), roughly rectangular macula on T5. Sterna largely brown to dark brown, S1 black basally (the black notched apicomedially), S2 and S3 blackish on apical margin, S3 and S4 each with a dark, broad yellow band, S5 with variously shaped, yellow marks on medially and apicolaterally.

Legs largely brown; the following portions are black or blackish: all coxae largely except anteriorly, all trochanters narrowly basoventrally, all femora basally except dorsally. In specimens with developed black portions, all coxae and trochanters nearly wholly black, the

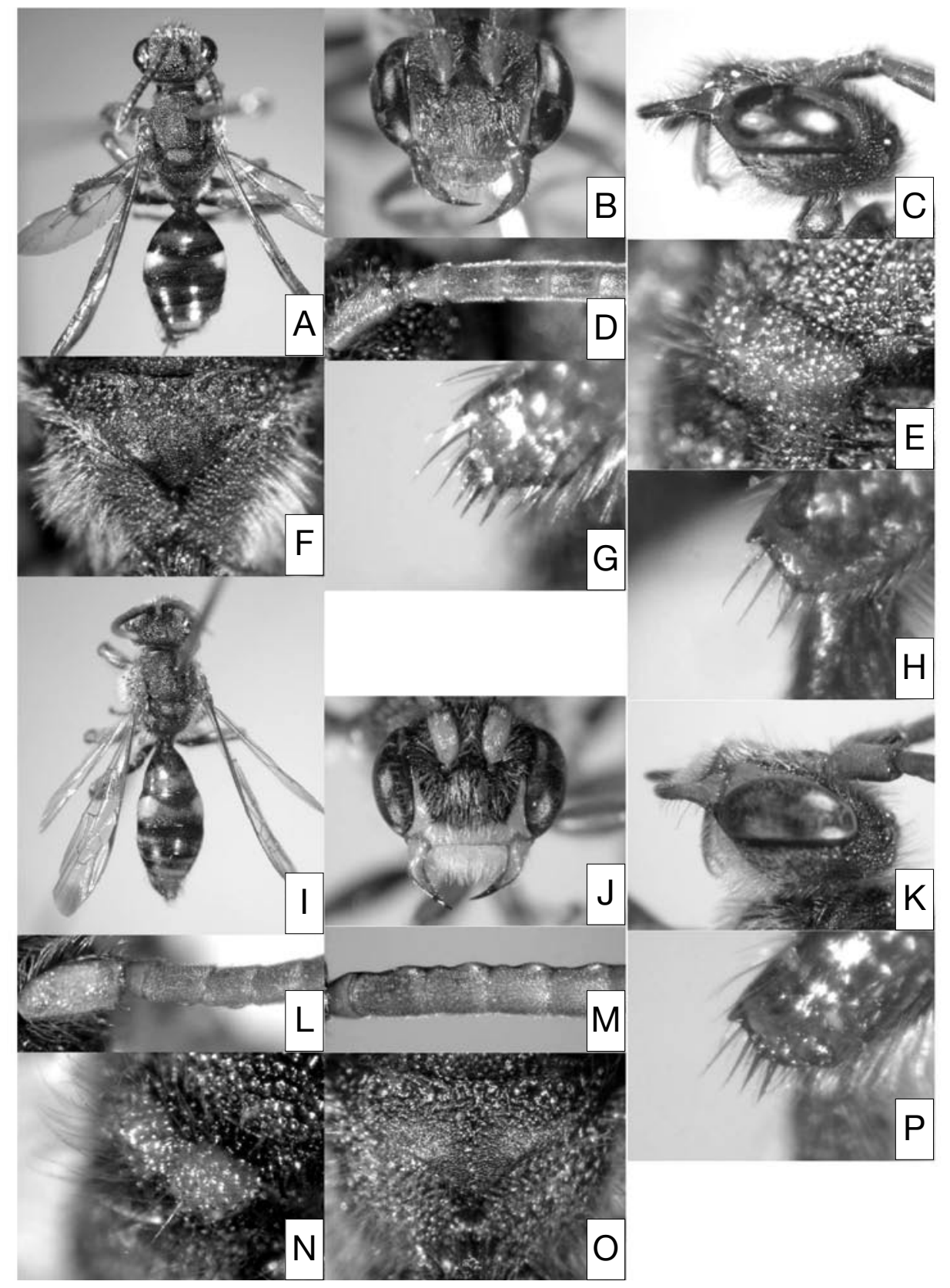

Fig. 75. Nomada shirakii Yasumatsu et Hirashima. Female: A-H. Male: I-P. A, I: habitus, dorsal view. B, C, J, K: head. D, L, M: antenna. E, N: scutellum. F, O: propodeal triangle. G, H, P: apicomedian setae on hind tibia. 
black on femora extending beyond midpoint toward apices of segments.

Sculpture: Punctures on labrum small and dense. Those on clypeus and supraclypeal area much larger and denser.

Punctures on scutellum variable, usually evidently sparser than those on scutum, but sometimes as dense as those. Lateral and dorsal sides outside triangle on propodeum densely areolate, denser than on mesopleuron, except sparsely rugose portion under spiracle. Propodeal triangle irregularly coarsely rugose on basal half, the remaining portion tessellate or polished.

Terga faintly microsculptured with sparse punctules, sometimes T1 nearly impunctate. Pygidial plate with small, dense punctures.

Vestiture: Vestiture on labrum white or pale brown, plumose and comparatively dense. That on clypeus and supraclypeal area white or pale brown, appressed, plumose, short, very sparse. That on lower genal area near hypostoma pale brown, erect, plumose, as long as on apical margin of labrum.

Vestiture on scutum inconspicuous, short, appressed. Vestiture on scutellum erect and longer. That on mesopleuron erect, much longer than on scutum, plumose, not dense, whitish, slightly darker on lower portion. That on posterolateral to dorsal surface of propodeum outside triangle white, strongly plumose, suberect, dense as to form loose hair patch, frequently these patch restricted on narrowly lower posterolateral portion.

Pseudopygidium small, composed of strongly translucent scale-like hairs, apical margin of T5 can be seen. Pygidial plate covered with robust, short dense hairs, obscuring integument, usually apical margin widely hairless.

Structure: Body length 7-10 mm. CD:UID:LID 50:50:41. OCD/LOD 1.4.

Interantennal elevation moderately raised. Inner eye margins moderately convergent below. Clypeus weakly raised and produced anteriorly. Labrum 1.7 times as wide as long; distinct labral tooth at the center, accompanied by indistinct carina on each side; apical portion below labral tooth weakly produced anteriorly, not upcurved; apical margin strongly serrated with a triangular protuberance medially. Mandible somewhat slender, strongly curved at the midpoint. Preoccipital ridge angulate, gradually rounded apically. Relative length of FL1-3 1:1.7:1.4, relative length to apical width of FL1 0.9-1.0 times, FL2 1.6-1.7 times, FL3 1.4 times.

Scutellum weakly to moderately raised, anterior surface flat, median furrow shallow. Pygidial plate reddish brown, apical margin widely rounded, shallowly notched at apex.

Fore femur moderately built. Apicomedian setae on hind tibia four in number, posteriormost seta slenderer, longer, pale brown, others usually robust, or slender as posteriormost seta, pale brown to dark brown, all the same in length or slightly shorter anteriorly.

Male.

Color: Head black; the following portions are yellow: mandible except apical one-fourth dark red or black, labrum, clypeus on apical one-third to narrow margin but sometimes the yellow portion interrupted medially, malar area, lower paraocular area extending up along inner eye margin to level of lower margin of antennal socket. Scape broadly yellow or brown anteriorly, black posteriorly, flagellar segments brown anteriorly, black posteriorly.

Mesosoma black except as follows: collar on the top (much narrower than in female) and scutellum are reddish brown. Pronotal lobe brown. Elliptical yellow macula usually present on anterior portion of mesopleuron, but variously developed in size, sometimes lacking.

Metasoma largely black, T1 dark brown on apical half, containing a pair of small black spots, apicomedian portion of the basal black produced posteriorly; the following portions are yellow: a pair of round maculae on T2 with intermacular area brown, a pair of transversely thin yellow bands each on T3 and T4 (narrowly interrupted in the middle, or in less macula-developed specimens, reduced to small spots on lateral side of the segment), complete band on $\mathrm{T} 4$, transversely long, rectangular macula on T5, medially upcurved band each on S2-4 (variously developed in size, frequently lacking), S5 apicomedially.

Legs reddish brown; the following portions are black: all coxae except apical portion sometimes tinged with yellow, all trochanter except anteriorly, fore and mid femora ventrally, hind femur except dorsally. The latter black portion on anterior surface gradually narrower and disappears toward ventral side of segment.

Sculpture: As in female, but somewhat shallower on scutum.

Vestiture: Vestiture on labrum white, strongly plumose, erect. That on clypeus and supraclypeal area similar to that on labrum but appressed, dense as to obscure integument.

That on lower genal area near hypostoma erect, longer than on labrum, plumose.

Vestiture on scutum and scutellum pale brown tinged with golden, erect, weakly plumose, on scutellum slightly longer. That on mesopleuron fine, plumose, white, evidently longer than on scutum, moderately 

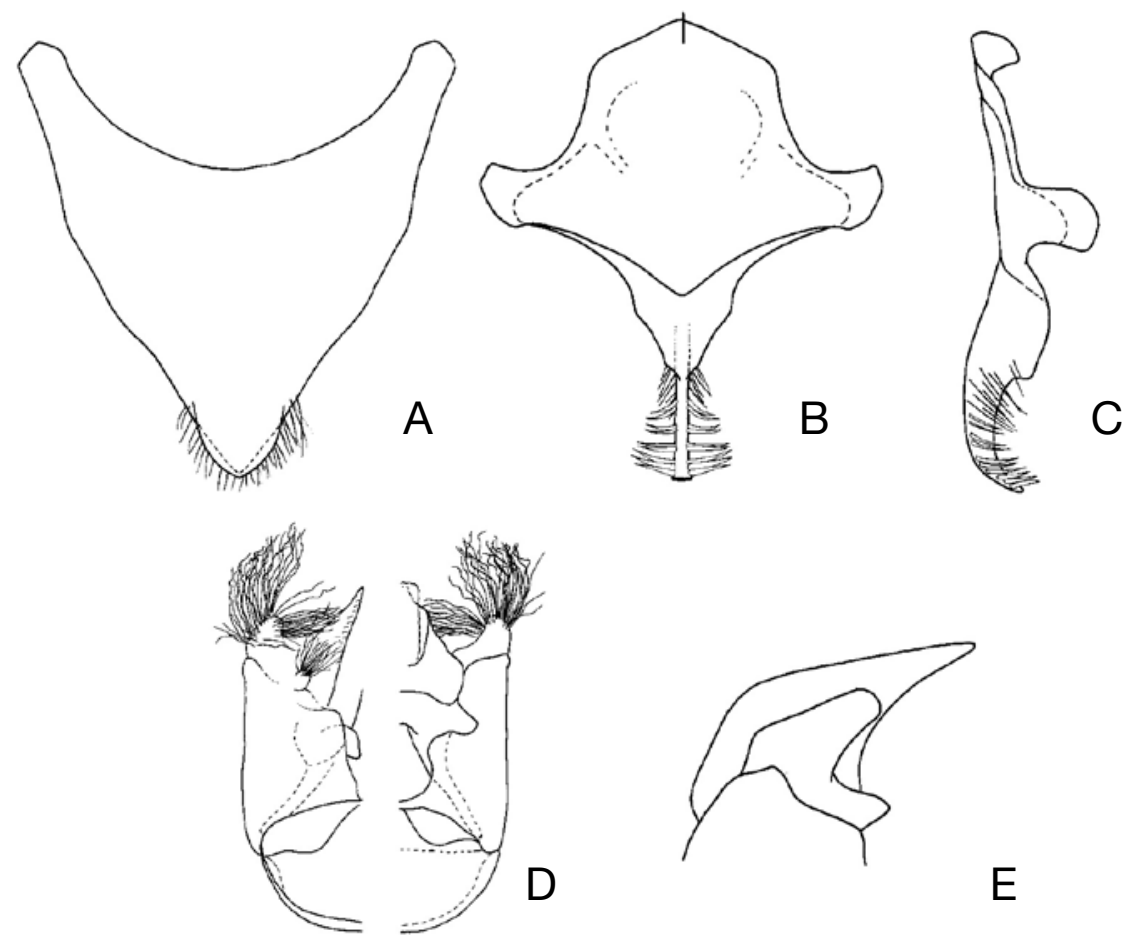

$E$

Fig. 76. Nomada shirakii (male). A: 7th metasomal sternum, ventral view. B: 8th sternum, dorsal view. C: the same, lateral view. D: genital capsule (left, ventral view; right, dorsal view). E: penis valve and gonostylus, lateral view (vestiture omitted).

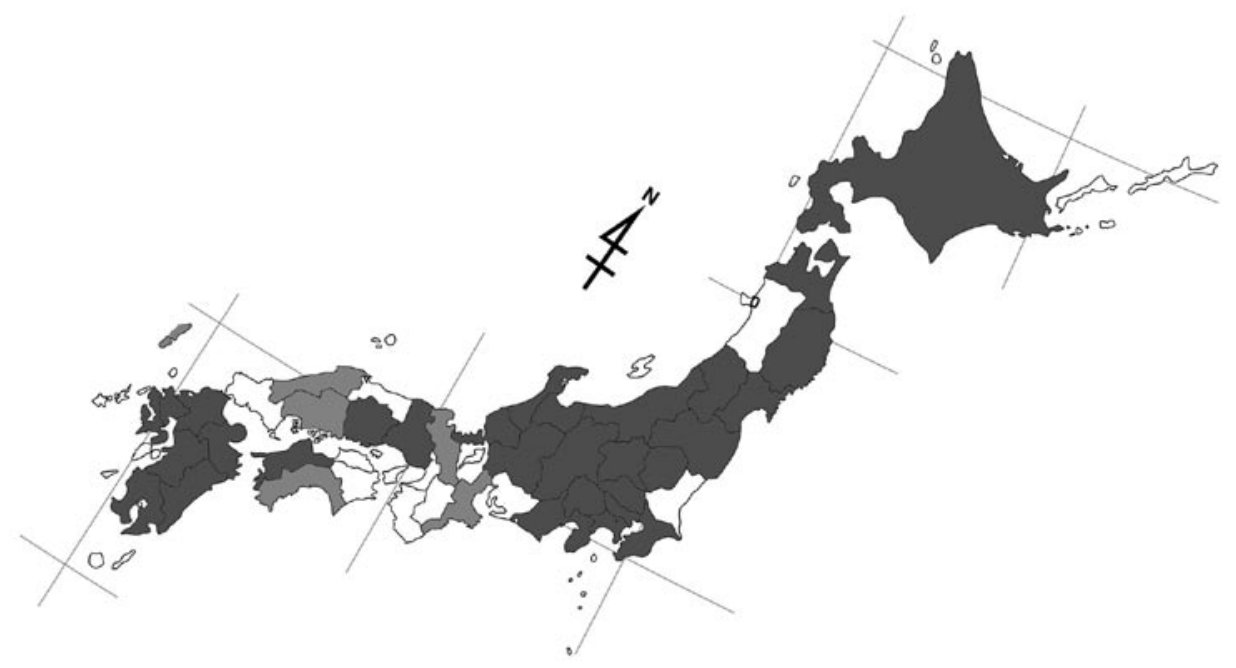

Fig. 77. Distribution of N. shirakii on the Japanese mainlands. Densely shaded: prefectures with the specimens examined in the present study. Lightly shaded: prefectures with records in literature, but no specimens examined in the present study. 
Table 28. Seasonal change of number of the captured individual of N. shirakii in Japan (Number of females indicates at the left of slash in cell, that of males at the right. E: early, M: mid, L: late).

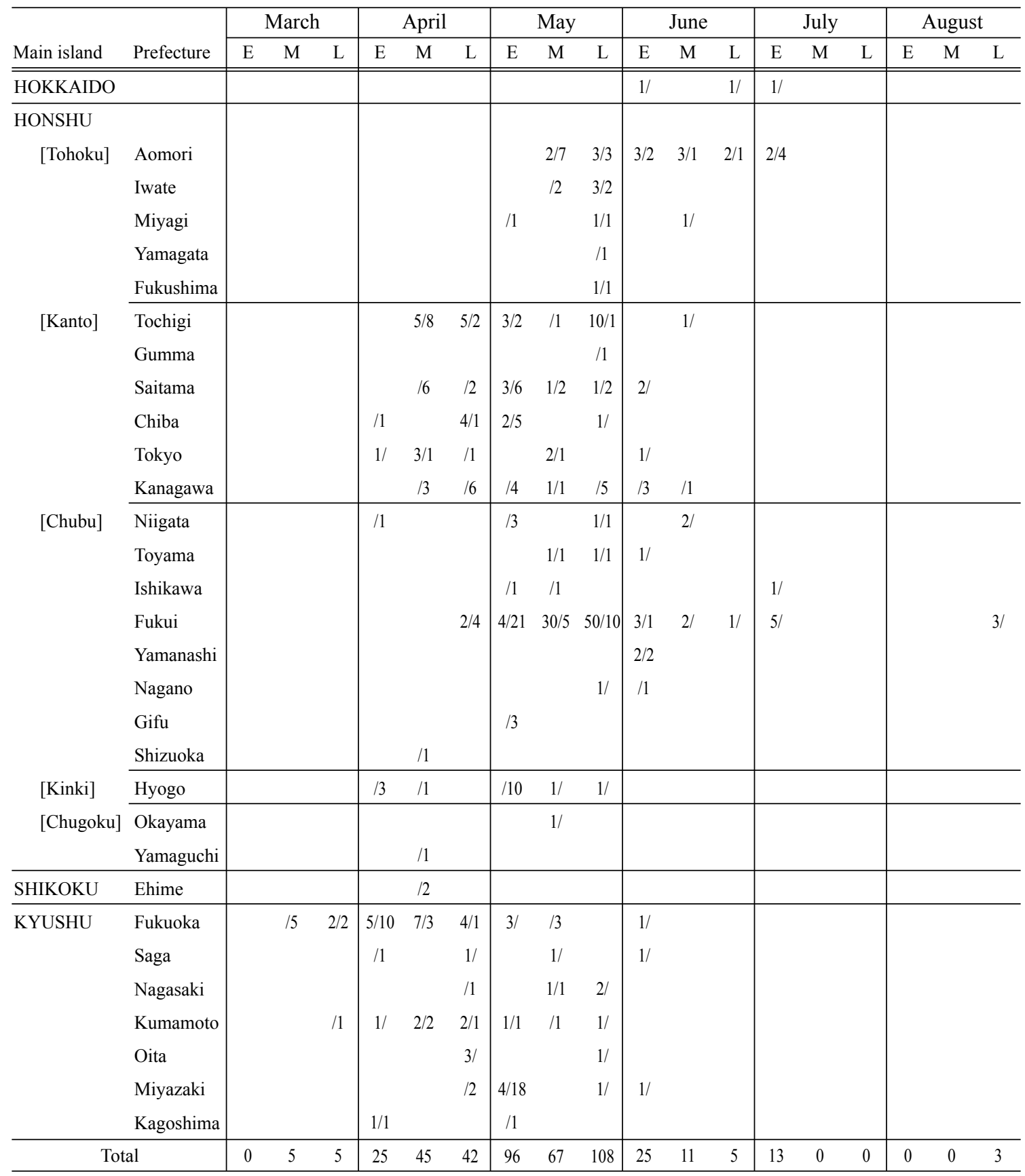

dense, erect. That on posterolateral to dorsal surface of propodeum outside triangle similar to that on scutum, but paler in color, slightly sparser.

Vestiture on ventral surface of fore femur as long as or slightly shorter than the maximum width of segment, that on ventral surface of mid femur much shorter than the maximum width of segment. That on ventral surface of hind femur with sparse, erect, moderately long.
Structure: Body length 6.5-9.5 mm. CD:UID:LID 50:50:43. OCD/LOD 1.7.

The following aspects are different from female: relative length of FL1-3 1:2.0:1.7, relative length to apical width of FL1 0.6 times, FL2 1.5- 1.6 times, FL3 1.1-1.2 times, tyloidea developed on FL2-10, those on FL2-6 highly raised, oval (those on FL3 and FL4 nearly circular), narrower and lower successively on the fol- 
lowing segments as so to become a ridge-shaped on last two segments; pygidial plate shallowly emarginated at apex, sometimes widely triangularly emarginated; hind femur moderately built, basoventral flattened surface reaching to midpoint of segment, shallowly depressed in posterior view. Apicomedian setae on hind tibia similar in shape and variation to those of female, sometimes posteriormost seta gently curved anteriorly.

Male terminalia: 7th metasomal sternum as in Fig. 76-A. 8th as in Fig. 76-B, C. Gonostylus short, rounded at apex; vestiture simple, moderately dense, sinuate apically; basoventral lobe greatly produced, with simple, long, not sinuate vestiture. Penis valve produced posteriorly beyond gonostylus, apex extending much beyond apex of gonostylus in lateral view. Gonocoxite with moderately deep dorsal invagination; inner dorsal lobe wider than long, with apex truncate.

Distribution. Japan (Hokkaido, Honshu, Shikoku, Kyushu, Tsushima Is.).

Specimens examined. Holotype (ELKU), 우, attached with two labels as follows: "[Kyusyu](sic.)/ Takamiya/ (Fukuoka)/ 9. iv. 1950/ T. Shiraki \&/ Y. Hirashima (white rectangular and typed)", "Holotype/ Nomada shirakii/ Yasumatsu et/ Hirashima (pale orange rectangular with handwritten letters)".

Other specimens: We have examined about 250 individuals in each sex. On the localities, see Fig. 77. Some of them are listed as follows: JAPAN [Honshu] Iwate: 1 ठ', Kassenjo, Yamagata V., 12. v. 1990 (T. Chiba, NIAES). Yamagata: 10', Oguni, 27. v. 1976 (O. Tadauchi, ELKU). Gumma: 10', Lake Baraki, Tsumagoi-mura, 29. v. 1977 (H. Kawano, NIAES). Nagano: 10', Tokiwa, Saku, 1. vi. 1999 (T. Nambu). Gifu: 3ठ', Hatahoko, Mt. Norikura, 8. v. 1976 (O. Tadauchi, ELKU). Shizuoka: 1 ○', Shizuoka, 19. iv. 1954 (S. Taniguchi, ELKU). Hyogo: $3 \sigma^{\nearrow}$, Kiyoshikojin, Settsu, 7. iv. 1955 (K. Komatsu, ELKU). Yamaguchi: 10', Hagi, 14. iv. 19?? (Collector unknown, NSMT). [Shikoku] Ehime: 10', Ochiai, Kuma-machi, 15. iv. 1976 (O. Tadauchi, ELKU). [Kyushu] Saga: 10', Kami-ozoegawa, Fuji, 5. iv. 2002 (R. Murao, ELKU). Nagasaki: 1우10', Mt. Ariakeyama, Izuharamachi, Tsushima-shi, Tsushima Is., 19. v. 2003 (T. Tano, K. Mitai Coll.). Kumamoto: 1우20', Tatsuda-Yama, Kumamoto City, 14, iv. 2005 (N. Sugiura). Oita: 3우, Mt. Hanamureyama, Shônai-machi, Oita-gun, 27. iv. 2005 (K. Mitai). Miyazaki: 2우150 , Ebino Highland, Ebinoshi, 9. v. 2005 (K. Mitai). Kagoshima: 10', NishinoOmote, Tanegashima, 4. iv. 1987 (K. Ogata, H. Nagase Coll.).

Biology. It is a univoltine species, collected from mid March to early July, with most records from April to June (Table 28). Three female individuals are collected in late August in Fukui Pref., Honshu, Japan. These specimens are regarded here not as the first generation but as the untimely occurred adults because they are very few, compared with the number of individuals collected in spring and because there are no differences among individuals collected in spring and in August. Floral associations are as follows: [Cruciferae] Brassica rapa, Rorippa indica. [Rosaceae] Spiraea cantoniensis, Stephanandra incisa. [Aceraceae] Acer buergerianum, Acer palmatum, Acer sieboldianum. [Boraginaceae] Omphalodes japonica. The host is unknown, but In Saga Pref., one female was observed to fly over the nest site of Andrena tsukubana Hirashima and enter a nest (personal observation).

Remarks. Haneda (1994) pointed out that there are some variant individuals of Nomada shirakii, and considered them possibly a good species. The variants Haneda reported differs from $N$. shirakii in the shape of mandible and apicomedian setae on hind tibia in both sexes, the coarser punctures on clypeus and scutellum in female, the narrower yellow macula on scape anteriorly in male and the less developed tyloidea in male. These differences between the two extremes are enough to consider as separate species, but the differences vary independently, and frequently the intermediates occur simultaneously in place and time. Therefore, we conclude the variants should be placed in the range of intraspecific variation of $N$. shirakii. Nomada uzenis Tsuneki, 1986 corresponds to the variant, Nomada iwakiyamana Tsuneki and N. kotomaria Tsuneki correspond to the normal individuals of $N$. shirakii.

28. Nomada silvicola Tsuneki, 1973

[Japanese name: Morino-kimadara-hanabachi] (Figs. 78-80; Table 29)

Nomada silvicola Tsuneki, 1973, Etizenia, 66: 87-90 [Holotype: Female. Type locality: Koike, Fukui, Honshu, Japan]; Alexander \& Schwarz, 1994, Univ. Kansas Sci. Bull., 55: 248 [in list].

Nomada hangani Tsuneki, Etizenia, 66: 132-134 [Holotype: Male], synonymized by Tsuneki, 1975: 464.

Nomada diervillae Tsuneki, 1973, Etizenia, 66: 138-139 [Holotype: Male] syn. nov.

\section{Redescription. \\ Female.}

Wintering generation.

Color: Head black; the following portions are reddish brown: mandible with apical one-fourth dark red, 
labrum, clypeus on apical one-third to apical half, malar area, thin line around compound eye, which is vague at upper inner eye margin. Antenna brown or blackish brown anteriorly, black posteriorly.

Mesosoma black; the following portions are reddish brown: collar on the top, pronotal lobe, tegula, short vague line along lateral margin of scutum, two maculae on scutellum, transverse elliptical macula on lower an- terior portion of mesopleuron.

Metasoma dark brown or blackish; the following portions are yellow: a pair of oval, close together maculae on T2, a thin, medially narrower or interrupted band each on T3 and T4, a transverse elliptical macula on T5, medially upcurved band each on S1-4, apical half of S6; the yellow on sterna tinged with brown.

Legs largely black; the following portions are dark

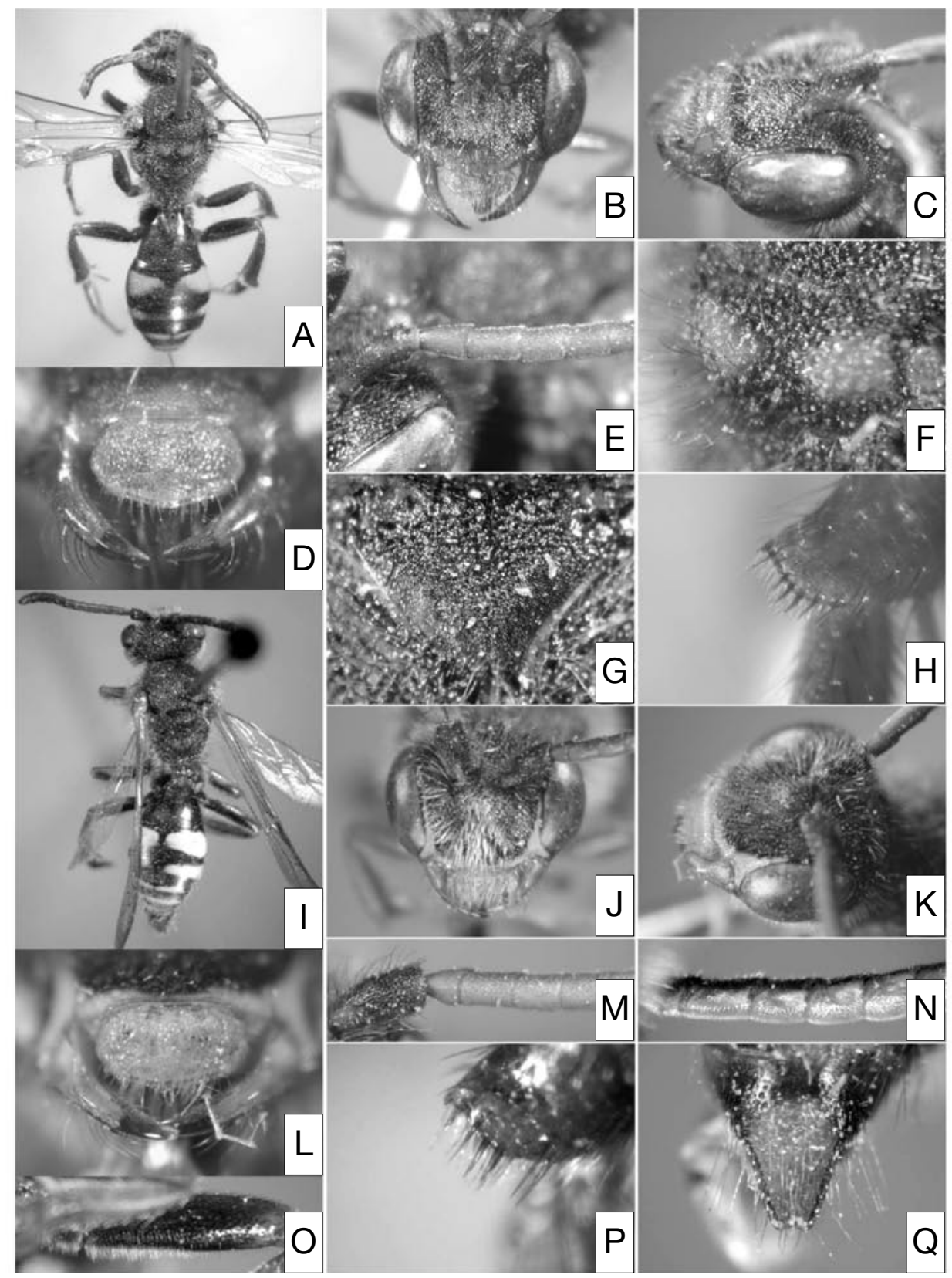

Fig. 78. Nomada silvicola Tsuneki. Female: A-H. Male: I-Q. A, I: habitus, dorsal view. B, C, J, K: head. D, L: labrum. E, M, N: antenna (E, M: anterior view. N: posterior view). F: scutellum. G: propodeal triangle. H, P: apicomedian setae on hind tibia. O: hind femur, anterior view. Q: pygidial plate. 
reddish brown: all coxae at apices, all trochanters on lower half of posterior surface, fore femur dorsally and anteroventrally, mid femur dorsally and on apical half, narrow apical portion of hind femur narrowly apically, all tibiae.

Sculpture: Punctures on labrum and clypeus small, distinct, dense. Those on supraclypeal area larger. Those on scutellum somewhat larger than on scutum. Mesopleuron areolate, shallower on anterior portion. Propodeum outside triangle densely but shallowly areolate, denser than on mesopleuron, except sparsely rugose portion on spiracular concavity and under the spiracle. Propodeal triangle irregularly coarsely rugose basally; two longitudinally parallel rugae present at posteromedially to medially, and a deep groove discernible between these rugae; interspaces of rugae and the remaining portion distinctly tessellate; tessellation stronger toward the middle so as to show transversely striate rugae in the middle.

Metasoma faintly microsculptured, with dense, considerably distinct punctules except punctules on T1; Punctules on T1 varied from much sparser to as dense as on the following terga. Pygidial plate puncture small, comparatively dense, interpunctural space granulose, impunctate margin very narrow.

Vestiture: Vestiture on labrum pale brown, fine, erect, weakly plumose, long on narrowly apical margin, otherwise much shorter. That on clypeus and supraclypeal area whitish or pale brown, short, very sparse, appressed, weakly plumose. That on lower genal area near hypostoma slightly longer than on apical margin of labrum.

Vestiture on scutum and scutellum fine, weakly plumose, erect, brown, intermixed with much darker brown hairs, slightly longer on scutellum. That on mesopleuron whitish intermixed with dark brown hairs, plumose, erect, slightly denser than on scutum. That on posterolateral to dorsal surface of propodeum outside triangle yellowish brown, erect, plumose, as dense as on mesopleuron, not forming a hair patch. Pseudopygidium pale brown, longitudinally short. Pygidial plate covered with very sparse, short hairs.

Structure: Body length $7.5 \mathrm{~mm}-12 \mathrm{~mm}$. CD:UID: LID 50:48:47. OCD/LOD 1.3.

Interantennal elevation highly. Inner eye margins weakly convergent below. Clypeus weakly raised and produced anteriorly. Labrum 1.7 times as wide as long with a distinct labral tooth present at apical one-third from apex, accompanied by indistinct carina on each side; apical portion below labral tooth triangularly produced anteriorly, not upcurved; apical margin not serrated, but sometimes longitudinal, impunctate space distinct above labral tooth. Preoccipital ridge highly carinate, especially very high at lateral portion. Scape somewhat narrower than flagellar segments. Relative length of FL1-3 1:1.1-1.2:0.9-1.0; relative length to apical width of FL1 1.3 times, FL2 1.5 times, FL3 1.2 times .

Scutellum highly raised, the convexities triangular conic; median furrow deep. Hypoepimeral area evidently, but not prominently convex. Posterior area around propodeal spiracle concave, with a sharp ridge.

Fore femur slender. Apicomedian setae on hind tibia six to eight in number, evenly spaced, divided into two types of shape: the posteriormost one to posterior three longer, slenderer, paler in color; the anterior four or five in number, shorter, distinctly thicker, dark brown or black.

Pygidial plate brown, triangular in dorsal view, lateral margin straight, not notched at apex.

First generation.

The following aspects are different from the wintering generation:

Color: Reddish brown portion on head darker and narrower than in the wintering generation. Mesosoma black; the following portions are dark reddish brown: sometimes collar on the top, pronotal lobe, tegula, top of convexities of scutellum. Color pattern on metasoma similar to the wintering generation, but ground color darker. Legs similar to the wintering generation, but the black wider, the reddish brown darker.

Sculpture: Punctures on body deeper and somewhat larger than on the wintering generation, especially prominently on scutum and scutellum, but on propodeal triangle same as in the wintering generation.

Vestiture: Vestiture on body much shorter than in the wintering generation, especially on scutum inconspicuous, dark brown, sparse, suberect.

Structure: Scutellum highly raised, the convexities roughly triangular conical; median furrow deep.

Male.

Wintering generation.

Color: Head black; the following portions are yellow or yellowish brown: mandible with apical one-third black, labrum, apical narrow margin of clypeus (sometimes becoming vague medially), malar area, thin line along lower inner eye margin extending up near to the level of lower margin of antennal sockets. In one specimen with developed yellow portions as follows: apical one-third of clypeus yellow; line along lower inner margin yellow, widened toward malar area. In other one specimen yellow portions reduced as follows: malar area 

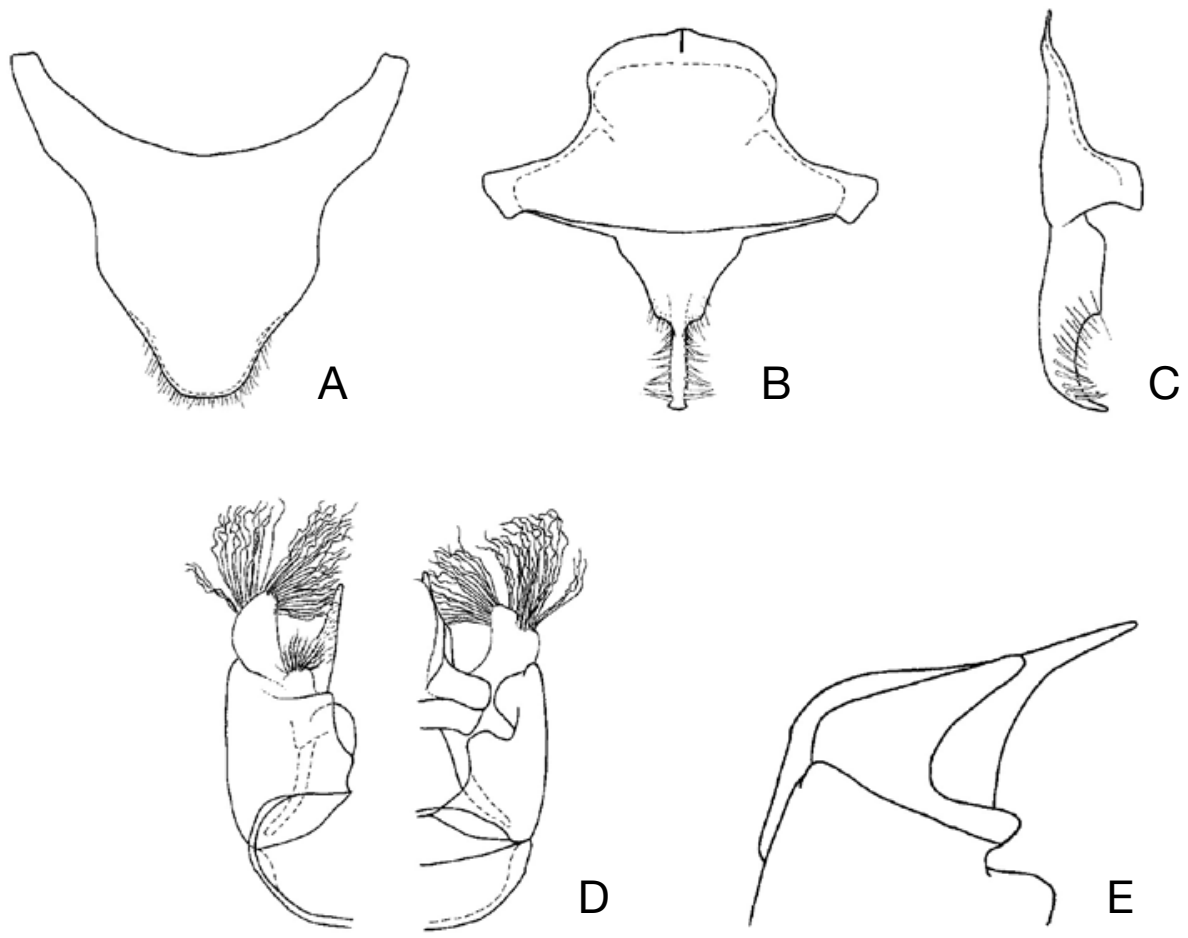

Fig. 79. Nomada silvicola (male). A: 7th metasomal sternum, ventral view. B: 8th sternum, dorsal view. C: the same, lateral view. D: Genital capsule (left, ventral view; right, dorsal view). E: Penis valve and gonostylus, lateral view (vestiture omitted).

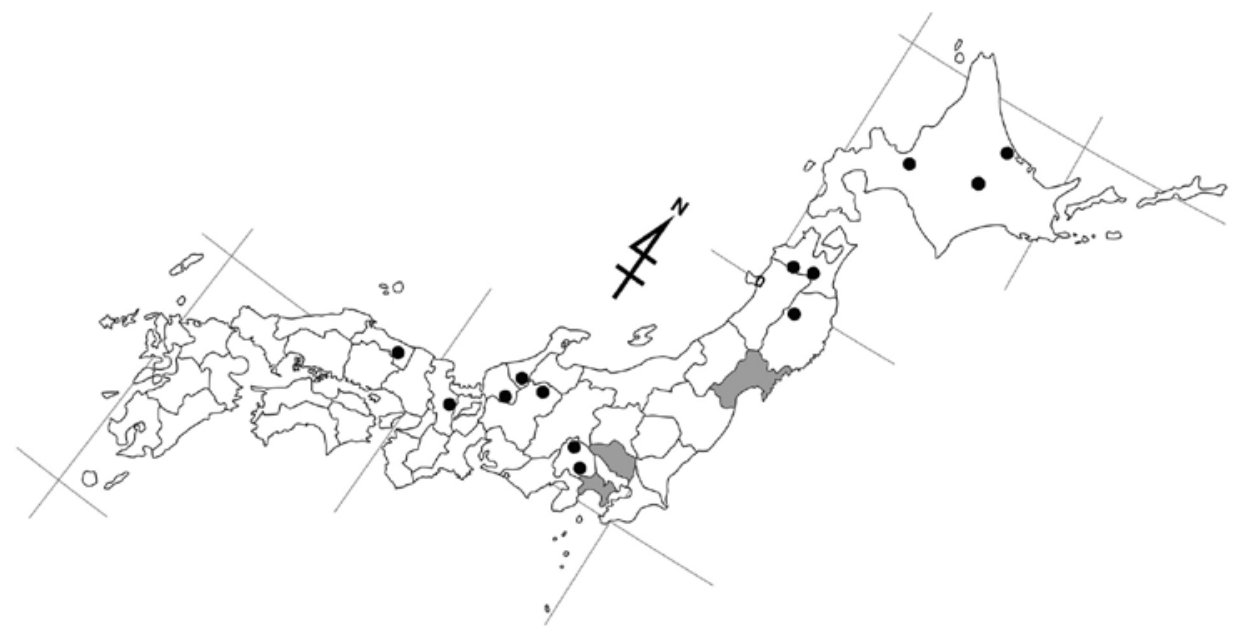

Fig. 80. Distribution of N. silvicola on the Japanese mainlands. Dots: localities. Shaded: Prefectures with records in literature, but no specimens in the present study. 
partially black; a line along lower inner margin became a vague spot. Antenna reddish brown anteriorly, black posteriorly but in one specimen scape wholly black.

Mesosoma black except peripheral margin of tegula dark brown.

Metasoma as in female except as follows: T5 with a complete short yellow band, T6 with a transverse oblong yellow macula, S2-5 each with a medially upcurved yellow band or brown band containing yellow spot in it, S6 yellow medio-apically.

Legs as in female.

Sculpture: Punctures on scutum and scutellum slightly deeper than in female, otherwise as in female.

Vestiture: Vestiture on labrum similar to female but slightly denser. That on clypeus and supraclypeal area similar to that on apical margin of labrum, but more strongly plumose, appressed, dense so as to obscure the integument. That on lower genal area near hypostoma slightly longer than on apical margin of labrum, strongly plumose, not dense.

Vestiture on scutum and scutellum yellowish pale brown or whitish, erect, moderately long, weakly plumose. That on mesopleuron similar to that on scutum, but more strongly plumose. That on posterolateral to dorsal surface of propodeum outside triangle similar to that on scutum, but evidently sparser.

Vestiture on ventral surface of fore femur slightly shorter than the maximum width of the segment. That of mid femur about as long as half of the maximum width of segments.

Structure: Body length 8-9.5 mm. CD: UID: LID 50:50:45. OCD/LOD 1.4.

The following aspects are different from female: clypeus raised moderately high, but evidently higher than in female; scape slightly wider than flagellar segments; relative length of FL1-3 1:1.6:1.3; relative length to apical width of FL1 0.9 times, FL2 1.6 times, FL3 1.3 times, tyloidea on FL1 absent, those on FL2-4 oval, weakly raised, those on the following segments recognized as obscure convex; scutellum moderately or highly raised; median furrow deep as in female; fore femur moderately built; hind femur moderately built, basoventral flattened surface discernible only narrowly basal portion, with moderately dense, short, suberect hairs; pygidial plate shallowly or more or less deeply emarginated at apex.

Male terminalia: 7th metasomal sternum as in Fig. 79-A. 8th as in Fig. 79-B, C. Gonostylus slender; vestiture long, simple, moderately dense, strongly sinuate apically; basoventral lobe strongly produced, with plumose, dense, long vestiture. Penis valve produced poste- riorly slightly beyond gonostylus, apex extending much beyond apex of gonostylus in lateral view. Gonocoxite with deep dorsal invagination; inner dorsal lobe as wide as long, with apex truncate.

First generation.

It is different from the wintering generation as follows:

Color: Yellow portion on apical margin of clypeus wider, ground color of metasoma more deeply black.

Sculpture: Punctures on scutum and scutellum larger and deeper. Those on terga slightly sparser but more distinct.

Vestiture: Vestiture on body much shorter than that in the wintering generation. That on ventral surface of hind femur somewhat shorter than in wintering generation.

Structure: Fore femora robust, crescent-shaped in front view.

Distribution. Japan (Hokkaido, Honshu).

Specimens examined. Holotype (MNHAH), 우, attached with two labels as follows: "Koike D/ Fukui, Jap/ 26-28. V. 1955/ K. Tsuneki [white rectangle and typed]", "Nomada/ silvicola/ Tsuneki 우/ Holotype [red rectangle with handwritten letters]"

Other specimens: We have examined 18 females and 9 males. On the localities, see Fig. 80. Some of them are listed as follows: JAPAN [Honshu] Iwate: 1우10', Ashiro, 8. vi. 1981 (Y. Maeta). Ishikawa: 1ठ', Betto, Mt. Hakusan, 9. v. 1985 (Y. Haneda). Gifu: 10', Kawaimura, Kichijo-gun, 21. viii. 1996 (H. Nagase). Kyoto: 1우, Hanase-pass, Sakyo, 17. v. 1997 (H. Suda). Tottori: 2 б', Ashizu, Chizu, 9. v. 2002 (Y. Maeta).

Biology. It is bivoltine, flies from May to mid June, and from late August to mid September (Table 29). Floral associations are as follows: [Compositae] Taraxacum officinale, Youngia denticulate.

Remark. The first generation is reported here for the first time. The female of the wintering generation is similar to $N$. leucophthalma, but can be separated by the much shorter setae on apicomedian portion of hind tibia and the second flagellar segment of nearly equal length (the second segment 1.5 times longer than the first in $N$. leucophthalma). The male of the wintering generation is similar to $N$. amurensis, but differs from them in the shorter second flagellar segment of antenna, the not highly raised clypeus. The female and male of the first generation are similar in structure and coloration to the same generation of $N$. amurensis, but can be separated easily by the shorter second flagellar segment of antenna in both sexes. 
Table 29. Seasonal change of number of the captured individual of N. silvicola in Japan (Number of females indicates at the left of slash in cell, that of males at the right. E: early, M: mid, L: late).

\begin{tabular}{|c|c|c|c|c|c|c|c|c|c|c|c|c|c|}
\hline \multirow[b]{2}{*}{ Main island } & \multirow[b]{2}{*}{ Prefecture } & \multicolumn{3}{|c|}{ May } & \multicolumn{3}{|c|}{ June } & \multicolumn{3}{|c|}{ August } & \multicolumn{3}{|c|}{ September } \\
\hline & & $\mathrm{E}$ & $\mathrm{M}$ & $\mathrm{L}$ & $\mathrm{E}$ & $\mathrm{M}$ & $\mathrm{L}$ & $\mathrm{E}$ & $\mathrm{M}$ & $\mathrm{L}$ & $E$ & $\mathrm{M}$ & $\mathrm{L}$ \\
\hline HOKKAIDO & & & $1 /$ & $2 /$ & & & & & & & & $1 /$ & \\
\hline \multicolumn{14}{|l|}{ HONSHU } \\
\hline \multirow[t]{2}{*}{ [Tohoku] } & Aomori & & $/ 1$ & & & & & & & & & $1 / 1$ & \\
\hline & Iwate & & & $1 /$ & $/ 1$ & & & & & & & & \\
\hline \multirow[t]{4}{*}{ [Chubu] } & Ishikawa & $/ 1$ & & & & & & & & & & & \\
\hline & Fukui & $1 /$ & & & & $1 /$ & & & & & & & \\
\hline & Yamanashi & & $/ 1$ & $8 / 1$ & & & & & & & 1 & & \\
\hline & Gifu & & & & & & & & & $/ 1$ & & & \\
\hline [Kinki] & Kyoto & & $1 /$ & & & & & & & & & & \\
\hline [Chugoku] & Tottori & 12 & & & & & & & & & & & \\
\hline \multicolumn{2}{|l|}{ Total } & 4 & 4 & 12 & 1 & 1 & 0 & 0 & 0 & 1 & & 3 & 0 \\
\hline
\end{tabular}

The record of this species from Oita Pref. (identified as Nomada diervillae: Yamazaki and Kato, 2003) were based on misidentification.

29. Nomada towada Tsuneki, 1973

[Japanese name: Towada-kimadara-hanabachi]

(Figs. 81-83; Table 30)

Nomada towada Tsuneki, 1973, Etizenia, 66: $72-73$ [Holotype: Female. Type locality: Narukawa, Aomori Pref., Honshu, Japan]; Tsuneki, 1986, Spec. Publ. Hym . Assoc., (32): 52-53 [diagnostic characters]; Alexander \& Schwarz, 1994, Univ. Kansas Sci. Bull., 55: 252 [in list].

Nomada osimana osimana Tsuneki, 1973, Etizenia, 66: 129-131 [Holotype: Male]; Tsuneki, 1975, Kontyû, 43: 470-473 [first description of female]; Tsuneki, 1986, Spec. Publ. Hym . Assoc., (32): 55-56 [diagnostic characters]. syn. nov.

Nomada osimana oirasensis Tsuneki, 1986, Etizenia, 66: 131 [Holotype: Male]; Tsuneki, 1975, Kontyû, 43: 473 [first description of female of the first generation]. syn. nov.

Nomada nanaensis Tsuneki, Etizenia, 66: 131-132 (Holotype: Male). syn. nov.

Nomada mamiyai Tsuneki, 1976, Kontyû, 44: 54-56 (Holotype: Male). syn. nov.

Nomada mutsuensis Tsuneki, 1986, Spec. Publ. Hym . Assoc., (32): 53-54 [Holotype: Male]. syn. nov.

Nomada yunokawana Tsuneki, 1986, Spec. Publ. Hym . Assoc., (32): 54-55 [Holotype: Male]. syn. nov.

Nomada yasuteyamana Tsuneki, Spec. Publ. Hym . As- soc., (32): 54 (Holotype: Male). syn. nov.

\section{Redescription.}

Female.

Color: Head largely reddish brown; the following portions are black; macula on antennal area except supraclypeal area always reddish brown, transverse elliptical macula surrounding ocelli (usually these two maculae fused partially), line on epistomal suture, broad line on genal area along preoccipital ridge from hypostoma up to vertex. Scape reddish brown anteriorly, black posteriorly, flagellar segments wholly reddish brown, but sometimes darkened apically.

Mesosoma black; the following portions are reddish brown: collar on the top, anterior margin of pronotum, pronotal lobe, axilla, a pair of large maculae usually occupying scutum except central line and anterior margin, but sometimes each macula reduced to two incompletely separated longitudinal lines, scutellum, mesopleuron except narrow peripheral margin and black macula of variable size on ventral side, metanotum, a pair of large maculae largely occupying propodeum except medial line and apicolateral portion of lateral side of propodeum. The latter macula on propodeum sometimes reduced in size to be similar to that of Nomada fukuiana.

Metasoma reddish brown, T1 black on basal half; the following portions are yellow: a pair of large oval maculae on T2 with intermacular area reddish brown, narrowly interrupted band on T4, large square maculae on T5. Sometimes maculae on T3 and T4 lacking, all terga more darkened.

Legs reddish brown; the following portions are 
tinged with dark brown: fore coxa dorsally, fore femur basoanteriorly and posteriorly, mid femur basally except dorsal portion, hind femur vaguely posteriorly. In specimens with developed black portions, the dark brown darker, much wider.

Sculpture: Punctures on labrum obliterated, sparse. Those on clypeus and supraclypeal area distinct but shallow, dense.

Punctures on scutellum smaller and denser than on scutum. Mesopleuron shallowly areolate. Lateral and dorsal sides outside triangle of propodeum areolate, much more densely and more distinctly than on mesopleuron. Propodeal triangle irregularly rugose on basal half and medial portion, the extension and raise of rugae vary individually, sometimes rugae considerably highly raised, show maze-like pattern which occupying mostly triangle, the remaining portion faintly tessellate.

Terga faintly microsculptured with much sparser,

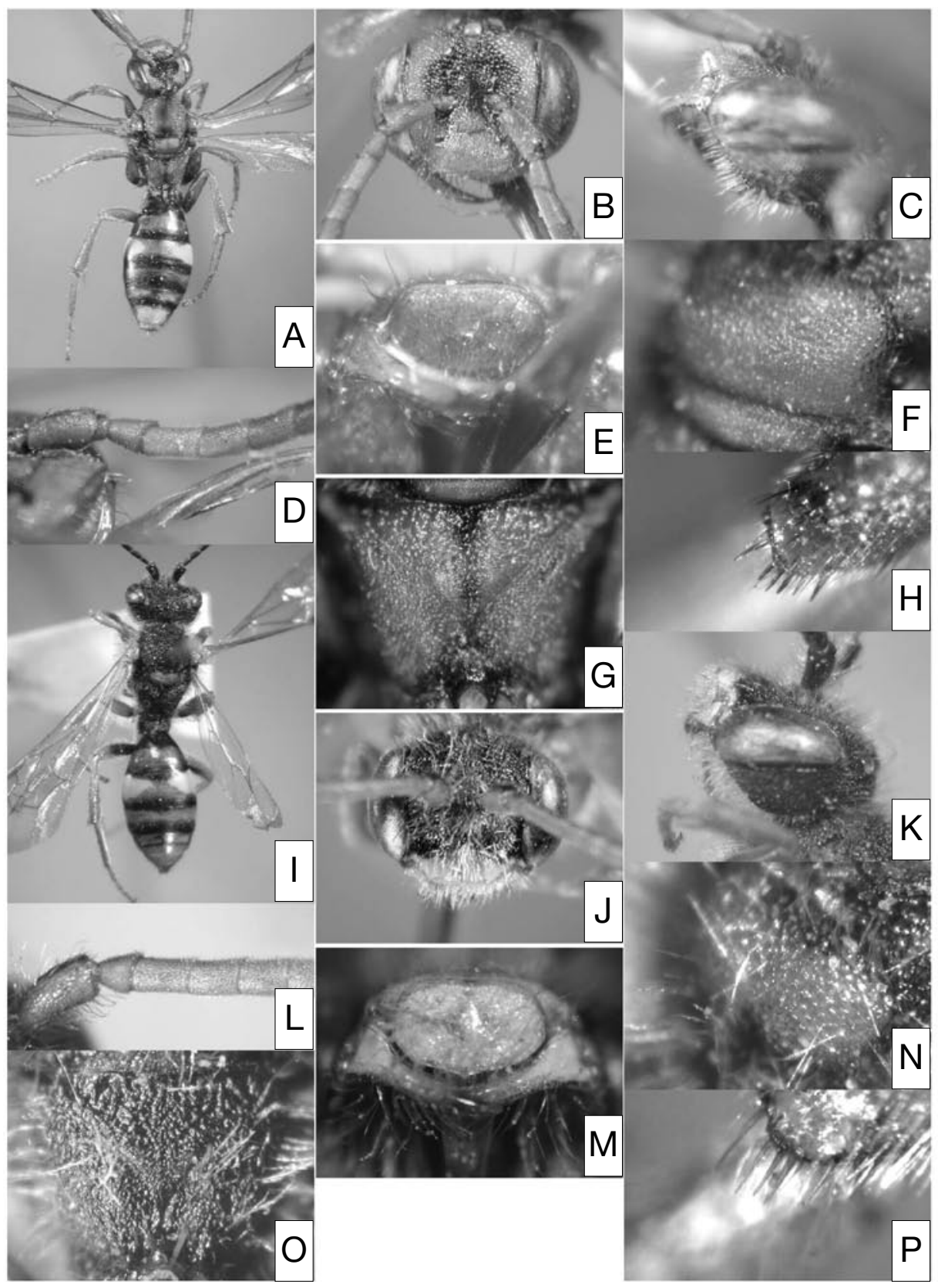

Fig. 81. Nomada towada Tsuneki. Female: A-H. Male: I-P. A, I: habitus, dorsal view. B, C, J, K: head. D, L: antenna. E, M: labrum. F, N: scutellum. G, O: propodeal triangle. H, P: apicomedian setae on hind tibia. 
indistinct punctules. Pygidial plate with small, dense punctures, interpunctural space granulose, impunctate margin very narrow.

Vestiture: Vestiture on labrum pale brown, sparse, weakly plumose and moderately long on apical margin otherwise much short. That on clypeus and supraclypeal area inconspicuous, very short and sparse, simple. That on lower genal area near hypostoma as long as on apical margin of labrum.

Vestiture on scutum and scutellum brown to dark brown, very short, simple, suberect. That on mesopleuron white, plumose, more or less sparse, evidently longer than on scutum. That on posterolateral corner of propodeum white, considerably short and difficult to discern, weakly plumose, not forming hair patch.

Terga with very short and sparse, appressed pubescence, T1 frequently virtually hairless. Pseudopygidium rudimentary, restricted on apicomedian edge of T5. Pygidial plate covered with sparse, very short hairs.

Structure: Body length 7-10.5 mm. CD:UID:LID 50:50:46. OCD/LOD 1.3.

Interantennal elevation moderately raised. Inner eye margins weakly convergent below. Clypeus weakly or moderately raised and weakly produced anteriorly. Labrum 1.5 times as wide as long, nearly flat; tooth slightly before the center, accompanied by indistinct carina on each side; apical portion weakly produced anteriorly, not upcurved; apical margin not serrated but with small triangular protuberance medially. Mandible slender. Preoccipital ridge rounded behind vertex, gradually angulated apically. Relative length of FL1-3 1:1.5:1.4, relative length to apical width of FL1 equal, FL2 1.7 times, FL3 1.5 times.

Scutellum weakly to moderately raised, anterior face flat and as wide as posterior face, median furrow absent. Pygidial plate brown, apical portion widely rounded, with a distinct notch at apex.

Fore femur moderately built. Apicomedian setae on hind tibia four to six in number, dark brown to black, moderately long and straight, sometimes posteriormost seta slightly curved, acute at apex, usually evenly spaced and slightly shorter anteriorly, sometimes a number of anterior setae closer together.

\section{Male.}

Color: Head largely black with dark yellow of size variable as follows: in specimens with developed black portions, only narrowly apical margin of clypeus dark yellow; in specimens with less developed black portions, dark yellow portions are clypeus on apical onethird, malar area, narrowly lower paraocular area. Labrum always dark yellow with blackish irregular spot of variable size in the middle, and mandible sometimes with black on basal anterior portion. Antenna reddish brown anteriorly, blackened posteriorly, paler apically; in melanic specimens scape black wholly, flagellar segments evenly black posteriorly.

Mesosoma black; the following portions are reddish brown: collar on the top, pronotal lobe, irregular macula on mesopleuron (the size variable ranging from small spot on anterior portion near pronotum, to large macula largely occupying mesopleuron), large one or separated two maculae on scutellum. In melanic specimens mesosoma wholly black except pronotal lobe.

Metasoma dark brown to black, T1 with a wide complete brown band; the following portions are yellow: a pair of large oval maculae each on T2 and T3 (the latter much thinner), narrowly medially interrupted band on T4, T5 and T6 largely except basal and lateral margins blackened, S2-6 largely yellow. In melanic specimens $\mathrm{T} 2$ and T3 with much smaller maculae, T1 and T4-6 strongly darkened wholly.

Legs reddish brown; the following portions are tinge with dark brown or black: upper side or upper half of all coxae, fore and mid femora basoposteriorly, hind femur posteriorly except apical portion.

Sculpture: Punctures on scutum and scutellum somewhat denser and deeper than on female, otherwise as in female.

Vestiture: Vestiture on labrum whitish, strongly plumose, long, somewhat longer apically, dense as to obscure integument. That on clypeus strongly plumose appressed otherwise as on labrum.

Vestiture on scutum and scutellum pale brown, weakly plumose, erect, long, on scutellum slightly longer than on scutum. That on mesopleuron whitish, longer and more strongly plumose than on scutum. That on posterolateral to dorsal surface of propodeum outside triangle similar to that on scutum, but slightly more strongly plumose, evenly dense, not forming distinct patch. T2 to T4 with a loose hair patch composed of pale brown, weakly plumose, long hairs on each lateral side, but sometimes lacking on $\mathrm{T} 2$, the remaining portion as in female.

Vestiture on ventral surfaces of fore and mid femora as long as or longer than the maximum width of each segment. That on ventral surface of hind femur moderately dense, long, erect.

Structure: Body length 6-10 mm. CD:UID:LID 50:50:40. OCD/LOD 1.8 .

The following aspects are different from female: interantennal carina weak, somewhat abruptly lowered anteriorly from level of anterior margin of antennal 

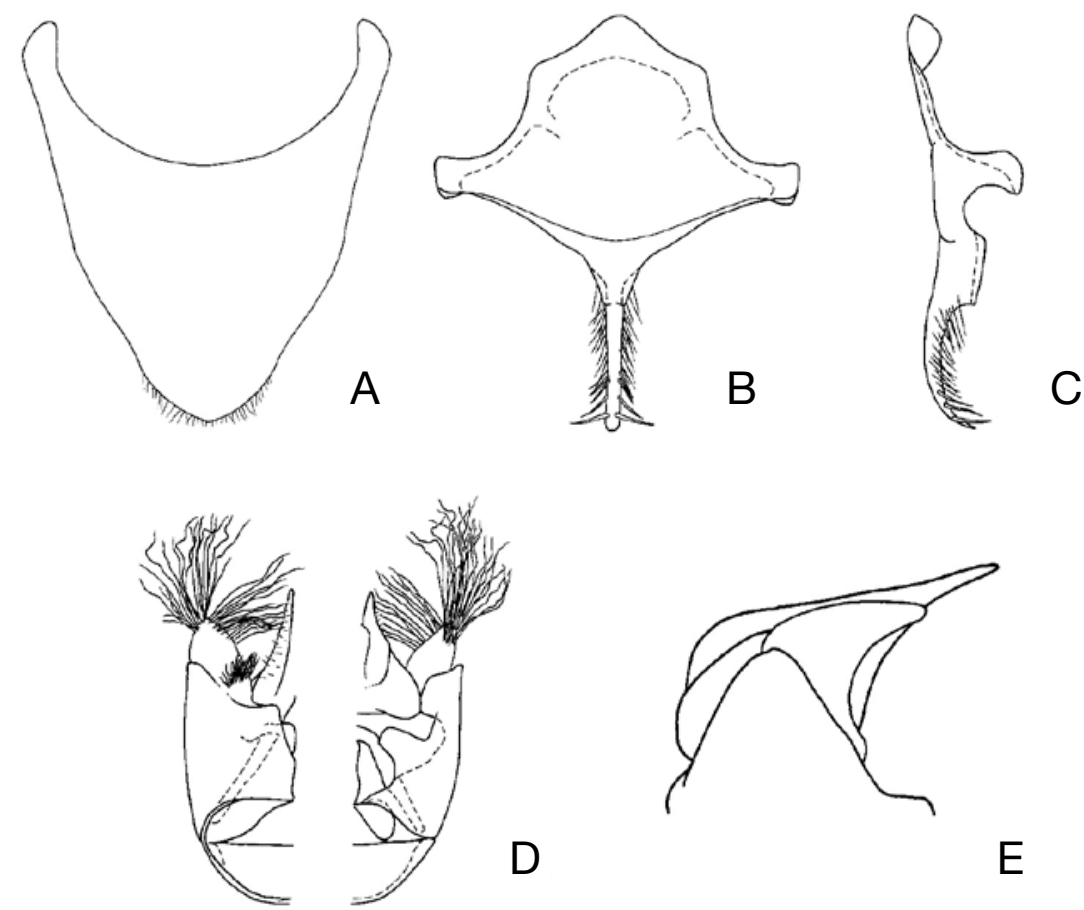

D

$\mathrm{E}$

Fig. 82. Nomada towada (male). A: 7th metasomal sternum, ventral view. B: 8th sternum, dorsal view. C: the same, lateral view. D: genital capsule (left, ventral view; right, dorsal view). E: penis valve and gonostylus, lateral view (vestiture omitted).

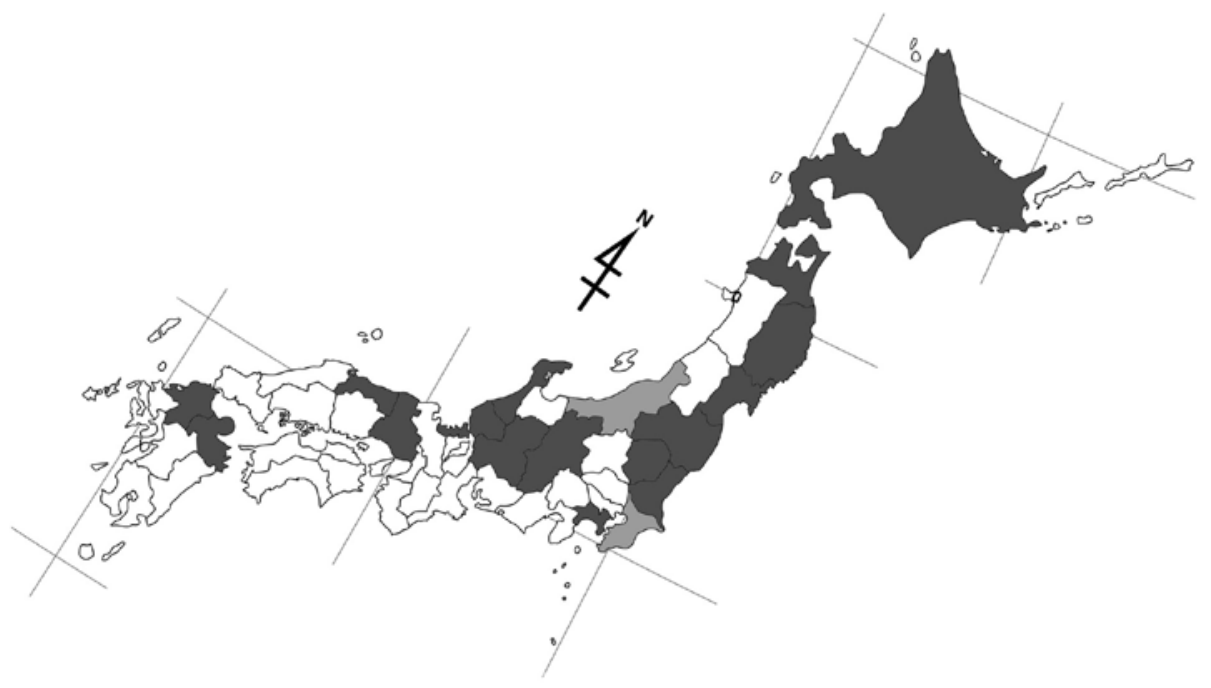

Fig. 83. Distribution of $N$. towada on the Japanese mainlands. Densely shaded: prefectures with the specimens examined in the present study. Lightly shaded: prefectures with records in literature, but no specimens examined in the present study. 
Table 30. Seasonal change of number of the captured individual of $N$. towada in Japan (Number of females indicates at the left of slash in cell, that of males at the right. E: early, M: mid, L: late).

\begin{tabular}{|c|c|c|c|c|c|c|c|c|c|c|}
\hline \multirow[b]{2}{*}{ Main island } & \multirow[b]{2}{*}{ Prefecture } & \multicolumn{3}{|c|}{ April } & \multicolumn{3}{|c|}{ May } & \multicolumn{3}{|c|}{ June } \\
\hline & & $\mathrm{E}$ & $\mathrm{M}$ & $\mathrm{L}$ & $\mathrm{E}$ & $\mathrm{M}$ & $\mathrm{L}$ & $\mathrm{E}$ & $M$ & $\mathrm{~L}$ \\
\hline "HOKKAIDO & & & & & & $/ 1$ & $1 /$ & $1 /$ & & \\
\hline \multicolumn{11}{|l|}{ HONSHU } \\
\hline \multirow[t]{4}{*}{ [Tohoku] } & Aomori & & $3 / 9$ & $5 / 7$ & $4 / 7$ & $3 / 2$ & $6 / 2$ & $1 / 4$ & & $1 / 1$ \\
\hline & Iwate & & $/ 1$ & $1 /$ & $/ 1$ & $/ 2$ & $/ 1$ & & & \\
\hline & Miyagi & $1 / 1$ & $1 / 1$ & 16 & $2 / 2$ & $2 / 4$ & & & & 1/ \\
\hline & Fukushima & & & & & & $1 /$ & & & \\
\hline \multirow[t]{2}{*}{ [Kanto] } & Tochigi & & & & 5/ & & $1 / 1$ & $1 /$ & & \\
\hline & Kanagawa & & & & $/ 1$ & & & & & \\
\hline \multirow[t]{4}{*}{ [Chubu] } & Ishikawa & $/ 1$ & & & $1 / 6$ & $1 / 1$ & & $/ 1$ & & \\
\hline & Fukui & & $/ 2$ & $1 /$ & $1 / 2$ & $/ 3$ & & & & \\
\hline & Nagano & & & & & $2 /$ & & & & \\
\hline & Gifu & & & & $/ 1$ & & & & & \\
\hline [Kinki] & Hyogo & & & & $/ 1$ & & & & & \\
\hline [Chugoku] & Tottori & & & & $1 / 10$ & & & & & \\
\hline \multirow[t]{2}{*}{ KYUSHU } & Fukuoka & & & $/ 2$ & $3 / 15$ & $1 / 1$ & $1 /$ & & & \\
\hline & Oita & & & & & & $1 /$ & & & \\
\hline \multicolumn{2}{|l|}{ Total } & 3 & 17 & 22 & 63 & 23 & 15 & 8 & 0 & 3 \\
\hline
\end{tabular}

socket in profile; clypeus moderately raised, evidently higher than in female; relative length of FL1-3 1:1.7:1.5, relative length to apical width of FL1 0.9 times, FL2 1.6-1.7 times, FL3 1.5-1.6 times, tyloidea on FL1 absent, those on FL2-4 oval, weakly raised, those on the following segments recognized as obscure convex; scutellum weakly to moderately roundly raised, median furrow very shallow; pygidial plate narrowly emarginated at apex; fore femur slender; apicomedian setae on hind tibia slenderer and paler than in female, otherwise as in female; hind femur slender; basoventral flattened surface indistinct, ventral margin of segment straight in posterior view.

Male terminalia: 7th metasomal sternum as in Fig. 82-A. 8th as in Fig. 82-B, C. Gonostylus moderately long; vestiture long, simple, moderately dense, weakly sinuate apically; basoventral lobe weakly developed, with long, simple, weakly sinuate vestiture. Penis valve produced posteriorly slightly beyond gonostylus, apex extending much beyond apex of gonostylus in lateral view. Gonocoxite with deep dorsal invagination; inner dorsal lobe longer than wide, with apex truncate.

Distribution. Japan (Hokkaido, Honshu, Kyushu).

Specimens examined. Holotype (MNHAH), 우, attached with two labels as follows: "Narukawa/ Towada,
Japan/ 28. v. 1959/ K. Shimoyama (white rectangular and typed except the date data handwritten)", "N. towada 우/ Tsuneki/ HOLOTYPE (red rectangular with handwritten letters)".

Other specimens: We have examined about $60 \mathrm{fe}-$ males and 100 males. On the localities, see Fig. 83. Some of them are listed as follows: JAPAN [Honshu] Iwate: 10', Isarizawa, Morioka C. 14. iv. 1991 (T. Chiba, NIAES). Fukushima: 1우, Nakayama, Koriyama, 23. v. 1975 (O. Tadauchi, ELKU). Kanagawa: 10', Shiraishisawa, alt. 1100m, Tanzawa, 2. v. 2002 (H. Sainohira, H. Nagase Coll.). Ishikawa: 4ð', Shiramine, 1. v. 1988 (Y. Haneda). Nagano: 2오, Oyanohara, Otari, 15. v. 1976 (O. Tadauchi, ELKU). Gifu: 10', Hatahoko, Mt. Norikura, 8. v. 1976 (O. Tadauchi, ELKU). Hyogo: 10', Yuzuruha Dam, Mihara-cho, Awaji-shima Is., 1. v. 1990 (C. Naito, MNHAH). Tottori: 1우11万', Ashizu, Chizu, 9. v. 2002 (Y. Maeta). [Kyushu] Fukuoka: 1우80', Mt. Hikosan, 9. v. 1951, (Y. Hirashima, ELKU). Oita: 1우, Sobosan, 26. v. 1932 (H. Hori, ELKU).

Biology. It is a univoltine species, collected from early April to late June (Table 30). Floral associations are as follows: [Rosaceae] Prunus grayana. [Compositae] Petasites japonicus, Taraxacum officinale. The host is unknown. 
Remarks. Female of N. towada, like that of N. fukui$a n a$, is characteristic by the short FL2, the low scutellum, and the rudimentary pseudopygidium. Females of $N$. towada and $N$. fukuiana differ each other by subtle but several differences as follows: in $N$. towada the apical flagellar segments not wholly black whereas in $N$. fukuiana at least apical three flagellar segments wholly black; the clypeus in $N$. towada raised not as highly as that in $N$. fukuiana; the pseudopygidium in $N$. towada less rudimentary than in N. fukuiana; the convexity of the scutum and the scutellum in $N$. towada somewhat higher than those in N. fukuiana; in N. fukuiana the lateral face of the pronotum tessellate with sparse superimposed punctures on the anterior portion, and transversestriate on the posterior portion, with a longitudinal distinct step between the two portions, due to the posterior portion abruptly recessed from the anterior, whereas in $N$. towada the pronotum without such a step or, if present, it extends very shortly from the dorsal of the pronotum; in N. towada T2 with two well-separated yellow maculae (rarely partially fused), whereas in $N$. fukuiana $\mathrm{T} 2$ with two narrowly separated yellow maculae (in a few specimens) or two largely fused maculae or a complete yellow band (in most specimens).

The male of $N$. towada is also similar to that of $N$. fukuiana, but can be separated by the characters in the antennal color, the scutellum, and the maculae on T2 as in the case of female. In addition, the structure of clypeus also separates them: in the male of $N$. towada the apicolateral edge is at most weakly angulated, not to form a carina, whereas in N. fukuiana, the apicolateral edge is distinctly angulated to form a more or less keeled carina. The male of $N$. towada also similar to Nomada panzeri orientis Tsuneki, the separation from it is difficult; see the remarks of $N$. panzeri orientis.

The record of this species from Oita Pref. (identified as Nomada mutsuensis: Yamazaki and Kato, 2003) was based on misidentification.

30. Nomada xantha Mitai, Hirashima et Tadauchi, sp. nov.

[Japanese name: Togenaga-kimadara-hanabachi] (Figs. 84-86; Table 31)

\section{Description.}

Female.

Color: Head largely yellow; the following portions are black; macula on antennal area except supraclypeal area yellow, line on epistomal suture, transversely elliptical macula tinged with brown surroundig ocelli on vertex, and line on genal area along the preoccipital ridge from hypostoma up to level of top of compound eye in profile. Mandible yellow except apical one-third blackish. Antenna wholly brown.

Mesosoma black; the following portions are variegated with yellowish brown and bright yellow: collar on the top yellow, apicolateral margin of pronotum yellow, pronotal lobe yellow, tegula brown, two lines along the lateral margin of scutum largely yellow, inner two lines on medial portion of scutum wholly yellowish or reddish brown, a large macula almost occupying mesopleuron yellowish brown, containing transverse elliptical bright yellow macula in brown, axilla, scutellum and metanotum wholly bright yellow, a pair of large maculae on posterolateral corner of propodeum.

Metasoma largely brown to dark brown, T1 black on basal half, each terga on apical narrow margin blackish; the following portions are dark yellow but maybe bright yellow in fresh specimen: a pair of round spots each on T1-3 (those on T2 much larger than others), large macula on T5 medially. S1 with longitudinal small spot medially, S2-4 each with medially upcurved broad band which interrupted thrice on $\mathrm{T} 2$, interrupted medially on T3. T4 wholly black in one specimen.

Legs pale brown except all coxae partially black posteriorly.

Sculpture: Punctures on labrum small, dense. Those on clypeus and supraclypeal area evidently larger and distinct.

Punctures on scutellum as on scutum. Mesopleuron densely areolate. Propodeum outside triangle densely areolate, denser than on mesopleuron. Propodeal triangle coarsely irregularly rugose basally and medially, the remaining portion distinctly tessellate.

Terga with indistinct, small, dense punctules. Pygidial plate with small, dense punctures.

Vestiture: Vestiture on labrum yellowish, plumose, moderately dense. That on clypeus and supraclypeal areas yellowish, plumose, appressed, very sparse. That on lower genal area near hypostoma more or less longer than on apical margin of labrum.

Vestiture on scutum moderately dark brown, simple, short, erect. That on mesopleuron yellowish, strongly plumose, long, suberect. That on posterolateral to dorsal surface of propodeum outside propodeal triangle similar to that on mesopleuron, dense to form loose hair patch.

Pseudopygidium well developed as normal in female Nomada. Pygidial plate covered with dense hairs.

Structure: Body length $9.5 \mathrm{~mm}$. CD:UID:LID 50:50:45. OCD/LOD 1.3.

Interantennal elevation moderately raised. Inner eye margins distinctly convergent below. Clypeus moder- 
ately raised and weakly produced anteriorly. Labrum 1.5 times as wide as long; distinct labral tooth present at or slightly before the middle, accompanied by indistinct carina on each side; the apical portion below labral tooth weakly produced anteriorly, weakly upcurved; apical margin indistinctly serrated with distinct triangular protuberance. Mandible simple, acute at apex. Preoccipital ridge angulated. Relative length of FL1-3 1:1.9:1.5, relative length to apical width of FL1 equal, FL2 twice, FL3
1.6 times.

Scutellum highly raised, anterior facet flat, median furrow wide and deep. Pygidial plate triangular at apical portion, slightly expanded apically.

Fore femur slender. Apicomedian setae on hind tibia 12-14 in number, pale brown, considerably long, thin, all straight, sometimes posterior several setae slightly curved posteriorly, gradually shorter anteriorly.

Male.

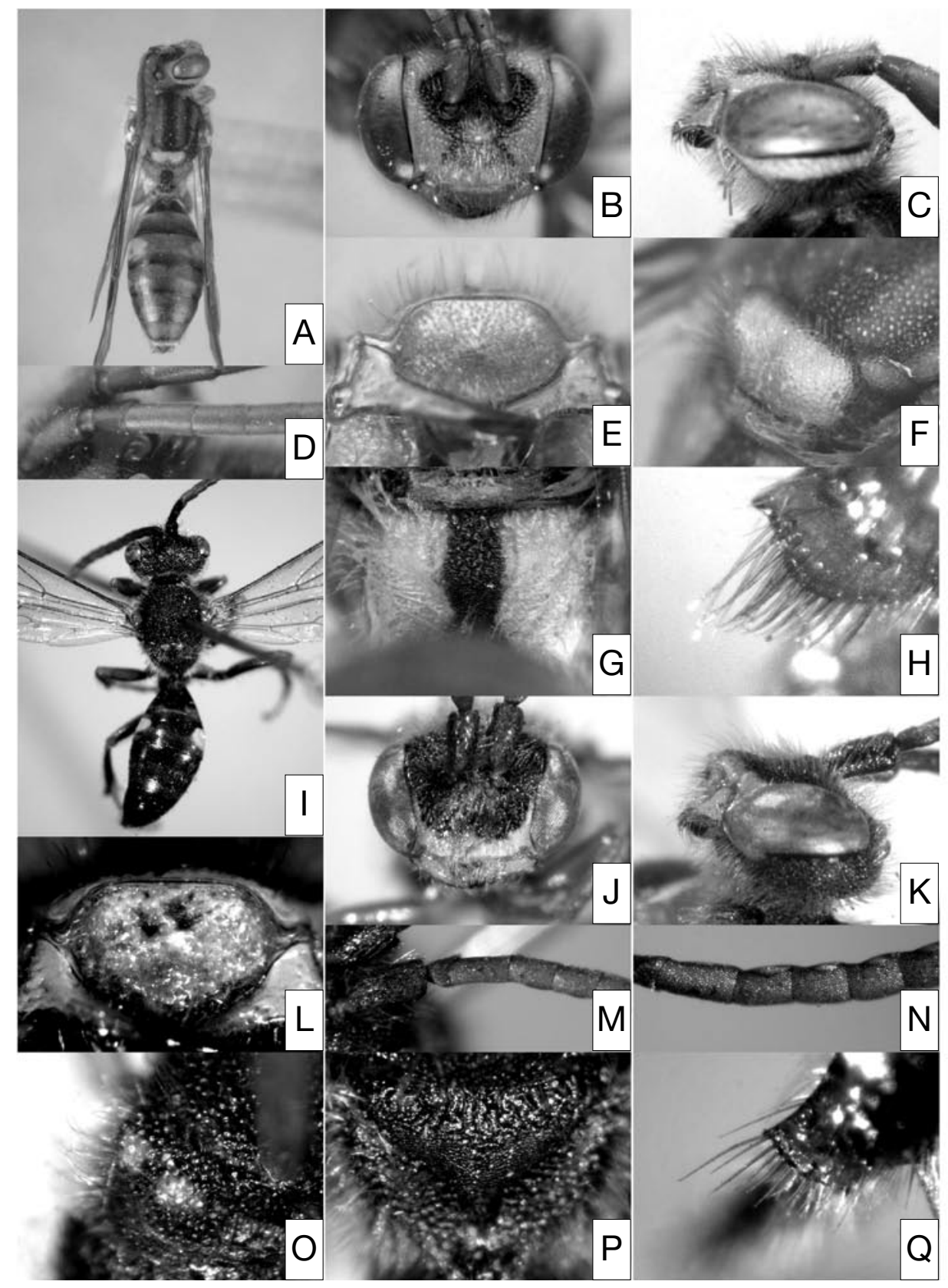

Fig. 84. Nomada xantha sp. nov. Female: A-H. Male: I-Q. A, I: habitus, dorsal view. B, C, J, K: head. D, M, N: antenna. E, L: labrum. F, O: scutellum. G, P: propodeal triangle. H, Q: apicomedian setae on hind tibia. 
Color: Head largely black; the following portions are yellow; labrum, mandible with apical one-third blackish, clypeus on apical half, malar area, lower paraocular area narrowly extending up along inner eye margin to level of antennal socket, line on genal area along lower outer eye margin extending up shortly from hypostoma.
Scape partially yellow anteriorly, black posteriorly, flagellar segments brown anteriorly, darkened apically, black posteriorly. In one specimen, scape wholly black.

Mesosoma black; the following portions are bright yellow: collar on the top, pronotal lobe, two maculae on scutellum of considerably variable size, small trans-
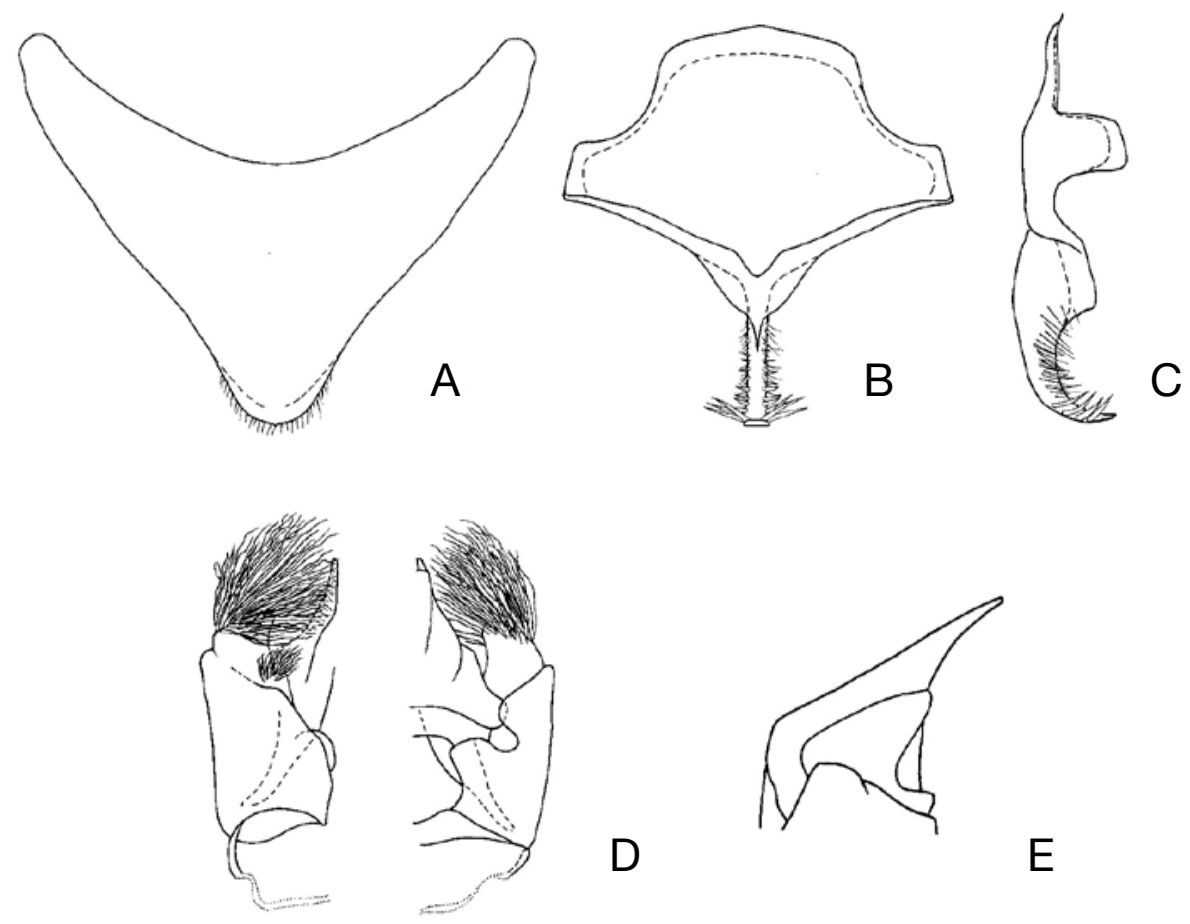

$\mathrm{D}$

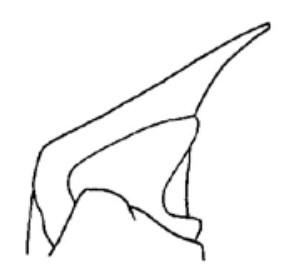

$\mathrm{E}$

Fig. 85. Nomada xantha sp. nov. (male). A: 7th metasomal sternum, ventral view. B: 8th sternum, dorsal view. C: the same, lateral view. D: genital capsule (left, ventral view; right, dorsal view). E: penis valve and gonostylus, lateral view (vestiture omitted).

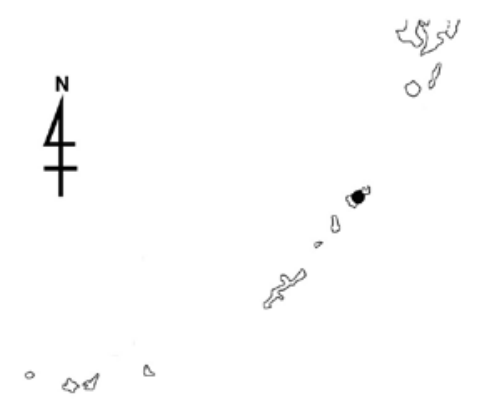

Fig. 86. Distribution of $N$. xantha sp. nov. in the Nansei islands. Dot: locality of the specimens examined in the present study. 
Table 31. Seasonal change of number of the captured individual of N. xantha in Japan (Number of females indicates at the left of slash in cell, that of males at the right. E: early, M: mid, L: late).

\begin{tabular}{c|ccc|ccc|ccc}
\hline \multirow{2}{*}{ Nansei Islands } & \multicolumn{3}{|c|}{ March } & \multicolumn{3}{c|}{ April } & \multicolumn{3}{c}{ May } \\
\cline { 2 - 11 } & $\mathrm{E}$ & $\mathrm{M}$ & $\mathrm{L}$ & $\mathrm{E}$ & $\mathrm{M}$ & $\mathrm{L}$ & $\mathrm{E}$ & $\mathrm{M}$ & $\mathrm{L}$ \\
\hline \hline Amami-Oshima & & & $/ 1$ & $/ 5$ & & & $/ 1$ & $3 /$ \\
\hline Total & 0 & 0 & 1 & 5 & 0 & 0 & 1 & 3 & 0 \\
\hline
\end{tabular}

versely elliptical macula on anterior portion of mesopleuron. Sometimes a pair of small yellow spots present on posterolateral corner of propodeum.

Metasoma largely dark brown to black but it is unclear that blackness is artifact of preservation; T1 brown on apical half and T2 on intermacular space brown, posterior margin of brown portion on $\mathrm{T} 1$ produced posteriorly; the following portions are yellow: a pair of round spots on T2, a pair of small transverse spots on lateral side of T3, short transverse band on T6.

Legs largely pale brown; following portions are black: all coxae except apically, all trochanter posteriorly, fore femur ventrally, mid femur ventrally and posteriorly except apical portion, hind femur except dorsally, spots or lines on posterior surfaces of fore and mid tibiae.

Sculpture: Compared with female, punctures on scutum somewhat denser and deeper, sculpture on propodeum outside propodeal triangle shallower, punctures on terga much sparser.

Vestiture: Vestiture on labrum pale brown or yellowish, moderately long evenly, plumose. That on clypeus and supraclypeal area yellowish, longer than on labrum, weakly plumose, suberect. That on lower genal area near hypostoma much longer than on labrum, considerably dense.

Vestiture on scutum and scutellum similar to that on clypeus, pale brown, weakly plumose, erect, long, on scutellum slightly longer than on scutum. That on mesopleuron whitish, longer and more strongly plumose than on scutum. That on posterolateral to dorsal surface of propodeum outside triangle similar to that on scutum, but slightly more strongly plumose, and sparser, not forming hair patch.

Vestiture on terga much sparser than in female.

Vestiture on ventral surface of fore femur considerably sparse, as long as the maximum width of segment, that of mid femur similarly sparse, slightly shorter than the maximum width of segment. That on ventral surface of hind femur sparse, erect, straight.

Structure: Body length 8-9 mm. CD:UID:LID 50:50:41. OCD/LOD 1.6.
The following aspects are different from female: clypeus weakly raised and produced anteriorly; scape wider than flagellar segments; relative length of FL1-3 1:2.4:1.8, relative length to apical width of FL1 0.8 times, FL2 2.2 times, FL3 1.6 times, tyloidea on FL1 absent, that on FL2 indistinctly delimited, narrowly ridge-shaped, those on FL3-10 distinctly delimited, highly raised, oval, that on ultimate segment distinct, not highly raised, oval; scutellum as in female, but median furrow shallow; pygidial plate shallowly or more or less deeply emarginated at apex; hind femur very slender; basoventral flattened surface narrow, extended toward apex slightly beyond midpoint of segment, evidently depressed in posterior view; apicomedian setae on hind tibia seven or eight in number, shaped as in female, but sparser and thinner, anterior several setae indistinct in surrounding hairs.

Male terminalia: 7th metasomal sternum as in Fig. 85-A. 8th as in Fig. 85-B, C. Gonostylus thick, short; vestiture dense, simple, feebly sinuate apically; basoventral lobe developed, with simple, long, sinuate vestiture. Penis valve produced posteriorly much beyond gonostylus, apex much extending beyond apex of gonostylus in lateral view. Gonocoxite with deep dorsal invagination; inner dorsal lobe as wide as long, with apex truncate.

Distribution. Japan (Amami-Oshima Is.).

Specimens examined. Holotype (Type No. 3248. ELKU), 우, attached one label as follows: "V-15-1953/ Ryukyu Is./ T. SHIRAKI", "Amami/ Shinokawa (on the underside)".

Paratypes: all are from Amami-Oshima Is. and deposited in ELKU as follows: 10 , Mt. Yuwan, 1. v. 1953 (T. Shiraki); Shinokawa, 1우, 11. v. 1953, 1우, 15. v. 1953 (T. Shiraki); 1우, Shinmura, 16. v. 1953 (T. Shiraki); 5ð', Shinmura, 4-5. iv. 1956 (S. Miyamoto); 10', the locality unspecified, 29. iii. 1958 (M. Takahashi).

Biology. It is endemic at present to Amami-Oshima Is., collected from late March to mid May (Table 31). The host and floral association are unknown.

Remarks. The female has the long, close together apicomedian setae on hind tibia which is somewhat similar to Nomada pacifica Tsuneki, but differs from it 
in the much more widely developed yellow macula on body, the apically acute mandible. The male is similar to Nomada flavoguttata (Kirby), Nomada montverna Tsuneki, and Nomada hakonensis Cockerell in general appearance, but can be recognized from them by the coarsely rugose propodeal triangle, the deeply excavated basoventral surface of hind femur, and the much longer apicomedian setae on hind tibia.

\section{Artificial key to the all Japanese species}

\section{Female}

1 Interantennal elevation flattened on top, or wholly rounded without a distinct carina. [active in summer to autumn] .................................. 2

- Interantennal elevation with longitudinal keeled carina.

2 Face with a pair of distinct, large bright yellow maculae; pseudopygidium with a fringe of setae which are melanized, sharply pointed and upcurved at apex N. yanoi Tsuneki

- Face without such macula; pseudopygidium without such fringe...

3 Apicomedian setae on hind tibia lacking [FL1: FL2= 1: 1.2, FL2 1.2 times as long as the apical width; face black except yellow or dark brown short line along lower inner eye margin; scutellum wholly black] N. esana Tsuneki

- Apicomedian setae present 4

4 Scutellum wholly black or with small dark reddish brown spots [anterolateral margin of pronotum strongly angulate nearly at right angle; scutellum punctate as on scutum].. N. issikii Yasumatsu

- Scutellum with a large or a pair of bright yellow maculae ..... 5

5 Face with developed reddish brown macula [scutellum coarsely punctate, highly raised, median furrow deep and wide]. N. munakatai Tsuneki

- Face largely black without such macula .................... 6

6 Apicomedian setae on hind tibia short, more than ten in number; procoxal spine much longer than basal width of femur; body length less than $8 \mathrm{~mm}$ N. temmasana akitsushimae Mitai et al.

- Apicomedian setae less than six in number; procoxal spine shorter than basal width of femur; body length more than $7 \mathrm{~mm}$

7

7 Antenna and legs brownish yellow or pale brown; inner eye margins subparalleled; scutellum with a transversely elongate yellow macula; punctures on scutellum usually much larger and sparser than on scutum N. okamotonis Matsumura
- Antenna and legs largely black; inner eye margins convergent below; scutellum with two yellow maculae, which are divided by thin longitudinal black line; punctures on scutellum slightly larger and sparser than on scutum ( $N$. hakusana Tsuneki)....... 8

8 Narrowly yellow on lower paraocular area, clypeus and mandible; tegula brown; distributed in Honshu (Chubu District)

N. hakusana hakusana Tsuneki

- Broadly yellow on lower paraocular area, clypeus and mandible; tegulae wholly black; distributed in Hokkaido............. N. hakusana momoglonis Tsuneki

9 Propodeal triangle striate basally; posterolateral to dorsal surface of propodeum polished and impunctate or very sparsely punctate active in summer to autumn] 10

- Propodeal triangle irregularly rugose at least basally; posterolateral to dorsal surface densely punctate

Submarginal cells in fore wing two in number; pro podeum outside triangle polished without puncture N. koikensis Tsuneki

- Submarginal cells three, as normal in Nomada; propodeum outside triangle with sparse punctures .....11

11 Scutellum with a large or a pair of bright yellow maculae .......... N. galloisi Yasumatsu et Hirashima

- Scutellum with dark red or reddish brown macula

2 Body length more than $8 \mathrm{~mm}$; $\mathrm{T} 1$ reddish brown to yellowish brown; face with reddish brown portion N. roberjeotiana aino Tsuneki

- Body length 6.3-7.0 mm; T1 black; face nearly wholly black N. arasiana Tsuneki

13 Posterolateral to dorsal surface of propodeum with dense, strongly plumose, appressed or suberect vestiture, the integument below it concealed or obscured .14

- Posterolateral to dorsal surface of propodeum covered with sparse, erect to suberect vestiture. If appressed vestiture present, not dense to concealed the integument below it............................................ 28

14 Propodeal triangle irregularly coarsely rugose wholly, boundary of triangle carinated [body length 4-8 $\mathrm{mm}]$............................................................... 15

- Propodeal triangle irregularly basally, not wholly, boundary of triangle not carinated .........................16

15 Apicomedian setae on hind tibia thin, three in number, posteriormost setae long, the other two shorter and very thin; face black except apical portion of clypeus, malar area and inner margin of eyes brown to reddish brown ........................... okubira Tsuneki 
- Apicomedian setae three in number, anteriormost setae similar to that of okubira, but the other two much shorter and more robust than those of okubira; lower half of face reddish brown except black supraclypeal area N. pulawskii Tsuneki

16 Scutellum wholly evenly yellow to bright yellow ..17

- Scutellum reddish brown or partially yellow ........ 19

17 Apicomedian setae on hind tibia 12-14 in number; propodeum with a pair of large yellow maculae [distributed in Amami-Oshima Is., the Nansei Isls.]....... N. xantha Mitai et al. sp. nov. Apicomedian setae at most four in number; propodeum wholly black .. 18

18 Apicomedian setae on hind tibia needle-shaped as normal in female Nomada; active in summer to autumn ................... kaguya Yasumatsu et Hirashima

- Apicomedian seta flattened, slender leaf-shaped; active in spring N. aswensis Tsuneki

19 Terga variegated with black and reddish brown, without yellow macula.

- Terga with yellow macula 22

20 Clypeus extremely short; scutum sparsely punctate, area between punctures several puncture diameters wide in places and smooth............... taicho Tsuneki

- Clypeus moderately extended anteriorly; scutum densely punctate, area between punctures less than puncture diameter wide 21

21 Apicomedian setae on hind tibia robust, two in number; wholly dorsal surface of propodeum except triangle covered by very dense vestiture...................................................... N. ginran Tsuneki

- Apicomedian setae thin, three or four in number; Vestiture on dorsal surface of propodeum not so dense. N. erythra Mitai et al. sp. nov.

22 FL2 al least 1.8 times as long as apical width of segment...... 23

- FL2 at most 1.7 times as long as apical width of segment... 26

23 FL2 2.4-2.6 times as long as apical width of segment N. hakonensis Cockerell

- FL2 at most twice as long as apical width of segment..... 24

24 Submarginal cells in fore wing two in number; hypoepimeral area with punctures sparser and wider than the neighboring area ........ N. kinosukei Tsuneki

- Submarginal cells three, as normal in Nomada (rarely abnormally two); hypoepimeral area punctate as on the neighboring area

25 Head and mesosoma with moderately punctate (wintering and first generations); nearly always a reddish brown spot on supraclypeal area (winter- ing generation); reddish brown maculae on dorsal surface of propodeum large, nearly always expanding into propodeal triangle (wintering generation). N. flavoguttata (Kirby)

- Head and mesosoma with deeper punctures, especially on scutum and lateral surface of mesopleuron (wintering and first generations); supraclypeal area black (both generations); reddish brown maculae on propodeum small, always outside the triangle, and frequently lacking (both generations)........................................ montverna Tsuneki

26 Apicomedian setae on hind tibia five in number, posteriormost seta short, brown, needle-shaped, others black, considerably short, rounded wholly, close together................................... N. guttulata Schenck

- Apicomedian setae are not shaped above .............. 27

27 Mandible curved as normal in Nomada; black macula on face small; apicomedian setae on hind tibia four in number, shorter, evenly well-spaced, thin, pale brown................................. sabaensis Tsuneki

- Mandible curved strongly; usually black macula on face more developed; apicomedian setae four in number, usually robust, pale brown to dark brown except the posteriormost one..... N. shirakii Yasumatsu et Hirashima

28 Apicomedian setae on hind tibia 20-30 in number, close together as a bundle, each setae brown, rounded at apex........ nipponica Yasumatsu et Hirashima - Apicomedian setae not shaped above .................... 29

29 Apicomedian setae three in number, dark brown, posteriormost seta thin, long, straight, other two robust, flattened, rounded at apex, curved posteriorly, close together ..................... N. comparata Cockerell

- Apicomedian setae not shaped above ..................... 30

30 Apicomedian setae six or seven in number, posteriormost seta thin, straight, acute at apex, pale brown, others thicker, slightly curved, flattened, bluntly pointed at apex, dark brown or black.

N. fulvicornis jezoensis Matsumura Apicomedian setae not shaped above .....................31

31 Apicomedian setae four or five in number, black, long, slightly curved downward, bluntly pointed at apex, all similar in shape, somewhat shorter anteriorly but sometimes appear all the same in length [second radius-media vein in fore wing strongly curved mesally, so that third submarginal cell strongly narrower upward.].

. N. alboguttata etizenensis Tsuneki

- Apicomedian setae and wing cells are not shaped above .................................................................. 32

32 Mandible blunt, rounded or widely truncate at apex, 
sometimes feebly emarginated in truncate apex ... 33

- Mandible more or less acute apex. 36

33 Apicomedian setae on hind tibia four in number, robust, evenly well-separated; scutellum punctate evidently more sparsely than on scutum

N. abtana Tsuneki

- Apicomedian setae more than four in number, closely dense, thus difficult to discern individually; scutellum punctate as on scutum. .. 34

34 Body length 6-9 mm; FL1 evidently shorter than FL2 (F1:F2=1:1.8); labral tooth located about at the center; apicomedian setae on hind tibia long, gradually shorter posteriorly..... N. pacifica Tsuneki

- Body length 10-13.5 mm; FL1 slightly longer or as long as FL2; labral tooth located subapically; apicomedian setae evenly short..... 35

35 Propodeum black throughout or with reddish brown spots; FL1 slightly longer than FL2; distributed widely in Japan, Korea, China....... . japonica Smith

- Propodeum with large yellow spots; FL1 as long as FL2; distributed in Amami-Oshima Is., the Nansei Isls. N. amamiensis Hirashima

36 FL2 about as long as FL1 (FL1: FL2=1: 1.1-1.2) [propodeum wholly black; apicomedian setae on hind tibia six to eight in number, short, about as long as surrounding hairs] N. silvicola Tsuneki

- FL2 usually at least 1.5 times as long as FL1. If indistinct, propodeum with maculae

37 Apicomedian setae on hind tibia seven to ten in number, posteriormost seta slightly longer than others, the others considerably short, shorter than surrounding hairs [FL2 1.7-2.3 times as long as apical width of segment]. 38

- Apicomedian setae longer than surrounding hairs; if indistinct, setae more than ten in number 39

38 FL2 2.2-2.3 times as long as apical width of segment; supraclypeal area always reddish brown; apicomedian setae on hind tibia evenly separated, relatively thin ................................ $N$. fervens $\mathrm{Smith}$

- FL2 1.7 -1.8 times as long as apical width of segment; supraclypeal area sometimes black; apicomedian setae irregularly close together, relatively robust........................... amurensis Radoszkowsky

39 Apicomedian setae on hind tibia thin, more than ten in number . 40

- Apicomedian setae less than ten in number, about four to six in most species... 41

40 Body size at most $9.5 \mathrm{~mm}$; FL2 about twice as long as apical width of segment; propodeum with short, suberect or appressed hairs in fresh specimens, but very sparse to nearly hairless in many specimens; apicomedian setae on hind tibia long

N. harimensis Cockerell

- Body size 9-11 mm; FL2 2.2- 2.3 times as long as apical width of segment; propodeum with long, white, erect hairs; apicomedian setae short.....

N. pyrifera Cockerell

41 Dorsal surface of propodeum with a pair of longitudinal zigzag bright yellow maculae.

N. icazti Tsuneki

- Propodeum without such macula............................ 42

42 Pseudopygidium rudimentary................................. 43

- Pseudopygidium well developed............................. 44

43 Clypeus less highly raised; apical three segments reddish brown at least anteriorly; T2 with a pair of well-separated yellow maculae....N. towada Tsuneki

- Clypeus more highly raised; apical three flagellar segments usually wholly black; T2 with a complete yellow band, at most rarely narrowly interrupted .....

N. fukuiana Tsuneki

44 Pseudopygidium composed of long, not modified hairs [clypeus strongly produced anteriorly]

N. hackoda Tsuneki

- Pseudopygidium composed of scale-like modified hairs, as normal in female Nomada ...................... 45

45 Black macula on face widely developed................ 46

- Black macula on face not so developed.................. 48

46 Posterolateral to dorsal surface of propodeum outside triangle covered with dull white or white, short, erect, moderately plumose vestiture; lateral sides of T3-5 with white appressed pubescence, which evidently longer and denser than other portions of the terga, those on $\mathrm{T} 3$ and $\mathrm{T} 5$ sometimes indistinct.

N. asozuana Tsuneki

- Posterolateral to dorsal surface of propodeum outside triangle with minute, sparse, thus indistinct vestiture; lateral sides of T3-5 without pubescence above 47

47 Pseudopygidium prominently developed, composed of long, only subtle scale-shaped, disheveled hair ....

N. fusca Schwarz

- Pseudopygidium not so developed, at most as normal in female Nomada ............ N. leucophthalma (Kirby)

48 Labrum with obliterated sparse punctures, interpunctural space polished, three distinct labral teeth located on subapical margin [clypeus strongly produced anteriorly; scutellum punctate much more sparsely than scutum]............. N. maculifrons Smith

- Labrum with interpunctural space not polished, labral tooth located near at the center. 49

49 Posterolateral to dorsal surface of propodeum with white, minute, sparse, thus indistinct vestiture; scu- 
tellum weakly raised, with not particularly coarse punctures, median furrow shallow.

.N. panzeri orientis Tsuneki

- Posterolateral to dorsal surface of propodeum covered with usually golden or bright brown, long, erect dense vestiture; scutellum highly raised, prominently coarsely punctate, median furrow deep. N. calloptera Tsuneki

\section{Male}

(Males of N. asozuana, N. ecarinata, N. fusca, N. leucophthalma, N. munakatai, $N$. sabaensis, N. erythra, $N$. japonica, and N. pulawskii are not included)

1. Interantennal elevation flattened on top, or wholly rounded without a distinct carina [active in summer to autumn]

\section{2}

- Interantennal elevation with longitudinal keeled carina .

2 Axillae bright yellow [collar, pronotal lobe, tegulae, scutellum similarly bright yellow].

N. yanoi Tsuneki

- Axillae black. 3

3 Face with less developed yellow macula; usually labrum wholly black .................... N. issikii Yasumatsu

- Face with relatively developed yellow macula; labrum more or less with yellow portion.

4 Apicomedian setae on hind tibia lacking; scutellum black .............................................. N. esana Tsuneki

- Apicomedian setae present; scutellum with yellow macula 5

5 Body length less than $8 \mathrm{~mm}$; apicomedian setae on hind tibia, short, more than ten in number; procoxal spine much longer than basal width of femur.

N. temmasana akitsushimae Mitai et al.

- Body length more than $8 \mathrm{~mm}$; apicomedian setae less than 6 in number; procoxal spine shorter than basal width of femur 6

6 Antenna and leg largely brownish yellow or pale brownish; inner eye margins subparallel; punctures on scutellum usually much larger and sparser than on scutum N. okamotonis Matsumura

- Antenna and leg largely black; inner eye margins convergent below; punctures on scutellum slightly larger and sparser than on scutum. (N. hakusana Tsuneki).

\section{. .7}

7 Tegula bright yellow; distributed in Honshu (Chubu District) .................... hakusana hakusana Tsuneki

- Tegula brownish black; distributed in Hokkaido ...... .. N. hakusana momoglonis Tsuneki

8 FL1-3 roughly equal in length $\underline{\text { and }}$ relative length to each apical width of them less than 1.2 times ........ 9

- FL2 evidently longer than FL1, or relative length of FL2 to apical width of segment 1.4 times or more .... 12

9 Antenna 12-segmented 10

- Antenna 13-segmented, as normal in male Nomada

Submarginal cells in fore wing two in number ......... N. koikensis Tsuneki

- Submarginal cells three ............. N. arasiana Tsuneki

11 Body length more than $8 \mathrm{~mm}$; yellow maculae on metasoma developed, T1 reddish brown to yellowish brown........................ $N$. roberjeotiana aino Tsuneki

- Body length less than $8 \mathrm{~mm}$; yellow macula on metasoma not well developed, T1 black, rarely dark reddish brown....N. galloisi Yasumatsu et Hirashima

12 Mandible rounded or widely truncate at apex, sometimes feebly emarginated in truncate apex............ 13

- Mandible more or less acute at apex...................... 15

13 FL1-3 roughly equal in length; apicomedian setae on hind tibia 13- 16 in number, short, pale brown, close together, all similar in shape and length [distributed in Amami- Oshima Is., the Nansei Isls.]. N. amamiensis Hirashima

- FL2 at least 1.7 times longer than FL1; apicomedian setae are different in shape above............................14

14 FL2 1.7 times as long as FL1; apicomedian setae on hind tibia four in number, evenly well separated ......

.. N. abtana Tsuneki

- FL2 twice as long as FL1; apicomedian setae long, close together, intermixed with surrounding hairs, thus difficult to discern individually

N. pacifica Tsuneki

15 Basoventral portion of hind femur depressed and flattened, and vestiture on it dense, sinuate posteriorly ........................................................................16

- Basoventral portion of hind femur not depressed or shallowly so in most species. If distinctly depressed, vestiture on it relatively sparse, not sinuate........... 22

16 Propodeal triangle irregularly coarsely rugose wholly; boundary of triangle carinated....

N. okubira Tsuneki

- Propodeal triangle irregularly basally, not wholly; boundary of triangle not carinated ..17

17 Clypeus extremely short; apical half of propodeal triangle smooth; scutum sparsely punctate, area between punctures several puncture diameters wide in places and smooth ............................ taicho Tsuneki

- Clypeus normal; no smooth portion on propodeal triangle; scutum densely punctate, area between punctures less than puncture diameter wide ......... 18 
18 Scutellum with yellow macula.

- Scutellum with brown or reddish brown 21

19 Body length 7-12 mm; supraclypeal area with bright yellow spot; usually scutellum highly raised, median furrow deep. N. comparata Cockerell

- Body length 4.5-8 mm; supraclypeal area black; scutellum without or with shallow median furrow ..... 20

20 Active in summer; scutellum wholly yellow; depression of hind femur not prominent, at most reaching to midpoint of femur in posterior view.

.N. kaguya Hirashima

- Active in spring; scutellum black with a pair of yellow maculae; depression of hind femur prominent, extending beyond midpoint of femur in posterior view

N. aswensis Tsuneki

21 Apicomedian setae on hind tibia about ten in number, very thin, moderately long, pale in color, irregularly loosely close together, difficult to discern among surrounding hairs; depression of hind femur with weakly sinuate hairs

N. nipponica Yasumatsu et Hirashima

- Apicomedian setae two in number, short, brown; depression of hind femur with appressed basally and upcurved apically hairs

N. ginran Tsuneki

22 FL2 1.5 times as long as apical width of segment [apicomedian setae on hind tibia very long]

N. alboguttata etizenensis Tsuneki

- FL2 more than 1.5 times longer than apical width of segment .23

23 FL2 at least twice as long as FL1. .. 24

- FL2 less than twice as long as FL1 35

24 FL2 at least 2.4 times as long as apical width of segment .. 25

- FL2 at most 2.2 times as long as apical width of segment... 27

25 Scape bright yellow at least anteriorly; body length 9-11 mm N. pyrifera Cockerell

- Scape largely black, partially blackish brown; body length less than $9 \mathrm{~mm}$. .. 26

26 Body length 4.5- $7 \mathrm{~mm}$; tyloidea weakly developed only on FL4-5, very narrowly ridge-shaped; apicomedian setae on hind tibia three in number

N. hakonensis Cockerell

- Body length 8-9 mm; tyloidea on FL2 narrowly ridge-shaped, those on FL3-10 distinctly delimited, oval, highly raised; apicomedian setae seven to eight in number[distributed in Amami-Oshima Is., the Nansei Isls.] .................. xantha Mitai et al. sp. nov.

27 Tyloidea on FL2-6 distinctly delimited, oval, highly raised; FL2 at most 1.5-1.6 times as long as the apical width [mandible strongly curved at the midpoint; scape much broader than flagellar segments] N. shirakii Yasumatsu et Hirashima

- Tyloidea on FL2-6 not distinctly developed, usually narrowly low ridge-shaped; FL at aleast 1.8 times as long as the apical width....................................... 28

28 Tyloidea on last five segments shaped as conical tubercle [labral tooth located subapically; clypeus greatly produced anteriorly].... N. maculifrons Smith

- Tyloidea on corresponding portion not shaped as above 29

29 Mesopleuron with transversely elliptical bright yellow macula, which extends from anterior margin near to posterior margin of mesopleuron; procoxa on apical half bright yellow [scape bright yellow anteriorly; apicomedian setae on hind tibia four in number, thin, pale brown, acute at apex, evenly spaced]

..N. icazti Tsuneki

- Mesopleuron without yellow macula or, if present, it not extend near to posterior margin of mesopleuron; procoxa without such bright yellow portion.......... 30

30 Apicomedian setae on hind tibia three to four in number, all thin, posteriormost seta long, the other somewhat short; body length at most $6 \mathrm{~mm}$............31

- Apicomedian setae at least five in number, usually robust, very long or very short; body length at least $8 \mathrm{~mm}$. 33

31 Submarginal cells in fore wing two in number; hypoepimeral area punctate more sparsely than on neighboring area ...................... N. kinosukei Tsuneki

- Submarginal cells three; hypoepimeral area punctate as on neighboring area 32

32 Head and mesosoma moderately punctate (wintering and first generations); scutellum nearly always with bright yellow to dark reddish brown macula. (wintering generation) N. flavoguttata (Kirby)

- Head and mesosoma with deeper punctures, especially on scutum and lateral surface of mesopleuron (wintering and first generations); scutellum nearly always black. (both generations)

N. montverna Tsuneki

33 Apicomedian setae on hind tibia short, thin, close together; labral tooth located in the middle of labrum [scutellum wholly black, or rarely with a pair of small dark reddish brown maculae in wintering generation; scape wholly black, or partially dark brown to dark yellow anteriorly].....

N. amurensis Yasumatsu et Hirashima

- Apicomedian setae, robust, moderately to considerably long; labral tooth located not in the middle but near apical margin. 34

34 Scape bright yellow anteriorly; scutellum each with 
a pair of bright yellow maculae; apicomedian setae on hind tibia five or six in number, flattened, bluntly pointed at apex except posteriormost seta

..N. fulvicornis jezoensis Matsumura

- Scape black or at most dark yellow anteriorly; scutellum and propodeum usually black, sometimes small, reddish brown to red, two spots on scutellum; apicomedian setae six or seven in number, needleshaped, acute at apex ........... N. calloptera Cockerell

35 Labrum wholly black; apicomedian setae on hind tibia about ten in number, thin, all similar in shape but slightly shorter apically, close together, difficult to discern individually .........N. harimensis Cockerell

- Labrum largely yellow; apicomedian setae less than ten in number 36

36 Clypeal apicolateral corner angulated to form a weak ridge; apical three flagellar segments usually wholly black but sometimes lightening anteriorly; T2 with a complete yellow band, at most rarely narrowly interrupted [pygidial plate deeply, triangularly or roundly emarginated at apex]

N. fukuiana Tsuneki

- Clypeus without such a ridge; apical three segments reddish brown at least anteriorly; T2 without a complete yellow band but a pair of maculae 37

37 Hairs on hind femur short, about as long as half of the maximum width of the segment. [F2 1.6 times as long as the apical width of segment; scutellum black with deep median furrow; face with thin U-shaped yellow macula in wintering generation, and face wholly black in the first generation] N. silvicola Tsuneki

- Hind femur with longer hairs. 38

38 Clypeus highly raised and strongly produced anteriorly [F2 1.7 times as long as the apical width of segment; pygidial plate widely, triangularly or roundly emarginated at apex] N. hackoda Tsuneki

- Clypeus at most highly raised and not strongly produced anteriorly 39

39 F2 1.4-1.5 times as long as F1 [clypeus weakly raised; pygidial plate shallowly or scarcely emarginated at apex] ........................... N. guttulata Schenck

- F2 at least 1.7 times as long as F1 ......................... 40

40 F2 1.9-2.0 times as long as the apical width of segment; pygidial plate usually shallow but widely triangularly emarginated at apex........ N. fervens Smith

- F2 at most 1.8 times as long as the apical width of segment; pygidial plate narrowly, deeply emarginated at apex.

41 Yellow macula on face U-shaped: apical portion of clypeus, malar area and lower paraocular area along inner eye margins yellow

N. panzeri orientis Tsuneki

- Yellow macula on face restricted to narrow apical margin of clypeus and malar area; frequently malar area also wholly black, only apex of clypeus dirty yellow, or sometimes face wholly black.

..N. towada Tsuneki

\section{Remarks on the Japanese fauna of the genus Nomada}

Japan is composed of four main islands (Hokkaido, Honshu, Shikoku and Kyushu) and several thousand small islands, most of which are located on the eastern margin of the Palearctic Region. The series of southern islands that lie between Kyushu and Taiwan is called the Nansei Islands, and is the northwestern part of the Oriental Region. In the present study, examined materials from Shikoku and the Nansei Islands are relatively few, so that new taxonomical and distributional knowledge is expected from these areas.

Two hypotheses have been proposed to explain the origin of Nomada: the South America origin of Michener $(1979,2000)$, and the south Africa origin of Alexander $(1991,1994)$ (Alexander himself mentioned that his hypothesis "should be viewed with considerably skepticism"). However, regardless of the origin, Nomada has undergone considerable diversification in the Northern Hemisphere. As for the Palearctic Region, although the fauna of Nomada in Europe is well studied, that of in the eastern parts of the Palearctic Region such as Far East Russia, China, South and North Korea has not been fully surveyed. For example, only five Nomada species are listed from South Korea (Entomological Society of Korea \& Korean Society of Applied Entomology [ed.], 1994). Therefore, the discussion below is based on comparisons between the faunas of Japan and European countries.

Forty-nine Japanese species are recognized on the basis of the present study and other previous papers (Alexander \& Schwarz, 1994; Mitai, Hirashima \& Tadauchi, 2003; Mitai \& Tadauchi, 2004, 2005, 2006). Nomada ginran Tsuneki, 1973 was treated as a member of the bifasciata species group in Mitai \& Tadauchi (2004). Mr. Schwarz, however, pointed out that it should belong to the armata species group (personal communication). We agree with this opinion, and therefore treat $N$. ginran as a member of the armata species group below. The Japanese species are arranged into seven species groups as follows: 
Table 32. Distribution of the Nomada species in Japan.

Hk: Hokkaido. Hn: Honshu. S: Shikoku. K: Kyushu. : the specimens examined from the area in the present study. $\bigcirc$ : the record in literature only.

\begin{tabular}{|c|c|c|c|c|c|c|}
\hline Species & $\mathrm{Hk}$ & $\mathrm{Hn}$ & $\mathrm{S}$ & K & Nansei Islands & other localities \\
\hline \multicolumn{7}{|l|}{ roberjeotiana species group } \\
\hline \multicolumn{7}{|l|}{ N. arasiana } \\
\hline \multicolumn{7}{|l|}{$N$. galloisi } \\
\hline \multicolumn{7}{|l|}{ N. hakusana } \\
\hline \multicolumn{7}{|l|}{ N. issikii } \\
\hline \multicolumn{7}{|l|}{ N. koikensis } \\
\hline N. okamotonis & 0 & $\bullet$ & & 0 & & Northwest Asia \\
\hline \multicolumn{7}{|l|}{ N. roberjeotiana aino } \\
\hline \multicolumn{7}{|l|}{ N. temmasana akitsushimae } \\
\hline \multicolumn{7}{|l|}{ ruficornis species group } \\
\hline \multicolumn{7}{|l|}{ N. abtana } \\
\hline \multicolumn{7}{|l|}{ N. alboguttata etizenensis } \\
\hline \multicolumn{7}{|l|}{ N. amurensis } \\
\hline \multicolumn{7}{|l|}{ N. asozuana } \\
\hline \multicolumn{7}{|c|}{ Yakushima Is. } \\
\hline N. calloptera & 0 & 0 & & 0 & Tanegashima Is. & South Korea \\
\hline N. erythra & & & & & Amami-Oshima Is. & \\
\hline N. flavoguttata & 0 & $\bullet$ & 0 & 0 & $\begin{array}{l}\text { Tanegashima Is., } \\
\text { Yakushima Is. }\end{array}$ & $\begin{array}{l}\text { South Korea } \\
\text { Taiwan }\end{array}$ \\
\hline \multicolumn{7}{|l|}{ N. fukuiana } \\
\hline \multicolumn{7}{|l|}{ N. fulvicornis jezoensis } \\
\hline N. fusca & C & 0 & & & & Palearctic region \\
\hline N. guttulata & & O & & 0 & & Palearctic region \\
\hline \multicolumn{7}{|l|}{ N. hackoda } \\
\hline N. hakonensis & 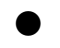 & 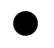 & 0 & 0 & & South Korea \\
\hline$N$. harimensis & O & 0 & 0 & 0 & & South Korea \\
\hline N. icazti & & 0 & 0 & 0 & & South Korea \\
\hline \multicolumn{7}{|l|}{ N. kaguya } \\
\hline \multicolumn{7}{|l|}{ N. kinosukei } \\
\hline N. koebelei & C & ? & 0 & 0 & & South Korea \\
\hline N. leucophthalma & 0 & 0 & & 0 & & Palearctic region \\
\hline N. maculifrons & $\bigcirc$ & $\bullet$ & 0 & 0 & & South Korea \\
\hline \multicolumn{7}{|l|}{ N. montverna } \\
\hline N. pacifica & 0 & 0 & 0 & 0 & & South Korea \\
\hline N. panzeri orientis & 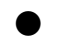 & ? & 0 & 0 & & South Korea \\
\hline \multicolumn{7}{|l|}{ N. pyrifera } \\
\hline \multicolumn{7}{|l|}{ N. sabaensis } \\
\hline \multicolumn{7}{|c|}{ Tanegashima Is. } \\
\hline \multicolumn{7}{|l|}{ N. silvicola } \\
\hline \multicolumn{7}{|l|}{ N. towada } \\
\hline N. xantha & & & & & Amami-Oshima Is. & \\
\hline
\end{tabular}


Table 32. Continued.

\begin{tabular}{|c|c|c|c|c|c|c|}
\hline Species & $\mathrm{Hk}$ & Hn & $S$ & $\mathrm{~K}$ & Nansei Islands & other localities \\
\hline \multicolumn{7}{|l|}{ armata species group } \\
\hline$N$. ginran & 0 & 0 & 0 & 0 & & South Korea \\
\hline \multicolumn{7}{|l|}{ basalis species group } \\
\hline N. amamiensis & & & & & Amami-Oshima Is. & \\
\hline N. japonica & 0 & 0 & 0 & 0 & $\begin{array}{l}\text { Okinawa-Honto Is., } \\
\text { Tanegashima Is. }\end{array}$ & $\begin{array}{l}\text { South Korea } \\
\text { China }\end{array}$ \\
\hline \multicolumn{7}{|l|}{ bifasciata species group } \\
\hline N. comparata & 0 & 0 & $\bigcirc$ & $\bullet$ & $\begin{array}{l}\text { Tanegashima Is., } \\
\text { Yakushima Is. }\end{array}$ & \\
\hline \multicolumn{7}{|l|}{ trispinosa species group } \\
\hline N. nipponica & & 0 & 0 & 0 & Tanegashima Is. & South Korea \\
\hline \multicolumn{7}{|l|}{ furva species group } \\
\hline N. okubira & 0 & 0 & 0 & 0 & Yakushima Is. & $\begin{array}{l}\text { South Korea } \\
\text { Taiwan }\end{array}$ \\
\hline N. pulawskii & $\bigcirc$ & 0 & & 0 & & \\
\hline N. taicho & & 0 & & 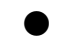 & & South Korea \\
\hline \multicolumn{7}{|l|}{ species group unassigned } \\
\hline \multicolumn{7}{|l|}{ N. esana } \\
\hline \multicolumn{7}{|l|}{ N. munakatai } \\
\hline \multicolumn{7}{|l|}{ N. yanoi } \\
\hline Total & 33 & 45 & 21 & 34 & 11 & \\
\hline $\begin{array}{l}\text { Percentage to tatal number } \\
\text { of species }\end{array}$ & $67 \%$ & $92 \%$ & $43 \%$ & $70 \%$ & $22 \%$ & \\
\hline
\end{tabular}

roberjeotiana species group: $N$. arasiana, $N$. galloisi, N. hakusana hakusana, N. hakusana momoglonis, $N$. issikii, $N$. koikensis, $N$. okamotonis, $N$, roberjeotiana aino, and N. temmasana akitsushimae.

ruficornis species group: N. abtana, $N$. alboguttata etizenensis, $N$. amurensis, $N$. asozuana, $N$. aswensis, $N$. calloptera, N. erythra, N. flavoguttata, N. fukuiana, N. fulvicornis jezoensis, N. fusca, N. guttulata, N. hackoda, $N$. hakonensis, $N$. harimensis, $N$. icazti, N. kaguya, $N$. kinosukei, N. koebelei, N. leucophthalma, N. maculifrons, N. montverna, N. pacifica, N. panzeri orientis, $N$. pyrifera, $N$. sabaensis, $N$. shirakii, $N$. silvicola, $N$. towada, and N. xantha.

armata species group: $N$. ginran. basalis species group: N. amamiensis and N. japoni$c a$.

bifasciata species group: $N$. comparata.

trispinosa species group: $N$. nipponica.

furva species group: N. okubira, N. pulawskii, and N. taicho.

species group undetermined: N. esana, N. munakatai, and N. yanoi

The distributions of the Japanese species are summarized in Table 32. The number of species is the largest for Honshu (45 species), followed by Kyushu (34 species). As shown in Table 33, the number of species in 
Table 33. Nomada faunas of 11 countries in the Palearctic and Nearctic regions.

\begin{tabular}{|c|c|c|c|c|c|c|c|c|c|c|c|c|c|}
\hline Species group & 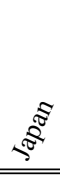 & $\sum^{\mathbb{E}}$ & $\underbrace{5}$ & & $\stackrel{\vec{E}}{\vec{E}}$ & s & 通 & है & $\underbrace{2}$ & 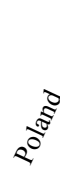 & $\omega^{8}$ & 2 & $\stackrel{2}{8}$ \\
\hline gigas & & & & & & & & & & & & & 1 \\
\hline integra & & 6 & 4 & 1 & 10 & 6 & 6 & 5 & 3 & 4 & 4 & & 20 \\
\hline adducta & & & & & & & & & & & & 4 & 4 \\
\hline vincta & & & & & & & & & & & & 11 & 14 \\
\hline odontophora & & & & & & & & & & & & & 3 \\
\hline vegana & & & & & & & & & & & & 27 & 57 \\
\hline roberjeotiana & 8 & 4 & 3 & 2 & 2 & 4 & 4 & 4 & 2 & 4 & 3 & 11 & 45 \\
\hline erigeronis & & & & & & & & & & & & 21 & 21 \\
\hline ruficornis & 30 & 36 & 27 & 17 & 48 & 34 & 42 & 35 & 21 & 26 & 19 & 230 & 417 \\
\hline armata & 1 & 11 & 5 & 1 & 15 & 9 & 7 & 6 & 6 & 6 & 3 & & 31 \\
\hline belfragei & & & & & & & & & & & & 2 & 3 \\
\hline superba & & 3 & 1 & 1 & 2 & 1 & 1 & 1 & 1 & 1 & 1 & 14 & 26 \\
\hline basalis & 2 & 4 & & 1 & 7 & 1 & 3 & 1 & 1 & 1 & & 2 & 21 \\
\hline bifasciata & 1 & 6 & 3 & 3 & 11 & 4 & 5 & 4 & 4 & 3 & 1 & & 16 \\
\hline trispinosa & 1 & & & & & & 1 & & & 1 & & & 10 \\
\hline furva & 3 & 12 & 3 & 1 & 13 & 8 & 8 & 7 & 5 & 3 & & & 81 \\
\hline species group & 7 & 8 & 7 & 8 & 8 & 8 & 9 & 8 & 8 & 9 & 6 & 9 & 16 \\
\hline species & 49 & 82 & 46 & 27 & 108 & 67 & 77 & 63 & 43 & 49 & 31 & 322 & 770 \\
\hline
\end{tabular}

The data above are derived from Rasmont et al. (1995) for France, Belgium, Luxembourg, and Switzerland; Pagaliano (1994) for Italy, Schwarz et al. (1996) for Austria and Germany, Peeters et al. (1999) for Netherlands, Ceraly (1995) for Poland, Janson at al. (1991) for Sweden, Alexander and Schwarz (1994) for North America and the world; "incertae sedis" are excluded.

Japan (49 species in seven species groups) is much lower than in Italy (108 species in eight species groups) and France (82 species in eight species groups), and also less than the number found in Germany (63 species in eight species groups) and Austria (77 species in nine species groups), roughly the same as in Poland (49 species in nine species groups), and more than those of Sweden (31 species in six species groups). It follows from the above data that the diversity of Nomada in Japan is moderate in comparison with the opposite areas in the Palearctic Region.

The roberjeotiana species group is distributed in Holarctic and Ethiopian Regions and is represented by a relatively large number of species (eight species) in Japan, compared with two to four species in other countries. The European species in this species group are mostly common among countries and are widely distributed in Europe, although this species group in Japan contains some rare species whose distributional records are sporadic. The following species are common with neighboring countries: $N$. issikii common with the $\mathrm{Ku}-$ rile Islands; $N$. okamotonis with northeast Asia; and $N$. temmasana with South Korea, but as a different subspecies.

The relative species richness of the ruficornis species group is low in France and Italy due to the richness of other minor species groups, but makes up more than half of all species in Japan and other European countries, except for the Netherlands. As for Japanese species, the species with restricted distributions are $N$. erythra and N. xantha, which are both endemic to Amami-Oshima Is. of the Nansei Islands. The species with many collecting localities over a wide distribution from Hokkaido to Kyushu are as follows: N. amurensis, $N$. flavoguttata, N. hakonensis, N. harimensis, N. panzeri orientis, and N. shirakii. Species common with the Eurasian fauna at the species level amount to 12 of the 30 Japanese species. 
The following four species groups are diversified in the Mediterranean subregion, but are represented by a few species in the eastern part of the Palearctic region: armata, basalis, bifasciata, and trispinosa species groups. In Japan, these groups are represented by one or two common and widely distributed species, except for $N$. amamiensis, which is endemic to Amami-Oshima Is. of the Nansei Islands.

The furva species group is distributed in the Palearctic, Oriental, and Australian Regions. The specieslevel taxonomy of this group in the Oriental Region is poorly known at present, thus a considerable addition of species expected when the fauna of the Oriental Region becomes better known. The Japanese fauna contains three species. Nomada okubira inhabits regions from Hokkaido to Nakanoshima Is. of the Nansei Islands, as well as South Korea, and is common and abundant at least on the four main islands of Japan.

The species groups that are distributed in the Palearctic Region but not in Japan are the odontophora, the superba, and the integra species groups. The odontophora species group is a small group and is restricted to Asia Minor, namely Turkey and Syria. The superba species group is distributed in both Nearctic and Palearctic Regions. Thirteen species are recognized in the Palearctic Region (Alexander \& Schwarz, 1994), of which N. sexfasciata Panzer has a wide distribution over Eurasia, but does not occur in Japan. The integra species group is represented by 15 species, with most species distributed in Europe to the western part of Russia.

\section{Acknowledgments}

We wish to express our gratitude to Assoc. Prof. S. Kamitani (ELKU) for their encouragement. Our cordial thanks are due to Prof. Emeritus J. Yukawa (Fukuoka) and Mr. D. Yamaguchi (ELKU) for their encouragement and kind assistance in the course of our study.

Our thanks are due to Mr. M. Schwarz (Linz), Dr. J. Gusenleitner (Oberösterreichischen Landesmuseum, Linz), Prof. A. Nakanishi (MNHAH) and Assist. Prof. Y. Hashimoto (MNHAH) for their help in our examining Nomada collection. Mr. M. Schwarz, in particular, kindly provided valuable advice, materials, and hospitality while visiting his home.

Mr. Y. Haneda (Fukui) generously gave us the valuable materials and penetrating observations which are vary helpful for the present study.

Prof. V. Kastcheev (Institute of Zoology, Kazakhstan) and Assist. Prof. Jashenko (Institute of Zoology, Kazakhstan) generously assisted us in field survey in

\section{Kazakhstan.}

We are also much indebted to the following entomologists for their encouragement and kindness in providing the valuable materials (omitted the titles of honor): M. Suwa (SEHU), K. Kinota (Hokkaido), S. Yamauchi (Aomori Pref. Museum), M. Yamada (Aomori), M. Hisamatsu (Ibaraki), T. Matsumura (Ibaraki), S. Makino (FFPRI), E. Katayama (Tochigi), K. Nakamura (Tochigi), K. Yasuda (NIAES), T. Nambu (Saitama), H. Suda (Chiba), T. Ishizaki (Tokyo University of Agriculture), T. Mita (Tokyo University of Agriculture), A. Shinohara (NSMT), H. Yoshitake (Tokyo University), H. Nagase (Kanagawa), H. Negoro (Toyama Science Museum), Y. Haneda (Fukui), H. Kuroakwa (Fukui), C. Nozaka (Fukui), T. Tano (Fukui), Makoto Kato (Kyoto University), Manabu Kato (Okayama), M. Saito (Okayama), Y. Maeta (Shimane), R. Miyanaga (Shimane University), N. Sugiura (Kumamoto University.), S. Ikudome (Kagoshima Women's Junior College), A. Dawut (ELKU), R. Murao (ELKU), T. Sugimoto (Fukuoka).

Lastly, special thanks due to Prof. Emeritus Y. Hirashima (Fukuoka) and the late Prof. emeritus K. Tsuneki. Without their excellent preceding taxonomic works on Nomada, the present study could not have be made. Especially, Mitai appreciates Dr. Hirashima giving me an opportunity to study Nomada, and critical comment and encouragement on the present study.

This is a Contribution from the Entomological Laboratory, Faculty of Agriculture, Kyushu University, Fukuoka (Ser. 6, No. 35)

\section{Literature cited}

Alexander, B., 1994. Species-groups and cladistic analysis of the cleptoparasitic bee genus Nomada (Hymenoptera: Apoidea). Univ. Kansas Sci. Bull., 55: $175-238$.

Alexander, B. \& M. Schwarz, 1994. A catalog of the Species of Nomada (Hymenoptera: Apidae) of the world. Univ. Kansas Sci. Bull., 55: 239-270.

Celary, W., 1995. Nomadini (Hymenoptera, Apoidea, Anthophoridae) of Poland. Monog. Fauny Polski, (20): 1-281.

Cockerell, T. D. A., 1911a. Bees in the collection of the U. S. National Museum. I. Proc. U. S. Nat. Mus., 39: 635-658.

Cockerell, T. D. A., 1914. Descriptions and records of bees, lviii. Ann. Mag. Nat. Hist., London, (8)13: 424-433.

Cockerell, T. D. A., 1918. Descriptions and records of bees, Ixxxii. Ann. Mag. Nat. Hist., London, (9) 2: 
476-482.

Haneda, Y., 1985. [Notes on Nomada guttulata Schenck and male of Nomada icazti Tsuneki]. Hôŷ-Tsûshin, (23): 1-4. (in Japanese.)

Haneda, Y., 1994. On the Apoidea (Hymenoptera) of Fukui Prefecture, Japan (VIII). Ent. J. Fukui, (10): 27-36. (in Japanese.)

Hirashima, Y., 1953. The insect fauna of Mt. Ishizuchi and Omogo valley, Iyo, Japan. Four new species of Apoidea (Hymenoptera). Trans. Shikoku Ent. Soc., 3: 132-136.

Hirashima, Y., 1965. Apidae. In: Yasumatsu, K., S. Asahina and T. Ishihara (eds.), Iconographia Insectorum Japonicorum, Colore Naturali Edita, Vol. III, pp. 309-310, pl. 155, Hokuryukan. Tokyo. (In Japanese.)

Hirashima, Y. \& O. Tadauchi, 2002. Adamon, a new subgenus of the genus Nomada Scopoli from Japan (Hymenoptera, Apidae). Esakia, (42): 47-54.

Ikudome, S., 1999. Family Anthophoridae. In: Yamane, S., S. Ikudome and S. Terayama (eds.) Identification Guide to the Aculeata of the Nansei Islands, Japan, pp. 646-656. Hokkaido University Press, Sapporo.

Ikudome, S., 2002. Bees collected in the garden of the Nasu Imperial Villa, Tochigi Pref., Japan (Hymenoptera, Apoidea). In: Tochigi Prefectural Museum (ed.) Flora and Fauna of the Nasu Imperial Villa. pp.151-155. (in Japanese.)

Janson, L.-Å, B. G. Svensson \& S. Erlandsson, 1991. Catalogus insectorum Sueciae. Hymenoptera, Apoidea. 3. Megachilidae, Anthophoridae and Apidae, Ent. Tidskr., 112: 93-99.

Kirby, W., 1802. Monographia Apum Angliae, Vol. 2, privately published, Ipswich.

Matsumura, S., 1912. Thousand Insects of Japan. Supplement.Vol. IV. Keiseisha, Tokyo.

Matsumura, T., 1970. Nesting habits of three species of Andrena in Hokkaido (Hymenoptera, Apoidea). J. Fac. Sci., Hokkaido Univ., Ser. VI, Zool., 17: 520-538.

Maeta Y., K. Goukon, N. Sugiura \& R. Miyanaga, 1996. Host records of cleptoparasitic bees in Japan (Hymenoptera, Apoidea). Jap. J. Ent., 64: 830-842.

Michener, C. D. 1944. Comparative external morphology phylogeny, and a classification of the bees. Bull. Am. Mus. Nat. Hist., 82: 151-326.

Michener, C. D., 2000. The Bees of the World. John Hopkins University Press, Baltimore and London.

Mitai K., O. Tadauchi \& Y. Hirashima, 2003. A systematic study of the roberjeotiana species group of the genus Nomada in Japan (Hymenoptera, Apidae). Jpn. J. Syst. Ent., 9: 297-318.
Mitai, K. \& O. Tadauchi, 2004. Taxonomic notes on the bifasciata species group of the genus Nomada (Hymenoptera: Apidae) in Japan. Esakia, (44): 91-101.

Mitai, K. \& O. Tadauchi, 2005. Systematic notes on the basalis and trispinosa species groups of the genus Nomada (Hymenoptera, Apidae) in Japan. Jpn. J. Syst. Ent., 11: 1-10.

Mitai, K. \& O. Tadauchi, 2006. Taxonomic notes on Japanese species of the Nomada furva species group (Hymenoptera: Apidae). Ent. Sci., 9: 239-246.

Murota, T. and H. Kurokawa, 2002. Is Andrena japonica (Andrenidae) a host of Nomada rengnio (Anthophoridae)? Ent. J. Fukui, (31): 17-20. (in Japanese.)

Pagliano, G., 1994. Catalogo degli Imenotteri Italiani. IV. (Apoidea: Colletidae, Andrenidae, Megachilidae, Anthophoridae, Apidae). Mem. Soc. Ent. Italiana, 72: 331-467.

Peeters, T. M. J., I. P. Raemakers \& J. Smit, 1999. Voorlopige atlas van de Nederlandse bijen (Apidae). European Invertebrate Survey-Nederland.

Radoszkowsky, O., 1876. Matériaux pour servir à une fauna hyménoptèrologique de la Russie. Hor. Soc. Ent. Rossicae (St. Petersburg), 12: 82-110.

Rasmont, P., P. A. Ebmer, J. Banaszak \& G. v. d. Zanden, 1995. Hymenoptera Apoidea Gallica. Bull. Soc. ent. France, 100: 1-98.

Schenck, A., 1861. Die Nassauische Bienen. Jahrb. Vereins Nat. Herzogthum Nassau, 14: 1-414.

Schwarz, M., F. Gusenleitner, P. Westrich \& H. H. Dathe, 1996. Katalog der Bienen Österreichs, Deutschlands und der Schweiz (Hymenoptera, Apidae). Entomofauna, Suppl., 8: 1-398.

Smith, F., 1869. Descriptions of Hymenoptera from Japan. Entomologist, 4: 205-208.

Smith, F., 1873. Descriptions of Aculeate Hymenoptera of Japan, collected by Mr. George Lewis at Nagasaki and Hiogo. Trans. Ent. Soc. London, 2: 181-206.

Suda, H., 1980. [Notes on hosts of the genus Nomada Scopoli]. Hôŷu-Tsûshin, (12): 1-10. (In Japanese.)

Sugiura, N., K. Mitai, T. Saito \& Y. Sugimoto, 2004. New records on the distribution of 3 species of the genus Nomada. Tsunekibachi, (2): 9-10. (in Japanese.)

Tsuneki, K., 1973. Studies on Nomada of Japan (Hym., Apidae). Etizenia, 66: 1-140.

Tsuneki, K., 1975. Corrigenda and addenda to the studies on Nomada (Hymenoptera, Apidae) of Japan. Kontyû, 43: 463-477.

Tsuneki, K., 1976a. New species of the genus Nomada Scopoli (Hymenoptera, Apidae) of Japan. Kontŷ, 44: 49-64. 
Tsuneki, K., 1976b. Additions to the Nomada-fauna of Japan (Hymenoptera, Apidae). Kontŷै, 44: 150-158.

Tsuneki, K., 1986. New species and subspecies of the Aculeate Hymenoptera from East Asia with some synonyms, specific remarks and distributional data. Spec. Pub. Jap. Hym. Assoc., (32): 1-60.

Yamazaki, K. \& M. Kato, 2003. Flowering phenology and anthophilous insect community in a grassland ecosystem at Mt. Yufu, western Japan. Cont. Biol. Lab. Kyoto Univ., 29: 255-318.

Yano, M., 1932. Nomada koebelei Cockerell. In: Esaki, T. et al. (eds.), Iconographia Insectorum Japonicum, Editio Prima, P. 216, Hokuryukan, Tokyo. (in Japanese.)

Yasumatsu, K., 1938. Die von Professor Dr. S. Matsumura beschriebenen Kucukcksbienen aus Japan. Ins. Mats., 13: 39-40.

Yasumatsu, K., 1939. Einige Nomada-arten aus den Kurilen und Sachalin (Zweiter Beitrag zur Kenntnis der Nomada-arten Japans) (HYM.: NOMADIDAE). Trans. Kansai Ent. Soc., 9: 5-7.

Yasumatsu, K., 1950. Nomada caloptera (sic.) Smith. In: Ishii, T. et al. (eds.), Iconographia Insectorum Japonicum, Editio Secunda, Reformata, P. 1490, Hokuryukan, Tokyo. (in Japanese.)

Yasumatsu, K. \& Y. Hirashima, 1951b. Two new species of the genus Nomada from Japan and Korea (Hymenoptera: Apidae). Trans. Shikoku Ent. Soc., 2: 53-56.

Yasumatsu, K. \& Y. Hirashima, 1953. Three new species of the genus Nomada from Japan and Korea (Hymenoptera, Apidae). Kontyû, 20: 29-36. 